\title{
WestVirginiaUniversity
}

THE RESEARCH REPOSITORY @ WVU

Graduate Theses, Dissertations, and Problem Reports

1998

\section{Resistance-in-series modeling in high-shear rotary ultrafiltration}

Ronald L. Vaughan Jr.

West Virginia University

Follow this and additional works at: https://researchrepository.wvu.edu/etd

\section{Recommended Citation}

Vaughan, Ronald L. Jr., "Resistance-in-series modeling in high-shear rotary ultrafiltration" (1998). Graduate Theses, Dissertations, and Problem Reports. 939.

https://researchrepository.wvu.edu/etd/939

This Thesis is protected by copyright and/or related rights. It has been brought to you by the The Research Repository @ WVU with permission from the rights-holder(s). You are free to use this Thesis in any way that is permitted by the copyright and related rights legislation that applies to your use. For other uses you must obtain permission from the rights-holder(s) directly, unless additional rights are indicated by a Creative Commons license in the record and/ or on the work itself. This Thesis has been accepted for inclusion in WVU Graduate Theses, Dissertations, and Problem Reports collection by an authorized administrator of The Research Repository @ WVU. For more information, please contact researchrepository@mail.wvu.edu. 


\title{
RESISTANCE-IN-SERIES MODELING IN HIGH-SHEAR ROTARY ULTRAFILTRATION
}

By

\author{
Ronald L. Vaughan, Jr.
}

\author{
A THESIS \\ Submitted to \\ The College of Engineering and Mineral Resources \\ at \\ West Virginia University \\ in partial fulfillment of the requirements \\ for the degree of \\ Master of Science \\ in \\ Engineering \\ Department of Civil and Environmental Engineering \\ Morgantown, West Virginia \\ 1998
}


(C) Copyright by

Ronald L. Vaughan, Jr. 1998 


\section{TABLE OF CONTENTS}

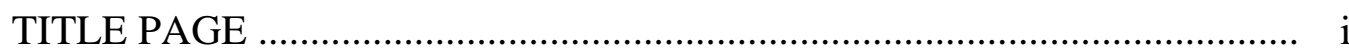

NOTICE OF COPYRIGHT _................................................................. ii

TABLE OF CONTENTS …........................................................................ iii-v

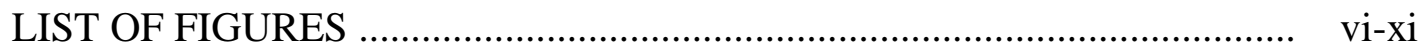

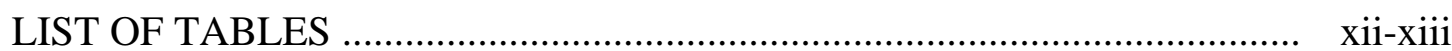

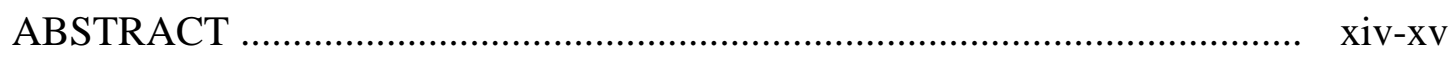

CHAPTER 1.0 INTRODUCTION _....................................................... 1-2

CHAPTER 2.0 BACKGROUND _.............................................................. 3-78

MEMBRANE SEPARATION PROCESSES....................................... 3-36

General Process Description ………………………............. 3-5

Operational Modes ……….............................................. 5-8

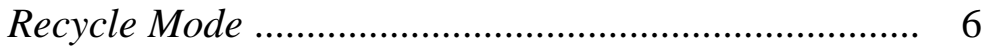

Semi-Batch Mode ..................................................... 6-8

Batch Mode …………............................................ 8

General Types of Membrane Separation Processes .................. 8-13

Reverse Osmosis and Nanofiltration .......................... 8. 8-12

Ultrafiltration and Microfiltration ............................ 12-13

Configurations of Conventional Membrane Modules .............. 13-19

Tubular Membrane Modules ....................................... 13-14

Hollow Membrane Fiber Modules .............................. 14-17

Spiral Wound Membrane Modules ............................... $17-19$

Plate and Frame Membrane Modules ........................ 19

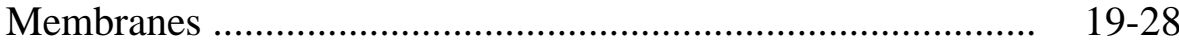

Factors Controlling Permeate Flux ........................................ 28... 28-35

Concentration Polarization …..................................... 28 28-32

Membrane Fouling ….............................................. $\quad 33-35$

Limitations of Conventional Cross-Flow Ultrafiltration 35-36

Systems

MODELING PERMEATE FLUX …………………........................ 36-63

Pressure-Controlled Region--Hagen-Poiseuille Model .......... 36-39

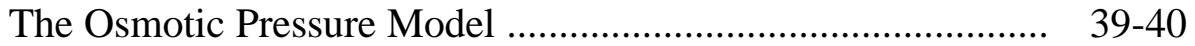

The Thin-Film Model .......................................... 40 40-41

The Resistance-in-series Model ............................. 41-43 
Mechanically Enhanced UF Systems........................................ 43-62

Flow Conditions in Rotary Membrane Systems ........... 48-53

Permeate Backpressure In A High-Shear Rotary UF

System

$54-56$

Mechanically Enhanced Ultrafiltration Case Studies $\quad$ 57-62

MEMBRANE TREATMENT OF OILY WASTEWATERS ............. $\quad 63-78$

Characteristics of Oil-In-Water (O/W) Emulsions And Oily 63-69

Wastewaters

Overview of Membrane Treatment of Oily Wastewaters ........ 69-78

Conventional Ultrafiltration Systems ......................... $69-72$

Mechanically Enhanced Ultrafiltration Systems .......... $72-78$

CHAPTER 3.0 INVESTIGATIVE APPROACH ........................................... 79-110

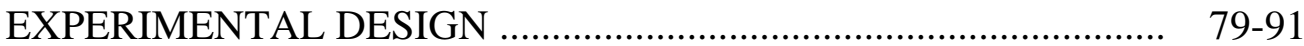

Experimental Conditions .......................................................... 79-8

Baseline Membrane Characteristics/Performance ....... 79-81

Baseline Metal-Working Fluid Characteristics ............ 81

Metal-Working Fluid Experiments ............................. 81-88

Data Presentation and Reduction............................................. $88-91$

MATERIALS AND METHODS _.................................................. 91-110

Experimental Apparatus ………………………………….... 91-95

Experimental Conduct ……….............................................. 95-110

Baseline Membrane Behavior .................................... 95-96

Membrane Cleaning Procedure ................................... $97-99$

Metal-Working Fluid Experiments ............................. 100-103

Feed Preparation ……………………............. 100-101

System Operation ……................................... 101-103

System Shutdown ........................................... 103

Analytical Methods .................................................... 103-108

Oil Content Analysis ....................................... 104

Metal-Working Fluid Density ........................... 104-105

Metal-Working Fluid Absolute Viscosity ......... 105-108

Metal-Working Fluid Particle Size Analysis .... 108

Quality Assurance/Quality Control ............................ 108 1110

CHAPTER 4.0 RESULTS ......................................................... 1111-211

BASELINE MEMBRANE PERFORMANCE EXPERIMENTS ......... 1111-117

BASELINE METAL-WORKING FLUID EXPERIMENTS .............. 117-121 
METAL-WORKING FLUID EXPERIMENTS

$121-211$

5\% MW Fluid -1750 rpm ...................................................... 121-131

5\% MW Fluid -1450 rpm ................................................... 131-135

5\% MW Fluid -1150 rpm ................................................. 135-140

10\% MW Fluid -1750 rpm .................................................... 140-144

10\% MW Fluid -1450 rpm ................................................ 144-149

10\% MW Fluid -1150 rpm .................................................. 149-154

15\% MW Fluid -1750 rpm .................................................. 154-159

15\% MW Fluid -1450 rpm ................................................. 160-163

15\% MW Fluid -1150 rpm ............................................... 163-168

20\% MW Fluid -1750 rpm ……………………………........ 168-172

20\% MW Fluid -1450 rpm .................................................. 173-177

20\% MW Fluid -1150 rpm .............................................. 177-182

30\% MW Fluid -1750 rpm ................................................ 182-187

30\% MW Fluid -1450 rpm ................................................. 187-191

30\% MW Fluid -1150 rpm …………………………........ 191-196

40\% MW Fluid -1750 rpm .............................................. 197-201

40\% MW Fluid -1450 rpm ............................................... 201-206

40\% MW Fluid -1150 rpm ................................................... 206-211

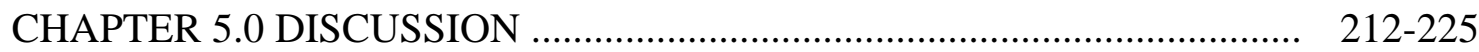

TOTAL MEMBRANE RESISTANCE............................................. 214-216

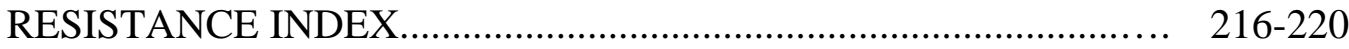

MODIFICATION OF THE RIS MODEL ..................................... 220-224

CHAPTER 6.0 CONCLUSIONS ........................................................ 225-226

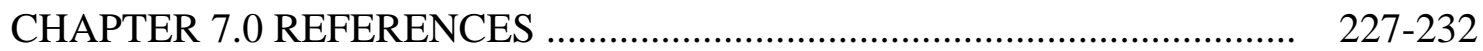

APPROVAL OF EXAMINING COMMITTEE ............................................ 233 


\section{LIST OF FIGURES}

$\begin{array}{lll}\text { Figure (2.1) } \quad \text { General membrane separation process. } & 4\end{array}$

$\begin{array}{lll}\text { Figure (2.2) Schematic of semi-batch and batch operation modes. } & 7\end{array}$

Figure (2.3) The useful ranges of the four general membrane separation 9 processes (after Cheryan (1986) and Perry and Green (1997)).

$\begin{array}{lll}\text { Figure (2.4) The phenomena of osmosis and reverse osmosis. } & 11\end{array}$

$\begin{array}{lll}\text { Figure (2.5) Schematic of a tubular membrane module. } & 15\end{array}$

$\begin{array}{lll}\text { Figure (2.6) Schematic of a hollow fiber membrane module. } & 16\end{array}$

$\begin{array}{lll}\text { Figure (2.7) } & \text { Schematic of a spiral wound membrane module. } & 18\end{array}$

Figure (2.8) Schematic of a plate and frame membrane module. 20

Figure (2.9) Relationship between permeate flux and transmembrane 23 pressure for a clean water feed.

Figure (2.10) Schematic of the passage of an oil droplet through the pores of 25 a membrane.

Figure (2.11) The theoretical relationship between permeate flux, transmembrane pressure, feed concentration, and hydraulic turbulence.

Figure (2.12) Schematic of the three primary solute transport mechanisms in membrane separation systems.

Figure (2.13) A schematic of a typical concentric cylinder module. 45

$\begin{array}{lll}\text { Figure (2.14) A schematic of a high-shear rotary UF pressure vessel. } & 47\end{array}$

Figure (2.15) Illustration of "conditioning shuttles." 49

Figure (2.16) The membrane radius and spacing in a high-shear rotary UF 52 system.

Figure (2.17) Schematic of emulsified oil droplet. $\quad 66$

Figure (2.18) An example of the typical flux versus pressure relationship 74 
observed by Vigo et al. at three operating tangential velocities.

Figure (2.19) Plot of permeate flux versus operational time for both temperature and membrane rotational speed excursions conducted by Reed et al.

Figure (3.1) A hypothetical plot of permeate flux versus time for a constant membrane rotational speed and constant MW fluid concentration with increasing applied pressure.

Figure (3.2) A hypothetical plot of average permeate flux versus average transmembrane pressure at each applied pressure for a constant membrane rotational speed and constant MW fluid concentration.

Figure (3.3) A schematic of the membrane vessel. 92

Figure (3.4) A schematic of the experimental apparatus. 93

$\begin{array}{lll}\text { Figure (3.5) A schematic of the rheometer. } & 107\end{array}$

Figure (4.1) The average permeate flux at each applied pressure/membrane 112 rotational speed in the virgin membrane/distilled water experiment.

Figure (4.2) The slopes of the regression lines fitted to the average permeate flux data at 110 and $135{ }^{0} \mathrm{~F}$ in the virgin membrane/distilled water experiment.

Figure (4.3) A plot of the average permeate flux versus average transmembrane pressure for the clean water flux experiment.

Figure (4.4) Density versus \% metal-working fluid.

Figure (4.5) MW fluid absolute viscosity versus \% metal-working fluid.

Figure (4.6) Volume \% versus particle diameter for the 5\% MW fluid.

Figure (4.7) Volume \% versus particle diameter for the $10 \%$ MW fluid.

Figure (4.8) Volume \% versus particle diameter for the $20 \%$ MW fluid.

Figure (4.9) Volume \% versus particle diameter for the 30\% MW fluid.

Figure (4.10) Volume \% versus particle diameter for the 40\% MW fluid. 
Figure (4.11) Permeate flux versus time for the 5\%-1750 rpm experiment.

Figure (4.12) Average permeate flux versus average transmembrane pressure for the 5\%-1750 rpm experiment.

Figure (4.13) Average permeate flux versus average transmembrane 132 pressure for the 5\%-1750 rpm clean water flux experiment.

Figure (4.14) Permeate flux versus time for the 5\%-1450 rpm experiment.

Figure (4.15) Average permeate flux versus average transmembrane 134 pressure for the 5\%-1450 rpm experiment.

Figure (4.16) Average permeate flux versus average transmembrane 136 pressure for the 5\%-1450 rpm clean water flux experiment.

Figure (4.17) Permeate flux versus time for the 5\%-1150 rpm experiment.

Figure (4.18) Average permeate flux versus average transmembrane 139 pressure for the 5\%-1150 rpm experiment.

Figure (4.19) Average permeate flux versus average transmembrane 141 pressure for the 5\%-1150 rpm clean water flux experiment.

Figure (4.20) Permeate flux versus time for the 10\%-1750 rpm experiment.

Figure (4.21) Average permeate flux versus average transmembrane 143 pressure for the 10\%-1750 rpm experiment.

Figure (4.22) Average permeate flux versus average transmembrane 145 pressure for the $10 \%-1750$ rpm clean water flux experiment.

Figure (4.23) Permeate flux versus time for the 10\%-1450 rpm experiment.

Figure (4.24) Average permeate flux versus average transmembrane 148 pressure for the 10\%-1450 rpm experiment.

Figure (4.25) Average permeate flux versus average transmembrane 150 pressure for the 10\%-1450 rpm clean water flux experiment.

Figure (4.26) Permeate flux versus time for the 10\%-1150 rpm experiment.

Figure (4.27) Average permeate flux versus average transmembrane 153 pressure for the $10 \%-1150 \mathrm{rpm}$ experiment.

Figure (4.28) Average permeate flux versus average transmembrane 
pressure for the $10 \%-1150$ rpm clean water flux experiment.

Figure (4.29) Permeate flux versus time for the 15\%-1750 rpm experiment. 156

Figure (4.30) Average permeate flux versus average transmembrane 157 pressure for the $15 \%-1750 \mathrm{rpm}$ experiment.

Figure (4.31) Average permeate flux versus average transmembrane pressure for the 15\%-1750 rpm clean water flux experiment.

Figure (4.32) Permeate flux versus time for the 15\%-1450 rpm experiment. 161

Figure (4.33) Average permeate flux versus average transmembrane 162 pressure for the $15 \%-1450 \mathrm{rpm}$ experiment.

Figure (4.34) Average permeate flux versus average transmembrane pressure for the 15\%-1450 rpm clean water flux experiment.

Figure (4.35) Permeate flux versus time for the 15\%-1150 rpm experiment. 165

Figure (4.36) Average permeate flux versus average transmembrane 167 pressure for the $15 \%-1150 \mathrm{rpm}$ experiment.

Figure (4.37) Average permeate flux versus average transmembrane pressure for the $15 \%$-1150 rpm clean water flux experiment.

Figure (4.38) Permeate flux versus time for the 20\%-1750 rpm experiment. 170

Figure (4.39) Average permeate flux versus average transmembrane 171 pressure for the $20 \%-1750 \mathrm{rpm}$ experiment.

Figure (4.40) Average permeate flux versus average transmembrane 174 pressure for the 20\%-1750 rpm clean water flux experiment.

Figure (4.41) Permeate flux versus time for the 20\%-1450 rpm experiment. 175

Figure (4.42) Average permeate flux versus average transmembrane 176 pressure for the 20\%-1450 rpm experiment.

Figure (4.43) Average permeate flux versus average transmembrane 178 pressure for the 20\%-1450 rpm clean water flux experiment.

Figure (4.44) Permeate flux versus time for the 20\%-1150 rpm experiment. 179

Figure (4.45) Average permeate flux versus average transmembrane 181 pressure for the 20\%-1150 rpm experiment. 
Figure (4.46) Average permeate flux versus average transmembrane pressure for the $20 \%-1150 \mathrm{rpm}$ clean water flux experiment.

Figure (4.47) Permeate flux versus time for the 30\%-1750 rpm experiment.

Figure (4.48) Average permeate flux versus average transmembrane 185 pressure for the 30\%-1750 rpm experiment.

Figure (4.49) Average permeate flux versus average transmembrane 188 pressure for the 30\%-1750 rpm clean water flux experiment.

Figure (4.50) Permeate flux versus time for the 30\%-1450 rpm experiment.

Figure (4.51) Average permeate flux versus average transmembrane 190 pressure for the 30\%-1450 rpm experiment.

Figure (4.52) Average permeate flux versus average transmembrane 192 pressure for the $30 \%-1450 \mathrm{rpm}$ clean water flux experiment.

Figure (4.53) Permeate flux versus time for the 30\%-1150 rpm experiment.

Figure (4.54) Average permeate flux versus average transmembrane 195 pressure for the 30\%-1150 rpm experiment.

Figure (4.55) Average permeate flux versus average transmembrane 198 pressure for the 30\%-1150 rpm clean water flux experiment.

Figure (4.56) Permeate flux versus time for the 40\%-1750 rpm experiment.

Figure (4.57) Average permeate flux versus average transmembrane 200 pressure for the 40\%-1750 rpm experiment.

Figure (4.58) Average permeate flux versus average transmembrane 202 pressure for the $40 \%-1750 \mathrm{rpm}$ clean water flux experiment.

Figure (4.59) Permeate flux versus time for the 40\%-1450 rpm experiment. 203

Figure (4.60) Average permeate flux versus average transmembrane 205 pressure for the $40 \%-1450 \mathrm{rpm}$ experiment.

Figure (4.61) Average permeate flux versus average transmembrane 207 pressure for the $40 \%-1450 \mathrm{rpm}$ clean water flux experiment.

Figure (4.62) Permeate flux versus time for the 40\%-1150 rpm experiment. 
Figure (4.63) Average permeate flux versus average transmembrane 209 pressure for the 40\%-1150 rpm experiment.

Figure (4.64) Average permeate flux versus average transmembrane pressure for the $40 \%-1150 \mathrm{rpm}$ clean water flux experiment.

Figure (5.1) Average permeate flux versus average transmembrane membrane pressure for the $10 \%-1,750 \mathrm{rpm} ; 10 \%-1,450 \mathrm{rpm}$; and $40 \%-1,750$ rpm experiments.

Figure (5.2) $\quad \mathrm{R}_{\mathrm{m}}$ ' versus $\mathrm{O}_{\mathrm{k}}\left(\right.$ at each $\mathrm{R}_{\mathrm{j}}$ ).

$\begin{array}{lll}\text { Figure (5.3) } & \text { Resistance index versus } \mathrm{R}_{\mathrm{j}}\left(\text { at each } \mathrm{O}_{\mathrm{k}} \text { ). }\right. & 217\end{array}$

Figure (5.4) Resistance index versus $\mathrm{O}_{\mathrm{k}}$ (at each $\mathrm{R}_{\mathrm{j}}$ ) and $\mathrm{MW}$ fluid 219 viscosity versus $\mathrm{O}_{\mathrm{k}}$.

Figure (5.5) Limiting permeate flux versus MW fluid concentration at 221 1,$150 ; 1,450$; and $1,750 \mathrm{rpm}$.

Figure (5.6) Average radial Reynolds number versus MW fluid 222 concentration at 1,$150 ; 1,450$; and $1,750 \mathrm{rpm}$.

Figure (5.7) Modified RIS model results and experimental data for 224 representative $\mathrm{R}_{\mathrm{j}} \mathrm{OC}_{\mathrm{k}}$ combinations. 


\section{LIST OF TABLES}

PAGE

Table Typical membrane resistances for micro and ultrafiltration membranes.

Table Viscosity of water at several common operating temperatures.

Summary of typical $\mathrm{C}_{\mathrm{g}}$ values for several non-oily waste and process streams.

Table

Table

Table

Table

Table

Table

Table

Table

Table

Table

Table The average permeate flux at each applied pressure/membrane

Table

Typical $\mathrm{O} / \mathrm{G}$ concentration ranges for selected industrial wastewaters.

The $\mathrm{P}_{\mathrm{i}} \mathrm{R}_{\mathrm{j}}$ combinations studied in the baseline membrane characteristic experiment.

Average and maximum permeate backpressures at typical rotational speeds.

Metal-working fluid/membrane rotational speed combinations and applied pressure ranges investigated in this study.

A summary of the rotational and pressure hysteresis experiments conducted in this study.

A summary of the ceramic membrane characteristics.

A summary of the characteristics of the base/surfactant and acid cleaning solutions used in the standardized cleaning procedure.

The base MW package and water volumes added to make each concentration.

Specifications of the digital rheometer.

106

Specifications of the Coulter and Malvern particle size analysis

109 instruments. rotational speed combination in the virgin membrane/distilled water experiment.

The membrane resistance at 110 and $135^{0} \mathrm{~F}$ for set 1 and set 2 in the virgin membrane/distilled water experiment 
Table

The mean and median particle sizes reported by Coulter and the mean particle size reported by Malvern. 


\section{ABSTRACT \\ RESISTANCE-IN-SERIES MODELING \\ IN HIGH-SHEAR ROTARY \\ ULTRAFILTRATION}

By Ronald L. Vaughan, Jr.

Large volumes of spent oil-in-water emulsions are produced in the metal working (MW) industry. Conventional membrane separation technologies have come to the forefront of oily wastewater treatment alternatives, but are limited by the low permeate flux observed at high oil concentrations due to the difficulty pumping concentrated solutions at necessary high recirculation velocities. In high-shear rotary ultrafiltration (HSR-UF), disk membranes are rotated at speeds up to $1,750 \mathrm{rpm}$ to generate hydraulic turbulence, which scours the membrane surface. Thus, the pump is required only to provide transmembrane pressure and a small amount of recirculation.

A parametric waste-specific study was conducted to assess the ability of the resistance-in-series (RIS) permeate flux model to predict pressure-flux data collected in the HSR-UF of a synthetic MW fluid. Experiments were conducted using a pilot-scale HSR-UF system with a $0.11 \mu \mathrm{m}$ average-pore size membrane at a single temperature operating temperature of $110^{\circ} \mathrm{F}$. Experiments were conducted at discrete membrane rotational speed/MW fluid concentration combinations over an applied pressure range of 103 to $517 \mathrm{kPa}$ (15 to $75 \mathrm{psig}$ ), membrane rotational speeds of 1,150 to $1,750 \mathrm{rpm}$, and synthetic MW fluid concentrations of 5 to $40 \%$ MW fluid.

The RIS model was modified to include membrane rotational speed and oil concentration terms in order to predict the permeate flux at any given transmembrane pressure, rotational speed, and oil concentration. The modified RIS model adequately 
described the experimental data, although the model fit the data for higher rotational speeds better than lower rotational speeds. Total membrane resistance, $\mathrm{R}_{\mathrm{m}}$, , and the resistance index, $\Phi$, were determined. $\mathrm{R}_{\mathrm{m}}$ ' and the fouling resistance, $\mathrm{R}_{\mathrm{f}}$, were independent of operational parameters, and $R_{f}$ was found to be significantly lower than the intrinsic membrane resistance, $R_{m}\left(R_{f}=0.137 R_{m}\right)$, thus concluding that the HSR-UF system sufficiently minimized membrane fouling effects by minimizing the thickness of the solute boundary layer. $\Phi$ was a linear function of membrane rotational speed and a parabolic function of feed concentration. 


\section{CHAPTER 1.0 INTRODUCTION}

Metalworking (MW) fluids are used in rolling mill operations to control friction between the mill and workpiece, dissipate heat generated during the milling procedure, and to improve the surface quality of the workpiece. MW fluids are generally oil-inwater $(\mathrm{O} / \mathrm{W})$ emulsions that contain additives such as surfactants, antimicrobial agents, and antifoaming agents. After a period of time, the MW fluids must be discarded, resulting in large volumes of oily wastewaters which are commonly treated using conventional cross-flow ultrafiltration (UF). The UF residual has a high oil concentration and a lower volume than the original waste stream and is thus less expensive to dispose.

The primary limitation of conventional cross-flow UF is the large decline in permeate flux observed with increasing feed oil concentration. A high recirculation velocity is used to induce hydraulic turbulence which minimizes the accumulation of solute molecules on the membrane surface so that an acceptable permeate flux is maintained. However, as feed oil concentration increases, it becomes more difficult to maintain a high recirculation velocity due to an increase in feed viscosity. Decoupling the hydraulic cleaning action from recirculation/pressurization can minimize this problem. In the high-shear rotary UF (HSR-UF) system, disk membranes are rotated at speeds up to $1750 \mathrm{rpm}$ to induce hydraulic turbulence that scours the membrane surface while the pump is required only to provide transmembrane pressure and a small amount of recirculation flow. 
In this study, the applicability of the resistance-in-series (RIS) permeate flux model in representing data collected during the HSR-UF treatment of a synthetic oily waste was investigated. A parametric, waste-specific study was conducted to provide insight on the relationship between membrane rotational speed, transmembrane pressure, and permeate flux, and the RIS model was modified to include the three parameters. In the course of the study, oily waste parameters specific to the RIS model (e.g. total membrane resistance, $\left[\mathrm{R}_{\mathrm{m}}{ }^{\prime}\right]$; resistance index, $\left.[\Phi]\right)$ were determined. 


\section{CHAPTER 2.0 \\ BACKGROUND}

\section{MEMBRANE SEPARATION PROCESSES}

In this section, an overview of the main characteristics; operating modes; types of membrane separation systems; and configurations of conventional membrane modules are presented. Additionally, the factors that control system operation and the limitations of conventional membrane separation systems are discussed.

\section{General Process Description}

Membrane filtration is a fluid/fluid and particle/fluid separation technology used to separate dissolved substances and fine particles from water and wastewater. A general membrane separation process is shown schematically in Figure (2.1). A thin semipermeable membrane acts as a selective barrier that separates particles based on molecular or physical size. In general, water and constituents which are smaller than the membrane pore size are able to pass through the membrane as "permeate" while particles and molecules larger than the membrane pore size are retained. The retained particles and molecules, known as "concentrate," "retentate," or "residual," are returned to the feed tank to be concentrated further with time. "Permeate flux" is the term used to describe how fast permeate passes through a membrane. Flux is generally reported as volume/area-time. Permeate flux generally depends upon the individual membrane characteristics (e.g., membrane pore size and membrane surface charge), the characteristics of the feed stream (e.g., viscosity and solute particle size), and operating 


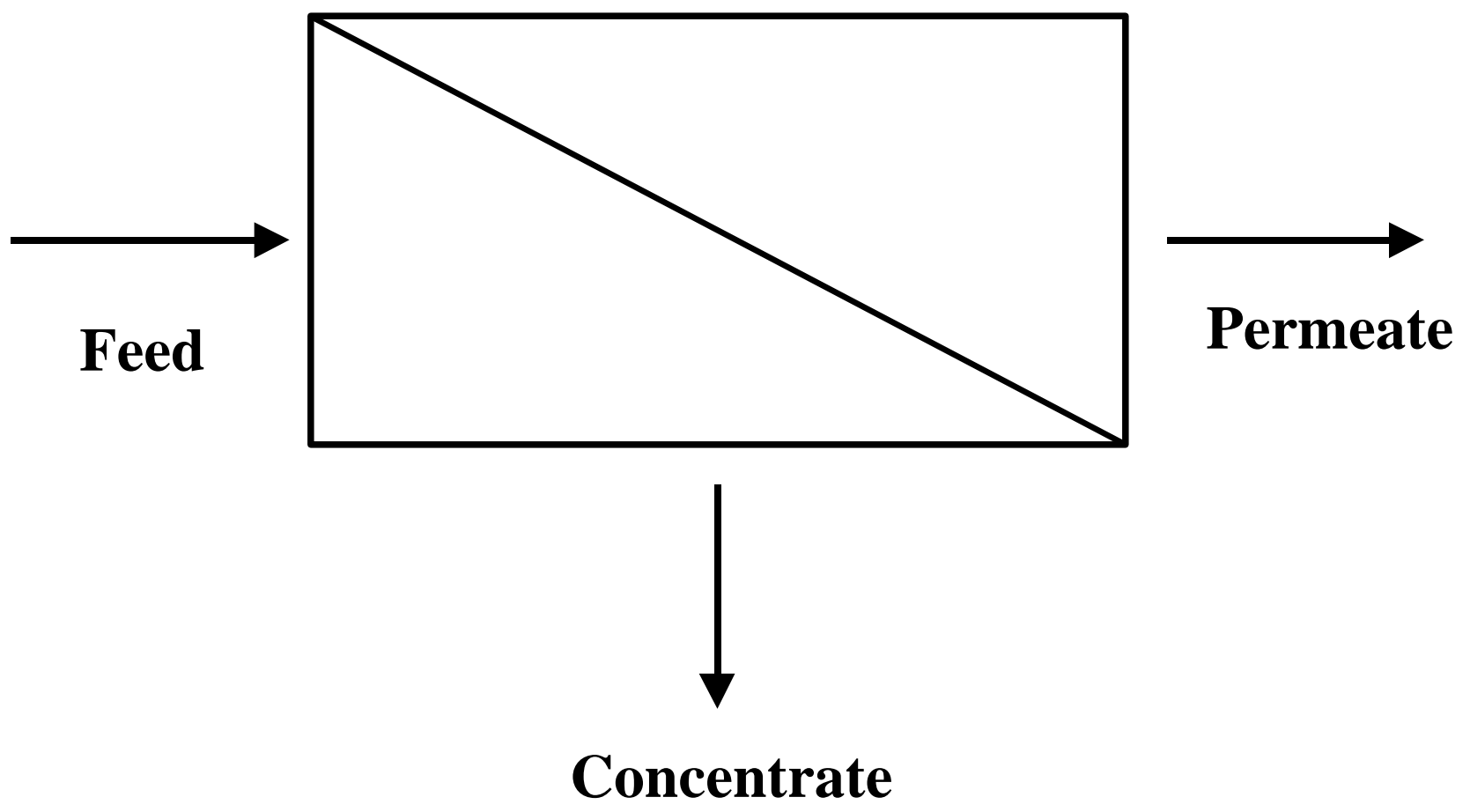

Figure (2.1)-General Membrane Separation Process. 
parameters (e.g., transmembrane pressure and feed temperature).

Most membrane separation systems used in industrial applications are operated in a cross-flow feed configuration as opposed to dead-end mode. In the cross-flow configuration, concentrate passes parallel to the membrane surface as opposed to perpendicular flow that is used in dead-end filtration. The accumulation of solute molecules at the membrane surface is decreased and the subsequent loss of permeate flux due to increased hydrodynamic resistance at the membrane surface is minimized by cross-flow induced hydraulic turbulence.

Membrane separation processes are gaining acceptance as viable alternatives to other treatment technologies such as dissolved air flotation and biological treatment. For example, membrane separation systems can be used to recover valuable materials from waste streams (e.g., reusable oil, metal salts, etc.) and to reduce the volume of waste sent for further treatment or disposal. Additional industrial applications of membrane separation systems include: MW wastewaters, pulp and paper wastewaters, commercial laundry wastewaters, landfill leachate, the production of high quality water used in the production of microelectronic circuits, and in beverage processing.

\section{Operational Modes}

Membrane separation systems are typically operated in one of three main filtration modes: (1) recycle mode, (2) semi-batch ("modified batch") mode, or (3) batch mode. Since membrane separation technologies are volume reduction processes, the concentration factor $(\mathrm{CF})$ is an important system efficiency parameter. The concentration factor is defined as the ratio of feed concentration at a given time to the initial 
concentration. Concentration factors are typically expressed as $1 \mathrm{X}, 2 \mathrm{X}$, etc., and increase with treatment time. Concentration factors in excess of 100 are possible with membrane separation technologies.

Recycle Mode

In recycle mode, feed is pumped from the feed tank into the membrane module. Permeate is forced through the membrane under pressure and is returned to the feed tank. Thus, the concentration of the solution in the feed tank remains constant over time. Since the feed solution is not concentrated over time, recycle mode is not used in industrial waste and process applications. However, membrane separation systems are frequently operated in recycle mode in laboratory studies when it is advantageous to maintain a constant feed concentration.

Semi-Batch Mode

In field applications, membrane separation systems are typically operated in either semi-batch or batch mode. A schematic of semi-batch and batch operation modes is presented in Figure (2.2). In semi-batch mode, fresh feed solution (at 1X) is added to the feed tank at the same rate permeate is produced and the feed solution is concentrated over time. The concentration of the feed solution in semi-batch operation is given in Equation (2.1).

$$
\mathrm{CF}_{\mathrm{sb}}=1+\mathrm{V}_{\text {perm }} / \mathrm{V}_{\text {feed }}
$$

where $\mathrm{CF}_{\mathrm{sb}}=$ concentration factor during semi-batch operation, $\mathrm{V}_{\text {perm }}=$ volume of permeate produced, and $\mathrm{V}_{\text {feed }}=$ volume of solution in feed tank (constant during semi- 


\section{ВАТCH}

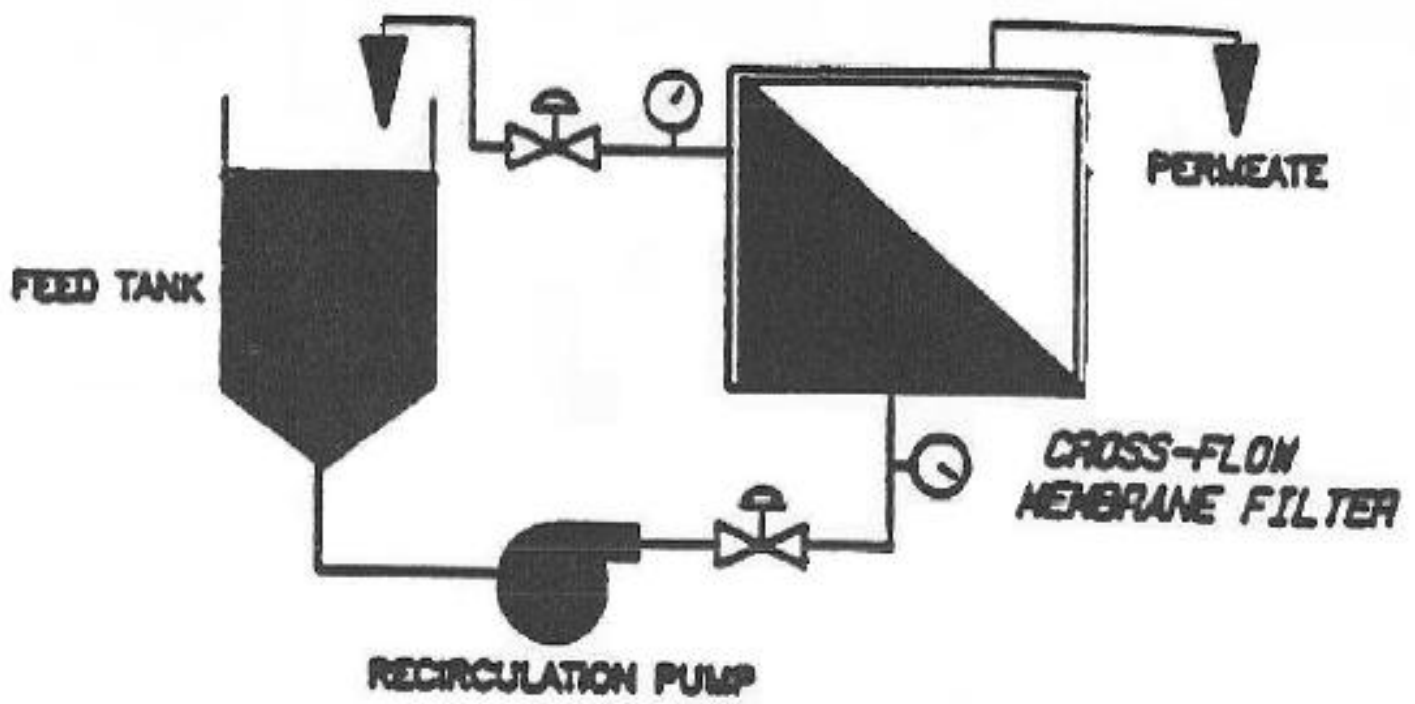

SEMI-BATCH

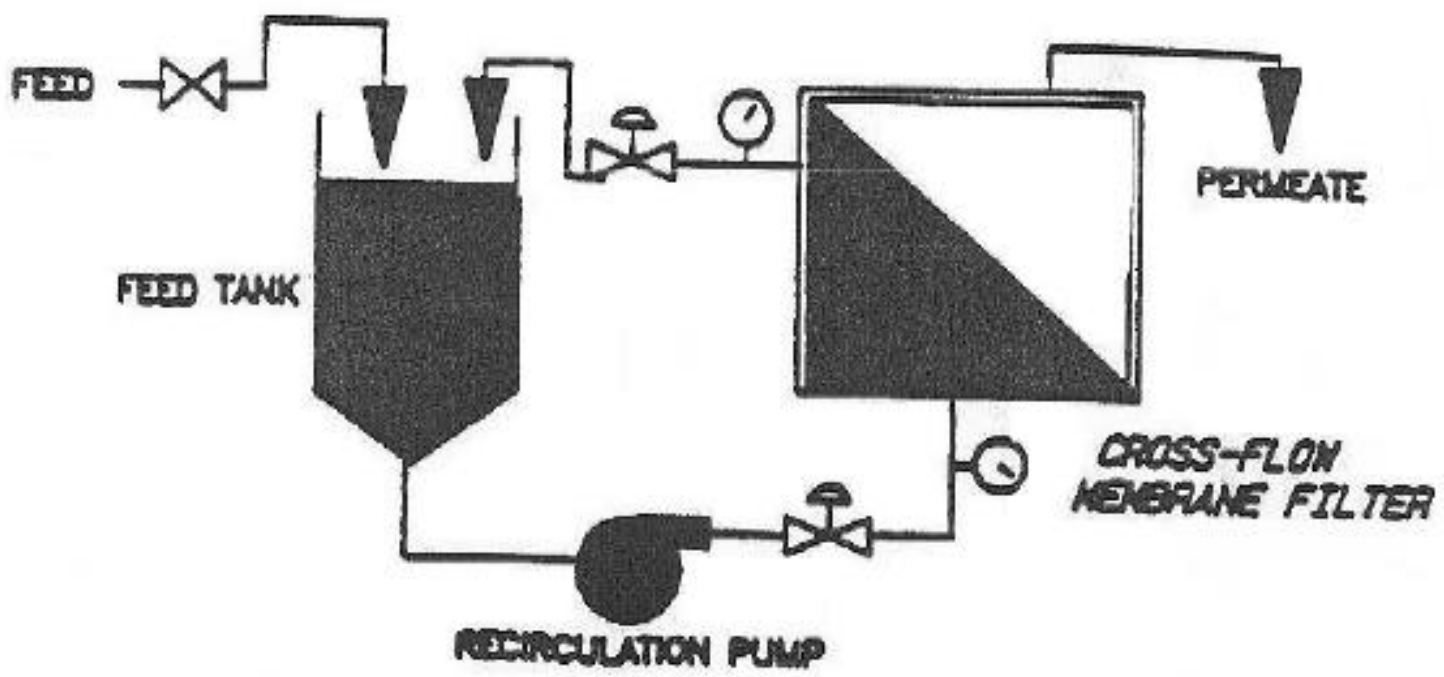

Figure (2.2)-Schematic Of Semi-Batch and Batch Operational Modes. 
batch operation). Semi-batch operation is the most frequently used operational mode in industrial applications.

\section{Batch Mode}

A schematic of batch operation mode was presented previously in Figure (2.2). In batch mode, which typically occurs at the end of semi-batch operation, fresh $1 \mathrm{X}$ solution is not added to the feed tank while permeate is removed. Thus, the feed volume is reduced and the concentrate remaining at the end of semi-batch operation is concentrated further. The concentration factor during batch operation is given in Equation (2.2).

$$
\mathrm{CF}_{\mathrm{b}}=\mathrm{CF}_{\mathrm{sb}} \times\left[\mathrm{V}_{\text {feed }} /\left(\mathrm{V}_{\text {feed }}-\mathrm{V}_{\text {perm }}\right)\right]
$$

where $\mathrm{CF}_{\mathrm{b}}=$ concentration factor during batch operation.

\section{General Types of Membrane Separation Processes}

Membrane processes are differentiated by the size of particles they separate. The four principle membrane separation techniques used to treat industrial waste and process waters are: reverse osmosis (RO), nanofiltration (NF), ultrafiltration (UF), and microfiltration (MF). The useful ranges of the four general membrane separation processes are presented in Figure (2.3) (after Cheryan (1986) and Perry and Green (1997)).

\section{Reverse Osmosis and Nanofiltration}

Membranes are characterized by the diameter of a particle or molecular weight of a molecule that is retained (known as the molecular weight cutoff (MWCO)) by the membrane. Additional details regarding membrane characteristics are presented later in Chapter 3.0. Reverse osmosis (RO) is a membrane separation technique used to separate 


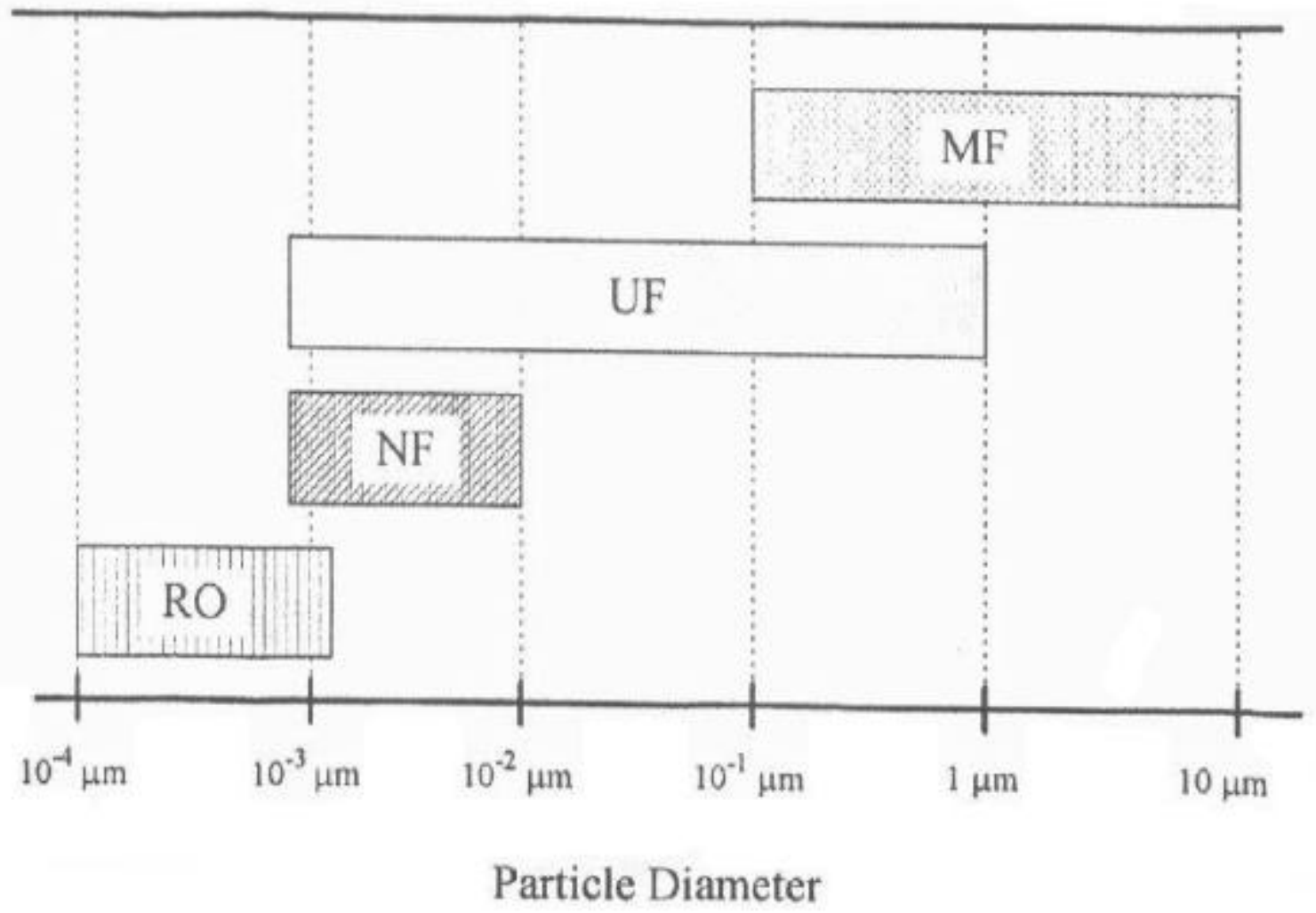

Figure (2.3)-The Useful Ranges Of The Four General Membrane Separation Processes (After Cheryan (1986) And Perry And Green (1997)). 
materials with diameters from $\sim 10^{-4}$ to $10^{-3} \mu \mathrm{m}$ (less than $\sim 200$ to $2,000 \mathrm{MWCO}$ ). RO is generally used to remove salts and ions from solutions. The phenomena of osmosis and reverse osmosis are presented schematically in Figure (2.4). Osmosis is the flow of solvent (usually water) through a semi-permeable membrane from a region of low chemical potential to a region of higher chemical potential. For example, when a salt solution and pure water are separated by a semi-permeable membrane, a net flow from the pure water to the saline side of the membrane will occur due to differences in the chemical potential (and thus, the osmotic pressure) of the two solutions. The salt solution will rise to a point at which the head is equal to the osmotic pressure, as presented schematically in Figure (2.4). In RO, the pressure on the salt solution is raised above the osmotic pressure so the net movement of water is from the more concentrated saline side to the pure water side of the semi-permeable membrane. Transmembrane pressures ranging from 500 to 2,000 psi are common in RO applications.

Reverse osmosis has been used in the production of potable water, most prominently in the Middle East and on islands where the demand for potable water exceeds the natural supply. Small RO units have also been incorporated into multistage flash distillation systems to provide potable water sources on ocean vessels. Additionally, RO is used to create ultra high quality water in the manufacture of microelectronic circuits and in the dewatering and concentrating of beverage streams (e.g., dewatering orange juice prior to freezing). 

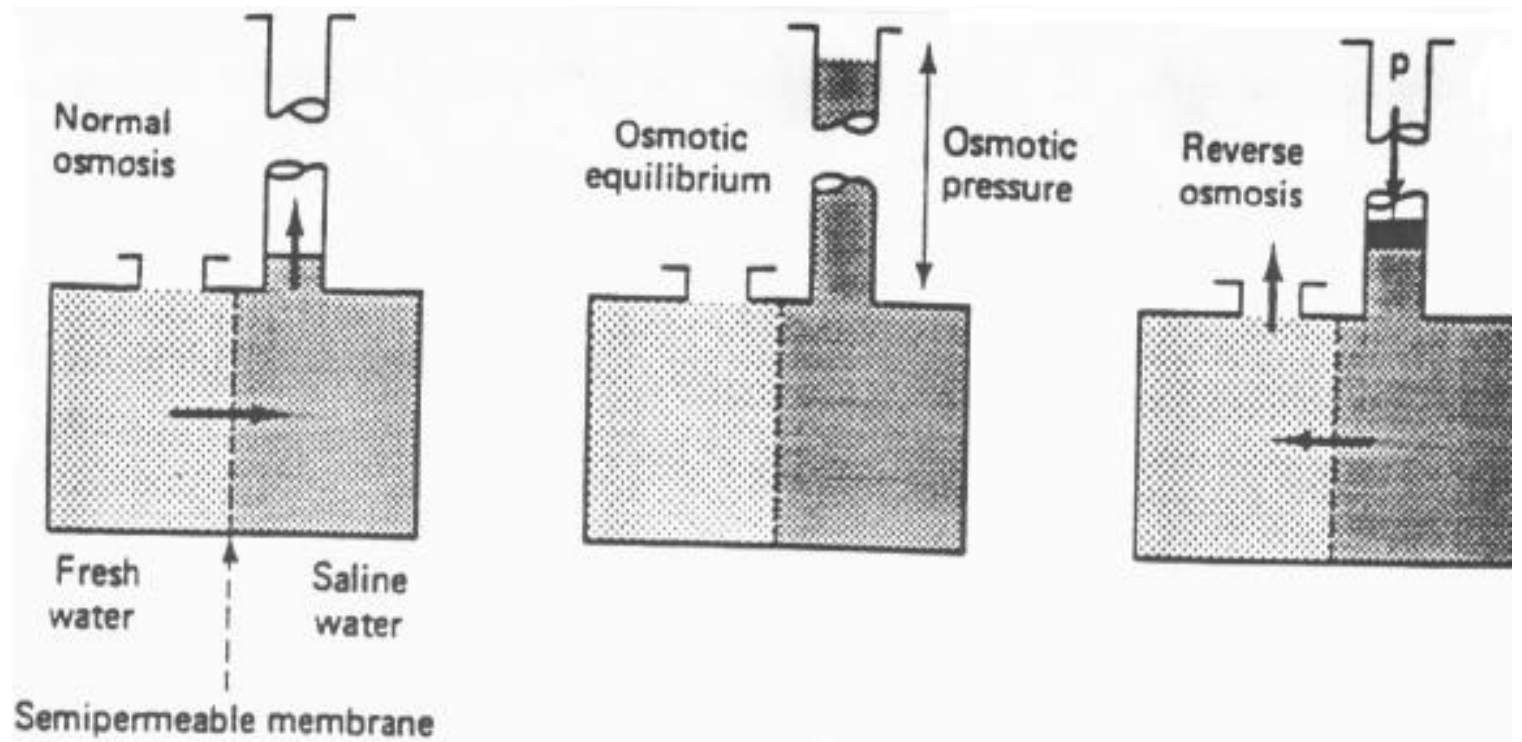

Figure (2.4)-The Phenomenon of Osmosis and Reverse Osmosis. 
Nanofiltration (NF) systems operate under the same basic principle as reverse osmosis. However, nanofiltration is generally used to remove particles in the $\sim 10^{-3}$ to $10^{-}$ ${ }^{2} \mu \mathrm{m}$ range $(2,000$ to $20,000 \mathrm{MWCO})$. Nanofiltration is often referred to as "loose RO" because nanofiltration operates on the same basic principle as RO but is applied to larger particle sizes. Smaller constituents of a waste or process stream (e.g., metal ions and dissolved salts) which would typically be removed using RO may pass through a nanofiltration membrane. Nanofiltration is often used to dewater pesticide and herbicide solutions. [Perry and Green 1997]

\section{Ultrafiltration and Microfiltration}

Ultrafiltration (UF) is a pressure-driven membrane technique based on a "sieving mechanism" in which particles are separated from solution based on size. UF is used to separate material in the $\sim 10^{-3}$ to $1 \mu \mathrm{m}$ size range $(\sim 2,000$ to $500,000 \mathrm{MWCO})$. Microfiltration (MF) is a similar membrane separation technique which is used to separate particles in the $\sim 10^{-1}$ to $10 \mu \mathrm{m}$ size range $(\sim 100,000$ to $>500,000 \mathrm{MWCO})$. Similarly to the case of reverse osmosis and nanofiltration, there is an overlap in the size range over which UF and MF are generally applied [Perry and Green 1997]. Thus, ultra and microfiltration are discussed as primarily one technique with the main distinction being the larger membrane pore size used in MF. Transmembrane pressures ranging from 5 to $150 \mathrm{psi}$ are common in UF and MF applications.

Ultrafiltration has been successfully applied to the treatment of concentrated oily wastes from MW processes such as sheet rolling and die cutting. UF has been used to treat wastewaters high in oil, grease, and solids while reducing the volume of waste sent 
for disposal, while at the same time recovering alkaline process cleaners for re-use. Additionally, Cheryan (1986) summarized the results from several studies in which UF was demonstrated to be an effective treatment method for a wide variety of waste and process streams including: (1) the dairy industry for skim, whole milk, and cottage cheese whey processing; (2) biotechnology/bioengineering for protein fractionation and recovery of valuable microbes; (3) food processing for protein and juice extraction; and (4) for the recovery of ink in the printing industry. [Cheryan 1986, Perry and Green 1997]

Similarly to UF, microfiltration has been applied to the treatment of oily wastewaters. MF is used in water treatment to remove cryptosporidium and giardia cysts. Additionally, MF is frequently used in the dairy industry (1) as a non-thermal method to remove bacteria from milk and protein products, (2) to separate fat from milk or dairy streams, and (3) to recover caustic agents used to clean dairy evaporators. [Perry and Green 1997]

\section{Configurations of Conventional Membrane Modules}

The most common module configurations used in commercial cross-flow filtration are tubular, hollow fiber, spiral wound, and plate and frame [Belfort 1988]. Tubular Membrane Modules

A schematic of a tubular membrane module is presented in Figure (2.5) [MacNeil and McCoy 1989]. A tubular membrane consists of a porous membrane material cast on a permeable support matrix housed inside a rigid hollow tube. Feed is recirculated through the tube at a velocity high enough to produce turbulence at the membrane surface. Permeate is forced radially through the membrane under pressure and is 
collected through a port in the rigid outer casing [Belfort 1988]. Tubular membranes are available in single or multi-tube configurations. Typical commercial tubular membranes can be operated at pressures up to 90 psig. These modules are generally 10 feet long and have inner tube diameters ranging from 0.5 to 1 inch. Typical flow rates necessary to achieve a sufficient shear in a 1 inch tubular membrane range from $\sim 30$ to $40 \mathrm{gal} / \mathrm{min}$ ( 114 to $151 \mathrm{~L} / \mathrm{min}$ ). Due to large channel sizes (typically 0.5 to 1 inch), tubular membranes are commonly used to treat waste and process streams with high solids concentrations. Additionally, the large flow channels make it easier to remove accumulated solute molecules using mechanical and chemical cleaning techniques [MacNeil and McCoy 1989]. The disadvantages of these membrane modules include a relatively low permeate flow rate per unit volume and a high volume hold-up per unit area of membrane [Belfort 1988].

\section{Hollow Fiber Membrane Modules}

A schematic of a hollow fiber membrane module is presented in Figure (2.6) [MacNeil and McCoy 1989]. Hollow fiber membrane modules consists of a bundle of fine tubes (typical inside diameters range from $\sim 20$ to $106 \mathrm{~mm}$ ) made of the membrane material bound at each end of the module by epoxy discs. Unlike tubular membranes, hollow fiber membranes do not have an underlying support structure. Feed is forced into the membrane module radially, under pressure, through a perforated tube in the center of the housing. Permeate flows through the individual fibers and is collected through epoxy tube sheets at the end of the module [MacNeil and McCoy 1989]. Transmembrane pressures of up to $40 \mathrm{psig}$ are common in hollow fiber modules [Belfort 1988]. 


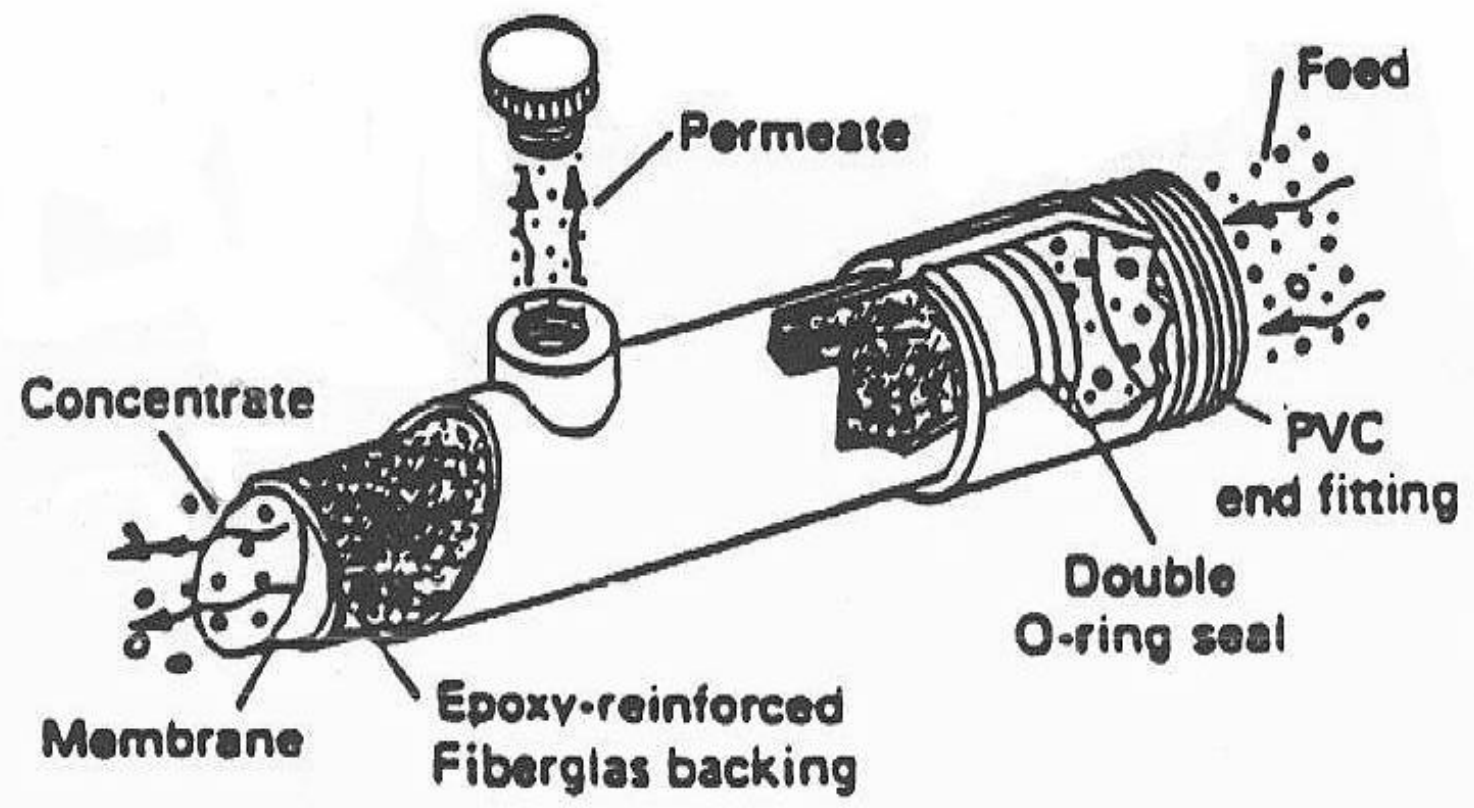

Figure (2.5)-Schematic of a Tubular Membrane Module 


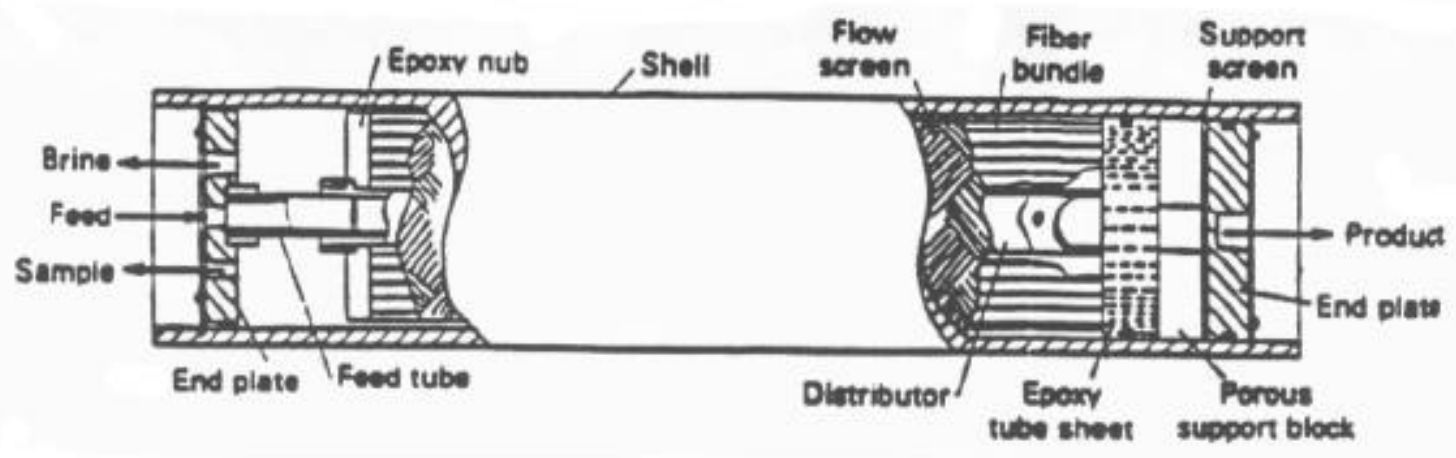

Figure (2.6)-Schematic Of A Hollow Fiber Membrane Module 
Additionally, hollow fiber membrane modules have a higher packing density than tubular modules but are more subject to fouling effects than tubular systems. Hollow fiber membranes cannot be mechanically cleaned [MacNeil and McCoy 1989]. However, the direction of permeate flow can be changed to effectively back-flush the membrane to remove fouling materials from the surface. Typically, lower final waste concentrations are obtained using a hollow fiber system than would be achieved with a tubular module due to pore plugging/fouling as the feed concentration is increased. [Belfort 1988]

\section{Spiral Wound Membrane Modules}

A schematic of a spiral wound membrane module is presented in Figure (2.7). A spiral wound membrane module consists of alternating layers of porous membranes, permeate carriers, and spacers, wrapped around a central hollow permeate collection tube. The feed solution flows axially through the wound membrane module. Permeate is forced through the porous membrane and is collected through the hollow center tube while rejected feed solution exits at the end of the module. Spiral wound membrane modules range from $\sim 5$ to $20 \mathrm{~cm}$ in diameter and can be operated at pressures up to $\sim 150$ psig. Typically, spiral wound membranes foul more easily than tubular membranes due to smaller waste flow channels (common spacer thicknesses range from 28 to $80 \mathrm{~mm}$ ). This factor, coupled with the fact that spiral wound modules cannot be mechanically cleaned, limits the application of these membrane configurations to waste and process streams with low solids concentrations [MacNeil and McCoy 1989]. However, spiral wound membranes have a significantly higher packing density than tubular and hollow fiber configurations, making spiral wound membranes applicable to the treatment of 


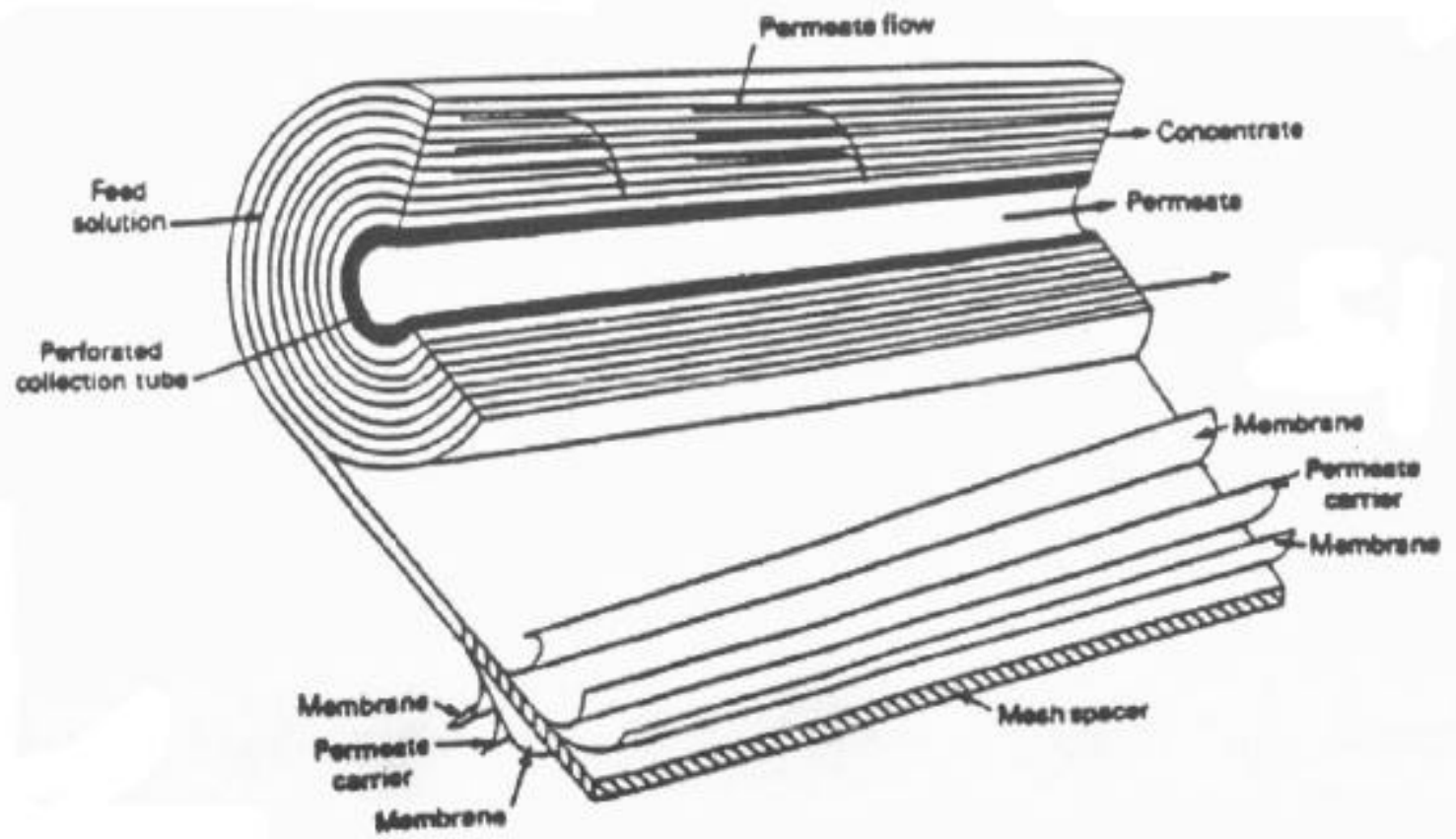

Figure (2.7)-Schematic of a Spiral Wound Membrane Module 
streams with high volume flow rates (and low solids concentrations) [Eringis et al. 1993]. Spiral wound units have primarily been used in laboratory-scale filtration units to recover proteins in the biotechnology field and have been considered for large-scale commercial bioprocessing applications [Belfort 1988].

Plate and Frame Membrane Modules

A schematic of a plate and frame membrane module is presented in Figure (2.8) [MacNeil and McCoy 1989]. In these systems, hollow disc-shaped spacers located between porous membranes are used to direct the feed radially along the membrane surface. A stack of multiple membranes separated by spacers is placed in series or in parallel inside a cylindrical housing. Permeate is forced through the membrane under pressure and is collected at the outer edges of the membrane disc plate. Concentrated solute is collected at the top of the stack. The advantages of this configuration include a relatively low volume hold-up per unit membrane area (a feature which is attractive for the recovery of valuable biologicals), and a thin channel height (typically 0.3 to $0.6 \mathrm{~mm}$ ) which permits these units to process highly viscous solutions. The disadvantages of this membrane configuration include susceptibility to channel plugging and difficulties in mechanical cleaning [Belfort 1988]. Additionally, the commercial application of plate and frame membrane configurations has been limited due to high capital cost relative to other filtration units [MacNeil and McCoy 1989].

\section{Membranes}

Membranes used in membrane separation processes are characterized by the diameter of a particle or molecular weight of a molecule that is retained (i.e., not allowed 


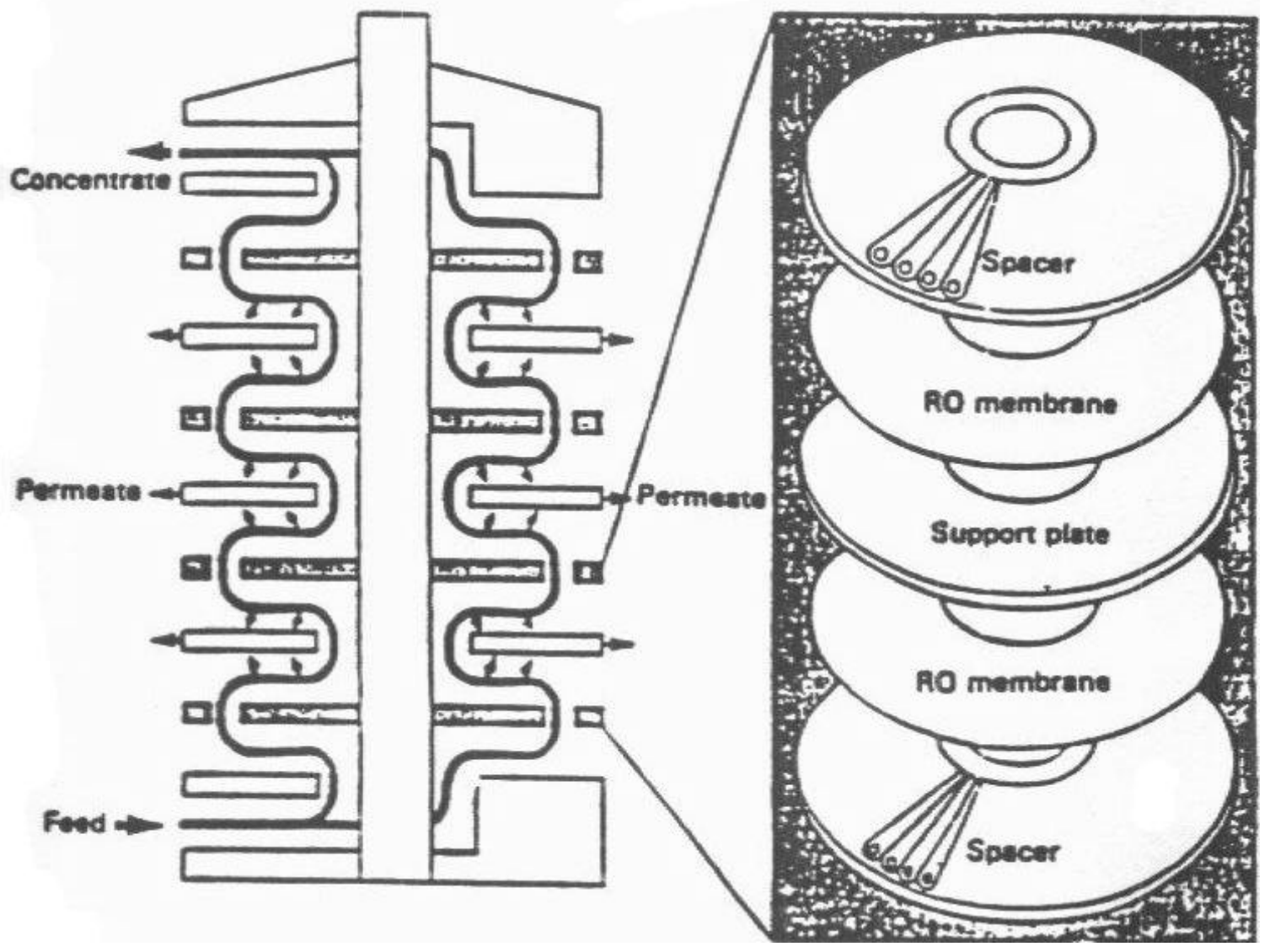

Figure (2.8)-Schematic Of A Plate And Frame Membrane Module 
to pass through) by the membrane. In theory, compounds having a molecular weight greater than the molecular weight cut off (MWCO) will be retained by the membrane and compounds with molecular weights less than the MWCO will pass through the membrane as permeate. However, the MWCO designation is somewhat misleading because a molecule having a molecular weight less than the membrane MWCO may still be retained by the membrane because of its unique three dimensional geometry.

Membrane materials must be able to withstand the mechanical, chemical, and biological stresses imposed during operation and cleaning without suffering appreciable losses in operating efficiency. Mir et al. (1977) discussed several general operational and feed parameters that must be considered in the treatment of wastewaters. The factors include $\mathrm{pH}$, ionic strength, temperature, and pressure. Additionally, membrane surface properties can also affect permeate flux and quality. Electrostatic repulsion between the membrane and the contaminant can be used to enhance waste solute retention and increase flux.

Membrane resistance is a measure of the hydraulic resistance to flow through a pore channel and is an intrinsic material property of the membrane due to the material properties of the membrane. The membrane resistance can be determined by applying Darcy's Law for a virgin membrane with clean water feed:

$$
\mathrm{J}=\Delta \mathrm{P}_{\mathrm{T}} / \mu \mathrm{R}_{\mathrm{m}}
$$

where, $\mathrm{J}=$ permeate flux, $\Delta \mathrm{P}_{\mathrm{T}}=$ transmembrane pressure, $\mu=$ water viscosity (absolute), and $\mathrm{R}_{\mathrm{m}}=$ membrane resistance. The assumption of well-developed laminar flow through the membrane pore channel is made when using Equation (2.3). The relationship 
between permeate flux and transmembrane pressure for a clean water feed is presented in Figure (2.9). When clean water is used as the feed, the slope of a regression line through the origin on the plot of permeate flux versus transmembrane pressure is inversely proportional to the product of the feed viscosity and the resistance of the membrane, $R_{m}$, as presented in Figure (2.9) [Cheryan 1986]. In this case, the membrane resistance is:

$$
\mathrm{R}_{\mathrm{m}}=1 /\left(\mu^{*} \text { slope }\right)
$$

A summary of typical resistances for several ceramic (aluminum oxide) micro and ultrafiltration membranes studied by Nazzal and Wiesner (1996) is presented in Table (2.1). Additionally, a resistance of $\sim 10^{12} \mathrm{~m}^{-1}$ was measured by Lipp et al. (1988) for a polymeric membrane used to treat oil-in-water emulsions in a stirred cell UF unit (membrane material and MWCO were not specified). The MF and UF membrane resistances reported by Nazzal and Wiesner (1996) and Lipp et al. (1988) were comparable to values measured by other researchers [Gutman 1987, Bhave 1991]

Membrane (material and pore size/MWCO) and operating conditions are selected to achieve adequate rejection of emulsified solutes while maintaining an acceptable permeate flux. The selection process is based primarily on empirical data and previous experience. However, Nazzal and Wiesner (1996) have developed a model for calculating the critical pressure, $\mathrm{P}_{\text {crit }}$, required to force the entry of an oil droplet into a membrane pore based on the Young-Laplace equation. A schematic of the passage of an oil droplet through the pores of a membrane is presented in Figure (2.10). The critical pressure is given by: 


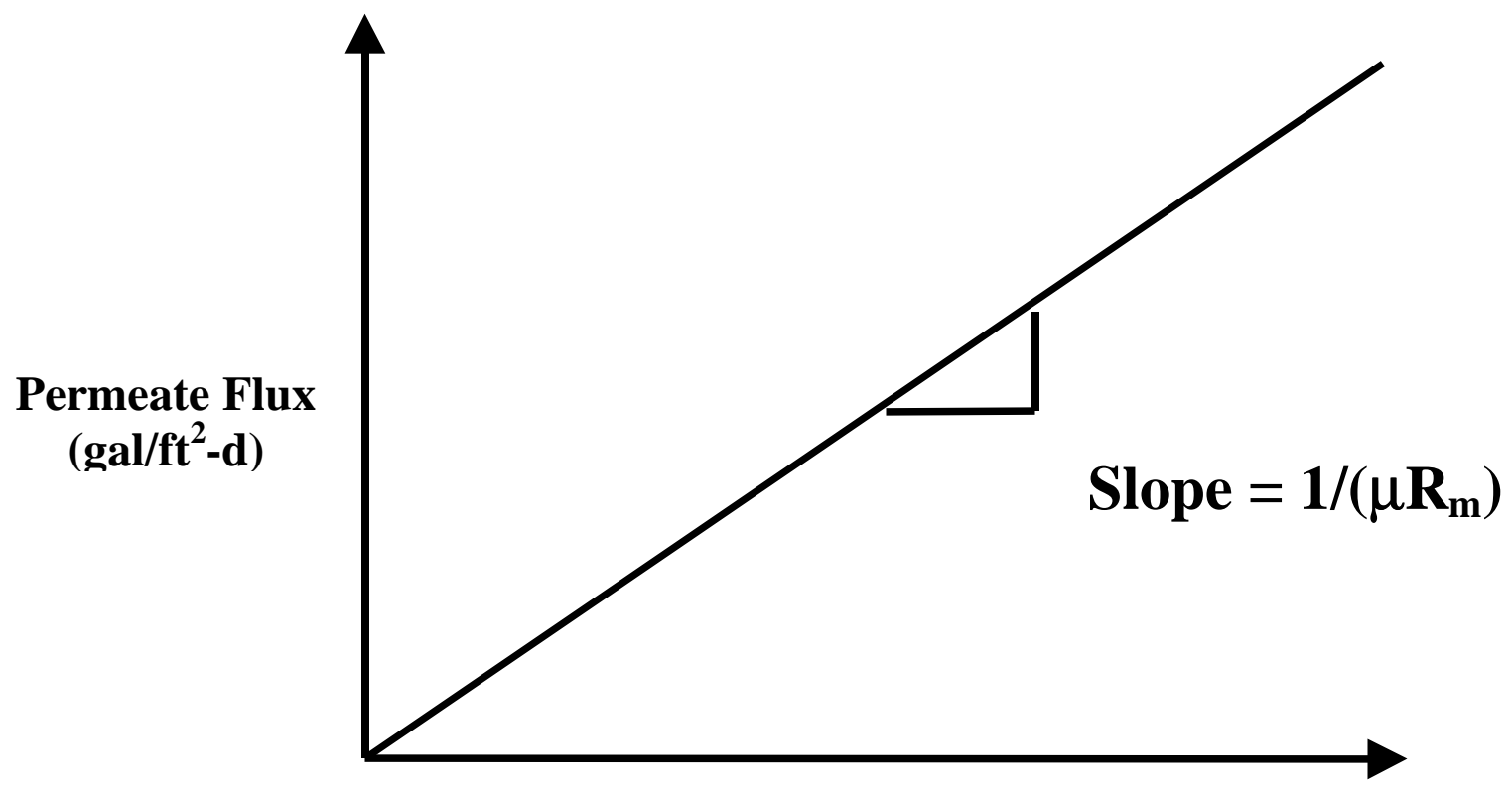

Transmembrane Pressure (psi)

Figure (2.9)-The Relationship Between Permeate Flux And Transmembrane Pressure For A Clean Water Feed 
Table (2.1)--Typical Membrane Resistances For Micro And Ultrafiltration Membranes [Nazzal And Wiesner 1996].

\begin{tabular}{||c|c||}
\hline \hline Pore diameter $(\mu \mathbf{m})$ & Membrane resistance $\left(\mathbf{m}^{-1}\right)$ \\
\hline \hline 0.8 & $1.5 \times 10^{11}$ \\
\hline 0.5 & $2.0 \times 10^{11}$ \\
\hline 0.2 & $5.0 \times 10^{11}$ \\
\hline 0.05 & $6.0 \times 10^{11}$ \\
\hline
\end{tabular}




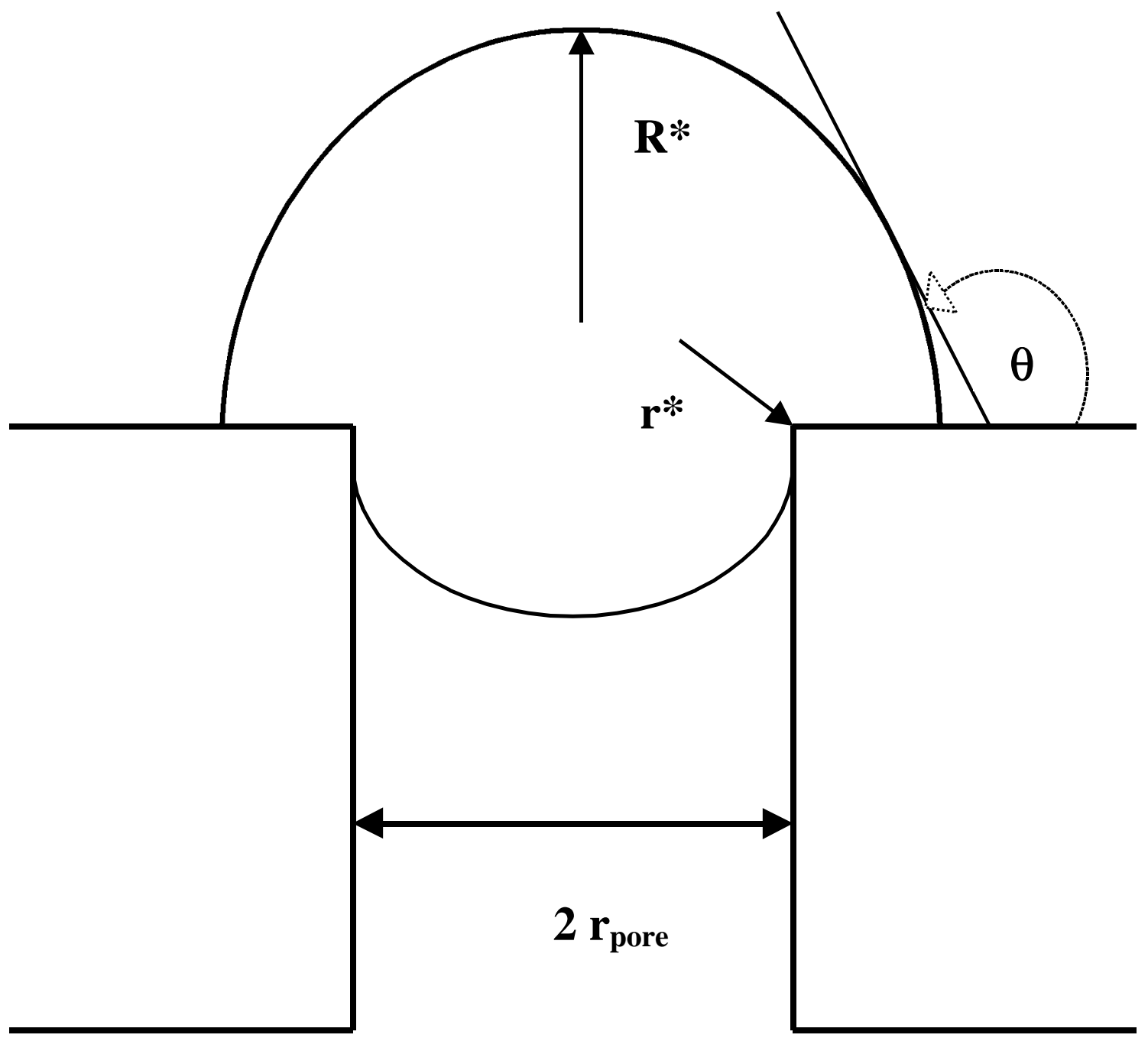

Figure (2.10)-Schematic Of Passage Of An Oil Droplet Through The Pores Of A Membrane 


$$
\mathrm{P}_{\text {crit }}=\left(2 \gamma_{\mathrm{o} / \mathrm{w}}\right)\left(1 / \mathrm{r}^{*}-1 / \mathrm{R}^{*}\right)
$$

where $\gamma_{\mathrm{o} / \mathrm{w}}=$ the interfacial tension between the oil and water, $\mathrm{r}^{*}=$ the radius of curvature of the advancing portion of the drop, and $\mathrm{R}^{*}=$ the radius of curvature of the lagging drop interface. This model presented in Equation (2.5) can be further expressed as:

$$
\begin{array}{r}
\mathrm{P}_{\text {crit }}=\left(2 \gamma_{\mathrm{o} / \mathrm{w}} \cos \theta / \mathrm{r}_{\text {pore }}\right)\left\{1-\left[\left(2+3 \cos \theta-\cos ^{3} \theta\right) /\right.\right. \\
\left.\left.\left[4\left(\mathrm{r}_{\mathrm{drop}} / \mathrm{r}_{\text {pore }}\right)^{3} \cos ^{3} \theta-\left(2-\sin \theta+\sin ^{3} \theta\right)\right]\right]^{1 / 3}\right\}
\end{array}
$$

where $\theta=$ contact angle, $r_{\text {drop }}=$ radius of the oil drop, and $r_{\text {pore }}=$ radius of the membrane pore. Equation (2.6) predicts that a membrane with a smaller pore size should require a higher transmembrane pressure to initiate oil droplet movement into the membrane pores for a given interfacial tension, contact angle, and drop size. Nazzal and Wiesner cited a common value for the contact angle, $\theta$, to be $155^{\circ}$ and a typical interfacial tension for oilin-water emulsions, $\gamma_{\mathrm{o} / \mathrm{w}}$, to be 55 dynes/cm.

Nazzal and Wiesner performed experiments using tubular ceramic (aluminum oxide) membranes with nominal pore sizes of $0.05,0.2,0.5$, and $0.8 \mu \mathrm{m}$. Contrary to the theoretical expectation of a distinct drop in solute rejection at or near $\mathrm{P}_{\text {crit }}$, distinct cutoffs in oil rejection were not observed at the critical pressure. Nazzal and Wiesner attributed this unexpected behavior to variations in the pore size around the nominal pore diameter in addition to the polydispersivity of oil droplet sizes (as observed by Lee et al. (1988)). Due to these factors, Nazzal and Wiesner recommend using Equation (2.6) as a rough estimate of the critical pressure and suggested including allowances for membrane pore and oil drop size variation when applying this model in practice. Additionally, the 
authors noted that this model may be valid when the membrane cut-off and hydrodynamics favor the accumulation of oil near the membrane surface (due to a change in the contact angle as the membrane becomes more oil-wet).

In Equation (2.7), a model similar to Equation (2.6) was used by Lee et al. (1984) to predict the pressure necessary to force an oil droplet through the pores of a membrane.

$$
P_{\text {cap }}=\left(2 \gamma_{\mathrm{o} / \mathrm{w}}\right)[\cos (\theta) / \mathrm{r}]
$$

where $\mathrm{P}_{\text {cap }}=$ capillary pressure of an emulsified oil droplet, $\gamma_{\mathrm{o} / \mathrm{w}}=$ the interfacial free energy (surface tension) between the oil and water, $\theta=$ contact angle, and $r=$ radius of the membrane pores. The capillary pressure of an emulsified oil drop is used as the basis for describing oil droplet rejection. Typically, the value of the contact angle, $\theta$, exceeds $90^{0}$ which implies that the membrane is more hydrophilic than oleophilic. For values of the contact angle in excess of $90^{\circ}$, the capillary pressure is negative and prevents the passage of oil droplets through the membrane pores against the applied pressure. Lee et al. assumed a contact angle of $180^{\circ}$. Lee et al. (1984) investigated the use of the capillary pressure model to predict the passage of oil through a polymeric membrane with a 20k MWCO in an Amicon S4OC stirred UF cell. In these experiments, initial oil concentrations of 1 to 5 vol.\% were used at a constant feed temperature of $20{ }^{0} \mathrm{C}$ and a constant stirring speed of $300 \mathrm{rpm}$. A breakthrough of oil droplets was not observed when the feed pressure was increased above the capillary pressure as calculated in Equation (2.7). The authors presented an explanation of these phenomena similar to that of Nazzal and Wiesner. Since the sizes of the membrane pores varied over a non-uniform 
distribution, the number of pores where the operating pressure exceeded the capillary pressure increased as the applied pressure was raised resulting in a more gradual breakthrough of oil than expected.

\section{Factors Controlling Permeate Flux}

\section{Concentration Polarization}

The theoretical relationship between permeate flux, transmembrane pressure, feed concentration, and hydraulic turbulence is presented in Figure (2.11). Under conditions of low transmembrane pressure, low feed concentration, and high hydraulic turbulence, permeate flux is linearly proportional to transmembrane pressure. The linear permeate flux/transmembrane pressure relationship is idealized in the case of a clean water feed. When clean water feed is ultrafiltered, there are theoretically no contaminants to either (1) plug the membrane pores or (2) accumulate on the membrane surface.

The buildup of solute at the membrane surface is known as "concentration polarization" and is largely responsible for the deviation of the product flux from the linear flux-pressure model presented in Equation (2.3). Primarily, three competing solute transport mechanisms occur in ultrafiltration: (1) convective transport of solute to the membrane surface (2) back diffusion of accumulated solute to the bulk solution, and (3) solute permeation through the membrane as presented schematically in Figure (2.12). Solute is convectively transported to the porous membrane surface and a fraction of the solvent is removed as permeate which results in a locally higher solute concentration at the membrane surface relative to the bulk solute concentration. As the transmembrane 


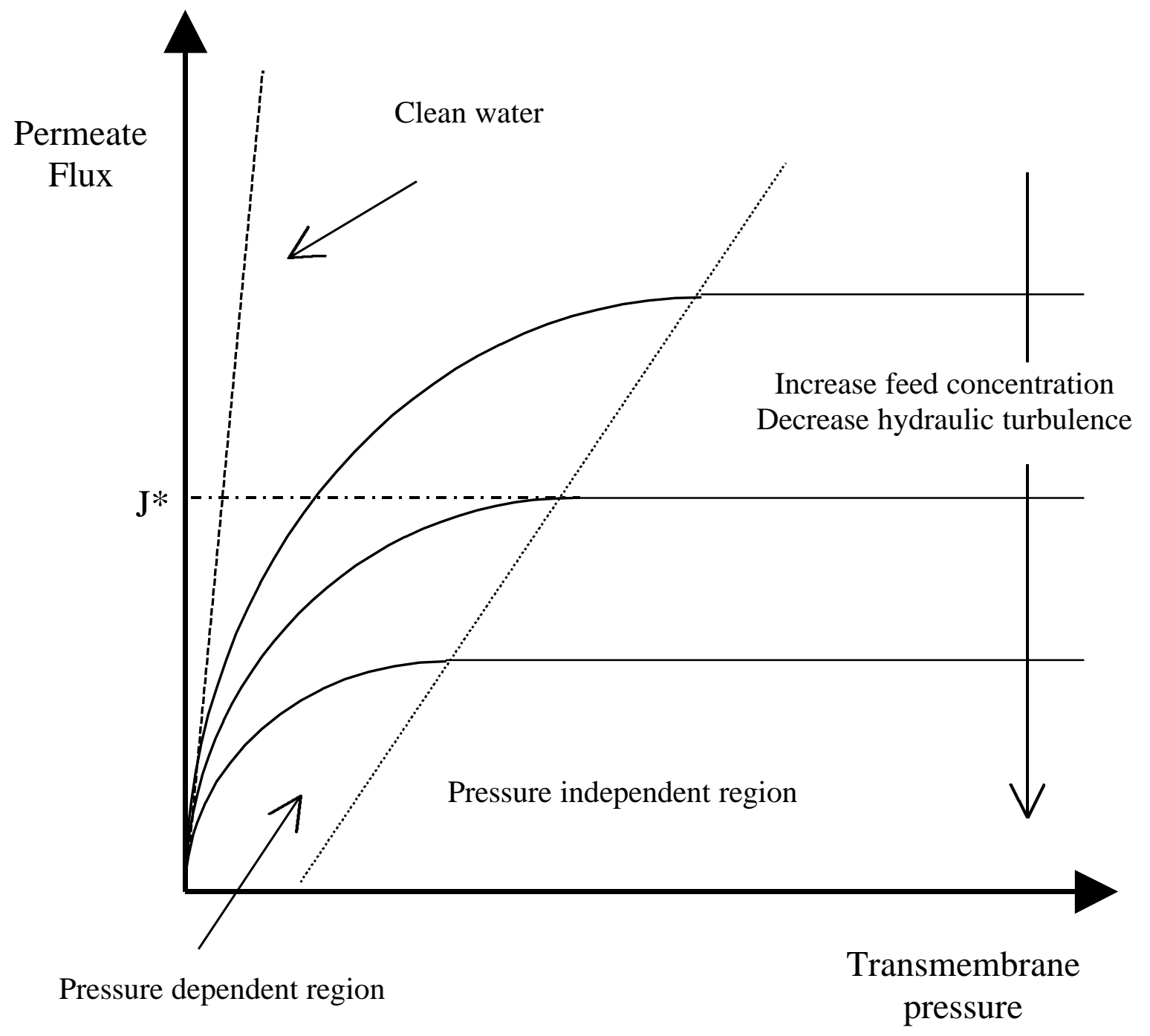

Figure (2.11) - The Theoretical Relationship Between Permeate Flux, Transmembrane Pressure, Feed Concentration, And Hydraulic Turbulence. 


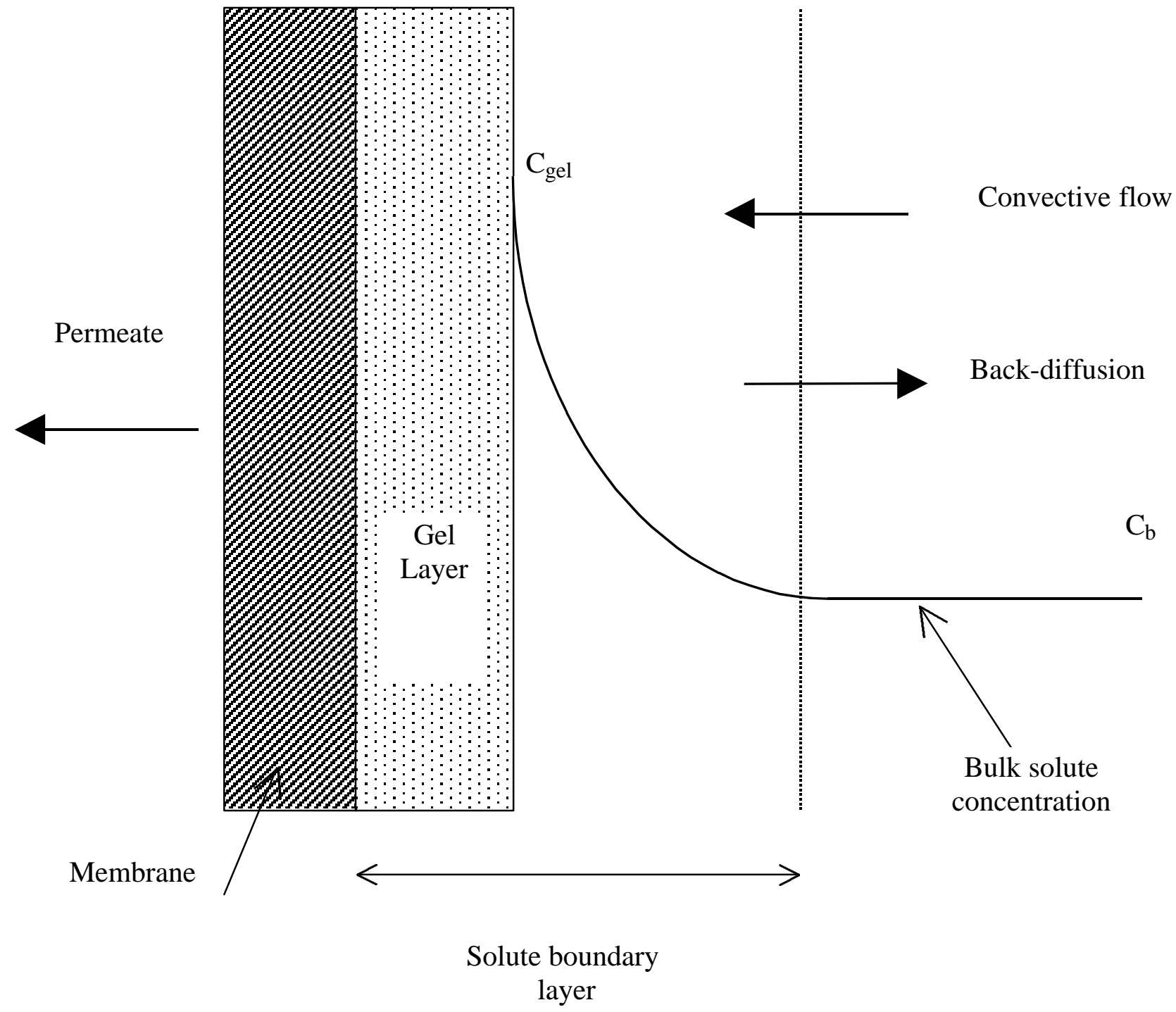

Figure (2.12)-Schematic Of The Three Primary Solute Transport Mechanisms In Membrane Separations Systems. 
pressure is increased, feed concentration is increased, or hydraulic turbulence is decreased, the permeate flux becomes independent of pressure.

In general, there are four operational and feed solution parameters which contribute to the formation of the polarized solute concentration boundary layer and subsequent asymptotic permeate flux response to increased transmembrane pressure: (1) transmembrane pressure, (2) feed concentration, (3) hydraulic turbulence, and (4) feed viscosity/temperature. Transmembrane pressure is the principle driving force in membrane separation systems. However, as transmembrane pressure is increased, there is a corresponding increase in convective transport of solute molecules to the membrane surface. A thicker solute boundary layer forms as a result of the enhanced convective transport of solute molecules to the membrane surface and the permeate flux becomes independent of transmembrane pressure.

Solute concentration in the feed is another parameter which limits permeate flux. As the solute concentration in the feed increases, permeate flux decreases due to the accumulation of solute molecules at the membrane surface. At high solute feed concentrations, it becomes difficult to pump a feed solution at high enough to minimize the thickness of the polarized concentration boundary layer. Thus, the permeate flux decreases as the solute concentration increases. The hydraulic turbulence in membrane separation systems also plays an important role in maintaining a satisfactory permeate flux. As hydraulic turbulence is increased, the permeate flux should theoretically also increase due to a decrease in the thickness of the polarized concentration boundary layer. Similarly, as the temperature of the feed solution is increased, permeate flux increases 
due to: (1) a decrease in the viscosity of the feed solution (which makes it easier to pump the feed solution at a high cross-flow velocity) or (2) an increase in the solute diffusivity (which results in an increased diffusion of solute molecules from the membrane surface back to the bulk solution). [Cheryan 1986]

Cheryan (1977) noted three operational characteristics which can be used to judge the extent of concentration polarization in a UF system: (1) deviation from the pure water line, (2) relatively rapid attainment of pressure-independent flux behavior, and (3) marked hysteresis effect observed on lowering the pressure. Although the deviation from the pure water flux may be attributed to a decrease in the driving force due to increased osmotic pressure, Cheryan believed the primary mechanism of flux decline was the increased $\mathrm{h}$ hydrodynamic resistance in the concentration boundary layer. Cheryan supported the argument in favor of flux decline due to the formation of a polarized gel layer. This was based on prior knowledge of the gel characteristics of soybean proteins and the gel-like behavior of highly structured macromolecules (at concentrations in excess of $\sim 10$ wt. \%), which were in good agreement with experimental values. Additionally, the hysteresis effects observed as pressure was varied in these experiments supported the hypothesis that interactions had occurred between solute molecules which were approaching a consolidated "close packed" configuration. Citing the marked differences in the mass transfer properties of feed solutions, Cheryan suggested that mass transfer models will have to be supplemented with experimental data to be used in UF process design [Cheryan 1977, Cheryan 1986]. 


\section{Membrane Fouling}

Membrane fouling can also result in a decrease in permeate flux over time. Fouling is a term used to describe the loss of throughput of a membrane device as it becomes chemically or physically changed by a process fluid. Fouling is different from concentration polarization. Both phenomena result in a reduced membrane system output and the resulting resistances due to both phenomena are additive. For example, when the flow rate in a cross-flow membrane separation system is reduced, permeate flux will decrease. If the decrease in permeate flux is due only to the effects of concentration polarization (i.e., the accumulation of solute molecules at the membrane surface), the permeate flux should return to the initial value when the flow rate is raised. However, if the permeate flux does not increase to the initial value when the flow rate is increased, membrane fouling is the operative flux decline phenomena.

Membrane fouling is primarily due to (1) pore plugging and/or (2) solute adsorption. In the case of pore plugging, solute molecules or other minor constituents of a feed stream (e.g., bacteria) are forced into the membrane pores resulting in a loss of permeate flow channels and thus a decrease in permeate flux. Pore plugging becomes more prevalent under operating conditions such as low hydraulic turbulence and high transmembrane pressure. At low hydraulic turbulence, a thicker solute layer accumulates on the membrane surface. When combined with high transmembrane pressure, the potential for forcing solute molecules into the membrane pores increases. Additionally, if solute molecules are small enough to enter the membrane pores, some solute may be adsorbed onto the pore walls. The adsorbed molecules decrease the effective pore 
diameter. As the effective pore diameter is decreased, the overall resistance to hydraulic flow increases and a decreased in permeate flux is observed. Solute adsorption is due principally to physical and/or chemical properties of the feed solution. [Jonsson and Tragardh 1990]

In both cases, the proper selection of operating conditions, pretreatment of the feed, and cleaning methods are important aspects to minimizing flux loss due to membrane fouling. For example, the transmembrane pressure should be balanced to provide maximum permeate flux at the minimum transmembrane pressure. Thus, an understanding of the flux-pressure relationship presented schematically in Figure (2.11) is important to the minimization of membrane fouling. Specifically, a membrane separation system should not be run at transmembrane pressures in excess of the value necessary to achieve a mass-transfer-controlled permeate flux.

Feed pretreatment is often stream or site-specific and has received little attention in the literature. However, steps such as removing free oil from a waste or process stream prior to the application of membrane separation are often used to minimize potential membrane fouling.

The primary method of restoring permeate flux lost to membrane fouling is membrane cleaning. Fouling which can be removed through membrane cleaning is called "reversible fouling" and fouling which cannot be removed through cleaning is called "irreversible fouling." Cleaning procedures are highly stream-specific. Although cleaning is used to restore permeate flux, the use of aggressive chemicals such as 
concentrated acidic and caustic solutions often results in shortened membrane life due to affects on membrane surface properties. [Perry and Green 1997]

\section{Limitations Of Conventional Cross-Flow Ultrafiltration Systems}

A major limitation in the application of conventional UF membrane systems (e.g., tubular, hollow fiber, etc.) for the treatment of industrial wastewaters has been the low permeate flux observed at high solute concentrations. With time, a solute boundary layer forms as solute molecules accumulate on the membrane surface due to convective mass transport. This accumulation of solute molecules at the membrane surface is referred to as concentration polarization and is shown schematically in Figure (2.11). If the accumulated solute layer is sufficiently thick, a decrease in permeate flow rate will occur. The buildup of solute molecules at the membrane surface is reduced by back diffusion of solute molecules from the region of high concentration near the membrane surface to the region of lower solute concentration in the bulk solution. The solute boundary layer thickness can be further reduced by providing enhanced hydraulic turbulence to "scour" the accumulated solute from the membrane surface. In conventional membrane systems the hydraulically induced turbulence is provided by recycling a large portion $(\sim 98 \%)$ of the concentrate back to the membrane unit producing high liquid velocities $(\sim 5 \mathrm{~m} / \mathrm{s})$ near the membrane surface. These large velocities increase turbulence, which reduces the thickness of the solute boundary layer. However, conventional systems are unable to maintain the high velocities necessary to minimize the deleterious effects of the solute boundary layer on permeate flux because of the difficulty in pumping viscous liquids at 
high flow rates as the concentrate is thickened with treatment time. [Murkes and Carlsson 1988, Reed et al. 1997]

\section{MODELING PERMEATE FLUX}

In this section, the Hagen-Poiseuille model for pressure-controlled permeate flux; the osmotic pressure model; the thin-film model; and the resistance-in-series (RIS) model are presented and discussed. Additionally, hydraulic turbulence modeling in both conventional and mechanically enhanced membrane separation systems is presented and discussed.

\section{Pressure-Controlled Region--Hagen-Poiseuille Model}

Many attempts at modeling permeate flux have been presented in the literature, though none of which have been entirely satisfactory at predicting flux response to changes in operational parameters (feed concentration, pressure, temperature, etc.) The theoretical relationship between permeate flux, transmembrane pressure, and feed concentration is presented in Figure (2.11). At low feed concentrations and low transmembrane pressures, the Hagen-Poiseuille model for stream-line flow through channels in an ideal membrane system is generally accepted as the best description of fluid flow through a microporous membrane:

$$
\mathrm{J}=\varepsilon \mathrm{r}^{2}\left(\Delta \mathrm{P}_{\mathrm{T}}-\Delta \pi\right) / 8 \mu \Delta \mathrm{x}
$$

where $\mathbf{J}=$ permeate flux, $\varepsilon=$ membrane surface porosity, $\mathrm{r}=$ mean pore radius, $\Delta \mathrm{P}_{\mathrm{T}}=$ hydraulic pressure difference between the feed and the permeate, $\Delta \pi=$ osmotic pressure difference between the feed and the permeate, $\mu=$ viscosity of fluid permeating the membrane, and $\Delta \mathrm{x}=$ membrane thickness. The osmotic pressure term is generally small 
compared to the applied pressure in ultrafiltration due to the relatively high molecular weights of the retained solutes [Cheryan 1986]. In this case, $\Delta \pi \ll \Delta \mathrm{P}_{\mathrm{T}}$ and Equation (2.8) can be simplified:

$$
\mathrm{J}=\varepsilon \mathrm{r}^{2} \Delta \mathrm{P}_{\mathrm{T}} / 8 \mu \Delta \mathrm{x}
$$

Several assumptions are made when using the Hagen-Poiseuille model [Bird et al. 1960]: (1) The flow through the pore channel is laminar. (Cheryan (1986) validated this assumption statistically and experimentally.) (2) The permeate is incompressible (3) Permeate flow is independent of time ("steady state" conditions.) (4) The permeate fluid is Newtonian (i.e., the shear force per unit area is linearly proportional to the negative of the velocity gradient). (5) End-effects are negligible (i.e., the flow is "fully developed"). Additionally, the fluid flowing through the pores is generally considered to be contaminant-free water. Therefore, it is customary to use the viscosity of water as the $\mu$ term in Equation (2.9) when modeling permeate flux as a function of applied pressure [Cheryan 1986]. The viscosity of water at several common operating temperatures is presented in Table (2.2) [Weast 1976].

In the Hagen-Poiseuille model, the permeate flux is controlled directly by the transmembrane pressure and inversely by the permeate fluid viscosity. Since the viscosity of a fluid is directly proportional to the solids concentration in the fluid and inversely proportional to the fluid temperature, an increase in temperature will result in an increased permeate flux while an increase in feed concentration will result in a decrease in permeate flux. As the transmembrane pressure or feed concentration are 
Table (2.2)--Viscosity Of Water At Several Common Operating Temperatures [Weast 1976].

\begin{tabular}{|c|c|}
\hline Temperature $\left({ }^{\mathbf{0}} \mathbf{C} /{ }^{\mathbf{}} \mathbf{F}\right)$ & Viscosity of water $(\mathbf{c P})$ \\
\hline $20 / 68$ & 1.002 \\
\hline $25 / 77$ & 0.8904 \\
\hline $30 / 86$ & 0.7975 \\
\hline $35 / 95$ & 0.7194 \\
\hline $40 / 104$ & 0.6529 \\
\hline $45 / 113$ & 0.5960 \\
\hline $50 / 122$ & 0.5468 \\
\hline $55 / 131$ & 0.5040 \\
\hline $60 / 140$ & 0.4665 \\
\hline
\end{tabular}


increased, the permeate flux will become independent of pressure due to the effects of a buildup of solute molecules at the membrane surface. This situation will be discussed in the pressure-independent section.

\section{The Osmotic Pressure Model}

An osmotic pressure results from the high solute concentration at the membrane surface. In general, the concentration of solute at the membrane surface if a function of convective transport of solute molecules from the bulk feed solution to the membrane surface and the back diffusion of solute molecules from the membrane surface to the feed solution, as presented schematically in Figure (2.12). When the osmotic pressure due to solute accumulation at the membrane surface is not negligible when compared to the applied pressure, Equation (2.8) is used to model the permeate flux. In this case, it is assumed that the deviation from clean water flux is due only to the osmotic pressure at the membrane surface and not to other phenomena such as increased hydrodynamic resistance due to accumulated solute molecules. Additionally, the relationship between osmotic pressure and solute concentration is presented in Equation (2.10).

$$
\Delta \pi=\Xi C^{\mathrm{n}}
$$

where $\Xi$ and $n=$ empirically determined constants and $C=$ solute concentration at the membrane surface.

The osmotic pressure model has been tested in only a few cases. The primary limitation in modeling permeate flux using the osmotic pressure model a lack of osmotic pressure data in the form of Equation (2.10). However, in ultrafiltration applications, osmotic pressure is typically small compared to applied pressures and is typically 
neglected in the modeling of macromolecular solutes (e.g., oil-in-water emulsions and dairy proteins). [Cheryan 1986]

\section{The Thin-Film Model}

As the transmembrane pressure or the solute concentration is increased, or the hydraulic turbulence in the system is decreased, the flux becomes independent of pressure due to a buildup of high solute concentration at the membrane surface, relative to the bulk solute concentration. In the thin-film model presented in Equation (2.11), the permeate flux in the pressure-independent ("mass transfer-controlled") region uses the concept of concentration polarization as a basis to describe the asymptotic flux-pressure relationship shown schematically in Figure (2.11).

$$
\mathrm{J}=(\mathrm{D} / \delta) \ln \left(\mathrm{C}_{\mathrm{m}} / \mathrm{C}_{\mathrm{b}}\right)
$$

As the solute concentration at the membrane surface increases, a viscous "gel layer" may form. The "gel layer" can be an actual gel or the "closest-packed" arrangement of solute molecules without phase separation resulting from the restricted mobility of solute molecules near the membrane surface. In the case of gel layer formation, Equation (2.11) is:

$$
\mathrm{J}=\mathrm{k}_{\mathrm{s}} \ln \left(\mathrm{C}_{\mathrm{g}} / \mathrm{C}_{\mathrm{b}}\right)
$$

where $\mathrm{C}_{\mathrm{g}}=$ solute gel layer concentration. Before the gel layer has formed, the permeate flux is a weak function of the bulk solute concentration, $\mathrm{C}_{\mathrm{b}}$, because the solute concentration at the membrane surface increases with $\mathrm{C}_{\mathrm{b}}$. However, once the gel layer has formed, the permeate flux decreases semi-logarithmically with increasing bulk solute 
concentration. The gel layer concentration can be determined by extrapolating the linear portion of the flux versus log (bulk concentration) plot to zero flux. The application of the thin-film model is restricted to the mass transfer-controlled region where the concentration boundary layer plays the primary role in limiting flux. Cheryan (1986) noted several common flaws in experiments performed to determine gel layer concentrations. In particular, Cheryan cited the need to maintain constant flow rates and/or turbulence in a system, particularly at high feed concentrations. Additionally, individual experiments should be performed at discrete feed concentrations as data from direct concentration experiments will include effects of feed aging, denaturation of feed solute due to heat or shear, and fouling.

\section{Resistance-in-series model}

The RIS approach to permeate flux modeling is where the layer of particles at the membrane surface is considered to be a physical barrier to permeate flow:

$$
\mathrm{J}=\Delta \mathrm{P}_{\mathrm{T}} / \mathrm{R}
$$

where $\mathrm{R}=$ overall resistance to hydraulic flow. In UF systems, $\mathrm{R}$ is composed of three individual resistance terms:

$$
\mathrm{R}=\mathrm{R}_{\mathrm{m}}+\mathrm{R}_{\mathrm{f}}+\mathrm{R}_{\mathrm{p}}
$$

where $\mathrm{R}_{\mathrm{m}}=$ intrinsic membrane resistance; $\mathrm{R}_{\mathrm{f}}=$ fouling resistance; and $\mathrm{R}_{\mathrm{p}}=$ concentration polarization resistance. $R_{m}$ is determined using pure water as the feed solution. In this case, Equation (2.4) is used by measuring permeate flux as a function of transmembrane pressure. Typically, $\mathrm{R}_{\mathrm{f}}$ is caused by solute adsorption on the membrane and/or membrane pore plugging. Since fouling leads to alterations in physical makeup of 
the membrane, $R_{f}$ and $R_{m}$ are grouped together to form the total membrane resistance, $\mathrm{R}_{\mathrm{m}}$ :

$$
\mathrm{R}_{\mathrm{m}}{ }^{\prime}=\mathrm{R}_{\mathrm{m}}+\mathrm{R}_{\mathrm{f}}
$$

The resistance due to concentration polarization is related to $\Delta \mathrm{P}_{\mathrm{T}}$ by:

$$
\mathrm{R}_{\mathrm{p}}=\Phi \Delta \mathrm{P}_{\mathrm{T}}
$$

where $\Phi=$ resistance index. $\Phi$ is a function of system mass transfer properties. Combining Equations 2.13-2.16 yields:

$$
\mathrm{J}=\Delta \mathrm{P}_{\mathrm{T}} /\left(\mathrm{R}_{\mathrm{m}}{ }^{\prime}+\Phi \Delta \mathrm{P}_{\mathrm{T}}\right)
$$

Unlike the Hagen-Poiseuille and thin-film models, both the pressure-dependent and pressure-independent regions can be predicted using the RIS approach. In the pressure-dependent region (low $\Delta \mathrm{P}_{\mathrm{T}}$, low feed concentration, high turbulence), $\mathrm{R}_{\mathrm{p}}<\mathrm{R}_{\mathrm{m}}$ ' and $\mathrm{J}$ is linearly related to $\Delta \mathrm{P}_{\mathrm{T}}$. This is because the concentration polarization layer is not very thick under these conditions. In the pressure-independent region (high $\Delta \mathrm{P}_{\mathrm{T}}$, high feed concentration, low turbulence), the concentration polarization layer becomes increasingly thicker and denser and $R_{p}>R_{m}$ '. Under these conditions, $J$ is independent of $\Delta \mathrm{P}_{\mathrm{T}}$ at a value of $1 / \Phi$. In order to increase the pressure-independent permeate flux, it is desirable to reduce $\Phi$ by increasing hydraulic turbulence or feed temperature or decreasing the feed concentration.

Additionally, it is possible to quantify the individual resistances thus identifying the different flux decline constituents and determine the magnitude of the effect each individual resistance has on the permeate flux (Jonsson and Tragardh 1990). UF 
operation can be optimized by determining which resistances are the largest under a given set of operating conditions and taking measures to either reduce the resistance in question or improving system performance by changing the operational parameters.

\section{Mechanically Enhanced UF Systems}

Membrane fouling and the subsequent decline in permeate flux is a major barrier preventing the wider application of membrane technology. Although significant progress has been made to improve the chemical, mechanical, and thermal properties of membrane materials, there has not been a corresponding development of methods to combat the accumulation of solute molecules at the membrane surface and subsequent fouling of the membranes. As a consequence, the performance of new membranes rapidly degrades to that of conventional membrane filter systems. To address the problem of flux decline due to accumulation of solute molecules at the membrane surface, several mechanically enhanced UF modules have been designed. Primarily, two general types of mechanically enhanced UF systems have been reported on in the literature: (1) the rotating concentric cylinder and (2) the stacked rotary disk systems which improve upon the conventional tubular and plate and frame configurations, respectively. In each of these systems, a high-shear is induced at or near the membrane surface by rotating the membrane or a surface parallel to the membrane.

In conventional membrane systems, maximum surface velocities of approximately $15 \mathrm{ft} / \mathrm{s}(4.6 \mathrm{~m} / \mathrm{s})$ are possible while surface velocities of $60 \mathrm{ft} / \mathrm{s}(18 \mathrm{~m} / \mathrm{s})$ are typical in rotary systems. It is possible to treat extremely concentrated wastes with high-shear rotary UF systems because the cleaning action is effectively decoupled from 
the pressurization/feed recirculation by rotating the membrane surface at high speeds. In high-shear rotary UF systems, the pump is needed only to provide transmembrane pressure (the driving force) and a small amount of recirculation while the membrane rotation induces turbulence needed to minimize the thickness of the concentration boundary layer [Murkes and Carlsson 1988, Reed et al. 1997].

A schematic of a typical concentric cylinder module is presented in Figure (2.13) [Belfort et al. "Part 1," 1993]. In these systems, the inner cylinder contains a rotating porous membrane. Under specific conditions that will be detailed in a following section, toroidally shaped Taylor vortices will form in the annulus between the inner and the outer cylinders creating turbulence at the membrane surface. The formation of these Taylor vortices, in addition to the primary high-shear flow through the membrane module help to maintain a satisfactory permeate flux by minimizing the accumulation of solute molecules at the membrane surface. Rotating concentric cylinder systems have been limited to research applications for two reasons: (1) the shear force is the same at every point along the surface of the rotating cylindrical membrane, and (2) the annular space between the membrane and vessel wall has been found to be a suitable environment for rejected solute species to react with the liquid being filtered (e.g., a catalyst, an enzyme, adsorbents, etc.) In the second case, the filtration unit can also function as a chemical reactor [Belfort 1988].

In a typical rotary stacked disk UF system, membranes are attached to a series of multiple support plates separated by solid disks mounted on a central shaft. In a rotary 


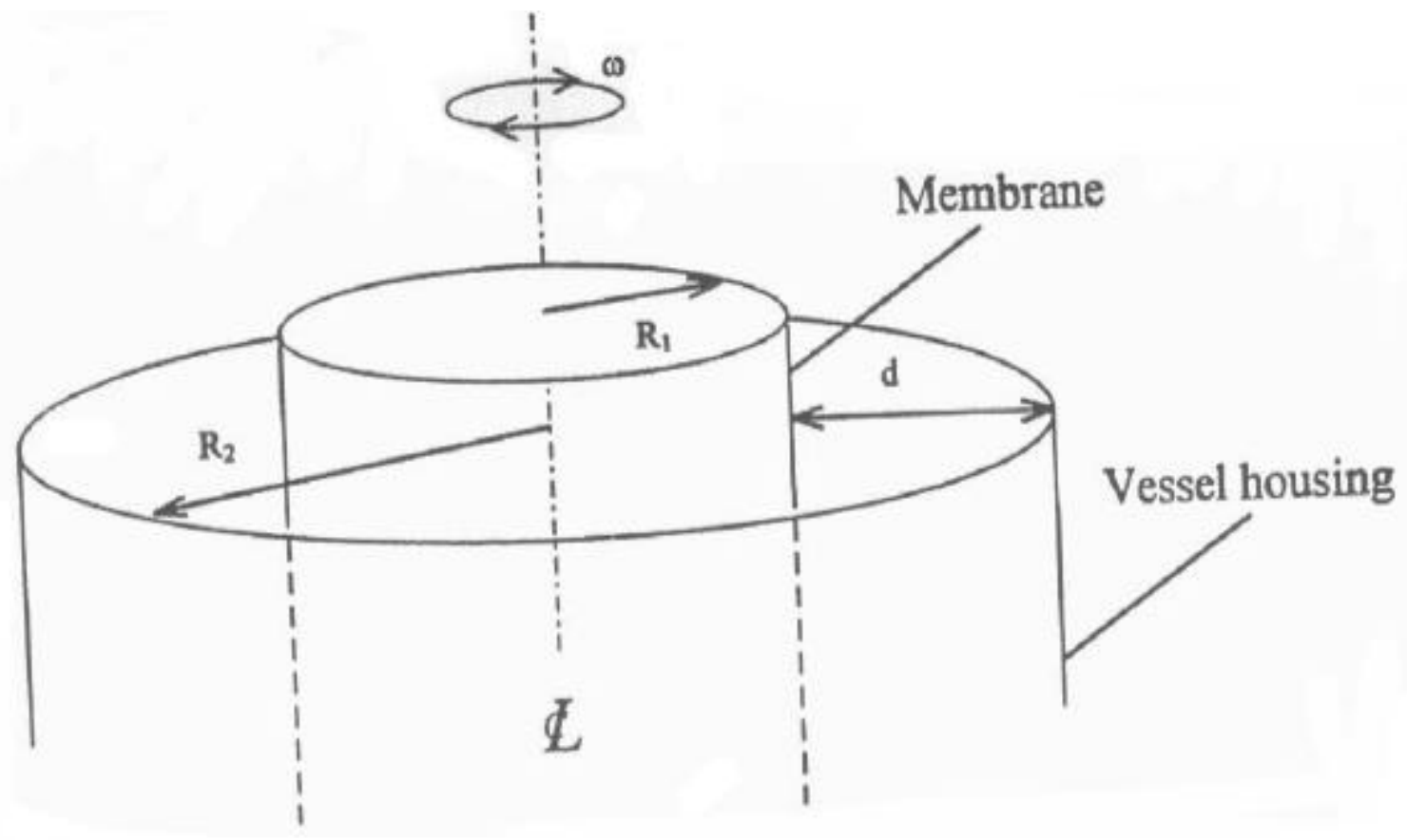

Figure (2.13)-A Schematic Of A Typical Concentric Cylinder Module 
stacked disk UF system, the membrane plate remains stationary while the solid disk rotates to induce turbulence, which minimizes the accumulation of solute molecules at the membrane surface. In some cases, small vanes have been added to the rotating disks to provide additional turbulence. Multiple disks can be connected in series or in parallel. Typically, a series arrangement is used in thickening/dewatering operations and a parallel arrangement is used when clarification is the principal objective of the process [Murkes and Carlsson 1988].

In rotary disk systems, the membrane-containing plates have traditionally remained stationary while the solid spacer disks are rotated due to difficulties in module design and operation such as devising an adequate sealing system for permeate collection through a rotating body. One recent variation on the rotary disk design is the SpinTek high-shear rotary ultrafiltration unit that has been studied by Reed et al. (ASCE 1997). In the SpinTek system, a series of round membrane disks packs are set on a hollow rotating shaft inside a cylindrical housing. A schematic of a high-shear rotary UF pressure vessel is presented in Figure (2.14). The fluid stream enters the membrane chamber under pressure and is distributed across the membrane surface by centrifugal and hydraulic action. Permeate is forced through the membrane, is collected through the hollow rotating shaft, and is discharged. The concentrate exits at the edge of the membrane pack and is returned to the feed tank to be further concentrated.

In a high-shear rotary UF unit, the rotation of the membrane disk is used to induce the hydraulic turbulence required to minimize the thickness of the concentration boundary layer. To enhance the effect of hydraulic turbulence, static turbulence 


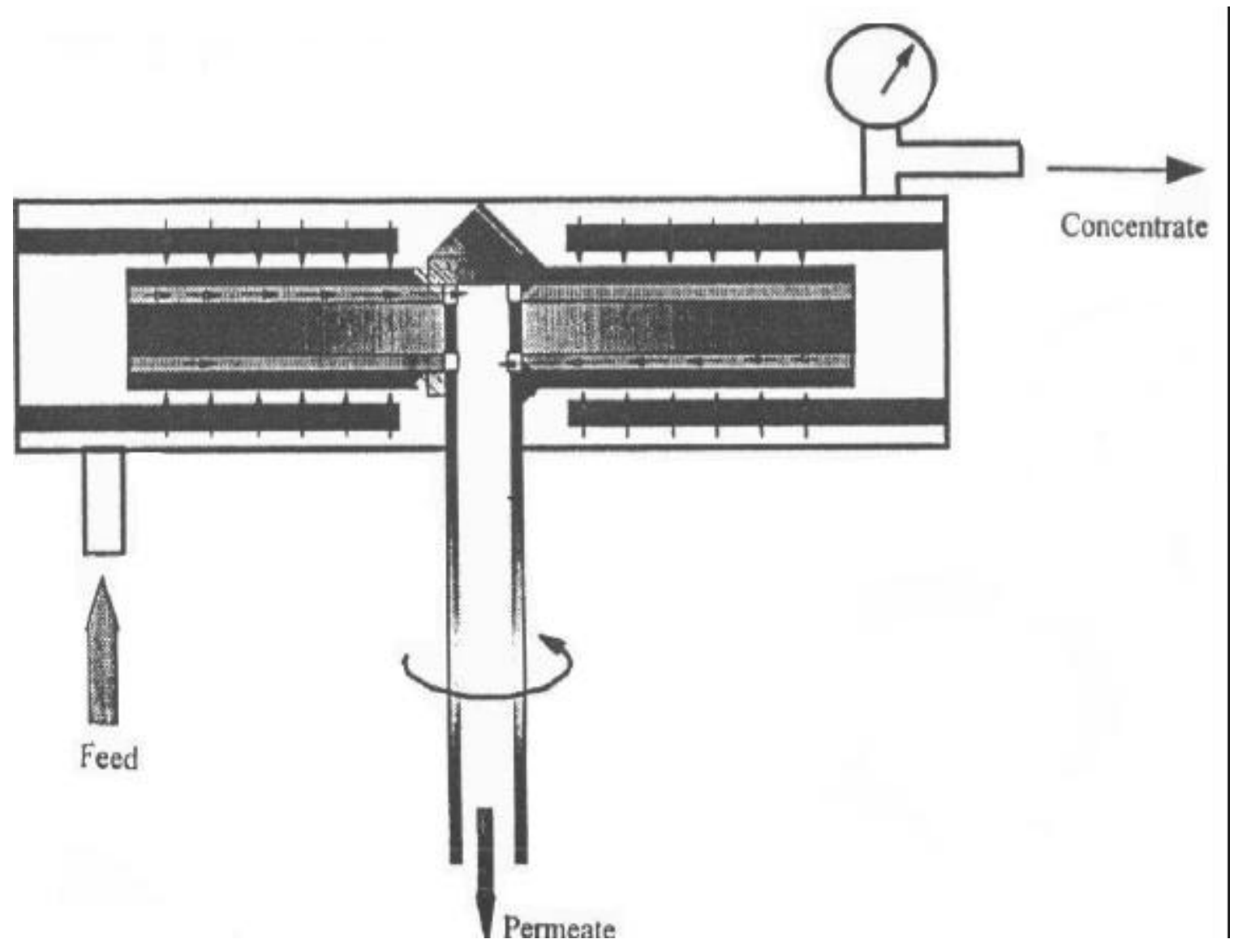

Figure (2.14)-Schematic Of A HSR-UF Pressure Vessel 
promoters ("wagon wheels") are located on both sides of the membrane disk pack to prevent vortex formation.

A less common mechanically enhanced UF system uses recirculating conically shaped "conditioning shuttles", illustrated in Figure (2.15), to remove deposits from the membrane surface. Multiple shuttles are connected to one another via a flexible cable. Shuttles are then forced through a tubular filtration device using the hydraulic flow of the feed solution. The conditioning shuttle system has not been commercialized and no data on its performance have been presented in the literature [Benson 1994].

\section{Flow Conditions In Rotary Membrane Systems}

In a rotating concentric cylinder UF membrane system, a high-shear is achieved by using the rotation of the inner cylinder (containing a porous membrane) to form Taylor vortices in the annular gap between the membrane surface and the vessel wall. For the geometry illustrated in Figure (2.13), the Taylor Number, Ta, is defined as:

$\mathrm{Ta}=\left(\omega \mathrm{R}_{1} \mathrm{~d} / \mu\right)\left[2 \mathrm{~d} /\left(\mathrm{R}_{1}+\mathrm{R}_{2}\right)\right]^{1 / 2}$

where $\omega=$ membrane rotational speed, $R_{1}=$ inner cylinder radius, $R_{2}=$ outer cylinder radius, $d=$ annular gap width, and $\mu=$ feed fluid viscosity. When the Taylor Number exceeds the critical value given in Equation (2.19) by increasing the membrane rotational speed, cellular vortex patterns, known as a "Taylor Vortices," will be formed. The critical Taylor Number, Ta $a_{\text {crit }}$, in the system was defined by Lieberherr (1978) as:

$$
\mathrm{Ta}_{\mathrm{crit}}=41.1+13.1 \mathrm{~d} / \mathrm{R}_{1}
$$




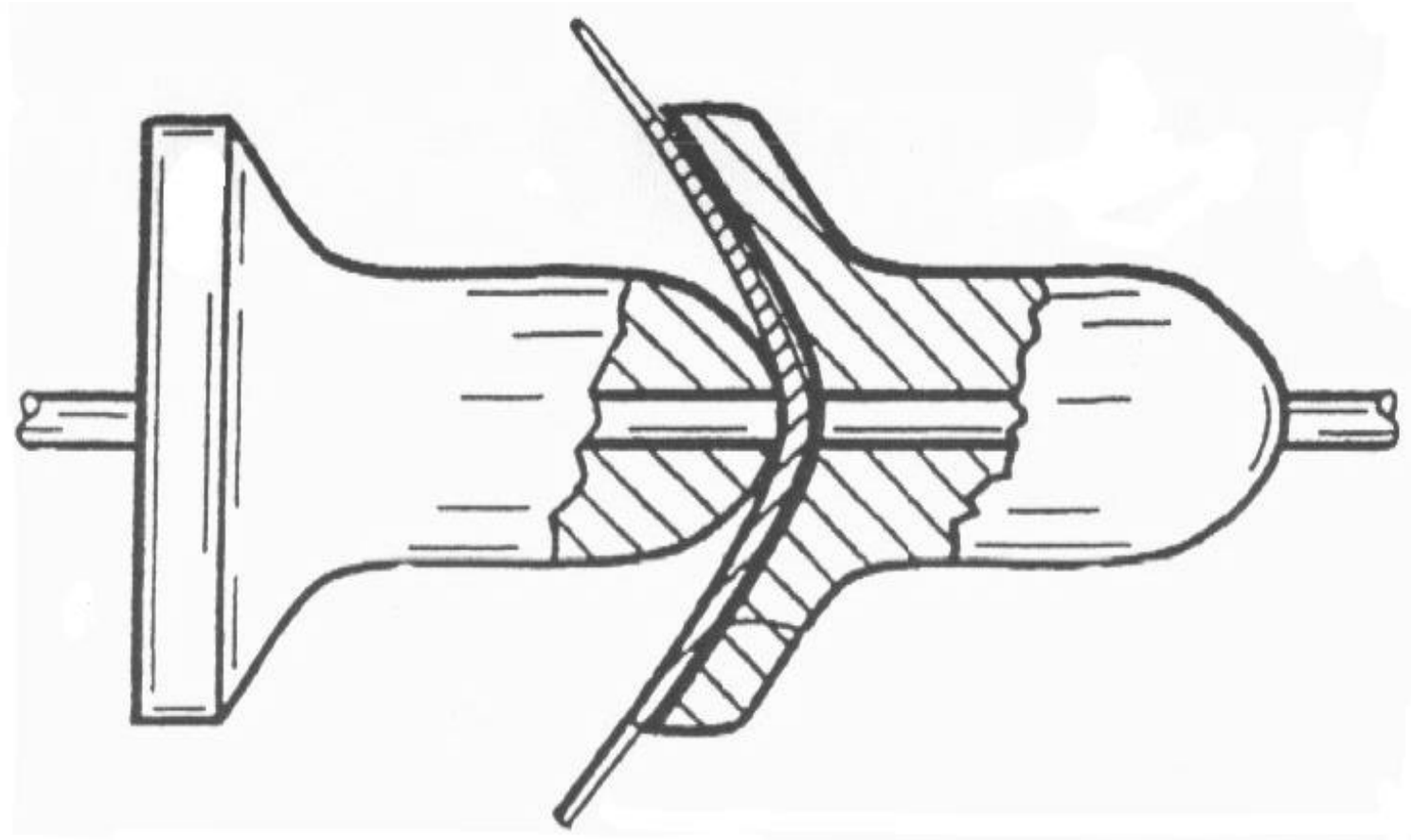

Figure (2.15)-Illustration Of "Conditioning Shuttles." 
As the membrane rotational speed is increased further, the flow becomes turbulent. Typically the transition to turbulent flow in rotating concentric cylinder modules occurs at $\mathrm{Ta} \geq 400$ [Murkes and Carlsson 1988].

In a rotary disk UF membrane system, a high-shear is achieved by rotating the membrane surface. The flow in the rotary disk system rotary disk system is characterized by two Reynolds Numbers: (1) in the axial direction between the membrane disk and the vessel housing presented in Equation (2.20) and (2) in the radial direction presented in Equation (2.21).

$$
\begin{aligned}
& \operatorname{Re}_{\mathrm{s}}=\omega \mathrm{s}^{2} / \nu \\
& \operatorname{Re}_{\mathrm{r}}=\omega \mathrm{r}^{2} / \nu
\end{aligned}
$$

where $\omega=$ rotational speed, $\mathrm{s}=$ spacing between the membrane and the housing, $\mathrm{r}=$ membrane radius, and $v=$ kinematic viscosity of feed solution. For a given feed solution, the maximum Reynolds Number occurs at the outer radius of the rotating disk and increases with rotational speed [Murkes and Carlsson 1988].

Ketola and McGrew (1968) identified four distinct flow regimes for a partially wetted rotating disk based on the radial Reynolds Number and the spacing ratio between the disk and the stationary wall. The membrane radius and spacing in a high-shear rotary UF system are presented in Figure (2.16). Ketola and McGrew assumed there is no radial net flow in the development of this set of flow conditions.

Case I--Laminar flow and narrow gap.

$$
\operatorname{Re}_{\mathrm{S}}<4 \text { and } \mathrm{Re}_{\mathrm{r}}<2 \times 10^{5}
$$


The laminar boundary layers are merged to produce a shear rate which varies inversely with spacing, $s$. The shear stress, $\tau$, in this case is:

$$
\tau_{\mathrm{I}}=\mu \omega \mathrm{r} / \mathrm{s}
$$

where $\mu=$ viscosity of the feed solution and $\rho=$ density of the feed solution.

Case II--Laminar flow and wide gap.

$$
\operatorname{Re}_{\mathrm{s}}>4 \text { and } \mathrm{Re}_{\mathrm{r}}<2 \times 10^{5}
$$

Under the Case II hydraulic flow condition, separate boundary layers are formed and the shear rate is independent of spacing, s. The shear stress in this case is:

$$
\tau_{\text {II }}=1.81 \rho v^{1 / 2}(\mathrm{~K} \omega)^{3 / 2} \mathrm{r}, 0<\mathrm{K}<1
$$

The area between the boundary layers moves like a solid body with a rotational speed of $\mathrm{K} \omega$, where $0<\mathrm{K}<1$ ( $\mathrm{K}$ is a dimensionless constant).

Case III--Turbulent flow and narrow gap.

$$
\operatorname{Re}_{\mathrm{r}}>2 \times 10^{5} \text { and } \mathrm{s} / \mathrm{r}<0.05
$$

The hydraulic flow under this condition is characterized by two merged turbulent boundary layers. The shear stress in this case is:

$$
\tau_{\text {III }}=0.008 \rho(\omega r)^{7 / 4}(\mathrm{v} / \mathrm{s})^{1 / 4}
$$




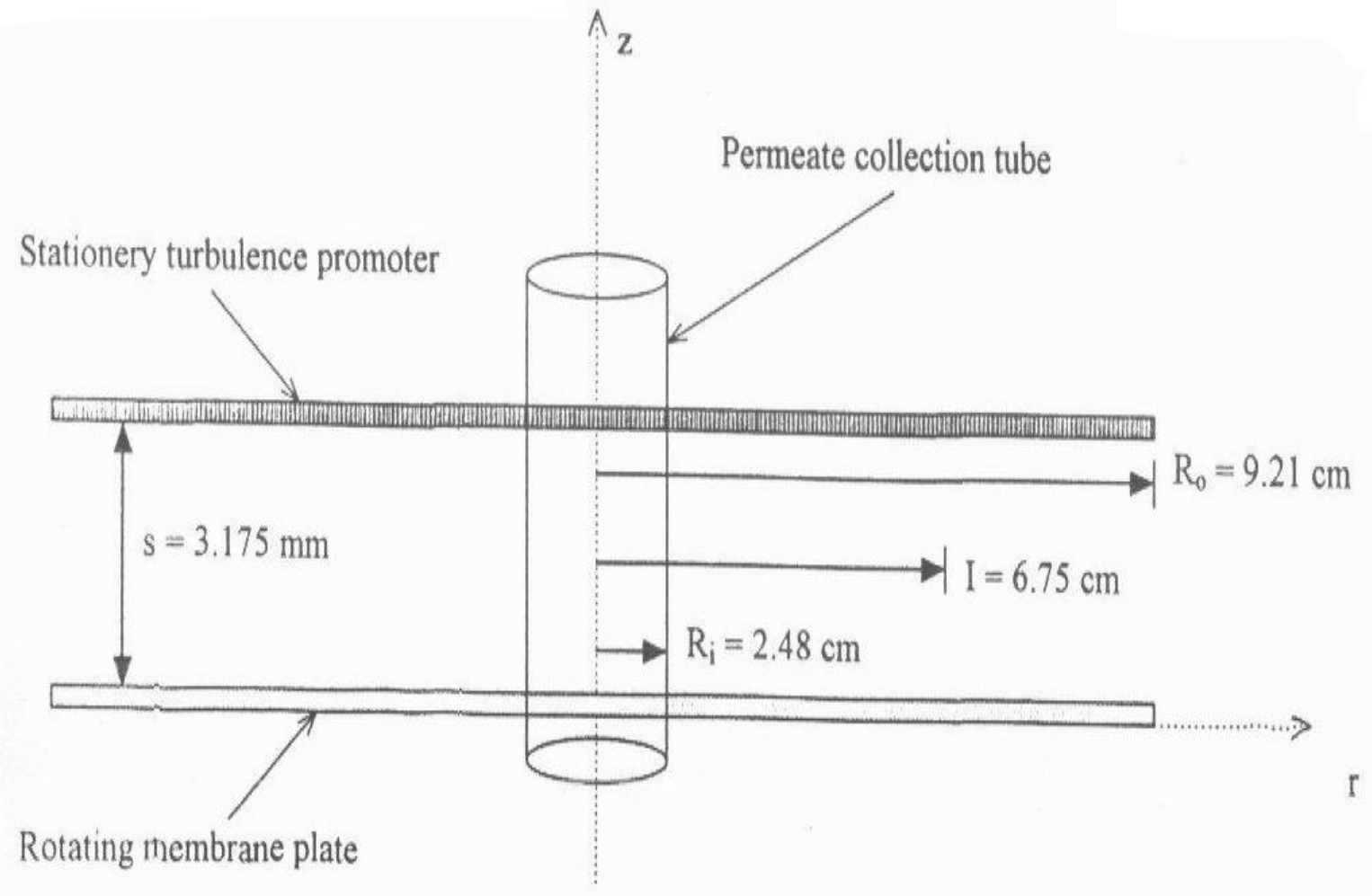

Figure (2.16)-The Membrane Radius And Spacing In A HSR-UF System 
Case IV--Turbulent flow and wide gap.

$$
\operatorname{Re}_{\mathrm{r}}>2 \times 10^{5} \text { and } \mathrm{s} / \mathrm{r}>0.05
$$

Under Case IV hydraulic flow conditions, two boundary layers are formed separated by a turbulent core region. The shear stress in this case is:

$$
\tau_{\mathrm{IV}}=0.057 \rho v^{1 / 5}(\mathrm{~K} \omega)^{9 / 5} \mathrm{r}^{8 / 5}, 0<\mathrm{K}<1
$$

Murkes and Carlsson reported that $\mathrm{K}$ values ranging from 0.4 to 0.5 gave good agreement with experiments for the laminar flow wide gap (Case II) and turbulent flow wide gap (Case IV) flow conditions. Additionally, when eight radial vanes were installed on a rotating membrane disk, a $\mathrm{K}$ value of $0.90(\underline{\sim} 1.0)$ was reported under turbulent flow wide gap (Case IV) conditions which gave a large increase in shear stress and a corresponding increase in filter flux.

In rotary membrane separation systems, the hydraulic turbulence represented by the Reynolds Number can be further expressed in terms of the membrane rotational speed, $\omega$, or the shear stress, $\tau$. Thus, the power law relationship presented can be expressed as:

$$
\mathrm{J}=f(\operatorname{Re} \text { or } \omega \text { or } \tau)^{\mathrm{n}}
$$

The value of $\mathrm{n}$ in Equation (2.26) can be determined by calculating the slope of a line through the data in a log-log plot of permeate flux in the mass transfer-controlled region versus Reynolds Number, the shear stress, or membrane rotational speed. A summary of $\mathrm{n}$ values for several process streams are presented in Table (2.3). 


\section{Permeate Backpressure In A High-Shear Rotary UF System}

In the high-shear rotary UF system illustrated previously in Figures (2.14) and (2.16), the central aim is to use membrane rotation to induce turbulence at the membrane surface to reduce the thickness of the flux-defeating solute boundary layer. However, in addition to providing turbulence in the system, membrane rotation has an impact on the net transmembrane pressure. The effects of membrane rotation on net transmembrane pressure in rotary concentric cylinder UF systems were reported on by Belfort et al. ("Part 1," 1993) and Dolcek et al. (1995). In the high-shear rotary UF system, nonuniformly distributed backpressure results from centrifugal force exerted on permeate due to membrane rotation. The permeate backpressure for a given membrane rotational speed and radius is expressed as:

$$
\mathrm{p}_{\text {back }}=\left[\rho(\omega \mathrm{r})^{2}\right] / 2
$$

where $\omega=$ rotational speed, $r=$ outer membrane radius, and $\rho=$ feed solution density. The maximum and minimum permeate backpressures are found at the maximum and minimum disk radii, respectively. The average backpressure due to centrifugal force on the permeate in the high-shear rotary UF system can be determined using the radius of gyration for a flat rotating ring as the radial term in Equation (2.27).

$$
p_{\text {back-avg }}=\left[\rho(\mathrm{I} \omega)^{2}\right] / 2
$$

where $\mathrm{I}$ = radius of gyration (an average radial property of a rotating body) for a flat rotating ring. The explicit form of the radius of gyration term for the rotating ring is [Weast 1976]: 
Table (2.3)--A Summary of $\mathbf{n}$ Values For Several Process Streams.

\begin{tabular}{||c|c|c|c|c||}
\hline Feed Solution & $\begin{array}{c}\text { Membrane } \\
\text { system }\end{array}$ & $\begin{array}{c}\text { State of } \\
\text { Turbulence }\end{array}$ & $\mathbf{n}$ & Reference \\
\hline \hline Skim milk & $\begin{array}{c}\text { Hollow } \\
\text { fiber }\end{array}$ & Laminar & 0.60 & Chiang 1982 \\
\hline $\begin{array}{c}\text { 7\% electrocoat } \\
\text { paint }\end{array}$ & $\begin{array}{c}\text { TC-1, 10- } \\
\text { mil, PM-30 }\end{array}$ & Turbulent & 1.17 & Porter 1979 \\
\hline $\begin{array}{c}\text { 15\% electrocoat } \\
\text { paint }\end{array}$ & $\begin{array}{c}\text { TC-1, 10- } \\
\text { mil, PM-30 }\end{array}$ & Laminar & 1.33 & Porter 1979 \\
\hline $\begin{array}{c}15 \% \text { electrocoat } \\
\text { paint }\end{array}$ & $\begin{array}{c}\text { TC-1,10- } \\
\text { mil, PM-30 }\end{array}$ & Turbulent & 1.23 & Porter 1979 \\
\hline $\begin{array}{c}0.9 \% \text { Carbowax } \\
1 " \text { dia. } \\
\text { tubular, } \\
\text { HFA-300 }\end{array}$ & Turbulent & 0.87 & de Filippi 1977 \\
\hline $\begin{array}{c}\text { Bovine serum } \\
\text { albumin }\end{array}$ & $\begin{array}{c}\text { Spinning } \\
\text { disk }\end{array}$ & Turbulent & 0.50 & Kozinski and Lightfoot \\
\hline $\begin{array}{c}\text { Oil-in-water } \\
\text { emulsion }\end{array}$ & $\begin{array}{c}1 \text { "dia. } \\
\text { tubular }\end{array}$ & Turbulent & 1.2 & Goldsmith et al. 1974 \\
\hline $\begin{array}{c}\text { Oil/water emulsion } \\
\text { High shear } \\
\text { rotary UF } \\
\text { system }\end{array}$ & Turbulent & 0.9 & Reed et al. 1997 \\
\hline
\end{tabular}




$$
\mathrm{I}=\left[\left(\mathrm{R}_{\mathrm{i}}{ }^{2}+\mathrm{R}_{\mathrm{o}}{ }^{2}\right) / 2\right]^{1 / 2}
$$

where $R_{i}=$ inner radius and $R_{o}=$ outer radius. The maximum permeate backpressure, $\mathrm{p}_{\text {back-max }}$, is observed along the outer radius of the rotating disk, $\mathrm{R}_{\mathrm{o}}$ :

$$
\text { pback-max }=\left[\rho\left(\omega R_{\mathrm{o}}\right)^{2}\right] / 2
$$

In the high-shear rotary UF system, the average transmembrane pressure, $\mathrm{p}_{\text {tmp-avg, }}$ is the difference between the gauge pressure, $p_{\text {gauge, }}$ and the average permeate back pressure, pback-avg:

$$
\mathrm{p}_{\text {tmp-avg }}=\mathrm{p}_{\text {gauge }}-\mathrm{p}_{\text {back-avg }}
$$

An important aspect of the pressure/rotation relationship in a high-shear rotary disk system is the need to set the system operating parameters to ensure a positive net transmembrane pressure:

$$
p_{\text {gauge }}>\text { p }_{\text {back-max }}
$$

where p $_{\text {back-max }}=$ maximum permeate backpressure (observed at the maximum membrane radius) for a given membrane rotational speed. If the condition in (2.32) is not met, the driving force will reverse, forming a vacuum which can force fluid from the permeate side of the membrane back to the concentrate side. Vacuum formation could result in serious operational difficulties such as membrane delamination and a loss in operating efficiency. 


\section{Mechanically Enhanced Ultrafiltration Case Studies}

In this section, general studies on the operation and modeling of mechanically enhanced UF systems are discussed. Studies that deal specifically with the mechanically enhanced ultrafiltration of oily wastewaters are discussed separately.

To minimize the effects of concentration polarization, Lopez-Leiva (1980) investigated the application of a rotating concentric cylinder membrane, a rotary disk and frame (RDF) module, and a "Roto-Shear" (RS) unit. The concentric cylinder membrane system was similar to the unit used by Belfort, et al. ("Part 1" and "Part 2" 1993) and Dolecek et al. (1995). The RDF module used whole plates to separate a series of stacked disk membranes and the RS unit used rotating blades situated in between membrane disks to enhance turbulence at the membrane surface. In a study using a feed solution of bovine serum albumin (BSA) at 0.5 to $1.0 \%$, Lopez-Leiva reported that the concentric cylinder module was effective at reducing the effects of concentration polarization to near negligible values at low feed solute concentrations and high cross-flow velocities. Experiments were conducted at membrane rotational speeds ranging from $\sim 250$ to 4250 $\mathrm{rpm}$, at $15^{\circ} \mathrm{C}$, and pressures ranging from 0.3 to $0.5 \mathrm{MPa}$ ( $\sim 4$ to $116 \mathrm{psig}$ ).

Lopez-Leiva (1980) examined the performance of the two rotary disk units using a feed solution of skim and whole milk. Lopez-Leiva reported that high concentrations ( $\sim 5 \%$ total solids) could be obtained using both the RDF and the RS rotary disk units. However, when the energy consumption per liter of milk processed as a function of total solids content was calculated, Lopez-Leiva reported that the RDF module was more energy efficient compared with the RS unit. Lopez-Leiva suggested that for the RS unit, 
which used blades placed between the membrane disks as turbulence promoters, vortices and wakes might have resulted in large energy losses. These energy losses were not transmitted to the concentration boundary layer and as a result, the energy did not go to improve mass transfer but was dissipated as heat.

Belfort et al. ("Part 1," 1993) performed a study to examine the performance of a rotating annular filter similar in design to the module presented schematically in Figure (2.13). In these experiments, the transmembrane pressure was corrected to account for the centrifugal pressure exerted on the permeate using a narrow-gap solution to the Navier-Stokes equations for azimuthal flow in an annulus and Darcy's Law for flow through a porous wall on the inner rotating cylinder. Rotational speeds ranged from 500 to 4,000 rpm and transmembrane pressures ranged from $\sim 20$ to $100 \mathrm{kPa}$ ( $\sim 3$ to $14.5 \mathrm{psig}$ ). These experiments were conducted using a $0.45 \mu \mathrm{m}$ polysulfone microfilter and a 100 $\mathrm{kDa}$ ultrafilter with feed solutions of cell cultures (bovine serum albumin, ovalbumin, and lactoglobulins).

The governing equation derived by Belfort et al. ("Part 1," 1993) for the wall velocity (or flux) is presented in Equation (2.33). The authors considered the components of the flow to be idealized (i.e., approximately laminar), without vortices, and weakly coupled to solve for the permeate flux in terms of the annular pressure and the permeate pressure:

$$
\mathrm{v}_{\mathrm{w}}=(\kappa / \Delta \mathrm{x})\left[\mathrm{P}_{1}-\rho \omega^{2} \mathrm{R}_{1}^{2}\left(\mathrm{~d} / 3 \mathrm{R}_{1}\right)\right]
$$

where $\kappa=$ membrane permeability, $\Delta \mathrm{x}=$ membrane thickness, $\mathrm{P}_{1}=$ pressure at the surface of the tubular membrane, $\rho=$ fluid density, $\omega=$ angular velocity of the rotating 
cylinder, $\mathrm{R}_{1}=$ radius of the tubular membrane, and $\mathrm{d}=$ distance between the inner tube filter and the vessel wall. Equation (2.33) is actually the lowest order expansion of a much more complicated expression. In the simplification it was assumed that the membrane thickness and annular spacing were much less than the membrane radius, $\mathrm{R}_{1}$ ("thin slit" approximation.") The Navier-Stokes equations were first simplified assuming the velocity in the radial direction was small. Additionally, the small gap assumption mentioned earlier was used. The alternative approach resulted in an equation with the same functional dependence as in Equation (2.33). In Equation (2.34), Belfort et al. ("Part 1," 1993) identified the centrifugal pressure due to membrane rotation, $\Delta \mathrm{P}_{\text {cent }}$.

$$
\Delta \mathrm{P}_{\text {cent }} \simeq\left(\rho \omega^{2} \mathrm{R}_{1}^{2}\right)\left(\mathrm{d} / 3 \mathrm{R}_{1}\right)
$$

Belfort et al. ("Part 1," 1993) then conducted experiments using commercially available cell culture media to empirically verify the flux-pressure model presented in Equation (2.33). In these experiments, large differences between theoretically predicted and experimental data were observed when the transmembrane pressure was not corrected to account for centrifugal pressure effects. However, when the centrifugal pressure correction was employed, the data from these experiments collapsed onto a single straight line $\left(\mathrm{r}^{2}=0.9485\right)$ as predicted by the governing equation given in Equation (2.33). The data in these experiments were entirely in the pressure-controlled region.

Since Belfort et al. did not have a detailed understanding of the influence of the solute deposition on the membrane surface as a function of transmembrane pressure, a phenomenological approach was used to study the effects of rotation on membrane 
fouling. Belfort et al. assumed the resistance to flow was directly dependent on transmembrane pressure and inversely proportional to the rotational speed. It was concluded that the transmembrane pressure (which itself is a function of rotation as presented in Equation (2.33)) can be used to: (1) clean the membrane by creating a highshear by forcing fluid through the vessel channel; (2) overcome the added resistance to flow created by pore narrowing, constriction, and plugging; and (3) to overcome a serial resistance to flow which results from a build-up of a gel/cake layer through upstream solute deposition on the membrane surface.

In a related paper, Belfort et al. ("Part 2," 1993) used the resistance in series approach to determine the serial resistance introduced by the accumulation of solute at the membrane surface and plotted the resistance against the transmembrane pressure. Experiments were conducted using a $0.45 \mu \mathrm{m}$ polysulfone microfilter and a $100 \mathrm{kDa}$ ultrafilter with feed solutions of deioniozed water, and 1 wt.\% solid suspensions of styrene-divinyl-benzene and styrene-polytoluene. An annular gap to membrane radius ratio of 0.1102 and transmembrane pressures ranging from $\sim 0$ to $30 \mathrm{kPa}$ (0 to $\sim 4.4 \mathrm{psi}$ ) were used in the study. A steady decrease in the resistance of the colloidal layer with increasing membrane rotation was observed. It was hypothesized that the increase in rotation had the effect of decreasing the thickness of the concentration boundary layer that resulted in a decreased hydrodynamic resistance.

In a theoretical assessment of rotating filter performance similar to those of Belfort et al. ("Part 1" and "Part 2," 1993), Dolecek et al. (1995) solved the NavierStokes and continuity equations with Darcy's Law to analyze the flow of a pure fluid 
through an annulus with a rotating inner porous wall. Dolecek et al. then compared the results with data presented by Belfort et al. ("Part 2," 1993). However, Dolecek et al. neglected the formation of Taylor vortices by restricting the experiments to flows below the critical Taylor number (i.e., the number above which Taylor vortices will form) to eliminate additional complications associated with accounting for the annular flow and subsequent pressure effects caused by the formation of Taylor vortices. For the rotating concentric cylindrical filtration system, Belfort et al. ("Part 2," 1993) presented the following expression for the Taylor Number, Ta:

$$
\mathrm{Ta}=\left[\mathrm{R}_{1} \omega\left(\mathrm{R}_{2}-\mathrm{R}_{1}\right) / \mathrm{v}\right]\left[\left(\mathrm{R}_{2}-\mathrm{R}_{1}\right) / \mathrm{R}_{1}\right]^{1 / 2}
$$

where $R_{1}=$ membrane radius, $R_{2}=$ vessel radius, and $v=$ kinematic viscosity of the feed solution. Since the shear rate at the surface of the membrane depended upon the rate of membrane rotation, the Taylor number was also a function of rotation.

Dolecek et al. identified three pressure terms as contributing to the overall driving force, $\Delta \mathrm{P}_{\text {total }}$, in the system given in Equation (2.36): (1) a centrifugal term $\left(\Delta \mathrm{P}_{\text {cent }}\right),(2) \mathrm{a}$ radial convection term $\left(\Delta \mathrm{P}_{\text {radial }}\right)$, and (3) a Darcy's Law term $\left(\Delta \mathrm{P}_{\text {Darcy }}\right)$ which accounted for the hydrodynamic resistance of the membrane. It was reported that in general, the pressure drop due to a change in the radial velocity was negligible when compared with the centrifugal and Darcy's Law terms (i.e., a weak axial pressure drop).

$$
\Delta \mathrm{P}_{\text {total }}=\Delta \mathrm{P}_{\text {cent }}+\Delta \mathrm{P}_{\text {radial }}+\Delta \mathrm{P}_{\text {Darcy }}
$$

Of particular interest in the rotating system was the "centrifugal pressure" term which was different than the expression developed in the simplified version of the rigorous development present by Belfort et al. ("Part 1," 1993). 


$$
\Delta \mathrm{P}_{\text {cent }}=\left\{\left(\rho \omega^{2}\right)^{*}\left[\mathrm{R}_{1}{ }^{2}-\left(\mathrm{R}_{1}-\Delta \mathrm{x}\right)^{2}\right]\right\} / 2
$$

where $\rho=$ fluid density, $\omega=$ angular velocity of the rotating cylinder, $R_{1}=$ radius of the tubular membrane, and $\Delta \mathrm{x}=$ membrane thickness.

$$
\Delta \mathrm{P}_{\text {radial }}=\left\{\left(\rho \mathrm{q}^{2} / 8 \pi^{2}\right)\left[1 /\left(\left(\mathrm{R}_{1}-\Delta \mathrm{x}\right)^{2}\right)-\left\{1 / \mathrm{R}_{1}^{2}\right)\right]\right\}
$$

where $\mathrm{q}=$ permeate flow rate.

$$
\Delta \mathrm{P}_{\text {Darcy }}=(\mathrm{q} / 2 \pi \kappa) \ln \left[\mathrm{R}_{1} /\left(\mathrm{R}_{1}-\Delta \mathrm{x}\right)\right]
$$

where $\kappa=$ membrane permeability. (Permeate side pressure was assumed to be zero.) The form of the Darcy's Law term is the same as shown by Belfort et al. ("Part 1" 1993).

The results of the theoretical model developed by Dolecek et al. were compared with experimental flux-pressure data observed by Belfort et al. ("Part 1," 1993). The experimental flux-pressure data were taken over a 20 to $\sim 90 \mathrm{kPa}$ (2.9 to $\sim 13 \mathrm{psi}$ ) range in which the data were entirely in the pressure-controlled region. The theoretical model tended to overestimate the permeate flux at any given pressure and rotational speed. The authors attributed the discrepancy to a hydrostatic backpressure in the permeate chamber $(\sim 2$ to $3 \mathrm{kPa})$ which tended to reduce the experimentally observed net $\Delta \mathrm{P}_{\text {total }}$. The formation of complex flow patterns such as Taylor vortices may have been an additional contribution to the difference between the model developed by Dolecek et al. and the experimental results observed by Belfort et al. ("Part 2," 1993). 


\section{MEMBRANE TREATMENT OF OILY WASTEWATERS}

In this section, general properties of oil-in-water emulsions and oily wastewaters is presented and discussed. Additionally, an overview of the membrane treatment of oily wastewaters is presented and discussed.

\section{Characteristics of Oil-In-Water (O/W) Emulsions and Oily Wastewaters}

The MW industry produces large volumes of oily wastewaters. Examples of MW processes which utilize large quantities of emulsified oils for lubrication, cooling, and quenching include metal rolling, forming, grinding, and cutting operations. Concentrations of oil and grease $(\mathrm{O} / \mathrm{G})$ vary widely across the MW industry. A summary of typical $\mathrm{O} / \mathrm{G}$ concentration ranges for selected industrial wastewaters is presented in Table (2.4) [Bennett 1988].

Oil is typically found in three forms in industrial processes: (1) free oil consisting of discrete oil droplets, usually $5 \mu \mathrm{m}$ in diameter or larger; (2) agglomerated oil made up of discrete oil droplets $5 \mu \mathrm{m}$ or less in diameter; and (3) emulsified oil in which fine globules of oil are dispersed in water by the addition of a chemical "emulsifier" [Laemmle 1992]. Free oil can be removed through gravity separation. Unstable emulsions containing agglomerated oil can be chemically broken. However, stable emulsions require increasingly sophisticated treatment techniques to meet more stringent effluent discharge guidelines. Traditionally, these wastewaters are treated using chemical addition followed by gravity separation techniques. Often, the effluent from chemicaladdition/solid-liquid separation processes required additional treatment prior to 
Table (2.4)--Typical O/G Concentration Ranges For Selected Industrial Wastewaters [Bennett 1988].

\begin{tabular}{|c|c|}
\hline Industry & O/G concentration range (mg/L) \\
\hline \hline Food processing & $100-1,000$ \\
\hline Textile (wool processing ) & $10-50$ \\
\hline Petroleum refining & $100-1,000$ \\
\hline Metal rinse water & $10-1,000$ \\
\hline Metal fabrication & $10,000-150,000$ \\
\hline Metal rolling & $4,000-50,000$ \\
\hline Commercial laundry & $100-2,000$ \\
\hline
\end{tabular}


discharge. In contrast, pressure-driven membrane separation systems can typically treat the waste in a single step and are gaining acceptance as an alternative treatment technology.

Emulsions are mixtures of either simple or compounded oils with water, stabilized by the use of emulsifiers and other additives such as secondary stabilizers/surfactants. Emulsified oils are widely used when both cooling and lubricating properties are required, whereas straight oils are used when lubrication is the main concern and cooling capacity is a minor factor. A schematic of an emulsified oil droplet is presented in Figure (2.17) (after Burke (1991)). In an oil-in-water emulsion, oil is said to be the "dispersed phase" and water is the "continuous phase." It is possible for an emulsion to have a net positive or neutral charge, depending upon the properties of the emulsifier. However, anionic emulsifiers are typically used in the cooling/lubricating fluids common in the MW industry. In a typical $\mathrm{O} / \mathrm{W}$ emulsion, oil globules are sequestered by a polar emulsifier, which consists of an oil soluble end and a negatively charged oleophobic/hydrophilic end. Typical oil globule sizes range from $\sim 0.2$ to $10 \mu \mathrm{m}$ [Laemmle 1992]. However, the size of oil globules in an O/W emulsion is not discrete throughout a solution but varies over some distribution which depends primarily on the ratio of oil to emulsifier, rather than on the oil content [Lipp, et al. 1988]. Since the typical size of the emulsified oil droplet is similar in size to, or greater than, the wavelength of visible light, these emulsions appear milky white. 


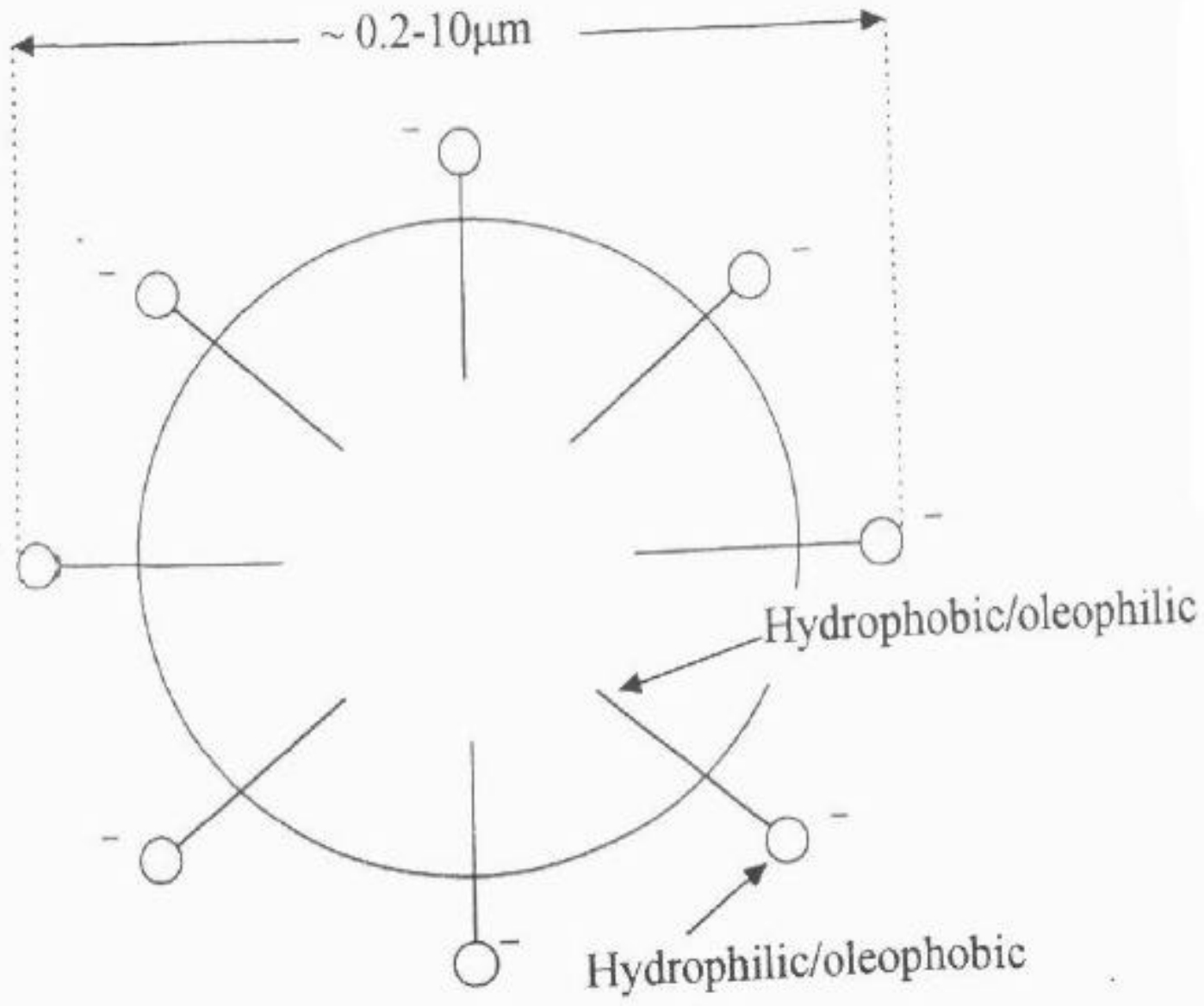

Figure (2.17)-Schematic Of Emulsified Oil Droplet (After Burke (1991).) 
The stability and lubricating characteristics of an $\mathrm{O} / \mathrm{W}$ emulsion used in MW processes are carefully balanced to optimize the operational properties of the solution. $\mathrm{O} / \mathrm{W}$ mixtures are thermodynamically unstable (i.e., state of lowest free energy is total phase separation). As a result, oil tends to separate from water in solution. To keep the oil droplets sequestered, emulsifiers and secondary stabilizers (chemicals that concentrate at the oil-water interface and prevent oil globule coalescence) are used. Since the hydrophilic end of the $\mathrm{O} / \mathrm{W}$ emulsion is negatively charged, the net surface charge of the emulsified oil droplet is negative. The emulsified oil droplets tend to stay dispersed due to electrostatic repulsion between the emulsified oil droplets. The emulsion is then said to be kinetically stable because the state of lowest free energy of the emulsion is still total separation. In general, stable emulsions tend to have a smaller average globule size distribution than unstable emulsions. Emulsion stability can vary over a wide range and is affected by the chemical nature of the oil and the concentrations of emulsifier and additives in the solution.

The ability of an O/W emulsion to provide sufficient lubrication is tied to the availability of the oil phase to lubricate (lubrication improves with oil availability). Both the emulsion stability and oil content control oil availability. Typically, oil availability increases as oil content increases and as emulsion stability decreases. Less stable emulsions are subject to rapid, often unpredictable, declines in stability over short periods of time. The transient behavior can lead to severe operating problems in MW processes such as rolling mill operations. Additionally, as the oil content in an emulsion increases, cooling capacity decreases because there is less water available for cooling. As a result, 
the stability and oil concentration of an emulsified MW fluid must be balanced to meet both the lubricating and cooling needs of each specific MW process, leading to the heterogeneous nature of wastewaters from the MW industry.

Since O/W emulsions are kinetically stable but not thermodynamically stable, the "batch life" of the coolant/lubricant package must also be taken into consideration. New emulsions are typically the most stable and have the least oil available for lubrication. Over time, the maximum performance of the emulsion is reached as emulsifiers are (1) depleted through biological degradation and (2) as debris generated in the emulsion provides nucleation sites for oil globule coalescence. However, as the emulsion is degraded further, the emulsion becomes so unstable as to be rendered useless and a new batch of emulsion must be introduced into the process. Emulsions that are initially more stable generally have a longer batch life than emulsions which are initially less stable [Laemmle 1992].

Typical $\mathrm{O} / \mathrm{W}$ emulsions used in rolling mill operations consist of complex proprietary mixtures of fatty acids and mineral oils, emulsifiers, biocides, stabilizers, anti-foaming agents, and rust inhibitors. The main $\mathrm{O} / \mathrm{G}$ components of these rolling mill oils are fatty acids and mineral oils. Wastewaters in rolling mill processes contain $\mathrm{O} / \mathrm{G}$ from coolant sprayed on metal strips to dissipate heat and lubricate the material sheets. Other contributions to $\mathrm{O} / \mathrm{G}$ concentrations in these wastewaters come from nonemulsified "tramp oils" which leak into the waste stream from ancillary mechanical operations (e.g., hydraulic fluids). Typical coolant/lubricant solutions used in MW operations contain approximately 5 to $10 \%$ emulsified oil and approximately 90 to $95 \%$ 
water [Laemmle 1992]. A common base oil package consists of $\sim 80 \%$ mineral oil and $\sim 20 \%$ additives (e.g., emulsifiers, anti-foaming agents, biocides, etc.). [Lee et al. 1984].

\section{Overview of Membrane Treatment of Oily Wastewaters}

Ultrafiltration has been successfully applied to the treatment of concentrated oily wastes from MW processes such as sheet rolling and die cutting. UF has been used to treat wastewaters high in oil, grease, and solids while reducing the volume of waste sent for disposal, while at the same time recovering alkaline process cleaner for re-use. The advantages of UF treatment of oily wastewaters over more traditional methods such as chemical addition solid/liquid separation include: (1) chemical additives are not necessary; (2) higher oil removal efficiencies; and (3) relative ease of use over other techniques [Lee et al. 1984].

\section{Conventional Ultrafiltration Systems}

Pinto (1978) reported that UF treatment of a waste cutting oil emulsions reduced the volume of wastewater by 95 to $98 \%$ and concentrated solids and oil as much as $60 \%$. Cheryan (1986) summarized the application of UF technology to the treatment of a mixed oily wastewater containing mineral oils, paraffin wax, oleic acid, and other oily constituents. The mixed waste stream was stabilized to minimize membrane fouling by adding a nonionic surfactant. The waste was then treated using Abcor tubular membranes $\left(72 \mathrm{~m}^{2}, 776 \mathrm{ft}^{2}\right.$ membrane area). The membrane pore size/molecular weight cut off (MWCO) was not specified. At an average pressure of 2.5 atm (37 psi), an

average permeate flux of $41 \mathrm{~L} / \mathrm{m}^{2}-\mathrm{h}\left(24 \mathrm{gal} / \mathrm{ft}^{2}-\mathrm{d}\right)$ was observed while maintaining a permeate water quality acceptable for direct discharge to the sanitary sewer. Oil and 
grease concentrations were reduced from $3,530 \mathrm{mg} / \mathrm{L}$ in the feed to $35 \mathrm{mg} / \mathrm{L}$ in the effluent. Further, a 94\% reduction in COD was observed after UF treatment of the oily wastewater.

Due to the heterogeneous nature of oily wastewaters, the type of membrane materials and MWCOs of membranes used to treat oily wastes varies widely. It was reported that, in general, oily wastewaters are not very demanding on membrane materials since the $\mathrm{pH}$ of the feed solution is typically less than 10 . However, since the exact composition of oily wastewaters can vary widely, a membrane material should ideally be able to withstand the wide range of $\mathrm{pHs}$ which may be encountered in the aggressive caustic and acidic cleaning procedures necessary to restore permeate flux. Common membrane materials used in the treatment of oily wastewaters include (1) polymeric (e.g., polyvinyliden fluoride (PVDF), polyamide, and polysulfone), (2) cellulose, and (3) ceramic.

Lipp et al. (1988) reported on the UF treatment of oil-in-water emulsions in which oil rejections of $99.9 \%$ were observed. Regenerated cellulose (5 and 30k MWCO), polysulfone (30k MWCO), polyacrylic (10k MWCO), and polyamide (100k MWCO) membranes were used in the experiments. Oil rejection was independent of membrane material and operating pressure. TOC rejections ranging from 96 to $98 \%$ were observed. Elevated TOC concentrations in the permeate, relative to the concentration of oil in the permeate, were attributed to the presence of lower molecular weight soluble additives (e.g., surfactants and stabilizers) that passed through the membrane. Although oil rejections of $99.9 \%$ were observed for each membrane material, Lipp et al. (1988) 
reported that regenerated cellulose membranes were the most easily cleaned. In contrast, Lipp et al. (1988) reported that the polysulfone membranes could not be cleaned effectively. Additionally, Canepa et al. (1988) used a tubular polysulfone membrane with a 20k MWCO to concentrate an oily waste down to $30 \%$ of its original volume. However, Canepa et al. did not discuss the durability/cleanability of the polysulfone membrane after treating the oily wastewater.

Mahdi and Skold (1991) used a tubular fluropolymer membrane with a MWCO of $20 \mathrm{k}$ to reduce the effluent mineral oil content of a synthetic water-based metal grinding coolant from $44 \mathrm{mg} / \mathrm{L}$ prior to processing to $1 \mathrm{mg} / \mathrm{L}$ after UF treatment. Bodzek and Konieczy (1992) used polyacrylonitrile (PAN) and polyvinyl chloride (PVC) tubular membranes with MWCOs ranging from 20 to 50k to treat a waste oil emulsion. Bodzek and Konieczy reported that COD retentions of greater than $95 \%$ were observed using these membranes. Additionally, polymeric membranes with MWCOs ranging from 5 to 50k were used by Zaidi et al. (1992) to remove oil successfully from oilfield brine. Reed et al. (Sep. Sci. \& Tech. 1997) reported the effective use of a 100k MWCO PVDF tubular membrane to concentrate a waste MW fluid to a maximum of 116 times its initial oil concentration of $\sim 0.2$ to $0.5 \%$.

Oil volume reductions of 95 to $99 \%$ were reported by Bodzek and Konieczny (1992) for the treatment of a MW lubricant using polyacrylonitrile (PAN) and polyvinyl chloride (PVC) tubular membranes with MWCOs ranging from 20 to 50k in a pilot-scale UF setup. Reed et al. (Sep. Sci \& Tech. 1997) reported on the pilot-scale treatment of an aluminum manufacturer's $\sim 0.2$ to $0.5 \%$ oil and grease wastewater using tubular PVDF 
UF membranes. Volume reductions ranging from 94 to $99 \%$ were reported in these experiments.

Membrane surface properties can also affect permeate flux and quality. Electrostatic repulsion between the membrane and the contaminant can be used to enhance waste solute retention and increase flux. For example, a membrane with a negative surface charge can be used to treat a waste containing a negatively charged contaminant. Reed et al. (Sep. Sci. \& Tech. 1997) reported that a negatively charged tubular membrane with a MWCO of 120k had a higher flux and similar permeate quality when compared with a membrane having a neutral surface charge and MWCO of 100k when treating a $\sim 0.2$ to $0.5 \% \mathrm{O} / \mathrm{G}$ wastewater. In this case, Reed et al. hypothesized that the electrostatic repulsion between the negative charge of the membrane surface and the negative charge of the emulsified oil droplets decreased the solute boundary layer thickness and oil adsorption on the membrane surface, which improved the membrane performance.

\section{Mechanically Enhanced Ultrafiltration Systems}

In an applied study on the ultrafiltration of oily emulsions, Vigo et al. (1985) investigated the effects of pressure, rotational speed, and oil concentration on permeate flux using freshly prepared cutting oil emulsions in a rotating concentric cylinder membrane system similar to the unit presented schematically in Figure (2.13). The main characteristics of the experimental unit used by Vigo et al. were: $40 \mathrm{~cm}$ height, $10 \mathrm{~cm}$ diameter, membrane area of $700 \mathrm{~cm}^{2}$, and variable membrane/wall gap ranging from 2.5 to $3.3 \mathrm{~mm}$. A maximum tangential rotation speed of $12 \mathrm{~m} / \mathrm{s}$ was possible with the 
rotating concentric cylinder system. Vigo et al. identified the formation of a solute boundary layer and subsequent fouling phenomena as the primary limiting factor in the efficient operation of ultrafiltration systems, particularly when treating highly viscous concentrated oily wastewaters. Vigo et al. suggested that the effects of the added hydrodynamic resistance of concentration boundary layer can be minimized by carefully controlling the hydrodynamic conditions in the UF unit through proper selection of membrane rotation, applied pressure, gap between membrane and vessel, and the "roughness" of the vessel wall.

In the rotating concentric cylinder membrane unit studied by Vigo et al., the formation of Taylor vortices was identified as the primary mechanism of high-shear formation at the membrane surface. Additionally, Vigo et al. reported that permeate flux was affected by the "roughness" of the vessel wall. When a 270 and a 140 mesh were used to line the vessel wall an increase in permeate flux over the non-lined case was observed. The 270 mesh, which produced a rougher surface compared to the 170 mesh, was more effective in enhancing the permeate flux. However, the exact mechanism of flux enhancement was not identified and the authors cited the need for a more systematic study of the effects of vessel roughness on permeate flux.

An example of the typical flux versus pressure relationship observed by Vigo et $a l$. at three operating tangential velocities is presented in Figure (2.18). Vigo et al. noted a more rapid transition from the pressure-controlled to the mass transfer-controlled regions as membrane rotational speed was decreased from a tangential velocity of 9 to 5 


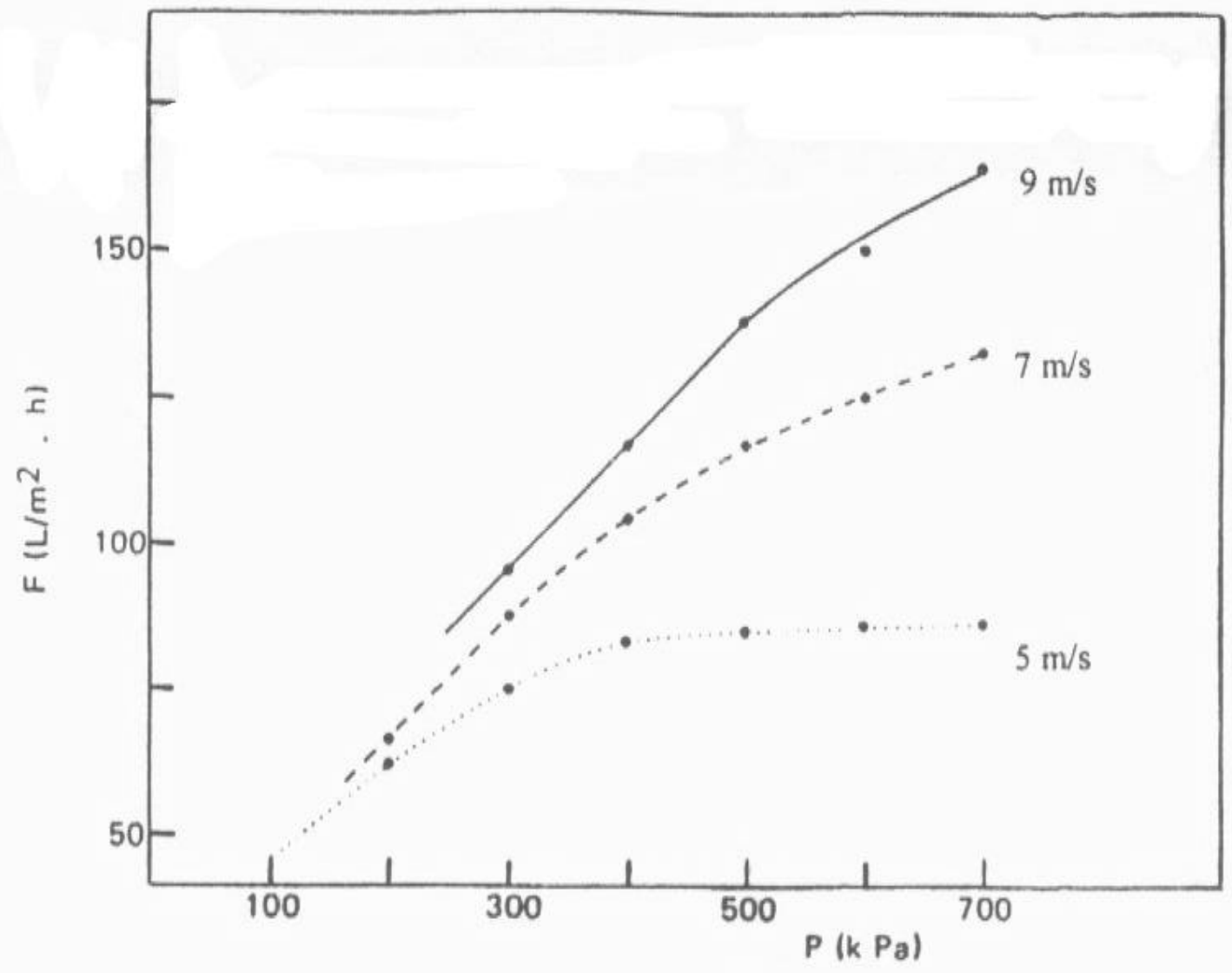

Figure (2.18)-An Example Of The Typical Flux Versus Pressure Relationship Observed By Vigo et al. At Three Operating Tangential Velocities. 
$\mathrm{m} / \mathrm{s}$. The rapid transition to pressure-independent flux was attributed to the increased accumulation of solute molecules at the membrane surface as the shear was decreased.

Additionally, the gap width between the membrane and the vessel wall was found to have an influence on the permeate flux, particularly at lower membrane rotational speeds. The authors attributed the effects of gap width to the different hydrodynamic conditions and the different size of the Taylor vortices. Vigo et al. also compared the results obtained with the rotating concentric cylinder UF module to a traditional tubular UF system and reported that the rotary unit gave greater operational flexibility over the tubular UF system and attributed the advantage to the decoupling of shear and feed pressure. Vigo et al. recommended operating at low feed pressures and high rotational speeds to minimize the thickness of the concentration boundary layer. In each case, this group observed oil rejections greater than $99.9 \%$ throughout the experiments with the rotating annular system.

Reed et al. (ASCE 1997) reported on an applied study of the treatment of an aluminum manufacturers oily wastewater using a high-shear rotary UF system. A comparison of a $100 \mathrm{k}(\sim 0.01 \mu \mathrm{m}$ pore size $)$ polyvinlyden fluoride membrane with a ceramic $\left(\mathrm{TiO}_{2} / \mathrm{Al}_{3} \mathrm{O}_{2}, 0.11 \mu \mathrm{m}\right.$ average pore size $)$ membrane in a high-shear rotary UF system was conducted. It was concluded that the performance of the ceramic membrane was superior to that of the PVDF with regard to flux quantity and quality as well as membrane cleaning/durability. In the experiments, an oily wastewater was concentrated from 5 to as high as $70 \%$ using a $0.11 \mu \mathrm{m}$ ceramic membrane in the HSR-UF system. 
Reed et al. (ASCE 1997) also reported on the effects of feed temperature on permeate flux. A plot of permeate flux versus operational time for temperature and membrane rotational speed excursions conducted by Reed et al. is presented in Figure (2.19). When the feed temperature was increased from 100 to $140{ }^{0} \mathrm{~F}$, for a $20 \%$ waste MW fluid feed treated in a high-shear rotary operated at 1,750 rpm, permeate flux increased by $\sim 45 \%$. However, the theoretically anticipated flux increase, based on the change in permeate viscosity, was $\sim 21 \%$. Reed et al. attributed the larger than anticipated increase in permeate flux to an increase in solute molecule diffusivity at elevated temperature. Thus, using the ceramic membrane, the researchers were able to make better use of a strong relationship between feed temperature and permeate flux by operating the system at higher temperatures than would have been possible with a PVDF membrane. Additionally, the ceramic membrane could be cleaned effectively (using $\mathrm{NaOH} /$ surfactant solution to adjusted to $\mathrm{pH} 2.2$ ) and reused after treating concentrated oily wastewaters (up to $70 \%$ oil in the feed). However, it was not possible to fully recover a satisfactory permeate flux when treating the same type of wastewater using the PVDF membrane. In this case, a new PVDF membrane was required for each experiment.

Reed et al. (ASCE 1997) also reported on the effects of membrane rotational speed and hydraulic turbulence on permeate flux in a HSR-UF system. An n value in Equation (2.26) of 0.90 was reported in the study by Reed et al. (ASCE 1997). The $\mathrm{n}$ value was consistent with the range of 0.8 to 1.2 for turbulent hydraulic flow condition reported by Cheryan (1986). The permeate flux repose to changes in membrane 


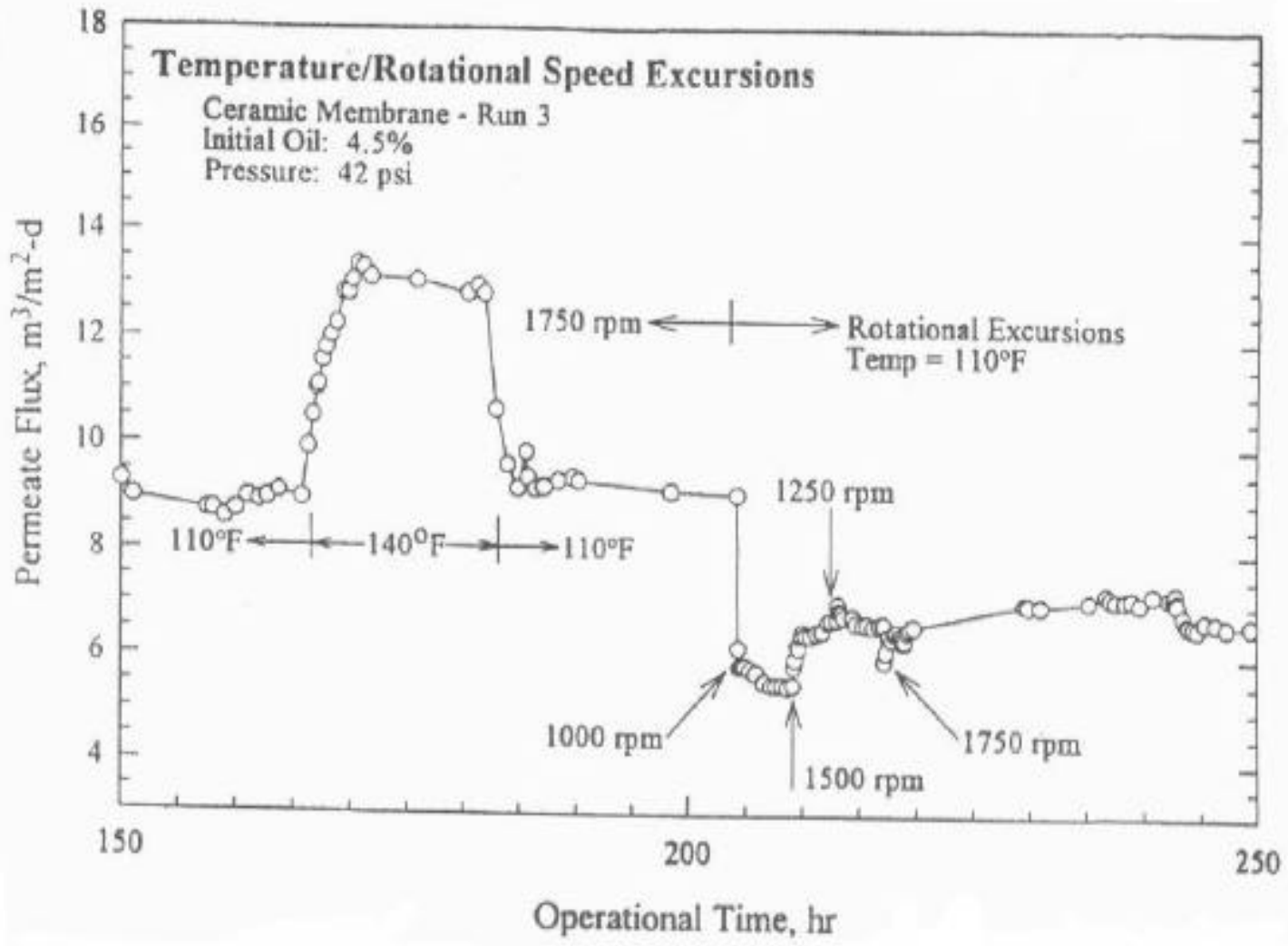

Figure (2.19)-Plot Of Permeate Flux Versus Operational Time For Temperature And Membrane Rotational Speed Excursions Conducted By Reed et al. 
was presented earlier in Figure (2.19). Reed et al. noted that when the membrane rotational speed was decreased from 1,750 to $1,000 \mathrm{rpm}$, permeate flux decreased. It was hypothesized that the decrease in permeate flux was due to an increase in the thickness of the solute concentration boundary layer at the membrane surface. When the membrane rotational speed was increased from 1,000 to 1,500 an increase in permeate flux was observed. The authors hypothesized that the increase in permit flux was due to a decrease in the thickness of the solute concentration boundary layer. A decrease in permeate flux was observed when the rotational speed was decreased from 1,500 to 1,250 rpm (similarly to the first decrease in rotational speed from 1,750 to $1,000 \mathrm{rpm}$ ). When the membrane rotational speed was increased from 1,250 to the pre-excursion value of $1,750 \mathrm{rpm}$, the permeate flux increased. However, the permit flux did not recover to the initial pre-excursion level. Reed et al. hypothesized that the gel layer was sufficiently stable to reduce the effects of increased hydraulic turbulence as the membrane rotational speed was raised. Thus, Reed et al. recommended running the high-shear rotary UF system at the highest rotational speed possible. 


\section{CHAPTER 3.0 INVESTIGATIVE APPROACH}

In this chapter, the experimental design and materials and methods used in this study are described. Quality assurance/quality control measures are also discussed. In this chapter, applied pressures are designated as $\mathrm{P}_{\mathrm{i}}$, membrane rotational speeds are designated as $\mathrm{R}_{\mathrm{j}}$, MW fluid concentrations are designated as $\mathrm{O}_{\mathrm{k}}$, and oil concentrations are designated as $\mathrm{OC}_{\mathrm{k}}$.

\section{EXPERIMENTAL DESIGN}

\section{Experimental Conditions}

\section{Baseline Membrane Characteristics/Performance}

Prior to beginning MW fluid experiments, baseline membrane performance data were collected using a clean water feed. The system was initially run at a constant applied pressure/membrane rotational speed combination until a quasi-steady state permeate flux was observed. After the initial period of operation at constant applied pressure and membrane rotation, $\mathrm{P}_{\mathrm{i}} \mathrm{R}_{\mathrm{j}}$ excursions were conducted at two feed temperatures (110 and $\left.135{ }^{0} \mathrm{~F}\right)$. The $\mathrm{P}_{\mathrm{i}} \mathrm{R}_{\mathrm{j}}$ combinations studied in the baseline membrane characteristic experiment are presented in Table (3.1). The average and maximum permeate backpressures over the range of membrane rotational speeds investigated in this study were accounted for to ensure a positive transmembrane pressure across the entire membrane disk. Average and maximum permeate backpressures at typical membrane 
Table (3.1)—The $\mathbf{P}_{\mathbf{i}} \mathbf{R}_{\mathbf{j}}$ Combinations Studied In The Baseline Membrane Characteristic Experiment.

\begin{tabular}{||c|c|}
\hline Applied pressure, $\mathrm{P}_{\mathrm{i}}(\mathrm{psig})$ & Membrane rotational speed, $\mathrm{R}_{\mathrm{j}}(\mathrm{rpm})$ \\
\hline \hline 65 & 1,750 \\
\hline 45 & 1,750 \\
\hline 25 & 1,750 \\
\hline 65 & 1,250 \\
\hline 45 & 1,250 \\
\hline 25 & 1,250 \\
\hline 65 & 250 \\
\hline 45 & 250 \\
\hline 25 & 250 \\
\hline
\end{tabular}


rotational speeds are presented in Table (3.2). The resistance of the virgin membrane,

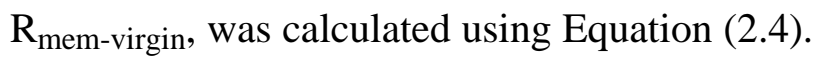

\section{Baseline MW Fluid Characteristics}

The MW fluid density, absolute viscosity, oil content, and particle size distribution were determined in small-scale experiments outside the high-shear rotary UF system. MW fluid concentration in these experiments ranged from 5 to $40 \%$. The density and absolute viscosity data were used to calculate the kinematic viscosity of the MW fluid. The Reynolds Number in the radial direction, presented in Equation (2.21), was then calculated and the hydraulic flow regime was determined for the experimental parameters examined in this study. Oil content analysis was performed to quantify the amount of oil present in the base MW fluid. Particle size analysis was performed by two independent laboratories to examine the effects of changing MW fluid concentration on the size and distribution of MW fluid particles in each solution.

\section{MW Fluid Experiments}

The effects of membrane rotational speed and applied pressure on the limiting permeate flux were studied in individual experiments. MW fluid concentrations ranged from 5 to $40 \%$, membrane rotational speeds ranged from 1,150 to 1,750 rpm, and applied pressures ranged from 15 to $75 \mathrm{psig.} \mathrm{MW} \mathrm{fluid/membrane} \mathrm{rotational} \mathrm{speed} \mathrm{combinations}$ and applied pressure ranges investigated in this study are presented in Table (3.3). The lowest concentration, 5\% MW fluid, was selected to approximate typical concentrations in the direct treatment of waste MW fluids in an industrial setting [Lammale 1992, Reed 
Table (3.2)--Average And Maximum Permeate Backpressures At Typical Rotational Speeds.

\begin{tabular}{|c|c|c||}
\hline $\begin{array}{c}\text { Membrane Rotational Speed, } \\
\mathrm{R}_{\mathrm{j}}(\mathrm{rpm})\end{array}$ & Average $\mathrm{p}_{\text {back }}(\mathrm{psi})$ & Maximum $\mathrm{p}_{\text {back }}(\mathrm{psi})$ \\
\hline 1,750 & 11.1 & 20.6 \\
\hline \hline 1,450 & 7.6 & 14.1 \\
\hline 1,250 & 5.7 & 10.6 \\
\hline 1,150 & 4.8 & 9.0 \\
\hline 850 & 2.6 & 4.9 \\
\hline 500 & 1.0 & 1.8 \\
\hline 250 & 0.3 & 0.5 \\
\hline
\end{tabular}


Table (3.3)--- $\mathbf{R}_{\mathrm{j}} / \mathbf{O}_{\mathrm{k}}$ Combinations And $\mathbf{P}_{\mathbf{i}}$ Ranges Investigated In This Study.

\begin{tabular}{|c|c|c|c|c|c|c||}
\hline \hline $\begin{array}{c}\mathrm{O}_{\mathrm{k}}, \% \text { MW fluid } \rightarrow \\
\mathrm{R}_{\mathrm{j}, \mathrm{rpm}}\end{array}$ & \multicolumn{1}{|c|}{5} & 10 & 15 & 20 & 30 \\
\hline 1750 & $172-517 \mathrm{kPa}$ & $172-517 \mathrm{kPa}$ & $138-517 \mathrm{kPa}$ & $138-483 \mathrm{kPa}$ & $172-483 \mathrm{kPa}$ & $172-483 \mathrm{kPa}$ \\
$(25-75 \mathrm{psig})$ & $(25-75 \mathrm{psig})$ & $(20-75 \mathrm{psig})$ & $(20-70 \mathrm{psig})$ & $(25-70 \mathrm{psig})$ & $(25-70 \mathrm{psig})$ \\
\hline 1450 & $172-517 \mathrm{kPa}$ & $172-517 \mathrm{kPa}$ & $172-483 \mathrm{kPa}$ & $103-483 \mathrm{kPa}$ & $172-483 \mathrm{kPa}$ & $138-483 \mathrm{kPa}$ \\
$(25-75 \mathrm{psig})$ & $(25-75 \mathrm{psig})$ & $(25-70 \mathrm{psig})$ & $(15-70 \mathrm{psig})$ & $(25-70 \mathrm{psig})$ & $(20-70 \mathrm{psig})$ \\
\hline 1150 & $172-517 \mathrm{kPa}$ & $172-517 \mathrm{kPa}$ & $103-483 \mathrm{kPa}$ & $103-483 \mathrm{kPa}$ & $103-483 \mathrm{kPa}$ \\
& $(25-75 \mathrm{psig})$ & $(25-75 \mathrm{psig})$ & $(15-70 \mathrm{psig})$ & $(15-70 \mathrm{psig})$ & $(15-70 \mathrm{psig})$ & $(15-70 \mathrm{psig})$ \\
\hline
\end{tabular}


et al. 1997]. The maximum membrane rotational speed of the high-shear rotary UF unit was $1,750 \mathrm{rpm}$. The lowest rotational speed of $1,150 \mathrm{rpm}$ was chosen to obtain data in the mass transfer-controlled region for the low MW fluid concentration experiments. The average and maximum permeate backpressures over the range of membrane rotational speeds investigated in this study were accounted for to ensure a positive transmembrane pressure across the entire membrane disk. Average and maximum permeate backpressures at typical membrane rotational speeds were presented in Table (3.2). The applied pressure was increased from low to high values to avoid biasing the limiting flux values by initially operating under conditions which are favorable to the accumulation of oil at the membrane surface and subsequent plugging of membrane pores. Data collected during these experiments included: permeate flux; permeate and concentrate $\mathrm{pH}$ and conductivity; and permeate and concentrate temperature. A standardized cleaning procedure was performed and a clean water flux was measured after each experiment. The membrane resistance, $R_{m e m}$, was calculated using Equation (2.4). $R_{m e m}$ was measured after each experiment to track the condition/performance of the membrane throughout the study.

To examine the stability of the gel layer, hysteresis experiments were performed separately from the $\mathrm{R}_{\mathrm{j}} \mathrm{O}_{\mathrm{k}}$ experiments presented previously in Table (3.3). A summary of rotational and pressure hysteresis experiments conducted in this study is presented in Table (3.4). Pressure hysteresis experiments were performed at the end of a discrete $\mathrm{R}_{\mathrm{j}} \mathrm{O}_{\mathrm{k}}$ experiment so as not to affect the limiting flux determination. Rotational hysteresis experiments at constant $\mathrm{P}_{\mathrm{i}} \mathrm{O}_{\mathrm{k}}$ combinations were conducted at the end of the study. 
Table (3.4)--A Summary Of The Rotational And Pressure Hysteresis Experiments Conducted In This Study.

\begin{tabular}{|c|c|c|}
\hline Experiment & $\begin{array}{c}\text { Rotational } \\
\text { hysteresis }\end{array}$ & $\begin{array}{c}\text { Pressure } \\
\text { hysteresis }\end{array}$ \\
\hline \hline $15 \%-70 \mathrm{psig}$ & $\mathrm{x}$ & \\
\hline $5 \%-45 \mathrm{psig}$ & $\mathrm{x}$ & \\
\hline $30 \%-1150 \mathrm{rpm}$ & & $\mathrm{x}$ \\
\hline $5 \%-1450 \mathrm{rpm}$ & & $\mathrm{x}$ \\
\hline
\end{tabular}


Steps were taken to minimize variations due to other experimental parameters (e.g., MW fluid characteristics, MW fluid temperature, and hydraulic flow). Synthetic MW fluids were freshly prepared in each experiment. Experiments were conducted in recycle mode for each $\mathrm{R}_{\mathrm{j}} \mathrm{O}_{\mathrm{k}}$ combination, to minimize the potential effects of changes in feed properties over time (e.g., emulsion breakdown due to high shear and heat) [Cheryan 1986]. Additionally, the potential bias toward decreased flux values during direct batchdown operation due to membrane fouling at higher MW fluid concentrations was minimized by performing experiments at discrete MW fluid concentrations. To minimize the effects of variable hydraulic turbulence in the each experiment, the system was operated at one membrane rotational speed with a concentrate return flow rate of $1.0 \pm$ $0.2 \mathrm{gpm}(3.75 \pm 0.75 \mathrm{~L} / \mathrm{min})$. The feed temperature was maintained at $110 \pm 2{ }^{0} \mathrm{~F}$. Additionally, a single ceramic membrane was used $(0.11 \mu \mathrm{m}$ average pore size $)$ for all experiments. A summary of the ceramic membrane characteristics is presented in Table (3.5). This membrane was made of the same material investigated by Reed et al. (ASCE 1997).

Quality assurance/quality control $(\mathrm{QA} / \mathrm{QC})$ procedures implemented in this study included a baseline membrane performance experiment to determine the resistance of the virgin ceramic membrane, $\mathrm{R}_{\text {mem-virgin. }}$ This experiment was performed at two temperatures to ascertain whether the change in permeate flux was due to the change in feed viscosity (due to change in temperature) or changes in other parameters such as alterations in the virgin membrane's properties under increased applied pressure. The resistance of the membrane, $R_{m e m}$, was calculated and tracked after each standardized 
Table (3.5)--A Summary Of The Ceramic Membrane Characteristics.

\begin{tabular}{|c||c||}
\hline Manufacturer & TRUMEM \\
\hline Lot number & CRM-011M-TA \\
\hline Chemical composition & $\mathrm{TiO}_{2} / \mathrm{Al}_{2} \mathrm{O}_{3}$ \\
\hline Mean pore size & $0.11 \mu \mathrm{m}$ \\
\hline Maximum pore size & $0.70 \mu \mathrm{m}$ \\
\hline Total membrane area & $0.53 \mathrm{ft}^{2}$ \\
\hline Maximum operating temperature & $>158{ }^{0} \mathrm{~F}$ \\
\hline Maximum operating pressure & $>150 \mathrm{psi}$ \\
\hline Thickness & $240 \mu \mathrm{m}$ \\
\hline Inner radius & $0.975 \mathrm{in}$. \\
\hline Outer radius & $3.625 \mathrm{in}$. \\
\hline Radius of gyration & $2.654 \mathrm{in}$. \\
\hline
\end{tabular}


cleaning procedure as a QA/QC check on the membrane's performance. Additionally, replicate experiments were performed for at least $10 \%$ of the $\mathrm{R}_{\mathrm{j}} \mathrm{O}_{\mathrm{k}}$ experiments. The limiting fluxes from the replicate experiments were compared to judge changes in membrane performance. Triplicate sampling and measurement was conducted when changes in $\mathrm{pH}$ and conductivity were observed. Analytical triplicates were performed in the MW fluid absolute viscosity and density experiments. Particle size samples, analyzed free of charge by two commercial laboratories, were not analyzed in triplicate.

\section{Data Presentation and Reduction}

A hypothetical plot of permeate flux versus time for a constant membrane rotational speed and constant MW fluid concentration (i.e., constant $\mathrm{R}_{\mathrm{j}}$ and $\mathrm{O}_{\mathrm{k}}$ ) with increasing applied pressure is presented in Figure (3.1). Individual permeate fluxes at each $\mathrm{P}_{\mathrm{i}}$ were averaged and plotted versus average transmembrane pressure for a constant $\mathrm{R}_{\mathrm{j}} \mathrm{O}_{\mathrm{k}}$ condition. A hypothetical plot of average permeate flux versus average transmembrane pressure at each applied pressure condition for a constant membrane rotational speed and MW fluid concentration is presented in Figure (3.2). The pressurecontrolled and mass transfer-controlled regions were determined for each discrete $\mathrm{R}_{\mathrm{j}} \mathrm{O}_{\mathrm{k}}$ experiment. The permeate flux in the mass transfer-controlled region, designated as $\mathrm{J}_{\mathrm{RjOk}}^{*}$, was determined by identifying the plateau region at which the permeate flux became independent of the average transmembrane pressure. The $\mathrm{P}_{\mathrm{i}}$ subscript was dropped from the flux term in the mass transfer-controlled region because $\mathrm{J}^{*}$ RjOk was pressure-independent in this region. 


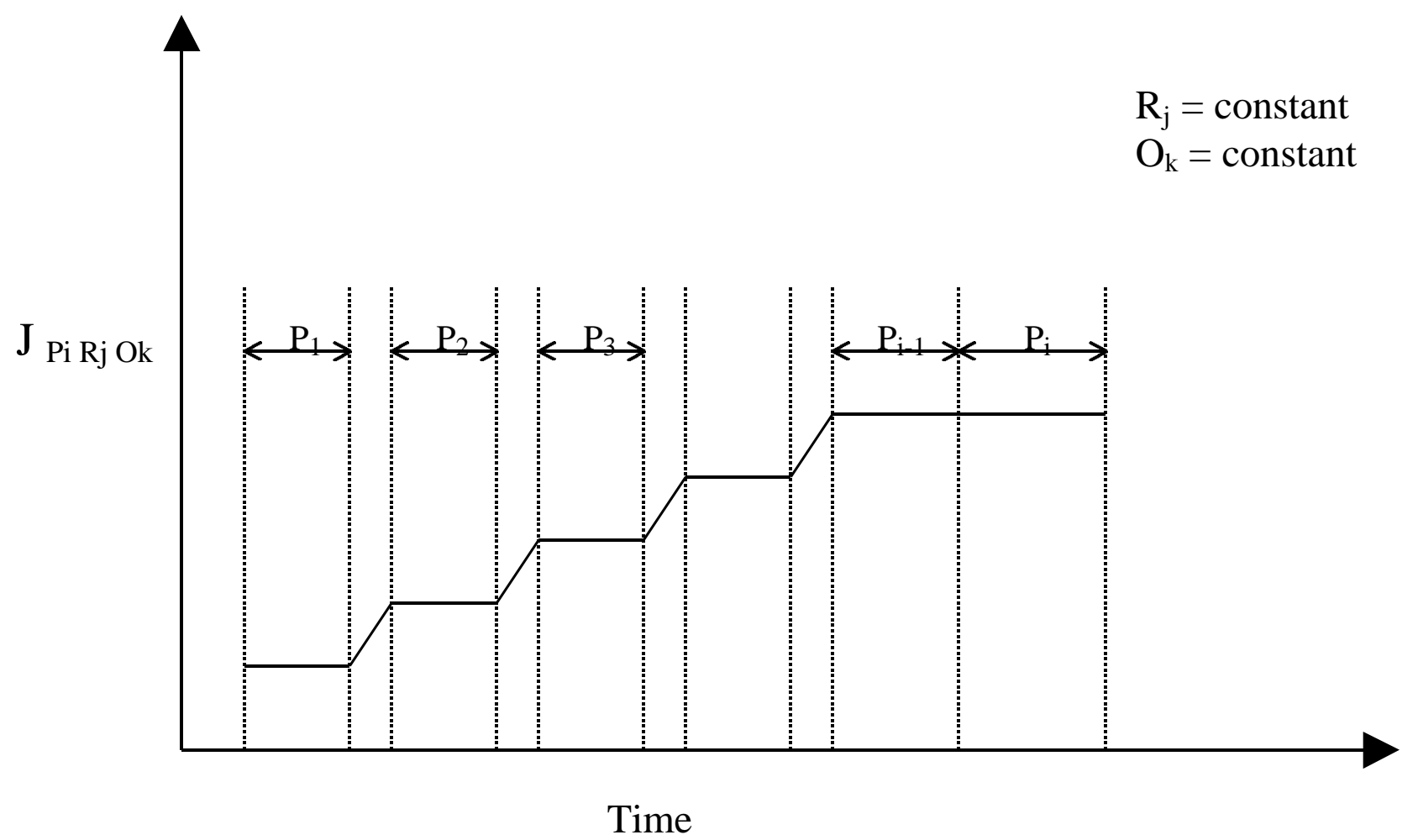

Figure (3.1)--A Hypothetical Plot Of Permeate Flux Versus Time For A Constant Membrane Rotational Speed And Constant MW Fluid Concentration With Increasing Applied Pressure. 


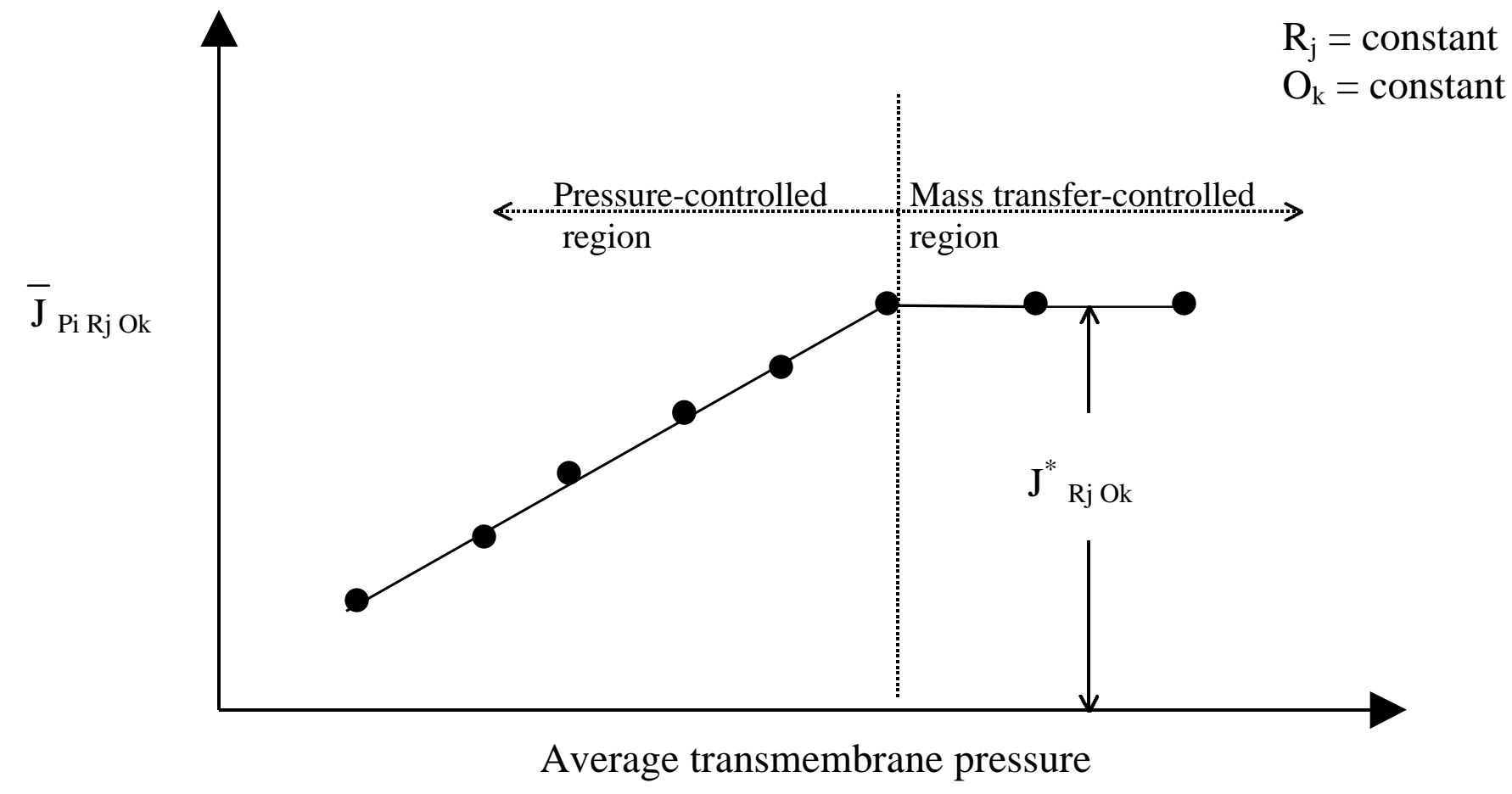

Figure (3.2)--A Hypothetical Plot Of Average Permeate Flux Versus Average Transmembrane Pressure At Each Applied Pressure Condition For Constant Membrane Rotational Speed And MW Fluid Concentration. 
The data collected in these experiments were used to investigate the application of the resistance-in-series model in predicting the permeate flux. Non-linear regressions were performed on the average flux-average transmembrane pressure data to determine the model-specific parameters (resistance index, $\Phi$, and total membrane resistance, $\mathrm{R}_{\mathrm{m}}{ }^{\prime}$ ). The parametric data was then used to determine trends between the RIS model parameters and the operational parameters $\left(\mathrm{R}_{\mathrm{j}}\right.$ and $\left.\mathrm{O}_{\mathrm{k}}\right)$.

The density and absolute viscosity were plotted versus the MW fluid concentration. The number of particles was plotted versus the particle diameter and the mean and median particle sizes for each MW fluid concentration were calculated and reported in table form. The membrane resistance was calculated after each experiment and plotted versus the run number. A regression line was fitted to these data to track trends in membrane performance over the course of the study.

\section{MATERIALS AND METHODS}

\section{Experimental Apparatus}

A single disk HSR-UF unit was used in this study. A schematic of the membrane vessel and the experimental apparatus are presented in Figures (3.3) and (3.4), respectively. In this system, one 8 inch $(20 \mathrm{~cm})$ round membrane disk pack was set on a hollow rotating shaft inside the vessel housing. The feed stream entered the membrane chamber under pressure and was distributed across the membrane surface by centrifugal and hydraulic action. Applied pressure was supplied by a Grundfos model CRN2 centrifugal pump capable of a maximum feed pressure of $\sim 78$ psi (at zero gpm outlet

flow rate). The operating temperature range of the pump was 5 to $250{ }^{0} \mathrm{~F}$ and the original 

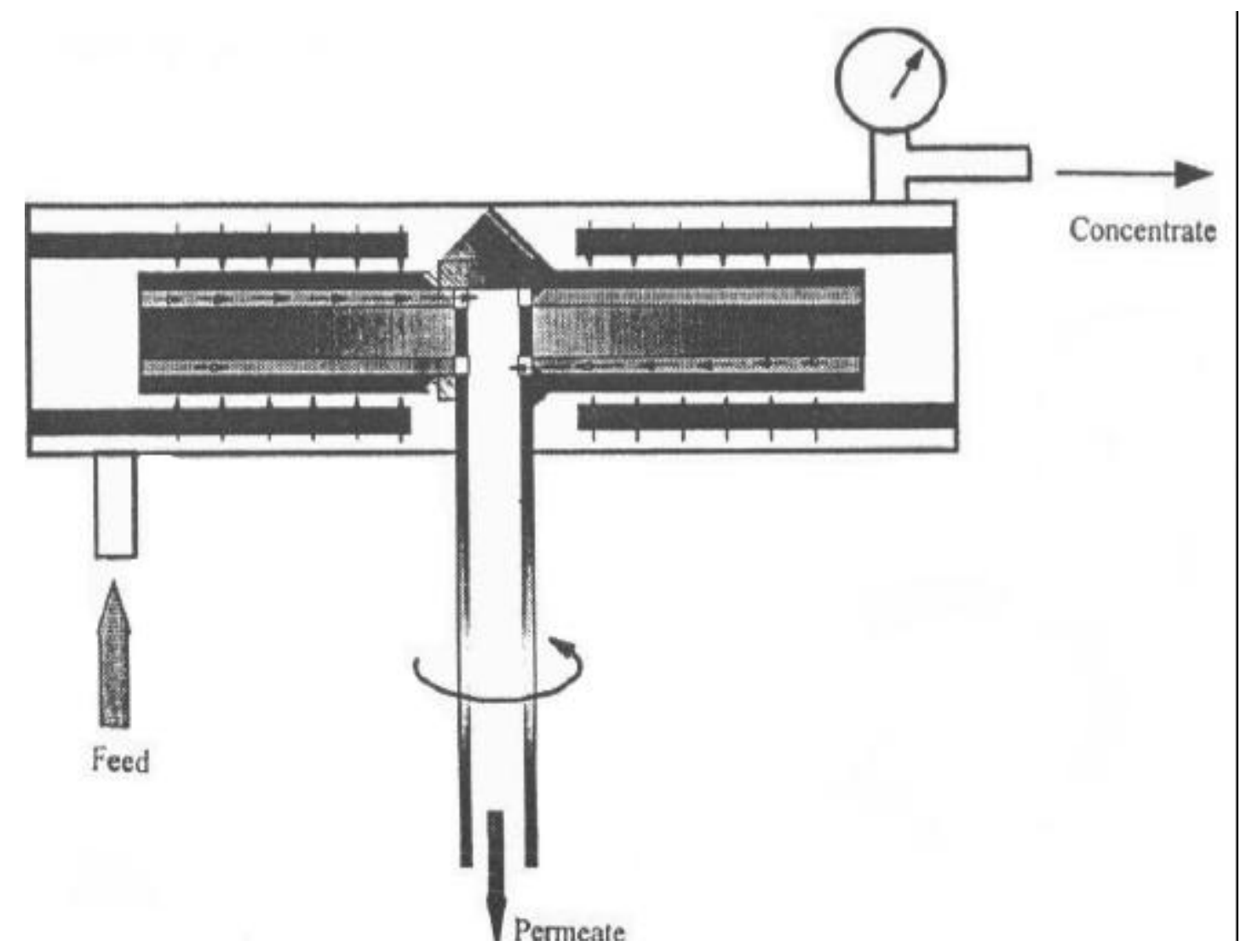

Figure (3.3)--A Schematic Of The Membrane Vessel. 


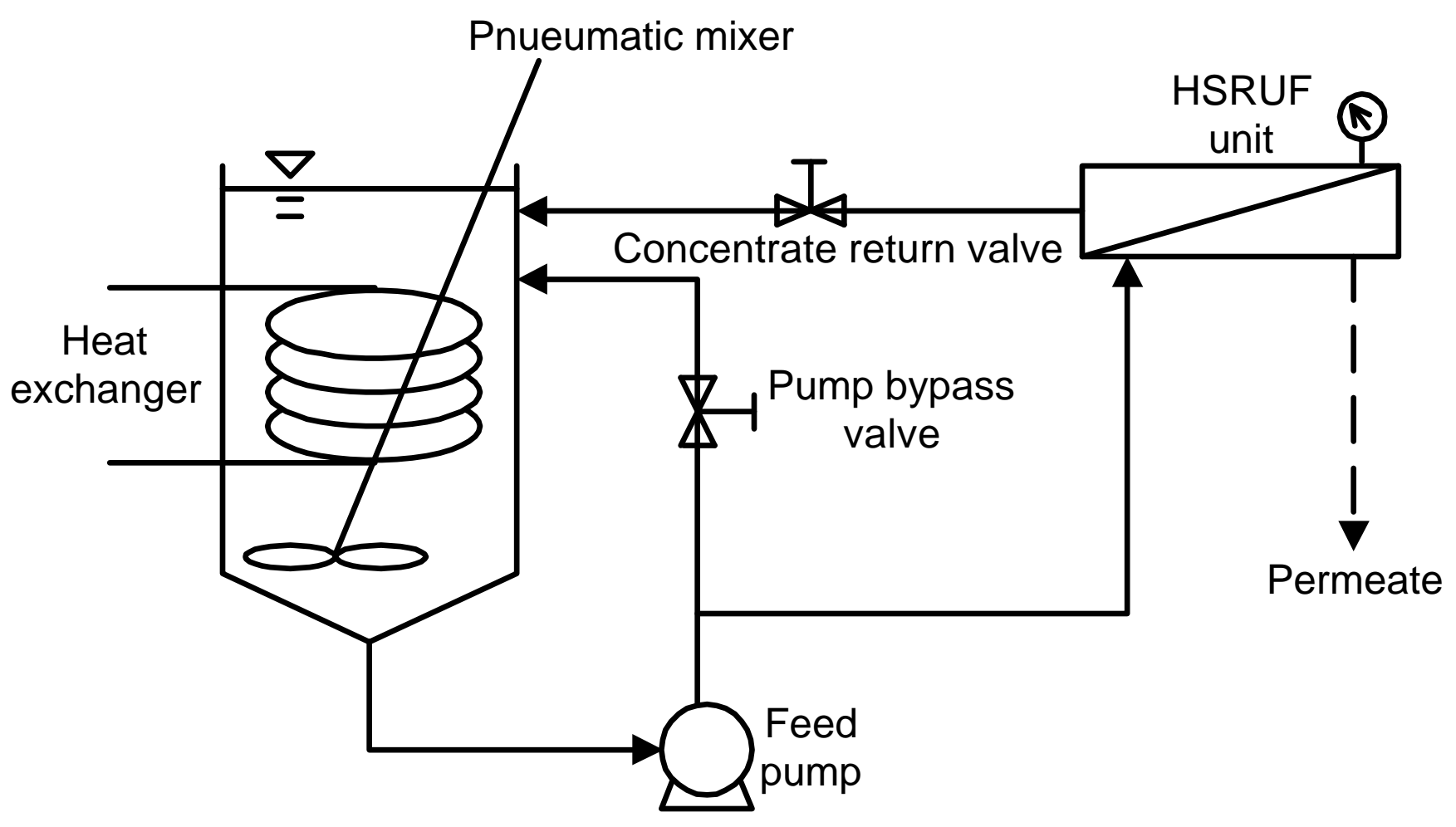

Figure (3.4) - A Schematic Of The Experimental Apparatus. 
equipment manufacturer single mechanical seal (carbide/tungsten carbide) was retrofitted with a double mechanical seal (tungsten carbide/tungsten carbide). The feed flow and pressure to the vessel were controlled using a bypass valve installed on the pump. The applied pressure was measured using a 100 psi maximum pressure gauge installed on the top of the pressure vessel. The pressure gauge, manufactured by McDaniel Controls, Inc., was graduated in 1 psi increments. The concentrate return flow rate was measured using a Signet 8511 turbine flow meter and was maintained at $1.0 \pm 0.2 \mathrm{gpm}(3.75 \pm 0.75$ $\mathrm{L} / \mathrm{min}$ ) throughout these experiments by adjusting return flow valve installed on the concentrate return line. Additionally, a shut-off ball valve was added to the concentrate return line so the return flow rate could be measured manually using a graduated cylinder and a stop watch. This procedure was used to periodically check the calibration of the turbine flow meter. The rotation of the membrane disk was used to induce the hydraulic turbulence required to minimize the thickness of the concentration boundary layer. Membrane rotation could be varied from 150 to $1,750 \mathrm{rpm}$. These limiting values were preset by the manufacturer and could not be altered on-site. A constant feed temperature of $110 \pm 2{ }^{0} \mathrm{~F}$ was maintained by passing tap water through a copper coil heat exchanger located in the feed tank. A Fisher Scientific digital temperature probe was installed in the feed tank to monitor the feed temperature throughout these experiments. An additional Fisher Scientific digital temperature probe was used to measure the temperature of the permeate collected during the permeate flow measurement. A pneumatic mixer was used to maintain feed homogeneity and to aid in temperature control. To minimize the loss of 
feed volume due to evaporation of water, a plastic lid with an access port for the pneumatic mixer was kept on the feed tank throughout the duration of these experiments.

\section{Experimental Conduct}

\section{Baseline Membrane Behavior}

Prior to beginning the MW fluid experiments the resistance of the virgin ceramic membrane, $R_{\text {mem-virgin }}$, was determined. This parameter was used as a basis to gauge the membrane's condition/performance throughout the course of this study. The high-shear rotary UF system was operated in recycle mode at $1,750 \mathrm{rpm}$ and 65 psig with a $40 \mathrm{~L}$ feed volume of distilled water (obtained from West Virginia University Civil and Environmental Engineering Laboratory's house supply) at $110 \pm 2{ }^{0} \mathrm{~F}$ to observe the permeate flux over time at constant operating parameters. A return flow rate of $1.0 \pm 0.2$ gpm was maintained throughout this experiment. The initial $\mathrm{pH}$ and conductivity of the distilled water were measured ( 6.35 and $2.75 \mu \mathrm{S} / \mathrm{cm}$, respectively). The permeate flux and the concentrate and permeate $\mathrm{pH}$; conductivity; and temperatures were measured regularly. The permeate flow was measured by disconnecting the permeate line from the feed tank and measuring the volume of permeate collected over a given period of time (typically one minute depending on the flow rate) using a graduated cylinder and a stopwatch.

Pressure and membrane rotational speed excursions conducted in this experiment were presented previously in Table (3.1). The operating parameters used in these experiments were selected to ensure a positive transmembrane pressure across the entire membrane disc. The system was run at each of the $\mathrm{P}_{\mathrm{i}} \mathrm{R}_{\mathrm{j}}$ conditions until a quasi-steady 
state permeate flux was obtained. In these experiments, flux was considered to be "quasisteady state" because of the constant, though often slow, decline in permeate flux observed over time in membrane filtration systems [Cheryan 1986, Jonsson and Tragardh 1990, Elmaleh and Naceur 1992]. The flux data at each $P_{i} R_{j}$ combination were then averaged and plotted versus the average transmembrane pressure and a least squares regression line was fitted to these data. The feed temperature was decreased to $110 \pm 2$ ${ }^{0} \mathrm{~F}$ and the system was operated at the same $\mathrm{R}_{\mathrm{j}} \mathrm{O}_{\mathrm{k}}$ combinations presented previously in Table (3.1). The flux data at each $\mathrm{R}_{\mathrm{j}} \mathrm{O}_{\mathrm{k}}$ combination were then averaged and plotted versus the average transmembrane pressure as was done for the $135{ }^{0} \mathrm{~F}$ experiments. The slopes of the regression lines through the flux versus average transmembrane pressure data at 110 and $135{ }^{0} \mathrm{~F}$ were determined from the least squares line fits. The change in $\mathrm{R}_{\text {mem }}$ with temperature was compared with the theoretically anticipated change in the absolute viscosity of water to ascertain whether quasi-steady state operational conditions were reached. In the case of quasi-steady state behavior, the change in $R_{\text {mem-virgin }}$ with temperature would correspond to the change in the inverse of the absolute viscosity of water. The virgin membrane resistance was calculated at both temperatures using

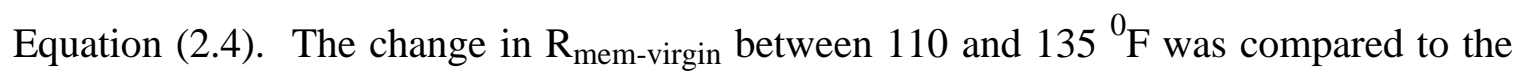
change in the inverse of the absolute viscosity of water to determine if quasi-steady state condition were reached. 


\section{Membrane Cleaning Procedure}

After completing an experiment, the system was stopped and the feed tank and lines were drained. The vessel was opened and physical observations of the membrane's condition were made. Particular attention was paid to the accumulation/formation of an oily ring or a gel-like layer on the membrane surface. Additionally, the membrane was inspected for scratches and tares. The membrane was then reinstalled and a standardized cleaning procedure was used. A summary of the characteristics of the base/surfactant and acid cleaning solutions used in the standardized cleaning procedure is presented in Table (3.6). Dawn dish washing detergent, an EDTA-containing surfactant, was added to the base cleaning solution to complex metals that may have built up on the membrane and to dissolve oils accumulated on the membrane surface. The membrane cleaning procedure is summarized below:

1. The system was flushed with 50 gallons $(190 \mathrm{~L})$ of hot tap water. The membrane was not operated at this time.

2. Five gallons (19 L) of distilled water was adjusted to $\mathrm{pH} 11.8$ using $\mathrm{NaOH}$ from a $1 \mathrm{M}$ stock solution stored with a soda scrubber.

- $200 \mathrm{~mL}$ of $1 \mathrm{M} \mathrm{NaOH}$ was necessary to raise the $\mathrm{pH}$ of the distilled water to 11.8 .

- Additionally, $30 \mathrm{~mL}$ of Dawn detergent was mixed into the water and $\mathrm{NaOH}$ solution.

- The $\mathrm{pH}$ and conductivity of the base/surfactant cleaning solution was measured and recorded.

- The base/surfactant cleaning solution was then heated to $135 \pm 2{ }^{0} \mathrm{~F}$ using the copper coil heat exchanger.

3. The membrane was cleaned by running the base/surfactant cleaning solution through the high-shear rotary UF system for 30 minutes at 1,750 $\mathrm{rpm}, 135 \pm 2{ }^{\circ} \mathrm{F}$, and $40 \mathrm{psig}$.

- Permeate flux was measured and recorded during the cleaning cycle. 
Table (3.6)--A Summary Of The Characteristics Of The Base/Surfactant And Acid Cleaning Solutions Used In The Standardized Cleaning Procedure.

\begin{tabular}{|c|c|c||}
\hline & Base/surfactant & Acid \\
\hline \hline $\mathrm{pH}$ & 11.8 & 2.2 \\
\hline conductivity & $3.8 \mathrm{mS} / \mathrm{cm}$ & $8.1 \mathrm{mS} / \mathrm{cm}$ \\
\hline Vol. stock NaOH added $(\mathrm{mL})$ & 200 & $\mathrm{x}$ \\
\hline Vol. Dawn added $(\mathrm{mL})$ & 30 & $\mathrm{x}$ \\
\hline Vol. $\mathrm{H}_{2} \mathrm{SO}_{4}$ added $(\mathrm{mL})$ & $\mathrm{x}$ & 185 \\
\hline
\end{tabular}

$\mathrm{x}=$ Not added to this solution. 
4. The system was drained and flushed with 50 gallons of hot tap water.

- 50 gallons was determined to be the volume necessary to reduce the $\mathrm{pH}$ of the effluent flush water to the $\mathrm{pH}$ of tap water after cleaning with $\mathrm{NaOH}$.

5. Five gallons (19 L) of distilled water was $\mathrm{pH}$ adjusted 2.2 using a stock $1 \mathrm{M} \mathrm{H}_{2} \mathrm{SO}_{4}$ solution.

- $185 \mathrm{~mL}$ of $1 \mathrm{M} \mathrm{H}_{2} \mathrm{SO}_{4}$ was necessary to reduce the $\mathrm{pH}$ of the distilled water to 2.2 .

- The $\mathrm{pH}$ and conductivity of the acid cleaning solution was measured and recorded.

- The acid cleaning solution was then heated to $135 \pm 2{ }^{0} \mathrm{~F}$ using the copper coil heat exchanger.

6. The membrane was cleaned by running the acid cleaning solution through the high-shear rotary UF system for 30 minutes at $1,750 \mathrm{rpm}, 135 \pm 2{ }^{0} \mathrm{~F}$, and 40 psig.

- Permeate flux was measured and recorded during the cleaning cycle.

7. The system was drained and flushed with 50 gallons of hot tap water.

- 50 gallons was determined to be the volume necessary to raise the $\mathrm{pH}$ of the effluent flush water to the $\mathrm{pH}$ of tap water after cleaning with $\mathrm{H}_{2} \mathrm{SO}_{4}$.

8. The membrane vessel was opened and physical observations of the membrane's condition were made as described earlier.

9. The membrane was reinstalled and a clean water flux (CWF) was measured at $110 \pm 2{ }^{0} \mathrm{~F} ; 1,750 \mathrm{rpm}$; at three applied pressure from 25 to 75 psig with a $40 \mathrm{~L}$ distilled water feed.

- The initial $\mathrm{pH}$ and conductivity of the distilled water used in the CWF experiment were measured and recorded.

- The average permeate flux versus the average transmembrane pressure was plotted.

- The slope of the line fitted to these data using linear regression analysis was determined and the membrane resistance was calculated as presented in Equation (2.4).

The standardized cleaning and clean water flux procedure was applied after each experiment and the membrane resistance was tracked throughout the study. 


\section{MW Fluid Experiments}

The HSR-UF system was used to treat synthetic emulsified MW fluids at the $\mathrm{R}_{\mathrm{j}} \mathrm{O}_{\mathrm{k}}$ combinations presented previously in Table (3.3). Each discrete $\mathrm{R}_{\mathrm{j}} \mathrm{O}_{\mathrm{k}}$ experiment was conducted in recycle mode, with a total feed volume of $40 \mathrm{~L}$, at a feed temperature of 110 $\pm 2{ }^{0} \mathrm{~F}$, and a return flow rate of $1.0 \pm 0.2 \mathrm{gpm}$

Feed Preparation: A base MW package was used to make the 5 to $40 \%$ MW fluid solutions in these experiments. The base MW fluid was obtained from a metal manufacturer's rolling mill and contained $85 \%$ oil and $15 \%$ proprietary additives (i.e., anti-foaming agents, film strength additives, etc.):

$$
\mathrm{OC}_{\mathrm{k}}=0.85\left(\mathrm{O}_{\mathrm{k}}\right)
$$

However, the specific components of the base MW package cannot be disclosed for proprietary reasons. The density, absolute viscosity, and particle size distributions of each MW fluid concentration were experimentally measured to determine baseline characteristics. The specific procedures for these analyses are described in the Analytical Methods Section.

Approximately $100 \mathrm{~L}$ of distilled water to make the feed oil package solution and cleaning solutions was obtained from West Virginia University Civil and Environmental Engineering Laboratory's house supply. The $\mathrm{pH}$ and conductivity of the distilled water were measured and compared with previously observed values to judge the quality of the water prior to being used in these experiments. The $\mathrm{pH}$ and conductivity ranges of distilled water used to make the feed MW fluid solutions were 6.69 to 7.27 and 1.17 to 
$6.88 \mu \mathrm{S} / \mathrm{cm}$, respectively. Forty-liter feed solutions were then made up in the feed tank by adding the appropriate volume of base MW package to distilled water. The base MW package and water volumes added to make each concentration are presented in Table (3.7).

System Operation: Prior to starting the system, the MW fluid solution was heated to 110 $\pm 2{ }^{0} \mathrm{~F}$ and the pneumatic mixer was turned on to homogenize the feed solution and to aid in heating. The feed temperature was measured using a Fisher Scientific digital temperature probe installed in the feed tank. The pneumatic mixer was run throughout each experiment. A plastic lid with an access port for the pneumatic mixer was kept on the feed tank to minimize the loss of feed volume due to the evaporation of water. The system was then started, the membrane rotational speed was set using the dial and digital control on the membrane unit, and the applied pressure was adjusted to its minimum value by adjusting the bypass valve on the feed pump. Additionally, the concentrate return flow rate, displayed on the Signet flow meter, was stabilized at $1.0 \pm 0.2 \mathrm{gpm}$ using the concentrate return flow valve. Periodically, the concentrate return flow rate was measured using a graduated cylinder and a stopwatch as a check on the flow meter calibration. When all operational parameters were stabilized, the permeate flux and permeate and concentrate conductivity; $\mathrm{pH}$; and temperature were measured regularly at each applied pressure condition. Flux measurements were made every five minutes for the first fifteen minutes at a pressure condition and then every ten to fifteen minutes thereafter. The permeate flow was measured by disconnecting the permeate line from the feed tank and measuring the volume of permeate collected over a given period of time 
Table (3.7)--The Base MW Package And Water Volumes Added To Make Each Concentration.

\begin{tabular}{|c|c|c||}
\hline $\begin{array}{c}\text { Feed MW fluid concentration } \\
\text { (\% base MW package) }\end{array}$ & $\begin{array}{c}\text { Volume of base MW } \\
\text { package added (L) }\end{array}$ & $\begin{array}{c}\text { Volume of distilled water } \\
\text { added (L) }\end{array}$ \\
\hline \hline 5 & 2 & 38 \\
\hline 10 & 4 & 36 \\
\hline 15 & 6 & 34 \\
\hline 20 & 8 & 32 \\
\hline 30 & 12 & 28 \\
\hline 40 & 16 & 24 \\
\hline
\end{tabular}


using a graduated cylinder and a stopwatch. The $\mathrm{pH}$, conductivity, and turbidity of the permeate sample was measured. The permeate temperature was measured using a Fisher Scientific digital temperature probe placed in the graduated cylinder as a permeate sample was being collected. To obtain a representative reading of the permeate temperature, the thermometer probe was agitated in the cylinder prior to measuring the temperature. The concentrate $\mathrm{pH}$ and conductivity were measured every fifteen minutes immediately after measuring permeate parameters. Since each experiment was conducted in recycle mode (i.e., constant $\mathrm{O}_{\mathrm{k}}$ ), all permeate was returned to the feed tank after measuring the flux, temperature, $\mathrm{pH}$ and conductivity.

System Shutdown: When the final applied pressure condition was completed, the membrane rotational speed was turned to the lowest setting of $150 \mathrm{rpm}$, the pump was shut off, and the power to the unit was disconnected. The vessel was opened and physical observations of the membrane's condition were made. Particular attention was paid to the accumulation/formation of an oily ring or a gel-like layer on the membrane surface. Additionally, the membrane was inspected for scratches and tares. The cleaning procedure detailed earlier was applied and a clean water flux was measured after each experiment. Following system cleaning, the entire experimental procedure was repeated again for a constant $\mathrm{R}_{\mathrm{j}} \mathrm{O}_{\mathrm{k}}$ combination as a function of applied pressure.

\section{Analytical Methods}

Prior to beginning an experiment, the $\mathrm{pH}$ and conductivity meters were calibrated using standard solutions. During these experiments, $\mathrm{pH}$ and conductivity were collected and analyzed in triplicate when changes in these parameters were observed. 
Oil Content Analysis: The oil content of the base MW fluid was determined using a method developed by the MW fluid manufacturer and a commercial rolling mill. The procedure is a variation on ASTM Method D 96, "Standard Test Method for Water and Sediment in Crude Oil by Centrifuge Method (Filed Procedure)."

The oil content procedure used in these analyses was:

1. Added $20 \mathrm{~mL}$ of $\mathrm{MW}$ fluid to a Babcock bottle then added $20 \mathrm{~mL}$ of a stock $760 \mathrm{~g} / \mathrm{L} \mathrm{NaHSO}_{4}$ solution.

2. Bottle shaken to mix sample and $\mathrm{NaHSO}_{4}$ solution.

3. Bottle was heated in boiling water bath for 30 minutes.

4. Added additional $\mathrm{NaHSO}_{4}$ solution up to neck of the Babcock bottle.

5. Samples were centrifuged at $2,500 \mathrm{rpm}$ for 1 hour.

6. Babcock bottle was refilled to the neck of the bottle with $\mathrm{NaHSO}_{4}$ solution.

7. Sample was centrifuged for and additional 20 minutes.

8. Percent oil was read directly from bottle graduation to the nearest $0.1 \%$.

MW Fluid Density: The densities of each MW fluid solution were determined at $110 \pm 1{ }^{0} \mathrm{~F}$ by measuring the mass of $100 \mathrm{~mL}$ of a stock solution in a tarred volumetric flask using a Denver Instrument Company Model 100A analytical balance (accurate to \pm $0.0001 \mathrm{~g})$. Each MW fluid solution was heated to $110 \pm 1{ }^{0} \mathrm{~F}$ on a laboratory heating plate. The temperature was measured using a Fisher Scientific digital temperature probe. A $100 \mathrm{~mL}$ sample of each heated MW fluid solution was transferred into a tarred $100 \mathrm{~mL}$ volumetric flask and its mass was measured. The temperature of the solution was then 
re-measured to determine if the temperature had deviated from the 109 to $111{ }^{0} \mathrm{~F}$ range. If the temperature was outside the specified range after measuring the mass, a new sample was measured. Additionally, analytical triplicates (i.e., three separate $100 \mathrm{~mL}$ samples from the same $1 \mathrm{~L}$ stock solution) were performed for each MW fluid concentration. The densities were then plotted versus MW fluid concentration and a regression line was fitted to the data.

MW Fluid Absolute Viscosity: The absolute viscosities of the standard MW fluid were determined at $110 \pm 1{ }^{0} \mathrm{~F}$ using a digital Brookfield model DV-III rheometer equipped with an ultra low (UL) absolute viscosity adapter and a built-in temperature probe. The specifications of the rheometer are presented in Table (3.8). A schematic of the rheometer is presented in Figure (3.5). A $500 \mathrm{~mL}$ sample of each MW fluid was heated to $110 \pm 1{ }^{0} \mathrm{~F}$ in a $600 \mathrm{~mL}$ beaker using a laboratory heating plate $(600 \mathrm{~mL}$ sample cell recommended by Brookfield Engineering Laboratories). The rheometer's built-in temperature probe was used to monitor the MW fluid temperature. The rheometer was positioned above the sample and heating plate, leveled, and immersed in the MW fluid up to the designated mark on the UL adapter. The absolute viscosity of each MW fluid was then measured at a shear rate of $5 \mathrm{rpm}(6.12 / \mathrm{sec})$. After analyzing the six MW fluids, stock solutions of 45,47 , and $48 \%$ MW fluid were prepared and analyzed to obtain additional absolute viscosity data due to a large increase in absolute viscosity observed between 40 and 50\% MW fluid. To check the accuracy of the rheometer, the absolute viscosity of deionized water was measured at $110 \pm 1{ }^{0} \mathrm{~F}$ and $5 \mathrm{rpm}(6.12 / \mathrm{sec})$. Absolute 
Table (3.8)-Specifications Of The Digital Rheometer.

\begin{tabular}{|c|c|}
\hline Manufacturer & Brookfield Engineering Laboratories \\
\hline Model & DV-III \\
\hline Speed range & 0 to $250 \mathrm{rpm}$ in $0.1 \mathrm{rpm}$ increments \\
\hline Viscosity accuracy & $\begin{array}{l} \pm 1 \% \text { of full scale range for a specific } \\
\text { spindle running at a specific speed. }\end{array}$ \\
\hline Temperature sensing range & $\begin{array}{l}-100 \text { to } 300{ }^{0} \mathrm{C} \\
\left(-148 \text { to } 572{ }^{0} \mathrm{~F}\right)\end{array}$ \\
\hline Temperature accuracy & $\begin{array}{l} \pm 1.0{ }^{0} \mathrm{C} \text { from }-100 \text { to } 150{ }^{0} \mathrm{C} \\
\pm 2.0{ }^{0} \mathrm{C} \text { from } 150 \text { to } 300{ }^{0} \mathrm{C}\end{array}$ \\
\hline
\end{tabular}




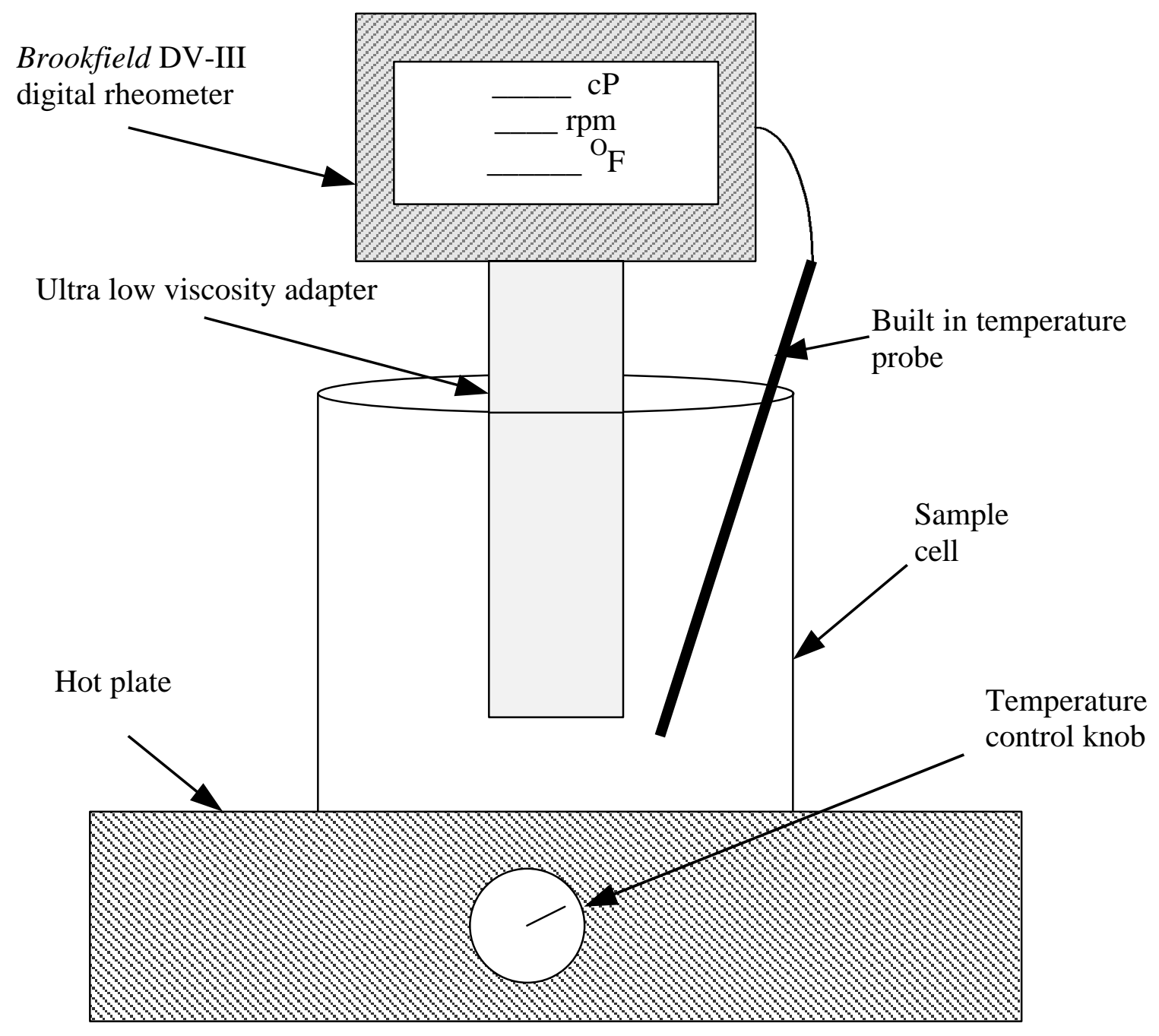

Figure (3.5)—A Schematic Of The Rheometer. 
viscosity measurements were performed in triplicate. The average absolute viscosity of the water sample was $0.56 \mathrm{cP}$ and ranged from 0.48 to $0.60 \mathrm{cP}$.

MW Fluid Particle Size Analysis: Samples of the 5, 10, 20, 30, and $40 \%$ MW fluids were sent to the Coulter Corporation and to Malvern Instruments for particle size analysis. Both the Coulter Corporation and the Malvern Corporation analyzed these samples free of charge. Triplicate analyses were not performed on these samples. The Coulter Corporation used a "Multisizer Model IIe" and the Malvern Corporation used a "Mastersizer S" laser diffraction system to measure the particle size distribution of these samples. Specifications of the Coulter and Malvern particle size analysis instruments are presented in Table (3.9). Both companies provided particle size distributions and summary statistics (mean and median) for each MW fluid sample.

\section{Quality Assurance/Quality Control}

Triplicate absolute viscosity and density measurements of MW fluids were made. The results of the triplicate analysis are presented in the Chapter 4. Triplicate analysis of particle size analysis sample was not performed since measurements were performed free of charge by two separate commercial laboratories. On-site measurements of particle sizes and distributions were not possible because West Virginia University's particle size analysis equipment was not operational. Experimental replicates were performed to gauge the effects of changes in membrane characteristics (due to pore plugging/fouling and chemical/surface changes due to MW fluid and chemical cleaning solutions) on limiting permeate flux. The results of the replicate experiments are presented then discussed in Chapters 4 and 5, respectively. The membrane resistance was calculated 
Table (3.9)--Specifications Of The Coulter And Malvern Particle Size Analysis Instruments.

\begin{tabular}{|l||l|l||}
\hline Manufacturer & Coulter Corporation & Malvern Instruments \\
\hline Model & Multisizer lie & Mastersizer S \\
\hline Particle size range & 0.4 to $1,200 \mu \mathrm{m}$ & 0.05 to $900 \mu \mathrm{m}$ \\
\hline
\end{tabular}


after each membrane cleaning to measure the membrane's condition throughout the study. Additionally, the baseline membrane performance experiments were performed at two temperatures to ascertain whether flux change was due to changes in feed viscosity (due to change in temperature) or to a change in some other parameter such as an alteration in the membrane properties under increased applied pressure. 


\section{CHAPTER 4.0 \\ RESULTS}

In this chapter, data from the baseline MW fluid and membrane performance experiments will be presented. The results of individual constant rotation/MW fluid concentration experiments (permeate flux and limiting permeate flux; permeate and concentrate $\mathrm{pH}$ and conductivity; total resistance to hydraulic flow in the pressurecontrolled region; and membrane resistance after cleaning) will be presented separately.

\section{BASELINE MEMBRANE PERFORMANCE EXPERIMENTS}

Clean water permeate flux versus time for the virgin membrane/distilled water experiment is presented in Figure (4.1). A decrease in permeate flux from an initial value of $2200 \mathrm{gal} / \mathrm{ft}^{2}-\mathrm{d}$ to a quasi-steady state flux of $870 \mathrm{gal} / \mathrm{ft}^{2}-\mathrm{d}$ at $\sim 11 \mathrm{hr}$. was observed. The initial decrease in permeate flux was similar to behavior observed by other researchers [Fane and Fell 1987, Elmaleh and Naceur 1992] and may have several causes. The initial flux decline may have been due to (1) membrane conditioning/compassion in which the physical properties of the virgin membrane were stabilized over time under an applied pressure; (2) pore plugging by residual materials from the membrane manufacturing process which were not fully rinsed out when the membrane was washed and wetted; (3) contaminants in the system (from process lines, feed pump, etc.); and (4) bacteria and trace colloids present in the distilled water. [Fane and Fell 1987, Elmaleh and Naceur 1992]

Permeate flux was averaged at each $\mathrm{P}_{\mathrm{i}} \mathrm{R}_{\mathrm{j}}$ combination. The average permeate flux at each applied pressure/membrane rotational speed combination in the virgin 


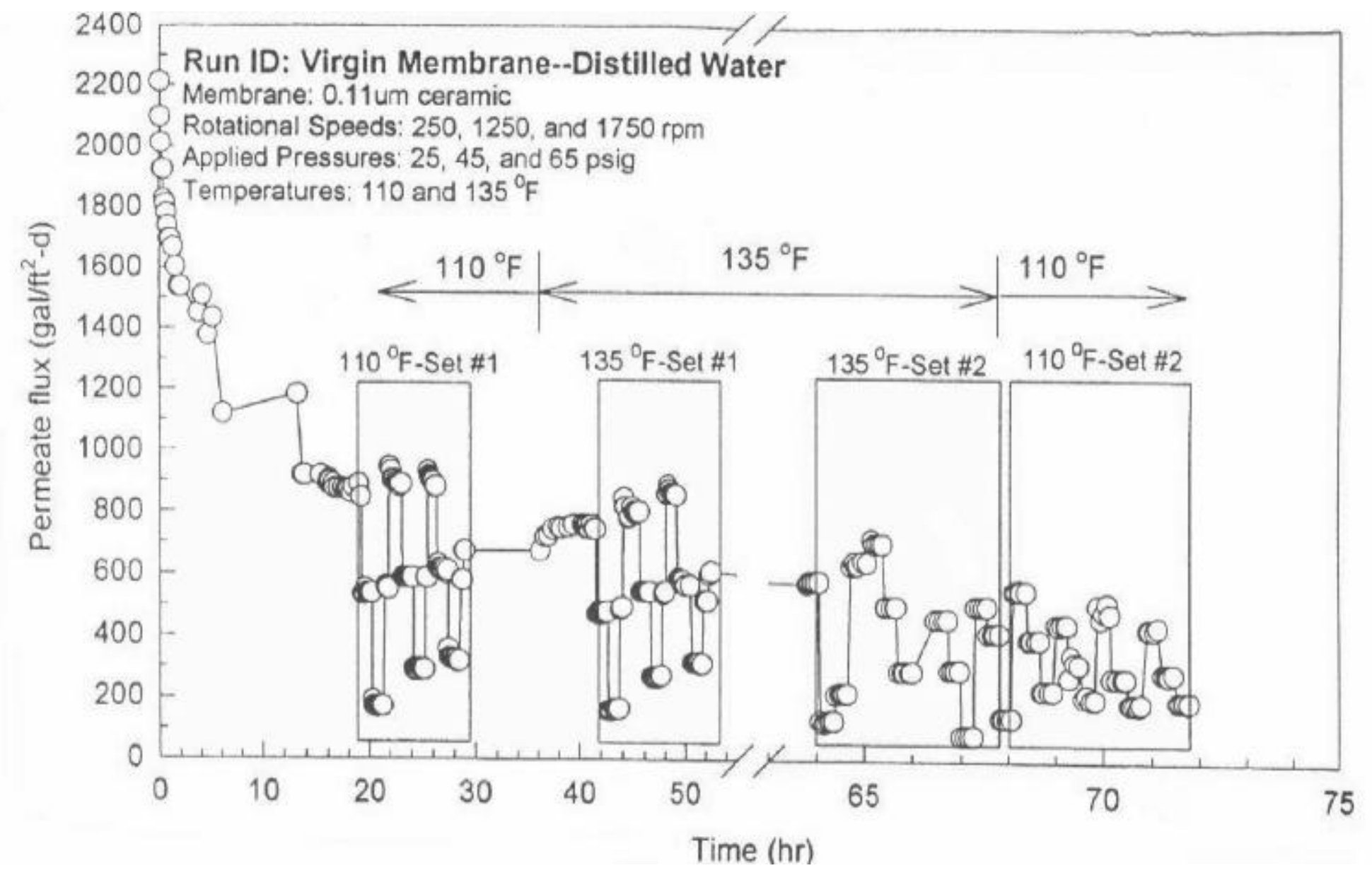

Figure (4.1) - Clean Water Permeate Flux Versus Time for the Virgin Membrane/Distilled Water Experiment 
membrane/distilled water experiment is presented in Table (4.1). A plot of average permeate flux versus average transmembrane pressure at 110 and $135{ }^{\circ} \mathrm{F}$ in the virgin membrane/distilled water experiment is presented in Figure (4.2). The first temperature excursion (temperature increased from 110 to $135{ }^{\circ} \mathrm{F}$ ) is designated as "Set 1 " and the second temperature excursion (temperature decreased from 135 to $110{ }^{0} \mathrm{~F}$ ) is designated as "Set 2." The membrane resistance calculated using Equation (2.4) at 110 and $135{ }^{\circ} \mathrm{F}$ for Set 1 and Set 2 in the virgin membrane/distilled water experiment are presented in Table (4.2). In Set 1 , the average permeate flux was higher at $110{ }^{0} \mathrm{~F}$ at each $\mathrm{P}_{\mathrm{i}} \mathrm{R}_{\mathrm{j}}$ combination. Consequently, the resistance of the membrane increased from $1.6 \times 10^{12} \mathrm{~m}^{-1}$ to $1.74 \times 10^{12} \mathrm{~m}^{-1}$ when the feed temperature was raised from 110 to $135{ }^{0} \mathrm{~F}$. In Set 1 , $\mathrm{P}_{\mathrm{i}} \mathrm{R}_{\mathrm{j}}$ and temperature excursions were started prior to the membrane reaching a constant physical/chemical condition. Permeate and concentrate $\mathrm{pHs}$ were approximately equal in the CWF experiment. The permeate $\mathrm{pH}$ ranged from 5.78 to 6.51 and averaged 6.10. The concentrate $\mathrm{pH}$ ranged from 5.58 to 6.45 and averaged 6.05. However, concentrate conductivity was greater than permeate conductivity. The permeate conductivity ranged from 1.88 to $7.87 \mu \mathrm{S} / \mathrm{cm}$ and averaged $3.90 \mu \mathrm{S} / \mathrm{cm}$. The concentrate conductivity ranged from 2.75 to $8.54 \mu \mathrm{S} / \mathrm{cm}$ and averaged $6.14 \mu \mathrm{S} / \mathrm{cm}$. Since the concentrate conductivity was greater than the permeate conductivity, it is hypothesized that charged colloids were retained on the membrane which resulted in a decrease in permeate flux over time. In Set 2, the membrane resistance was $2.16 \times 10^{12} \mathrm{~m}^{-1}$ at $135^{0} \mathrm{~F}$ and $2.70 \times 10^{12} \mathrm{~m}^{-1}$ at $110{ }^{0} \mathrm{~F}$. The change in membrane resistance from 135 to $110^{\circ} \mathrm{F}$ was $\sim 20 \%$, while the change in 
Table (4.1)—The Average Permeate Flux At Each Applied Pressure/Membrane Rotational Speed Combination In The Virgin Membrane/Distilled Water Experiment.

\begin{tabular}{|c|c|c|c|c|}
\hline $\begin{array}{c}\mathrm{P}_{\mathrm{i}} \mathrm{R}_{\mathrm{j}} \\
(\mathrm{psig} / \mathrm{rpm})\end{array}$ & $\begin{array}{l}\text { Set } \# 1--110^{0} \mathrm{~F} \\
\text { Avg. flux } \\
\text { [Range] } \\
\text { (gal./ft }{ }^{2} \text {-day) }\end{array}$ & $\begin{array}{c}\text { Set \#1--135 } \mathrm{F} \\
\text { Avg. flux } \\
\text { [Range] } \\
\text { (gal./ft }{ }^{2} \text {-day) }\end{array}$ & $\begin{array}{l}\text { Set } \# 2--110^{0} \mathrm{~F} \\
\text { Avg. flux } \\
\text { [Range] } \\
\text { (gal./ft }{ }^{2} \text {-day) }\end{array}$ & 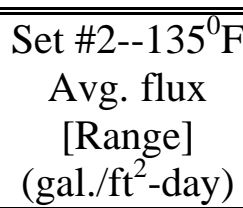 \\
\hline $65 / 1,750$ & $\begin{array}{c}869 \\
{[847-890]}\end{array}$ & $\begin{array}{c}753 \\
{[747-761]}\end{array}$ & $\begin{array}{c}459 \\
{[459-459]}\end{array}$ & $\begin{array}{c}580 \\
{[574-581]}\end{array}$ \\
\hline $45 / 1,750$ & $\begin{array}{c}538 \\
{[538-538]}\end{array}$ & $\begin{array}{c}476 \\
{[470-481]}\end{array}$ & $\begin{array}{c}294 \\
{[294-294]}\end{array}$ & {$[-]$} \\
\hline $25 / 1,750$ & $\begin{array}{c}172 \\
{[169-172]}\end{array}$ & $\begin{array}{c}165 \\
{[165-165]}\end{array}$ & $\begin{array}{c}83 \\
{[83-83]} \\
\end{array}$ & $\begin{array}{c}127 \\
{[122-129]}\end{array}$ \\
\hline $65 / 1,250$ & $\begin{array}{c}910 \\
{[883-948]}\end{array}$ & $\begin{array}{c}805 \\
{[797-818]}\end{array}$ & $\begin{array}{c}503 \\
{[503-503]}\end{array}$ & $\begin{array}{c}638 \\
{[632-646]}\end{array}$ \\
\hline $45 / 1,250$ & $\begin{array}{c}589 \\
{[589-589]}\end{array}$ & $\begin{array}{c}546 \\
{[546-546]}\end{array}$ & $\begin{array}{c}416 \\
{[416-416]}\end{array}$ & {$[-]$} \\
\hline $25 / 1,250$ & $\begin{array}{c}291 \\
{[287-294]}\end{array}$ & $\begin{array}{c}269 \\
{[266-273]}\end{array}$ & $\begin{array}{c}140 \\
{[140-140]}\end{array}$ & $\begin{array}{c}218 \\
{[215-219]}\end{array}$ \\
\hline $65 / 250$ & $\begin{array}{c}889 \\
{[883-898]}\end{array}$ & $\begin{array}{c}864 \\
{[858-876]}\end{array}$ & $\begin{array}{c}553 \\
{[553-556]}\end{array}$ & $\begin{array}{c}706 \\
{[703-718]}\end{array}$ \\
\hline $45 / 250$ & $\begin{array}{c}612 \\
{[603-617]}\end{array}$ & $\begin{array}{c}571 \\
{[567-581]}\end{array}$ & $\begin{array}{c}395 \\
{[395-395]}\end{array}$ & $\begin{array}{c}503 \\
{[503-503]}\end{array}$ \\
\hline $25 / 250$ & $\begin{array}{c}322 \\
{[316-327]}\end{array}$ & $\begin{array}{c}314 \\
{[309-316]}\end{array}$ & $\begin{array}{c}230 \\
{[230-230]}\end{array}$ & $\begin{array}{c}291 \\
{[291-291]}\end{array}$ \\
\hline
\end{tabular}




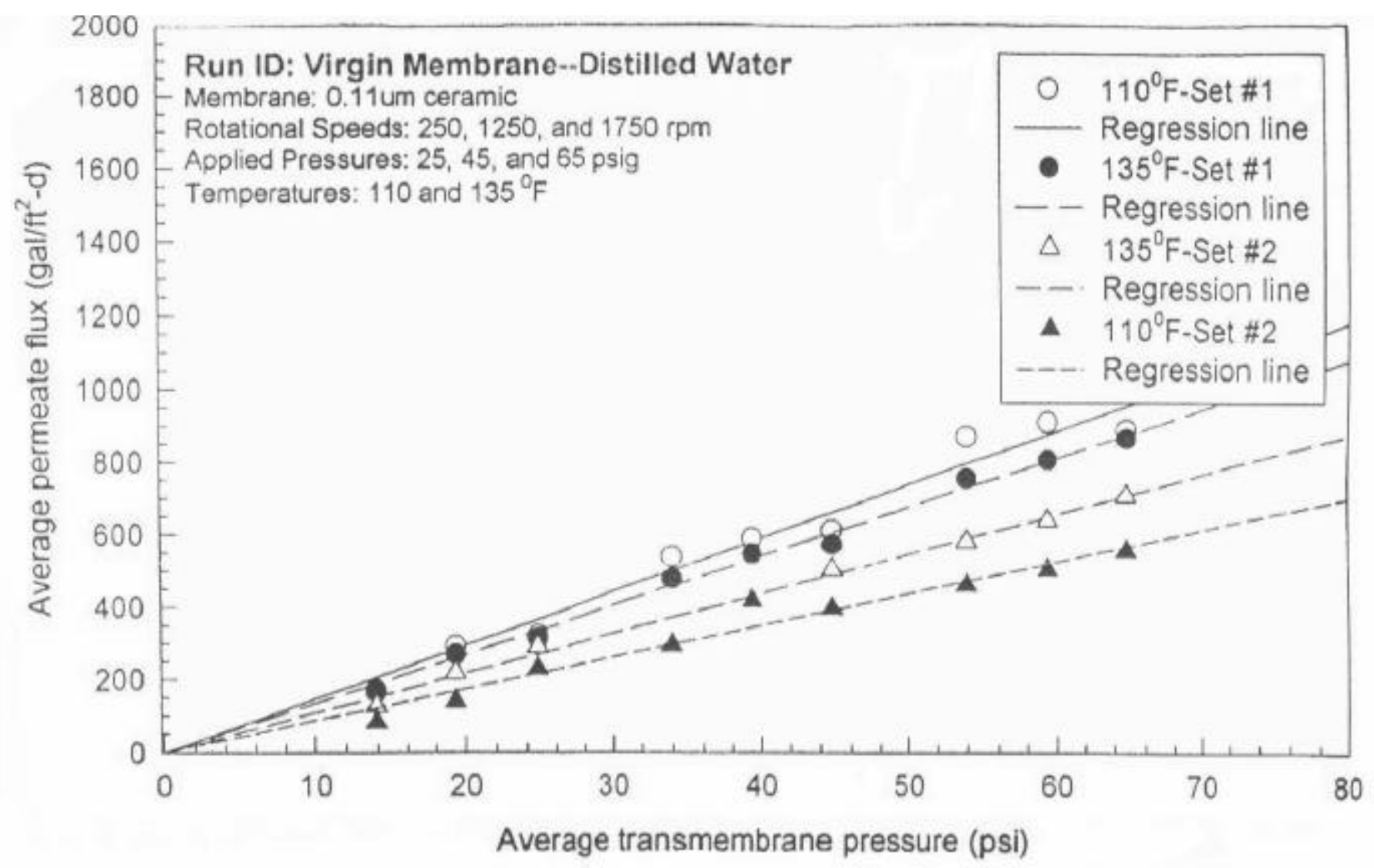

Figure (4.2) - Plot of Average Permeate Flux Versus Average Transmembrane Pressure at 110 and $135^{\circ} \mathrm{F}$ in the Virgin Membrane/Distilled Water Experiment 
Table (4.2)--The Membrane Resistance at 110 And $135{ }^{\circ}$ F For Set 1 and Set 2 In The Virgin Membrane/Distilled Water Experiment.

\begin{tabular}{||c|c|c||}
\hline Set \# & Temp. $\left({ }^{0} \mathrm{~F}\right)$ & $\mathrm{R}_{\mathrm{m}}\left(\mathrm{m}^{-1}\right)$ \\
\hline \hline 1 & 110 & $1.60 \times 10^{12}$ \\
\hline 1 & 135 & $1.74 \times 10^{12}$ \\
\hline 2 & 110 & $2.70 \times 10^{12}$ \\
\hline 2 & 135 & $2.16 \times 10^{12}$ \\
\hline
\end{tabular}


the inverse viscosity of water from 135 to $110{ }^{0} \mathrm{~F}$ was $21 \%$. Thus, the decrease in membrane resistance when the temperature was decreased from 135 to $110{ }^{0} \mathrm{~F}$ in Set 2 was most likely due to the increase in the viscosity of water while the effects of virgin membrane conditioning/compaction were minimal. The resistance of the virgin ceramic membrane was $2.70 \times 10^{12} \mathrm{~m}^{-1}$ calculated using Set 2 data (see Equation (2.4)).

Following the initial CWF experiment, the membrane was cleaned using the standardized cleaning procedure discussed in Chapter 3. After cleaning, the CWF was determined again using DI water $(\mathrm{pH}=6.61$ and conductivity $=6.58 \mu \mathrm{S} / \mathrm{cm})$. A plot of the average permeate flux versus average transmembrane pressure for the clean water flux experiment is presented in Figure (4.3). The resistance of the membrane measured after cleaning was $1.89 \times 10^{12} \mathrm{~m}^{-1}$. The resistance of the membrane after cleaning was lower than the resistance of the virgin membrane. It was hypothesized that the lower membrane resistance after cleaning was due to opening membrane pores and/or changes in membrane surface properties.

\section{BASELINE MW FLUID EXPERIMENTS}

Density versus \% MW fluid is presented in Figure (4.4). The density range at a given \% MW fluid is represented by error bars. The density decreased linearly $\left(\mathrm{r}^{2}=\right.$ 0.995) as the MW fluid concentration was increased from 5 to $50 \% \mathrm{MW}$ fluid. A plot of absolute viscosity versus \% MW fluid is presented in Figure (4.5). The data in Figures (4.4) and (4.5) were required for the radial Reynolds Number $\left(\operatorname{Re}_{r}\right)$ calculation (Equation $(2.35))$. 


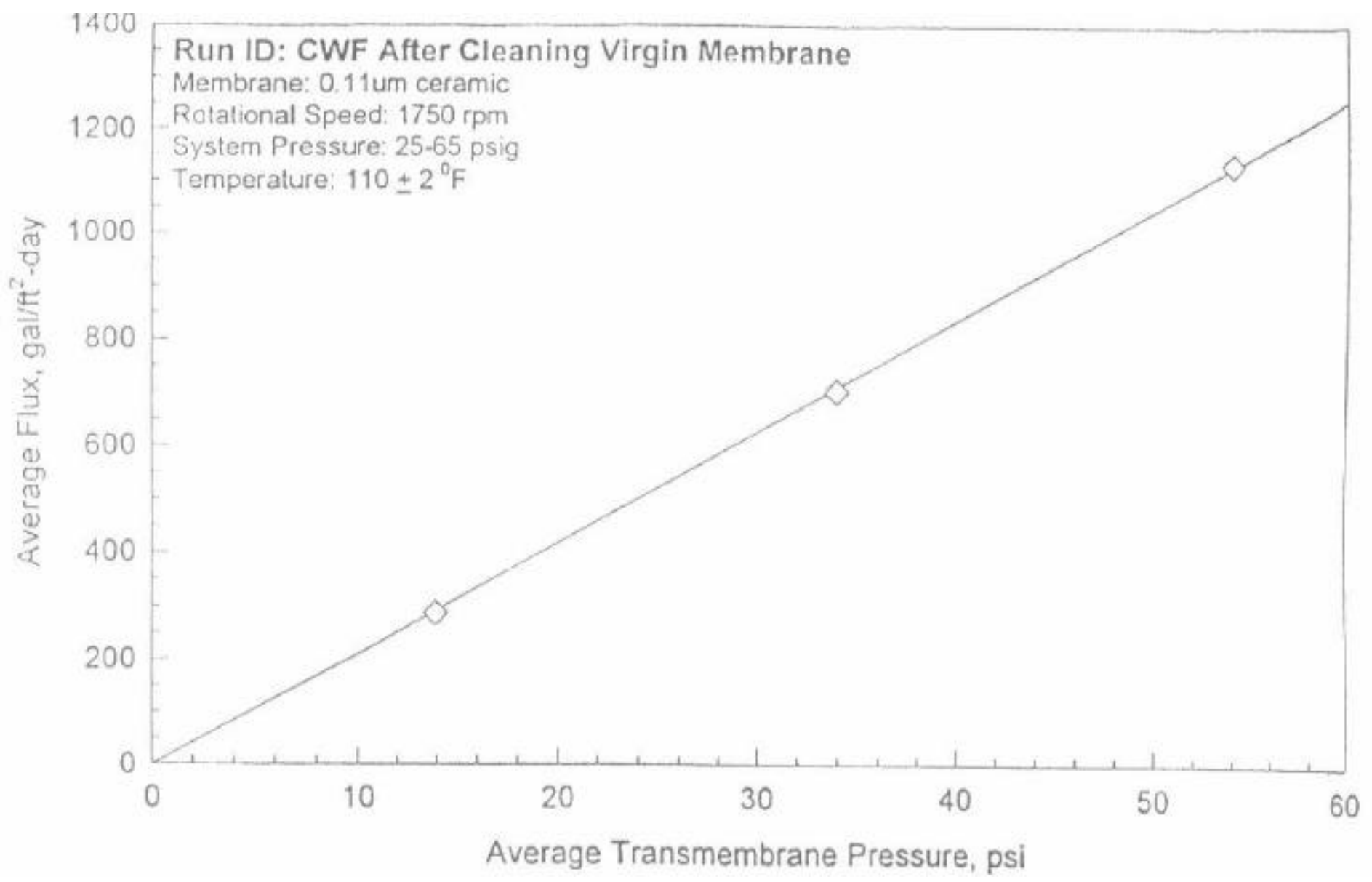

Figure (4.3) - Plot of Average Permeate Flux Versus Average Transmembrane Pressure Clean Water Flux Experiment 


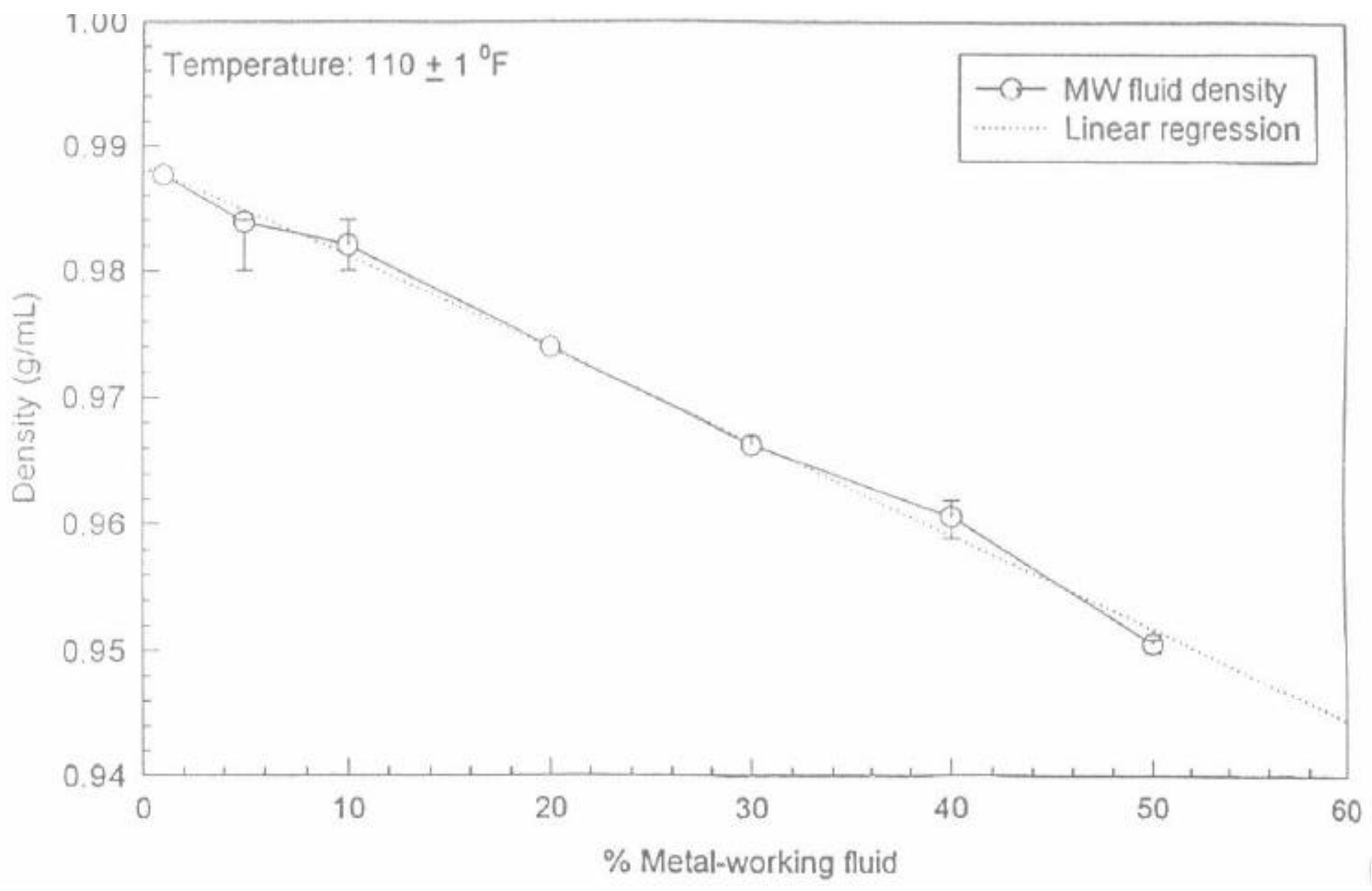

Figure (4.4) - Density Versus \% Metalworking Fluid 


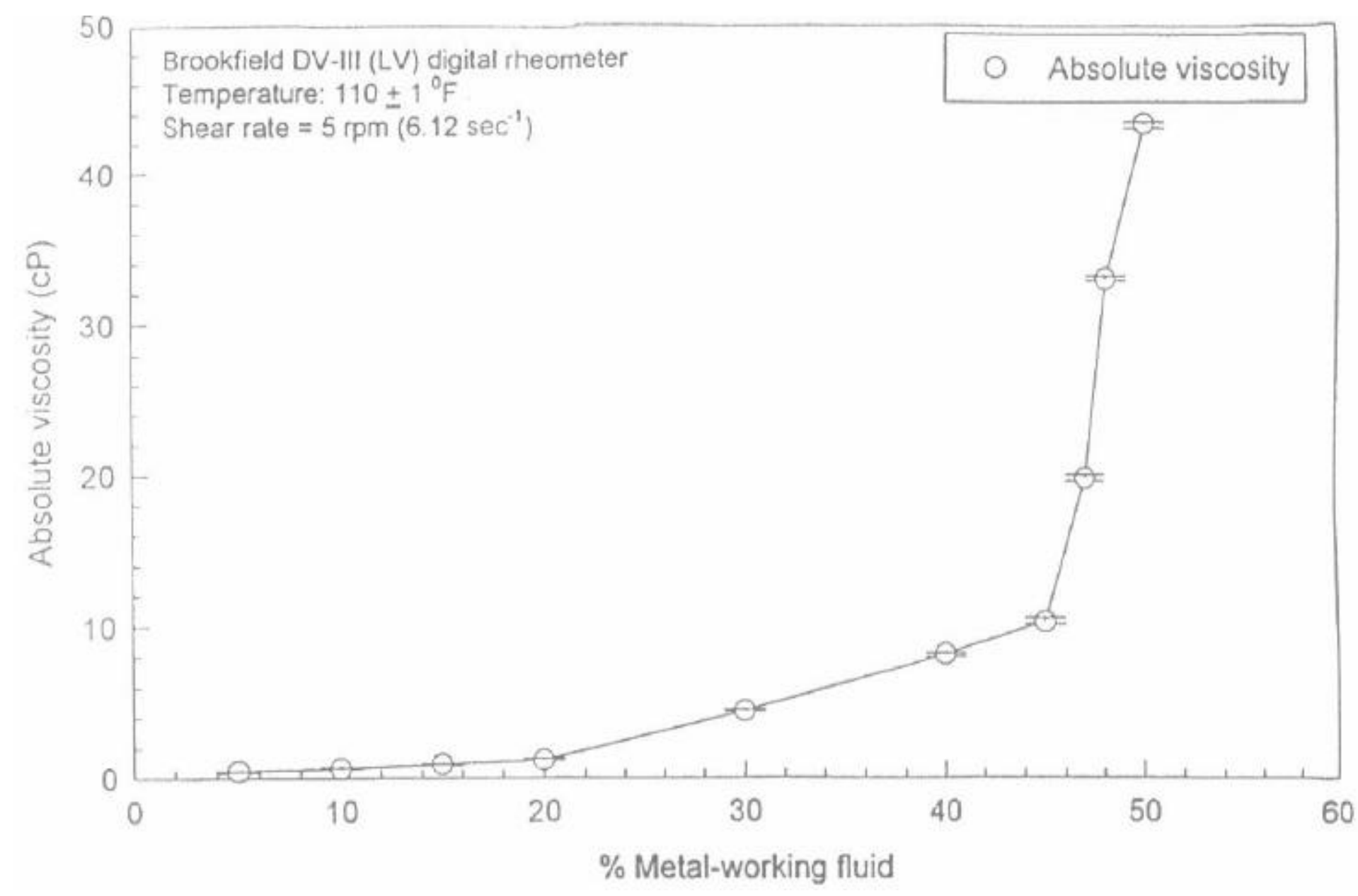

Figure (4.5) - MW Fluid Absolute Viscosity Versus MW Fluid 
Plots of the volume \% versus particle diameter for the 5, 10, 20, 30, and 40\% MW fluids analyzed on a Coulter Multisizer are presented in Figures (4.6), (4.7), (4.8), (4.9), and (4.10), respectively. The mean and median particle sizes reported by Coulter and the mean values reported by Malvern are presented in Table (4.3). The mean particle sizes as reported by Coulter were constant from 5 to $20 \%$ MW fluid but then decreased from $27.80 \mu \mathrm{m}$ at $20 \% \mathrm{MW}$ fluid to $11.87 \mu \mathrm{m}$ at $50 \% \mathrm{MW}$ fluid. Similar results were reported by Malvern: a decreased in mean particle size from $25.46 \mu \mathrm{m}$ at $20 \% \mathrm{MW}$ fluid to 9.00 $\mu \mathrm{m}$ at $50 \% \mathrm{MW}$ fluid. The mean particle sizes of the oil droplets were two orders of magnitude greater than the $0.11 \mu \mathrm{m}$ average pore size of the ceramic membrane. The stability of an oil-in-water emulsion is inversely proportional to the particle size. Consequently, the stability of the freshly prepared solutions increased as the MW fluid concentration was increased [Lammale 1992].

\section{MW FLUID EXPERIMENTS}

\section{$5 \%$ MW Fluid-1,750 rpm}

Permeate flux versus time for the 5\% MW Fluid-1,750 rpm experiment is presented in Figure (4.11). Permeate flux was stable at each applied pressure condition. The system was operated over an applied pressure range of 25 to 75 psig. The average permeate backpressure was $11.1 \mathrm{psi}$ for a membrane rotational speed of $1,750 \mathrm{rpm}$. The average permeate flux versus average transmembrane pressure for the 5\% MW Fluid1,750 rpm experiment is presented in Figure (4.12). No limiting flux, $\mathrm{J}^{*}$, was observed 


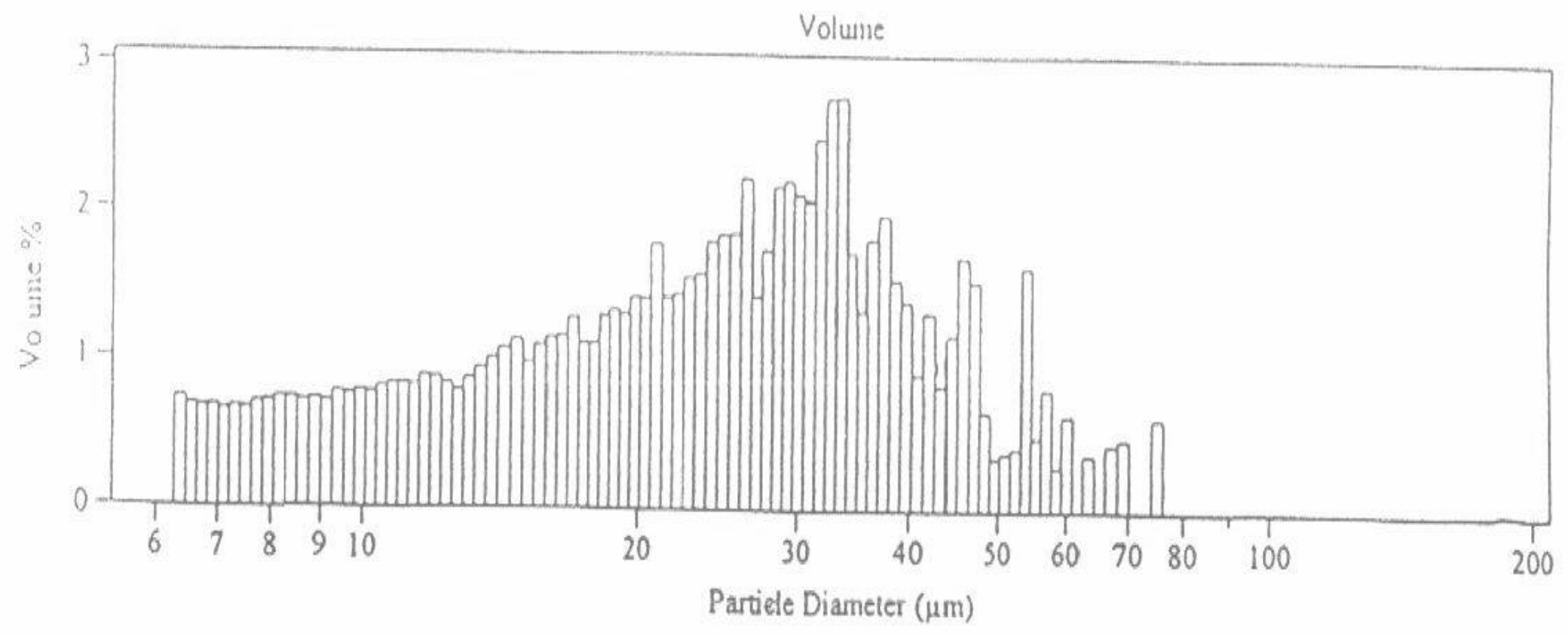

Figure (4.6) - Volume \% Versus Particle Diameter for 5\% MW Fluid 


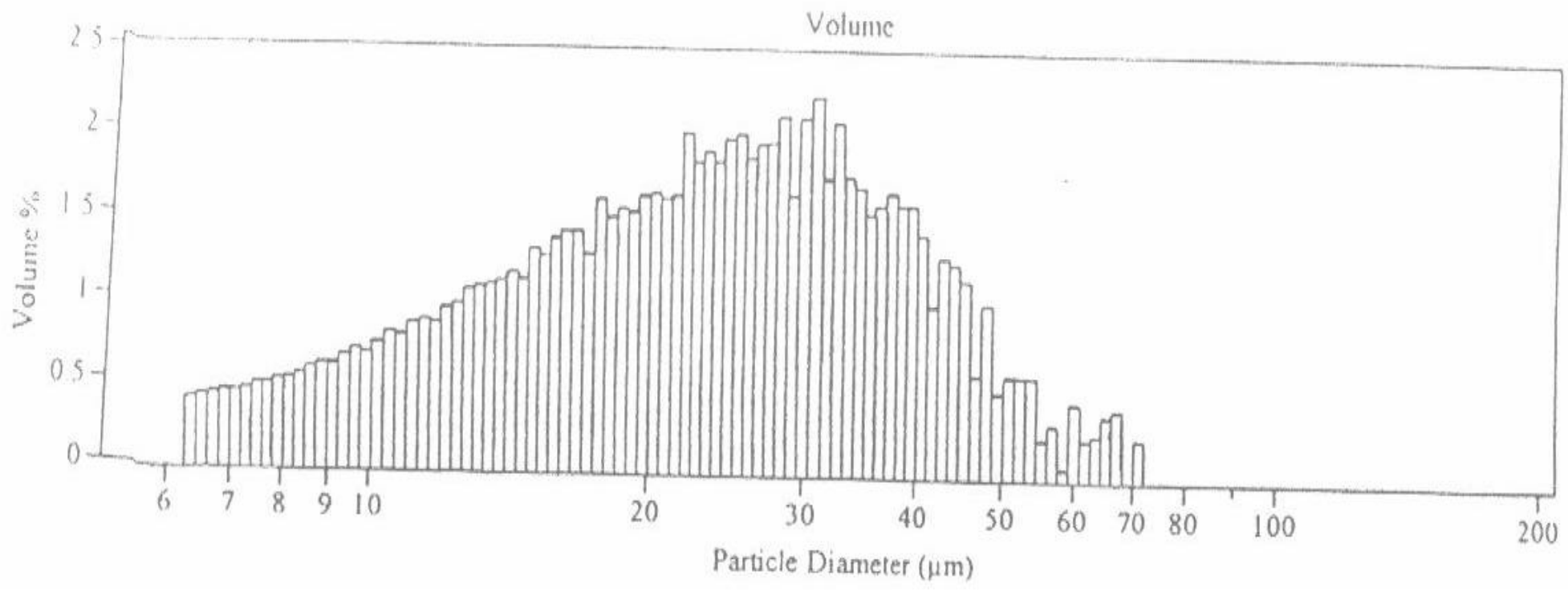

Figure (4.7) - Volume \% Versus Particle Diameter for 10\% MW Fluid 


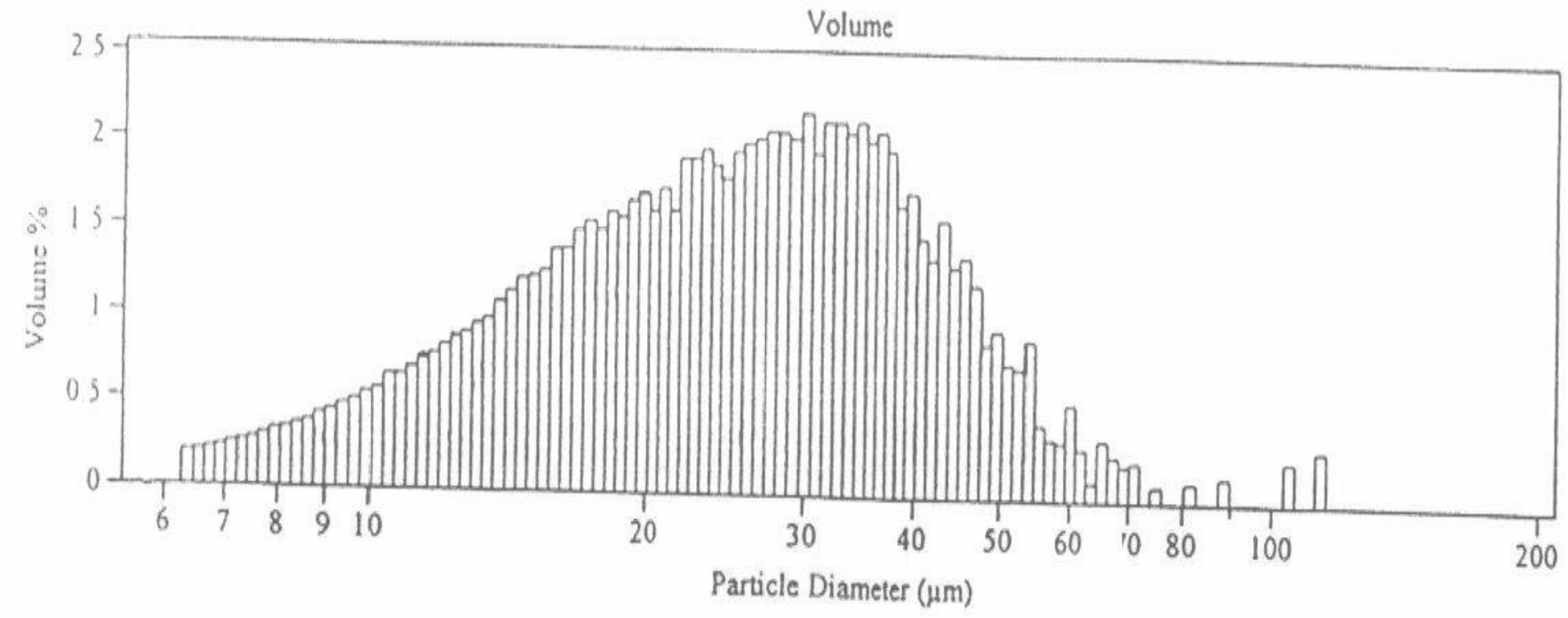

Figure (4.8) - Volume \% Versus Particle Diameter for 20\% MW Fluid 


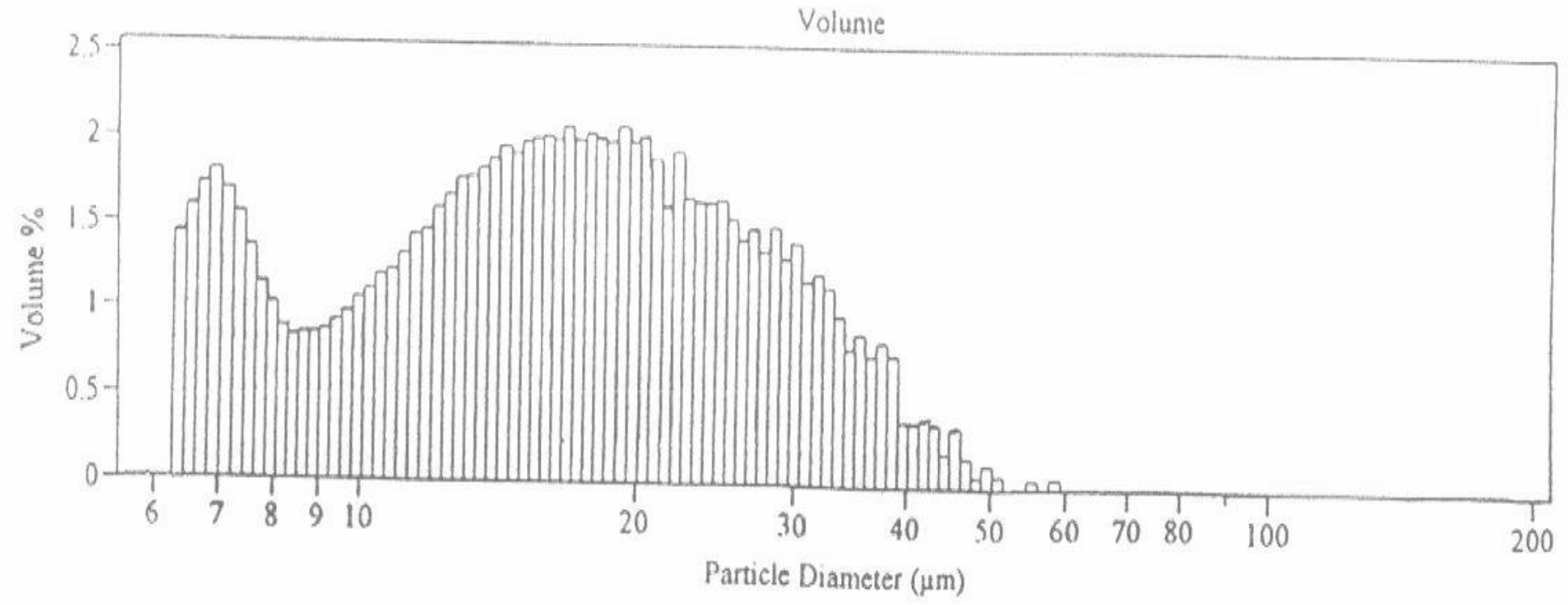

Figure (4.9) - Volume \% Versus Particle Diameter for 30\% MW Fluid 


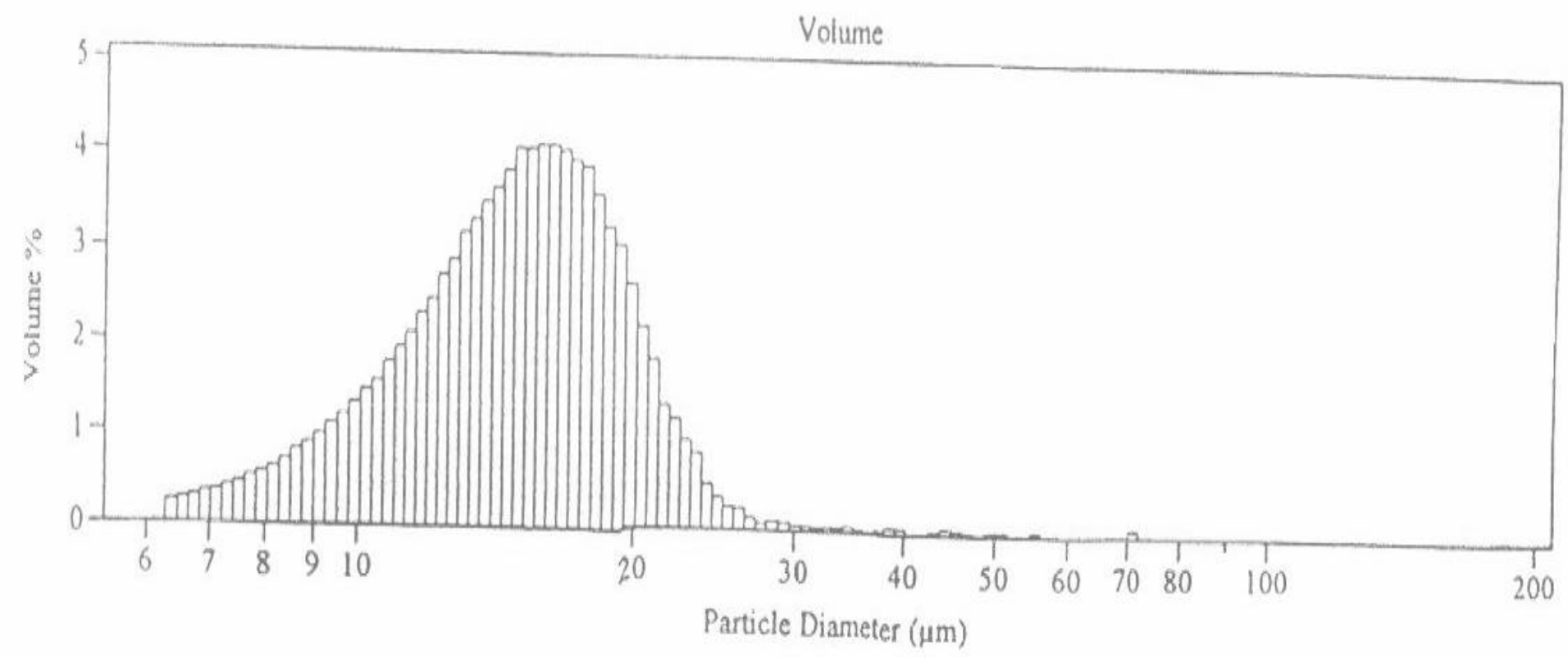

Figure (4.10) - Volume \% Versus Particle Diameter for 40\% MW Fluid 
Table (4.3)--The Mean And Median Particle Sizes Reported By Coulter and the Mean Particle Size Reported By Malvern.

\begin{tabular}{|c|c|c|c||}
\hline \hline \multicolumn{3}{|c|}{ Coulter } & Malvern \\
\hline \% MW fluid & Mean $(\mu \mathrm{m})$ & Median $(\mu \mathrm{m})$ & Mean $(\mu \mathrm{m})$ \\
\hline \hline 5 & 26.30 & 24.70 & 23.88 \\
\hline 10 & 25.37 & 23.39 & 17.86 \\
\hline 20 & 27.80 & 25.49 & 22.23 \\
\hline 30 & 18.17 & 16.40 & 15.67 \\
\hline 40 & 15.28 & 15.03 & 8.72 \\
\hline 50 & 11.87 & 9.00 & 3.90 \\
\hline
\end{tabular}




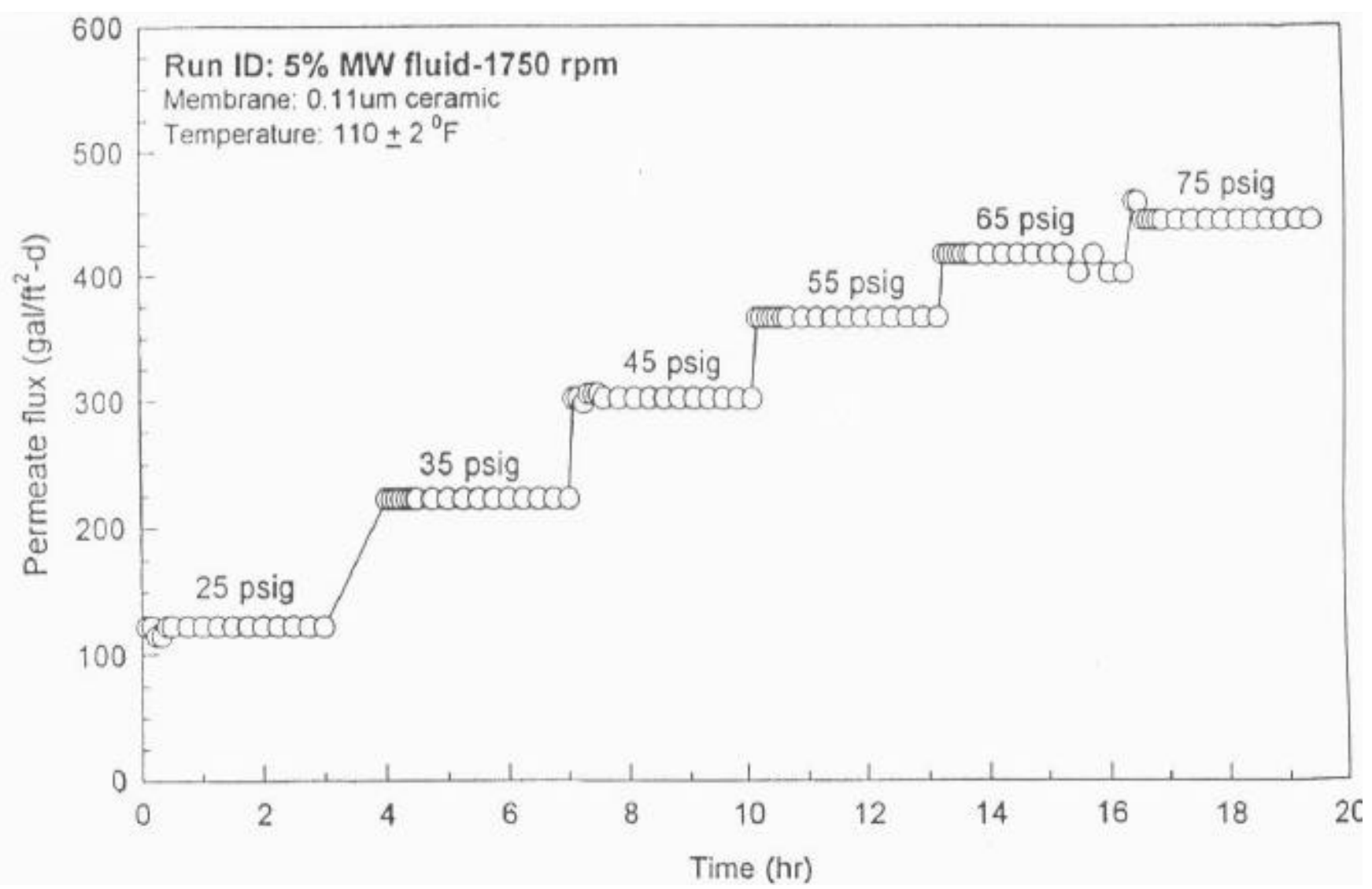

Figure (4.11) - Permeate Flux Versus Time for the 5\%-1,750 rpm Experiment 


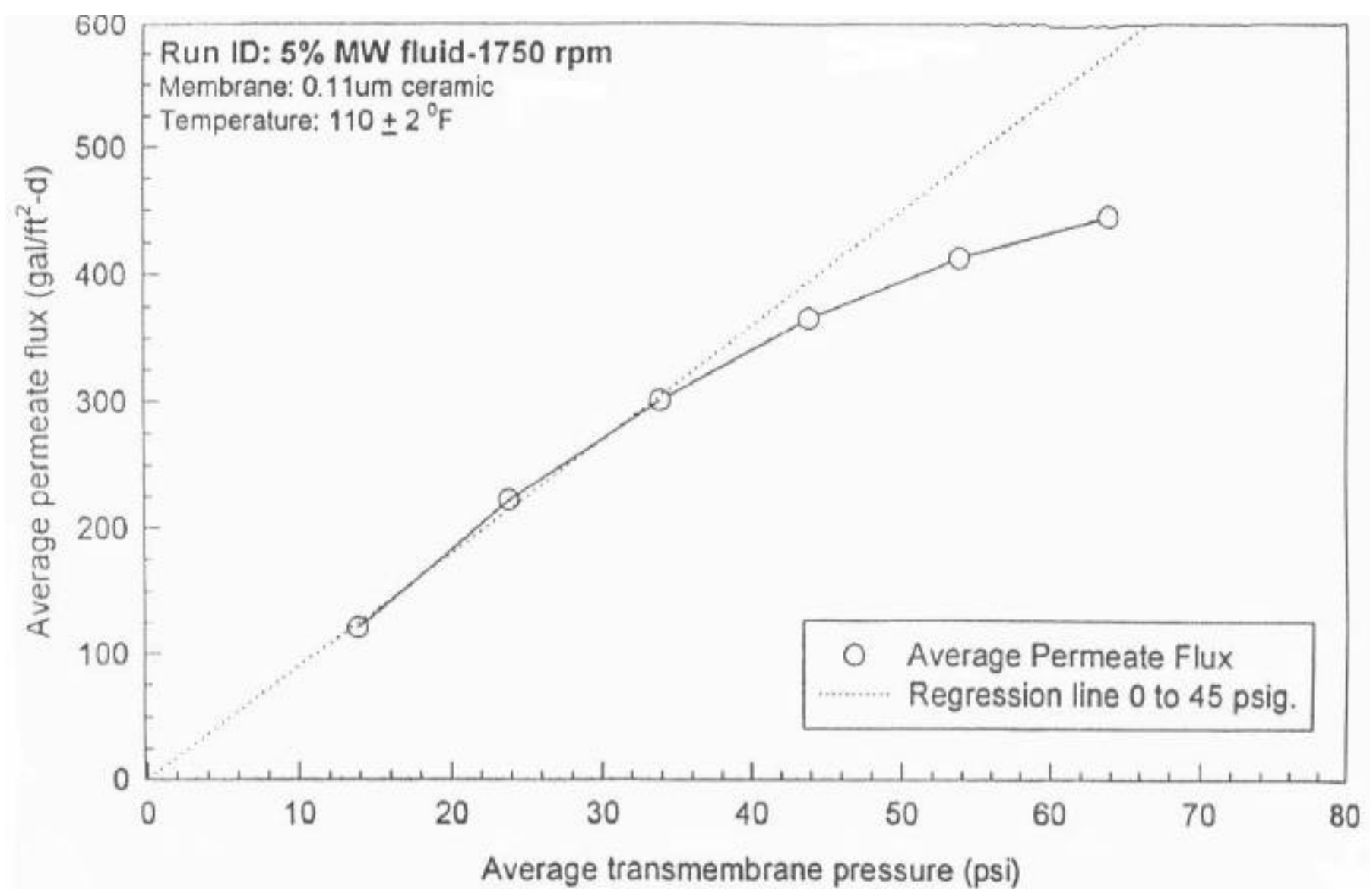

Figure (4.12) - Average Permeate Flux Versus Average Transmembrane Pressure for the 5\%-1,750 rpm Experiment 
over the applied pressure range studied in this experiment. However, the average flux data diverged from the regression line fitted to the data at pressures from 0 to $45 \mathrm{psig}$. It is hypothesized that the deviation from the linear flux-pressure relationship corresponded to a shift away from pressure-controlled to mass transfer-controlled flux behavior through no limiting permeate flux was observed. The slope of the regression line fitted to data from 0 to $45 \mathrm{psig}$ was $9.007 \mathrm{gal} / \mathrm{ft}^{2}-\mathrm{d}$-psi. The total resistance to hydraulic flow in the pressure-controlled region, $\mathrm{R}$, was $2.61 \times 10^{12} \mathrm{~m}^{-1}$.

The permeate $\mathrm{pH}$ ranged from 8.01 to 8.31 and averaged 8.16. The concentrate $\mathrm{pH}$ ranged from 7.67 to 8.25 and averaged 7.94. Permeate $\mathrm{pH}$ was constant in this experiment. A net decrease in concentrate $\mathrm{pH}$ was observed with time. Additionally, permeate $\mathrm{pH}$ was greater than concentrate $\mathrm{pH}$ throughout the 5\%-1,750 rpm experiment. The permeate conductivity ranged from 131 to $181 \mu \mathrm{S} / \mathrm{cm}$ and averaged $153 \mu \mathrm{S} / \mathrm{cm}$. The concentrate conductivity ranged from 211 to $278 \mu \mathrm{S} / \mathrm{cm}$ and averaged $254 \mu \mathrm{S} / \mathrm{cm}$. A net increase in concentrate conductivity and a net decrease in permeate conductivity over time was observed. Distinct step-wise changes in permeate and concentrate $\mathrm{pH}$ and conductivity were not observed as applied pressure was increased.

The membrane was cleaned using the standardized cleaning procedure discussed in Chapter 3. When the vessel was opened, a light sheen of oil was observed on the membrane surface. Thus, the membrane was hand-cleaned with dilute $(\sim 1 \%) \mathrm{H}_{2} \mathrm{SO}_{4}$. The membrane and system were then re-cleaned using the standardized cleaning procedure and additional visual observations of the membrane's condition were made. No oil was visible on the membrane surface after the second membrane cleaning. The 
$\mathrm{pH}$ and conductivity of the distilled water used to determine the membrane resistance after the second cleaning were 6.92 and $6.29 \mu \mathrm{S} / \mathrm{cm}$, respectively. A plot of the average permeate flux versus average transmembrane pressure for the 5\% MW Fluid-1,750 rpm clean water flux experiment is presented in Figure (4.13). The resistance of the membrane measured after the second cleaning was $1.96 \times 10^{12} \mathrm{~m}^{-1}$ (calculated using Equation (2.4)).

\section{5\% MW Fluid-1,450 rpm}

Permeate flux versus time for the 5\% MW Fluid-1,450 rpm experiment is presented in Figure (4.14). Permeate flux was stable at each applied pressure condition. The system was operated over an applied pressure range of 25 to 75 psig. The average permeate backpressure was 7.6 psi for a membrane rotational speed of $1,450 \mathrm{rpm}$. The average permeate flux versus average transmembrane pressure for the 5\% MW Fluid1,450 rpm experiment is presented in Figure (4.15). No limiting flux, $\mathrm{J}^{*}$, was observed over the applied pressure range studied in this experiment. However, the average flux data diverged from the line fitted to the data at pressures from 0 to $45 \mathrm{psig}$. It is hypothesized that the deviation from the linear flux-pressure relationship corresponded to a shift away from pressure-controlled to mass transfer-controlled flux behavior through no limiting permeate flux was observed. The slope of the regression line fitted to data from 0 to 45 psig was $8.071 \mathrm{gal} / \mathrm{ft}^{2}$-d-psi. The total resistance to hydraulic flow in the pressure-controlled region was $2.92 \times 10^{12} \mathrm{~m}^{-1}$.

The permeate $\mathrm{pH}$ ranged from 7.97 to 8.28 and averaged 8.12 . The concentrate $\mathrm{pH}$ ranged from 7.50 to 7.92 and averaged 7.61. Permeate $\mathrm{pH}$ was constant. Concentrate 


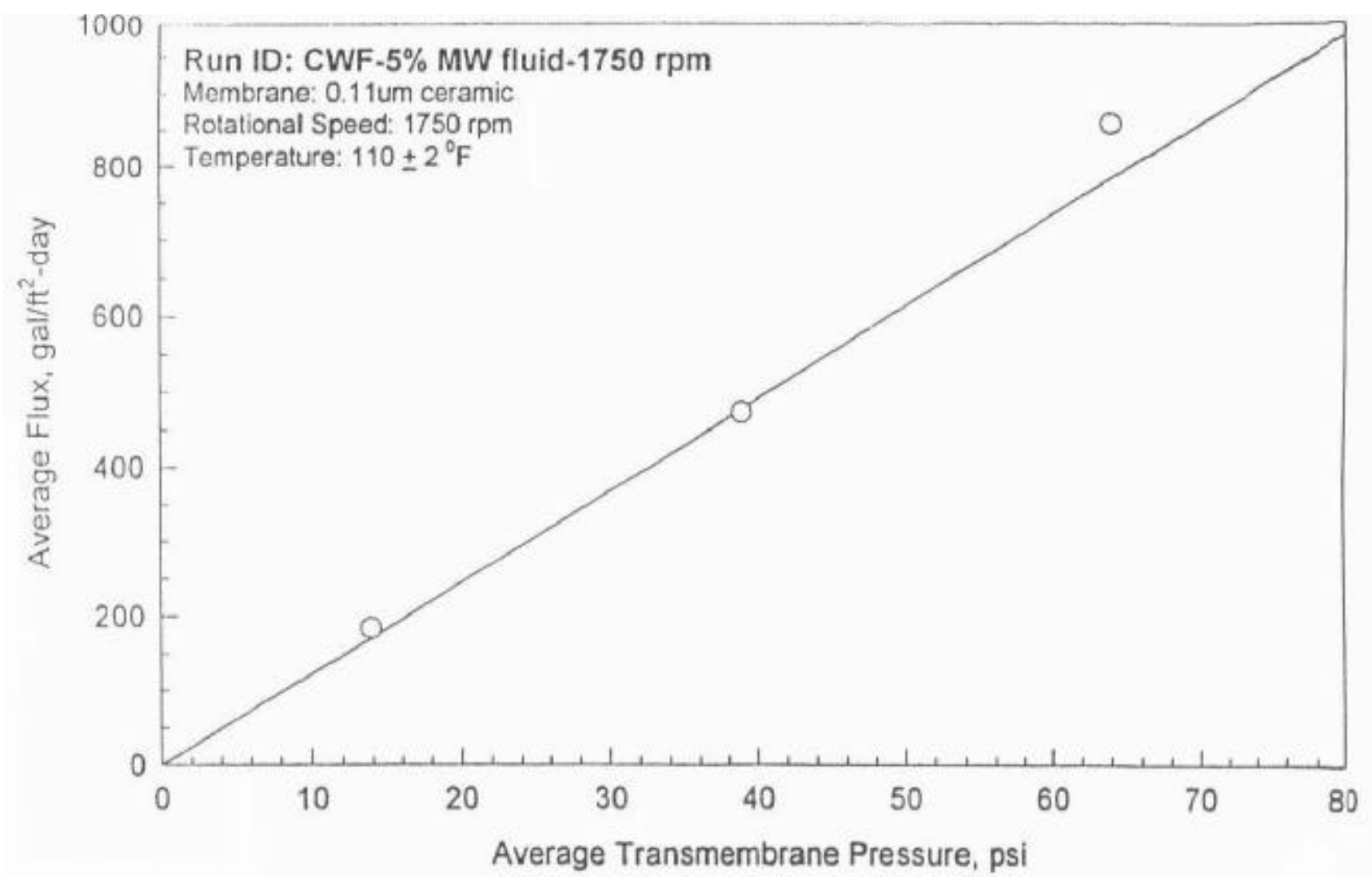

Figure (4.13) - Average Permeate Flux Versus Average Transmembrane Pressure for the 5\%-1,750 rpm Clean Water Flux Experiment 


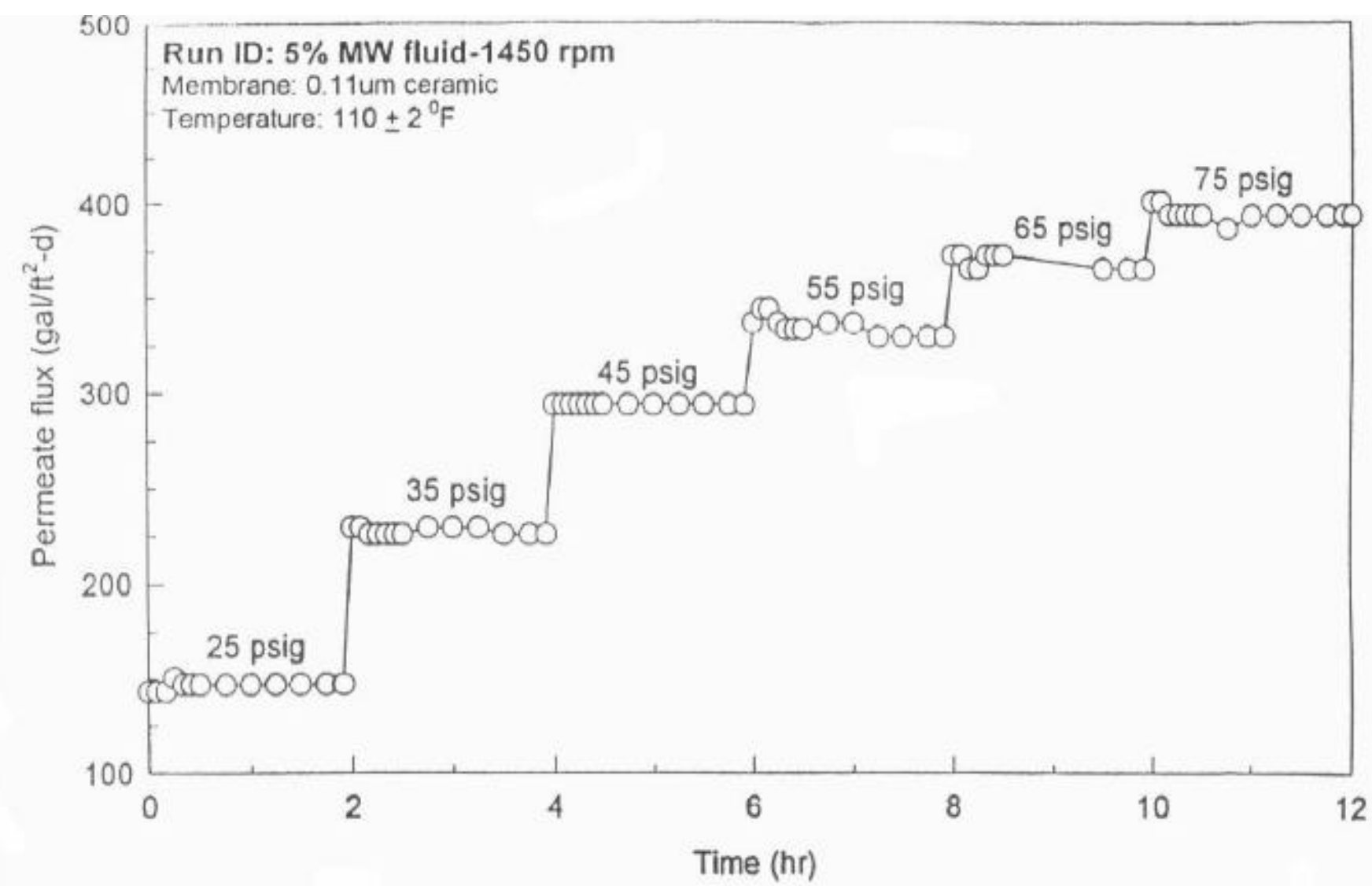

Figure (4.14) - Permeate Flux Versus Time for the 5\%-1,450 rpm Experiment 


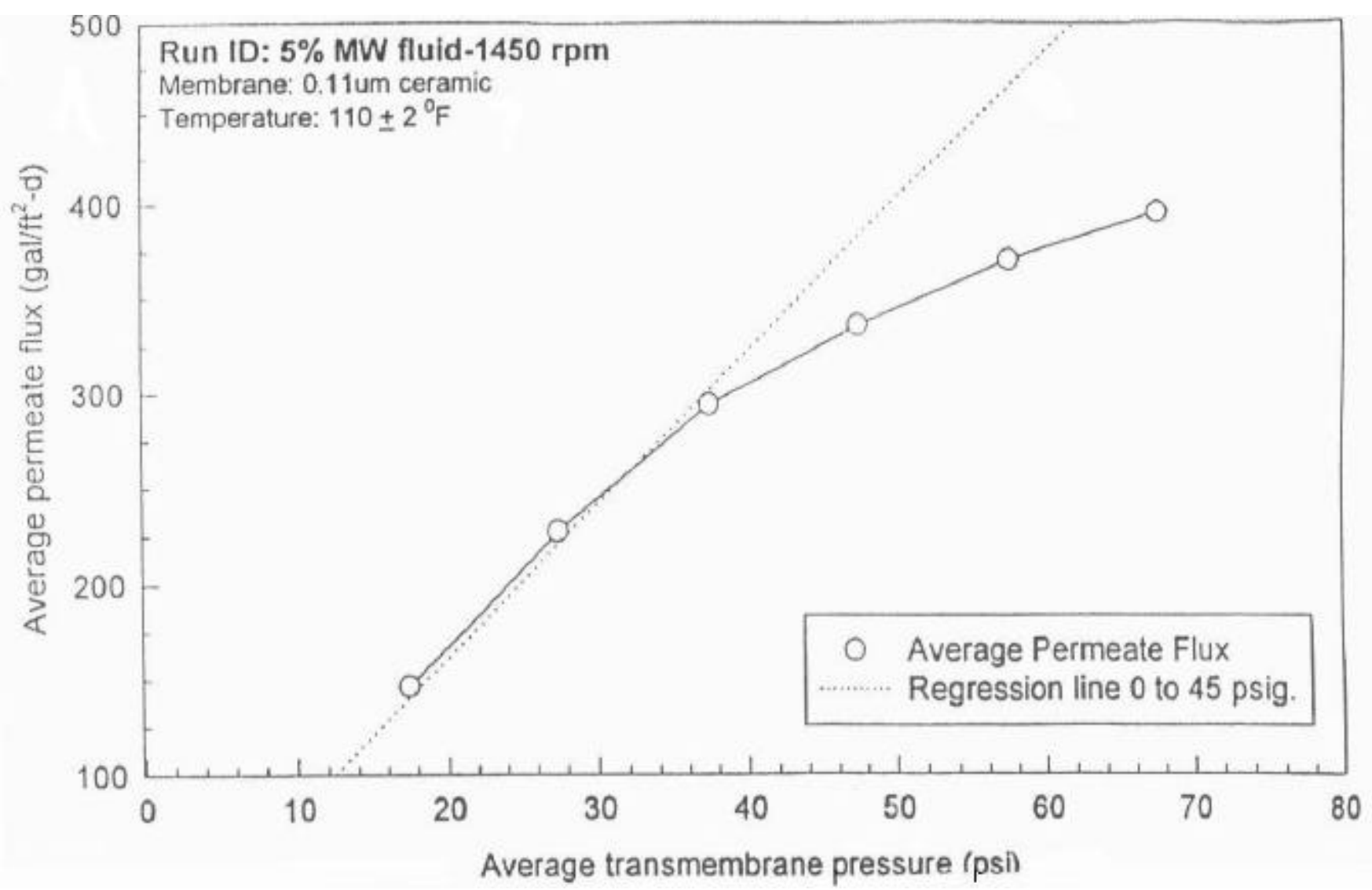

Figure (4.15) - Average Permeate Flux Versus Average Transmembrane Pressure for the 5\%-1,450 rpm Experiment 
$\mathrm{pH}$ decreased over the first $1 \mathrm{hr}$. then remained constant at $\sim 7.6$. Permeate $\mathrm{pH}$ was greater than concentrate $\mathrm{pH}$ throughout this experiment. The permeate conductivity ranged from 123 to $140 \mu \mathrm{S} / \mathrm{cm}$ and averaged $126 \mu \mathrm{S} / \mathrm{cm}$. The concentrate conductivity ranged from 165 to $200 \mu \mathrm{S} / \mathrm{cm}$ and averaged $188 \mu \mathrm{S} / \mathrm{cm}$. Permeate and concentrate conductivity were constant throughout this experiment. Distinct step-wise changes in permeate and concentrate $\mathrm{pH}$ and conductivity were not observed as applied pressure was increased.

The membrane was cleaned using the standardized cleaning procedure discussed in Chapter 3. No oil was visible on the membrane surface after cleaning. The $\mathrm{pH}$ and conductivity of the distilled water used to determine the membrane resistance after cleaning were 7.16 and $6.88 \mu \mathrm{S} / \mathrm{cm}$, respectively. A plot of the average permeate flux versus average transmembrane pressure for the 5\% MW Fluid-1,450 rpm clean water flux

experiment is presented in Figure (4.16). The resistance of the membrane was $1.55 \times 10^{12}$ $\mathrm{m}^{-1}$.

\section{5\% MW Fluid-1,150 rpm}

Permeate flux versus time for the 5\% MW Fluid-1,150 rpm experiment is presented in Figure (4.17). The system was operated over an applied pressure range of 25 to 75 psig. The average permeate backpressure was 4.8 psi for a membrane rotational speed of 1,150 rpm. At each applied pressure condition, permeate flux was observed to increase then drop off to a constant value. Permeate fluxes at the 25 and 35 psig applied pressure conditions were initially steady for $\sim 15 \mathrm{~min}$. at 223 and $302 \mathrm{gal} / \mathrm{ft}^{2}-\mathrm{d}$, 


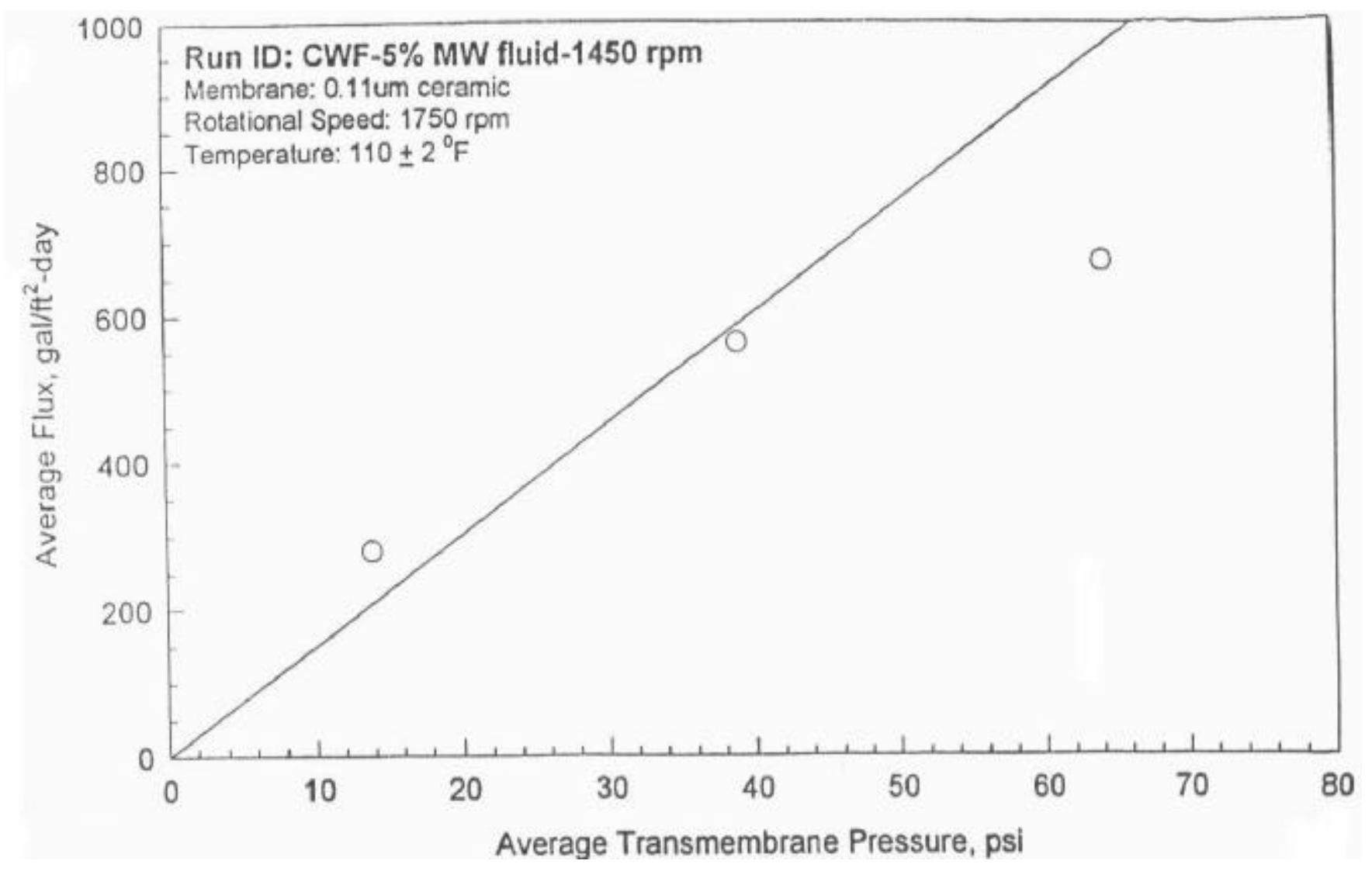

Figure (4.16) - Average Permeate Flux Versus Average Transmembrane Pressure for the 5\%-1,450 rpm Clean Water Flux Experiment 


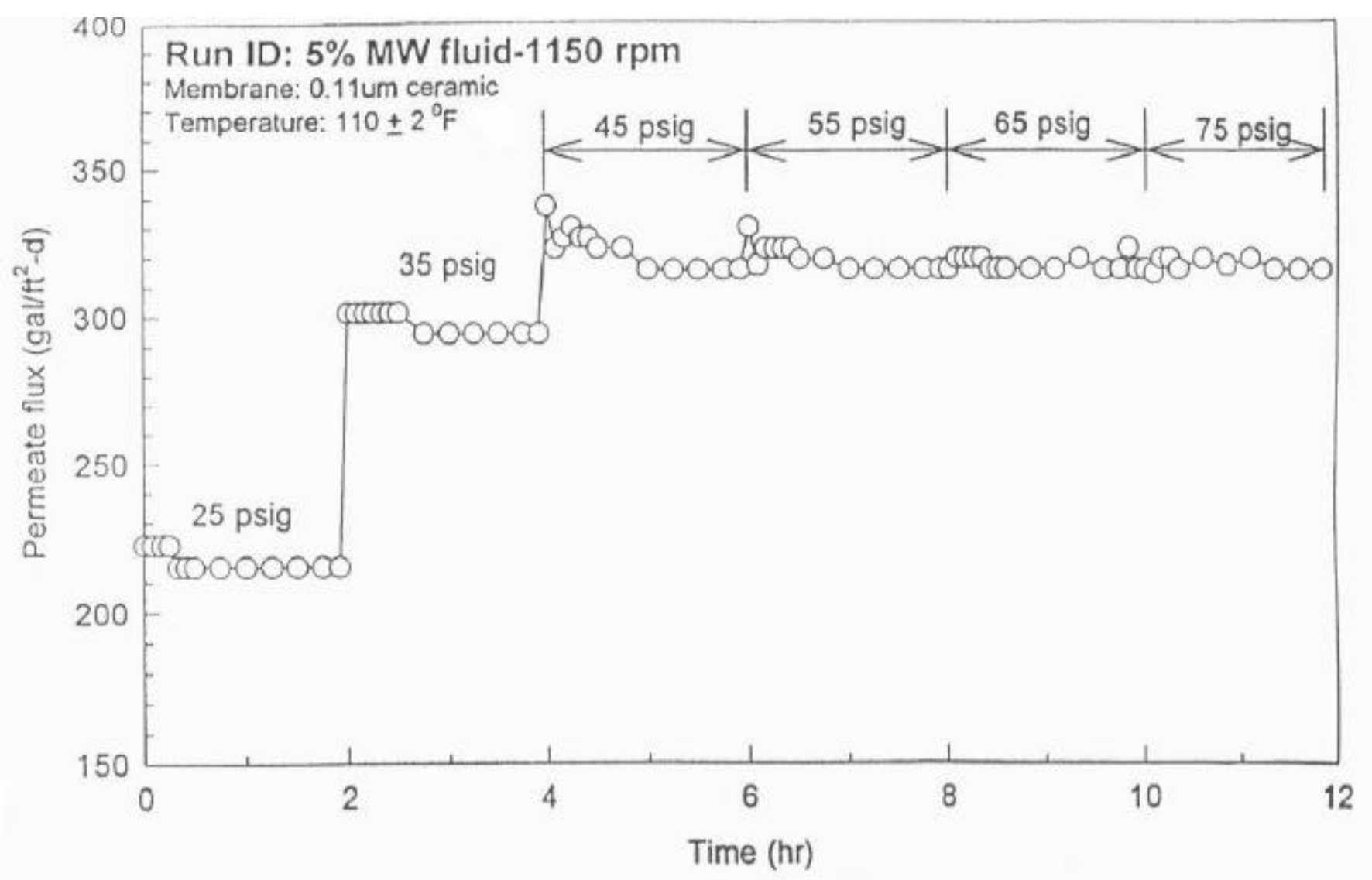

Figure (4.17) - Permeate Flux Versus Time for the 5\%-1,150 rpm Experiment 
respectively. The permeate fluxes at the 25 and 35 psig applied pressure conditions then decreased to constant values of 215 and $294 \mathrm{gal} / \mathrm{ft}^{2}-\mathrm{d}$, respectively. Similar initial increases in permeate flux were observed at the 45 to 75 psig applied pressure condition. However, the initial period of high permeate flux was shorter as the applied pressure was increased. At 65 and 75 psig applied pressure conditions, the initial increase in permeate flux was almost imperceptible. It is hypothesized that the initially higher permeate flux followed by a decrease at each applied pressure was due to the consolidation of the solute boundary layer at the membrane surface. The average permeate flux versus average transmembrane pressure for the 5\% MW Fluid-1,150 rpm experiment is presented in Figure (4.18). A limiting flux of $320 \mathrm{gal} / \mathrm{ft}^{2}-\mathrm{d}$ was observed at the 45 to $75 \mathrm{psig}$ applied pressure conditions. The slope of the linear regression fitted to the pressure-controlled data from 0 to $35 \mathrm{psig}$ was $10.151 \mathrm{gal} / \mathrm{ft}^{2}$-d-psi. The total resistance to hydraulic flow in the pressure-controlled region was $2.32 \times 10^{12} \mathrm{~m}^{-1}$.

The permeate $\mathrm{pH}$ ranged from 7.95 to 8.27 and averaged 8.12. The concentrate $\mathrm{pH}$ ranged from 7.50 to 8.17 and averaged 7.72. Permeate $\mathrm{pH}$ remained constant throughout this experiment. Concentrate $\mathrm{pH}$ decreased over the first $4.5 \mathrm{hr}$. then varied between $\sim 7.5$ and 7.7 through the end of the experiment. Permeate $\mathrm{pH}$ was greater than concentrate $\mathrm{pH}$ throughout this experiment. The permeate conductivity ranged from 99 to $137 \mu \mathrm{S} / \mathrm{cm}$ and averaged $115 \mu \mathrm{S} / \mathrm{cm}$. The concentrate conductivity ranged from 169 to $202 \mu \mathrm{S} / \mathrm{cm}$ and averaged $189 \mu \mathrm{S} / \mathrm{cm}$. Permeate and concentrate conductivity were 


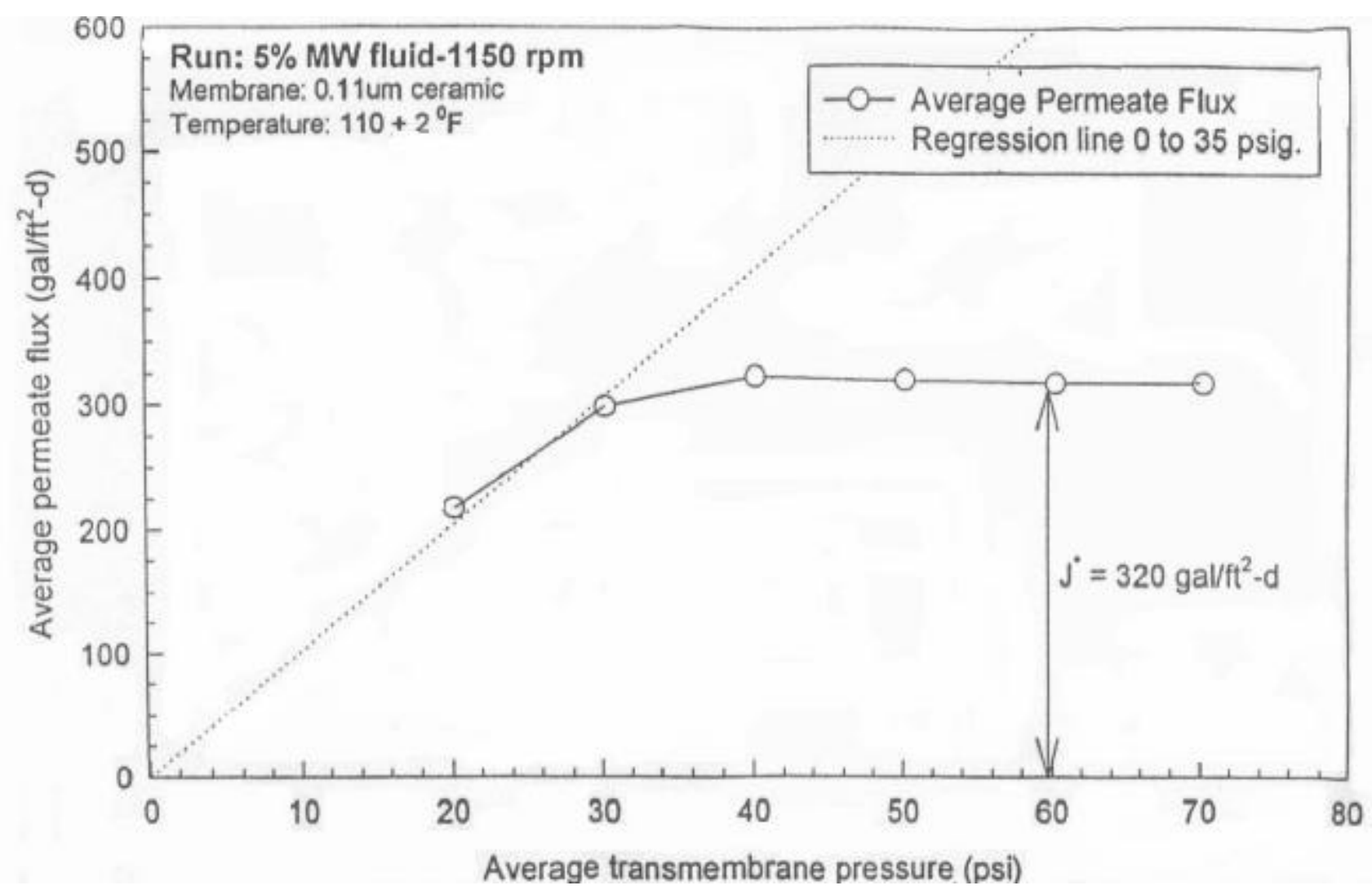

Figure (4.18) - Average Permeate Flux Versus Average Transmembrane Pressure for the 5\%-1,150 rpm Experiment 
constant throughout this experiment. Distinct step-wise changes in permeate and concentrate $\mathrm{pH}$ and conductivity were not observed as applied pressure was increased.

The membrane was cleaned using the standardized cleaning procedure discussed in Chapter 3. No oil was visible on the membrane surface after cleaning. The $\mathrm{pH}$ and conductivity of the distilled water used to determine the membrane resistance after cleaning were 7.27 and $3.79 \mu \mathrm{S} / \mathrm{cm}$, respectively. A plot of the average permeate flux versus average transmembrane pressure for the 5\% MW Fluid-1,150 rpm clean water flux experiment is presented in Figure (4.19). The resistance of the membrane was $1.13 \times 10^{12}$ $\mathrm{m}^{-1}$

\section{$10 \%$ MW Fluid-1,750 rpm}

Permeate flux versus time for the 10\% MW Fluid-1,750 rpm experiment is presented in Figure (4.20). Permeate flux was stable at each applied pressure condition. The system was operated over an applied pressure range of 25 to 75 psig. The average permeate backpressure was $11.1 \mathrm{psi}$ for a membrane rotational speed of $1,750 \mathrm{rpm}$. The average permeate flux versus average transmembrane pressure for the $10 \%$ MW Fluid1,750 rpm experiment is presented in Figure (4.21). A limiting flux of $400 \mathrm{gal} / \mathrm{ft}^{2}-\mathrm{d}$ was observed at the 65 and 75 psig applied pressure conditions. The slope of the regression line fitted to the pressure-controlled data from 0 to $55 \mathrm{psig}$ was $8.302 \mathrm{gal} / \mathrm{ft}^{2}-\mathrm{d}-\mathrm{psi}$. The total resistance to hydraulic flow in the pressure-controlled region was $2.84 \times 10^{12} \mathrm{~m}^{-1}$.

The permeate $\mathrm{pH}$ ranged from 7.97 to 8.28 and averaged 8.05. The concentrate $\mathrm{pH}$ ranged from 7.31 to 7.78 and averaged 7.52. Permeate and concentrate $\mathrm{pH}$ was 


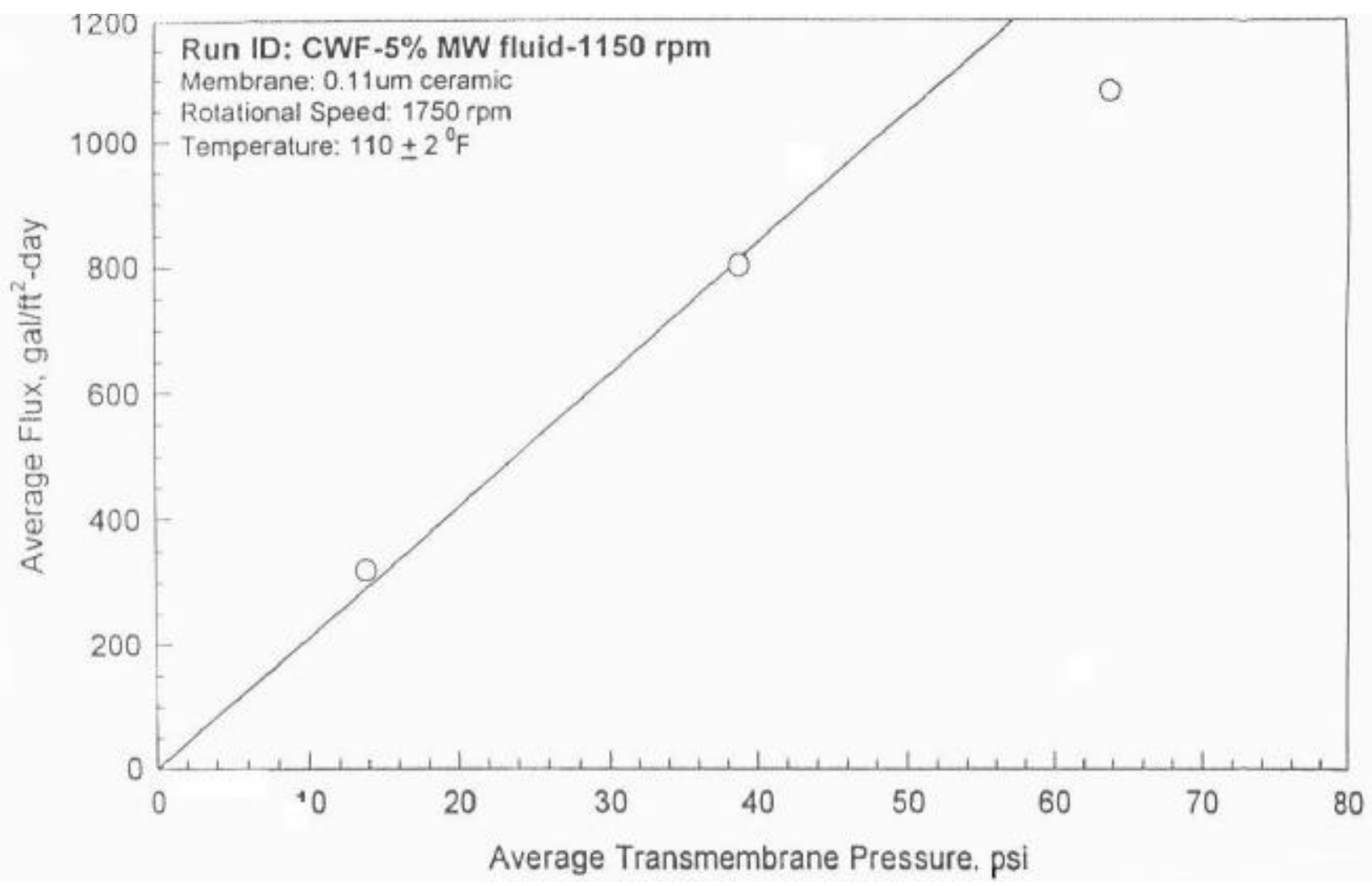

Figure (4.19) - Average Permeate Flux Versus Average Transmembrane Pressure for the 5\%-1,150 rpm Clean Water Experiment 


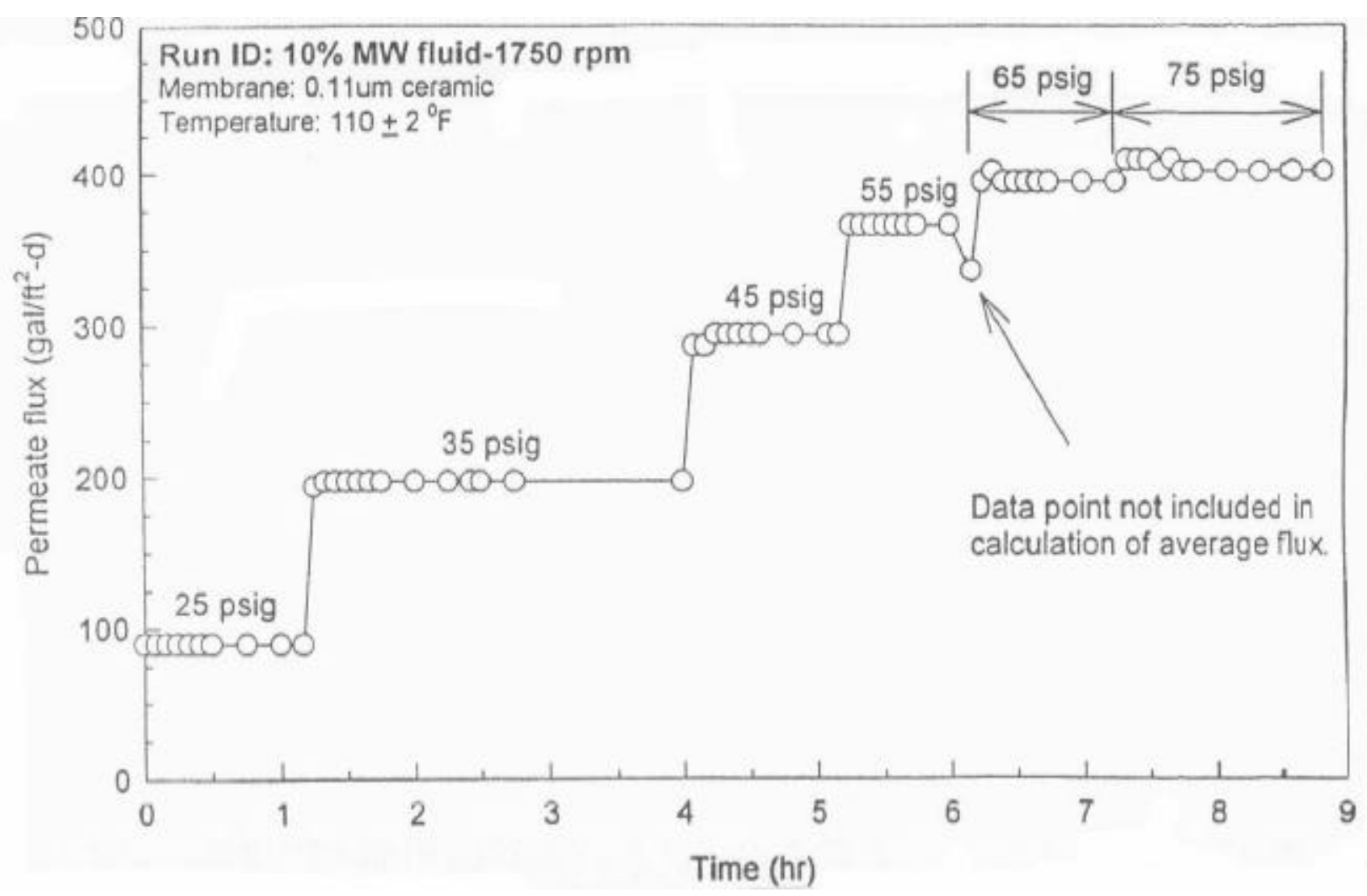

Figure (4.20) - Permeate Flux Versus Time for the 10\%-1,750 rpm Experiment 


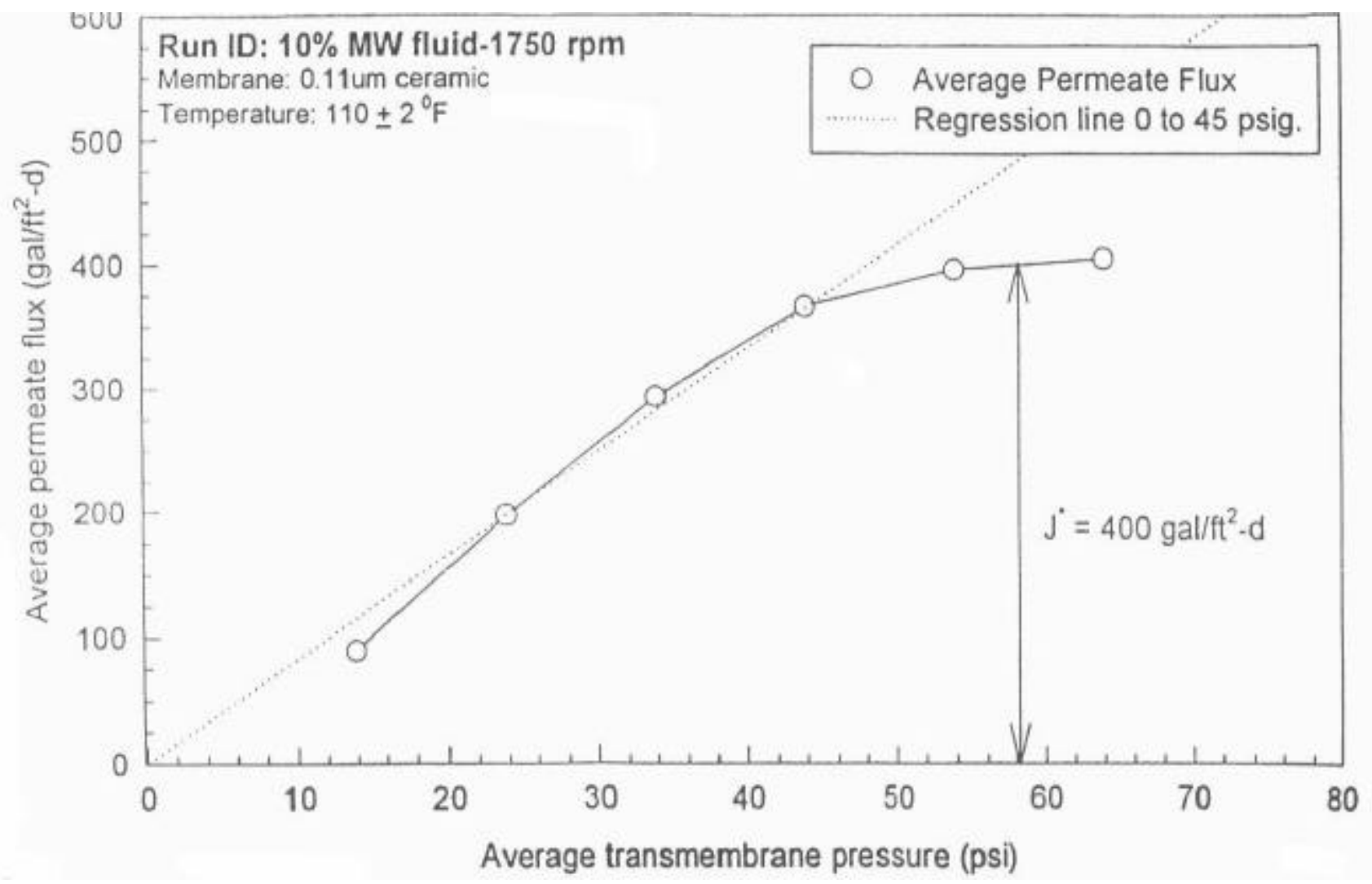

Figure (4.21) - Average Permeate Flux Versus Average Transmembrane Pressure for the 10\%-1,750 rpm Experiment 
constant and the permeate $\mathrm{pH}$ was greater than the concentrate $\mathrm{pH}$ throughout the $10 \%$ MW Fluid-1,750 rpm experiment. The permeate conductivity ranged from 245 to 291 $\mu \mathrm{S} / \mathrm{cm}$ and averaged $272 \mu \mathrm{S} / \mathrm{cm}$. The concentrate conductivity ranged from 242 to 343 $\mu \mathrm{S} / \mathrm{cm}$ and averaged $299 \mu \mathrm{S} / \mathrm{cm}$. Permeate conductivity was constant. A net increase in concentrate conductivity was observed. Permeate conductivity was greater than concentrate conductivity through $\sim 3.5 \mathrm{hr}$. then concentrate conductivity exceeded permeate conductivity through the end of the experiment. Distinct step-wise changes in permeate and concentrate $\mathrm{pH}$ and conductivity were not observed as applied pressure was increased.

The membrane was cleaned using the standardized cleaning procedure discussed in Chapter 3. No oil was visible on the membrane surface after cleaning. The $\mathrm{pH}$ and conductivity of the distilled water used to determine the membrane resistance after cleaning were 7.25 and $5.15 \mu \mathrm{S} / \mathrm{cm}$, respectively. A plot of the average permeate flux versus average transmembrane pressure for the 10\% MW Fluid-1,750 rpm clean water flux experiment is presented in Figure (4.22). The resistance of the membrane was $2.22 \times 10^{12} \mathrm{~m}^{-1}$.

\section{$10 \%$ MW Fluid-1,450 rpm}

Permeate flux versus time for the 10\% MW Fluid-1,450 rpm experiment is presented in Figure (4.23). Permeate flux was stable at each applied pressure condition. The system was operated over an applied pressure range of 25 to 75 psig. The average 


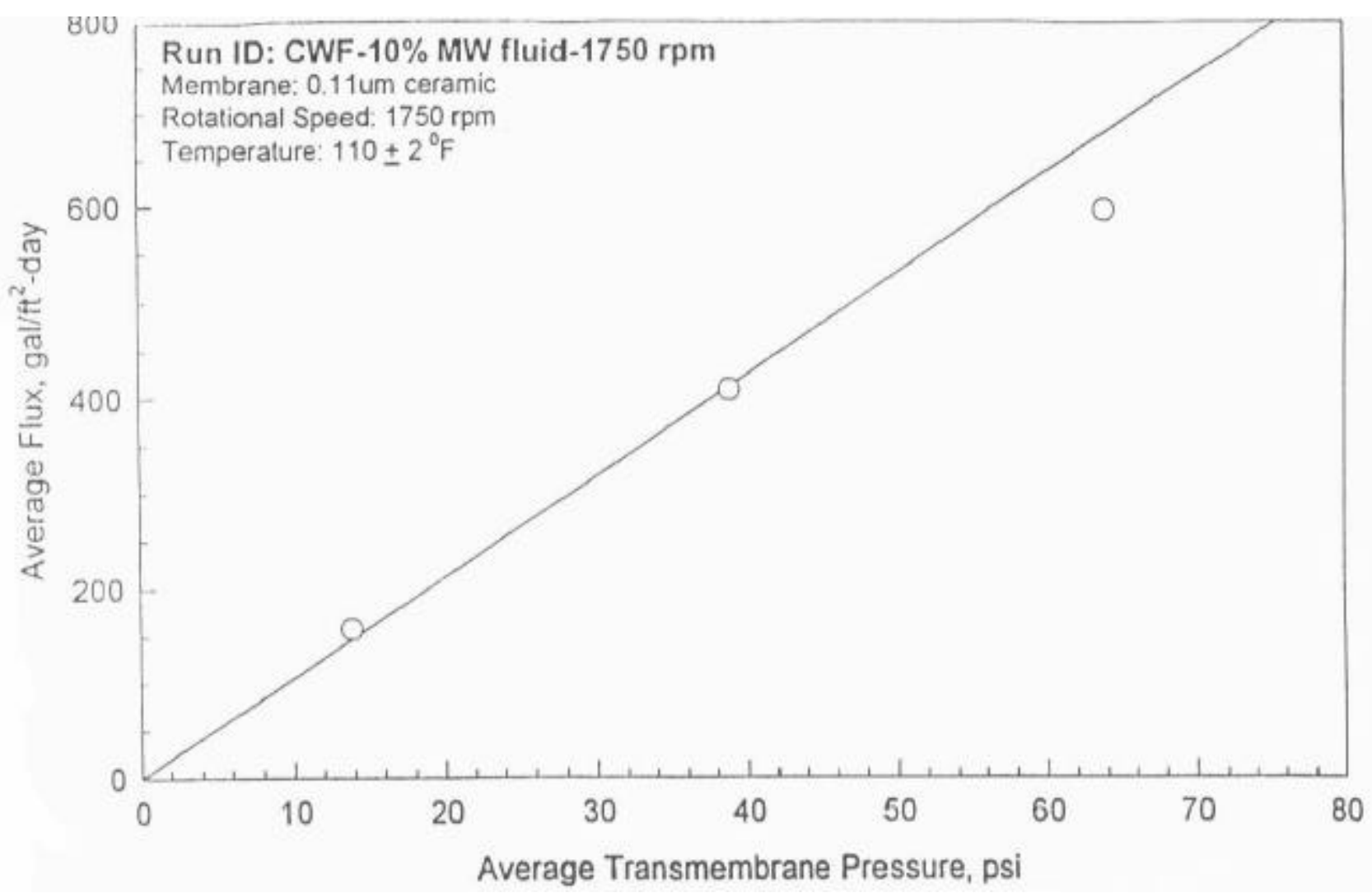

Figure (4.22) - Average Permeate Flux Versus Average Transmembrane Pressure for the 10\%-1,750 rpm Clean Water Flux Experiment 


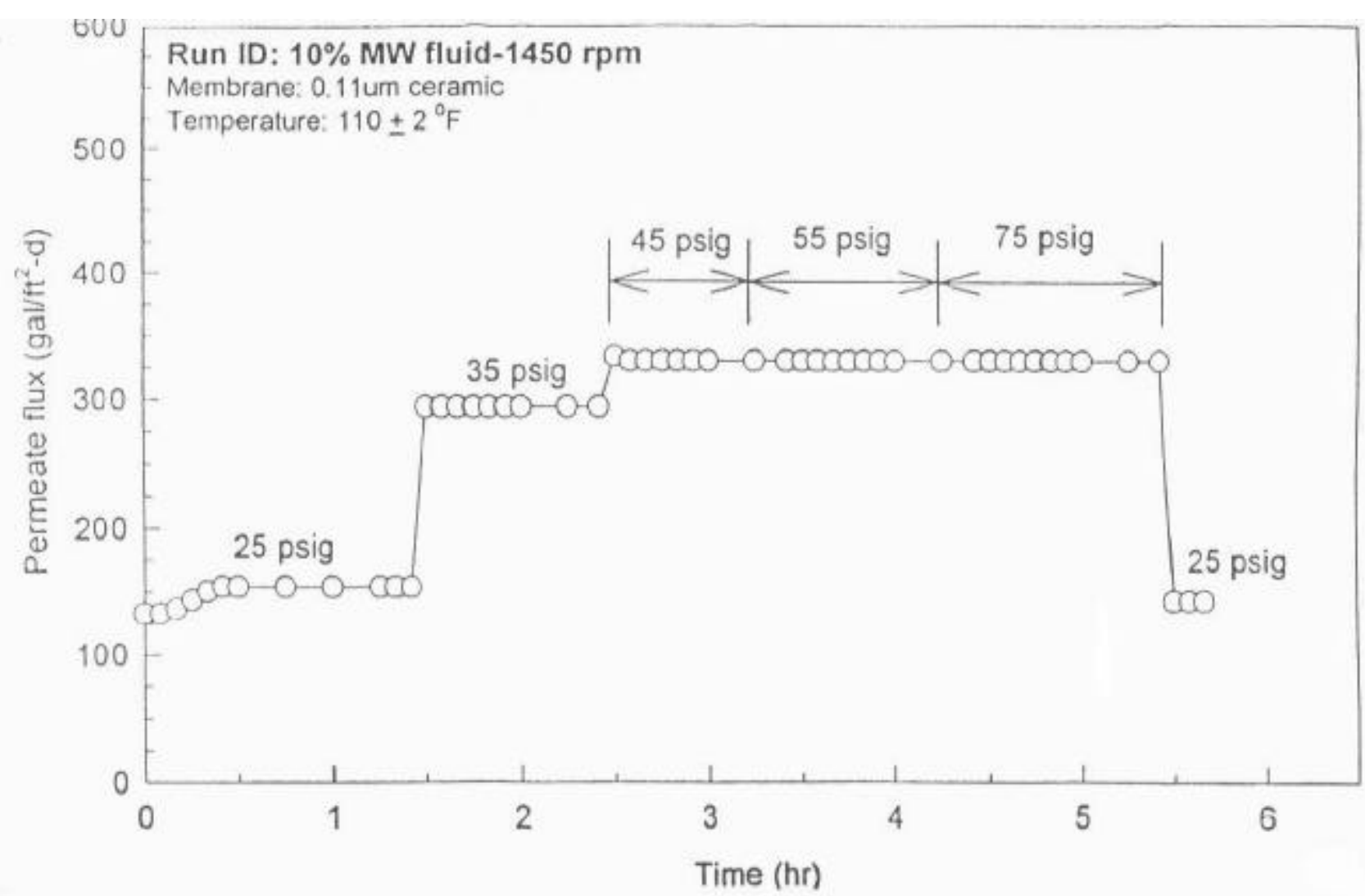

Figure (4.23) - Permeate Flux Versus Time for the 10\%-1,450 rpm Experiment 
permeate backpressure was 7.6 psi for a membrane rotational speed of 1,450 rpm. Due to operational problems with the feed pump, it was not possible to maintain a steady applied pressure at $65 \mathrm{psig}$. The permeate flux was $144 \mathrm{gal} / \mathrm{ft}^{2}-\mathrm{d}$ when the $25 \mathrm{psig}$ applied pressure condition was re-investigated after limiting permeate flux was determined. The initial permeate flux at the initial $25 \mathrm{psig}$ condition was $154 \mathrm{gal} / \mathrm{ft}^{2}-\mathrm{d}$. It is hypothesized that the lower permeate flux at the second 25 psig condition because either the membrane pores were plugged at higher applied pressures or solute molecules were adsorbed on the membrane surface. The average permeate flux versus average transmembrane pressure for the 10\% MW Fluid-1,450 rpm experiment is presented in Figure (4.24). A limiting flux of $330 \mathrm{gal} / \mathrm{ft}^{2}-\mathrm{d}$ was observed at the 45 to 75 psig applied pressure conditions. The slope of the regression line fitted to the pressure-controlled data from 0 to 35 psig was $10.177 \mathrm{gal} / \mathrm{ft}^{2}$-d-psi. The total resistance to hydraulic flow in the pressure-controlled region was $2.31 \times 10^{12} \mathrm{~m}^{-1}$.

The permeate $\mathrm{pH}$ ranged from 7.98 to 8.24 and averaged 8.08. The concentrate $\mathrm{pH}$ ranged from 7.51 to 7.83 and averaged 7.69. Permeate and concentrate $\mathrm{pH}$ were constant. Permeate $\mathrm{pH}$ was greater than concentrate $\mathrm{pH}$ throughout the $10 \% \mathrm{MW}$ Fluid$1,450 \mathrm{rpm}$ experiment. Permeate conductivity ranged from 240 to $301 \mu \mathrm{S} / \mathrm{cm}$ and averaged $274 \mu \mathrm{S} / \mathrm{cm}$. Concentrate conductivity ranged from 261 to $331 \mu \mathrm{S} / \mathrm{cm}$ and averaged $305 \mu \mathrm{S} / \mathrm{cm}$. A net decrease in permeate conductivity and a net increase in concentrate conductivity were observed. Permeate conductivity was greater than 


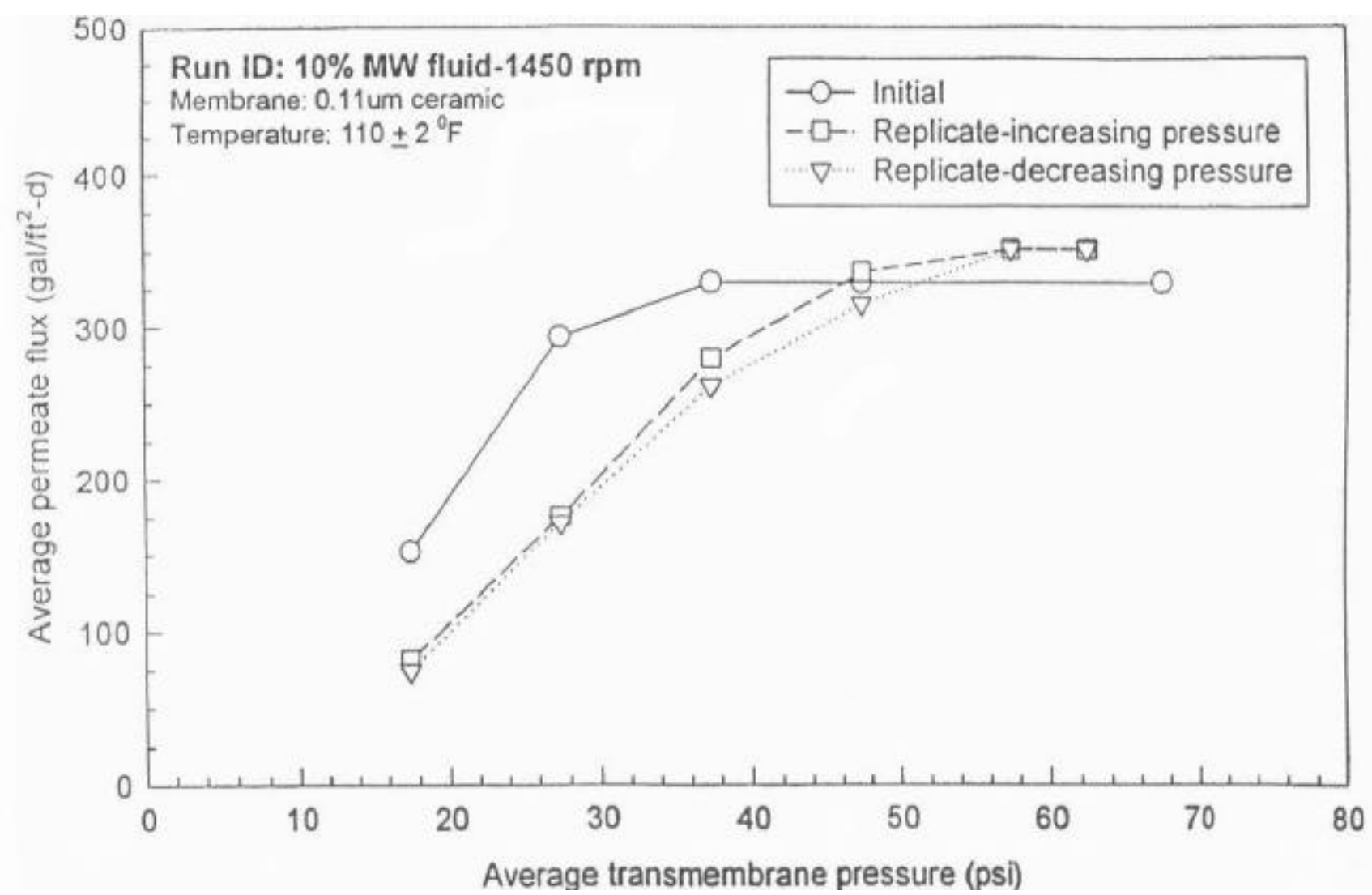

Figure (4.24) - Average Permeate Flux Versus Average Transmembrane Pressure for the 10\%-1,450 rpm Experiment 
concentrate conductivity through $\sim 2 \mathrm{hr}$. The concentrate conductivity then exceeded permeate conductivity. The increase in concentrate conductivity occurred approximately in the middle of the 35 psig applied pressure condition and continued through $\sim 3.5 \mathrm{hr}$. when the concentrate conductivity reached a constant value of $331 \mu \mathrm{S} / \mathrm{cm}$. Distinct stepwise changes in permeate and concentrate $\mathrm{pH}$ and conductivity were not observed as applied pressure was increased.

The membrane was cleaned using the standardized cleaning procedure discussed in Chapter 3. No oil was visible on the membrane surface after cleaning. The $\mathrm{pH}$ and conductivity of the distilled water used to determine the membrane resistance after cleaning were 6.69 and $4.24 \mu \mathrm{S} / \mathrm{cm}$, respectively. A plot of the average permeate flux versus average transmembrane pressure for the 10\% MW Fluid-1,450 rpm clean water flux experiment is presented in Figure (4.25). The resistance of the membrane was $2.51 \times 10^{12} \mathrm{~m}^{-1}$

\section{$10 \%$ MW Fluid-1,150 rpm}

Permeate flux versus time for the $10 \%$ MW Fluid-1,150 rpm experiment is presented in Figure (4.26). Permeate flux was stable at each applied pressure condition. The system was operated over an applied pressure range of 25 to 75 psig. The average permeate backpressure was 4.8 psi for a membrane rotational speed of $1,150 \mathrm{rpm}$. Due to operational problems with the feed pump, it was not possible to maintain a steady applied pressure at $65 \mathrm{psig}$. The permeate flux was $86 \mathrm{gal} / \mathrm{ft}^{2}-\mathrm{d}$ when the $25 \mathrm{psig}$ applied pressure condition was re-investigated after the limiting permeate flux was determined. The initial 


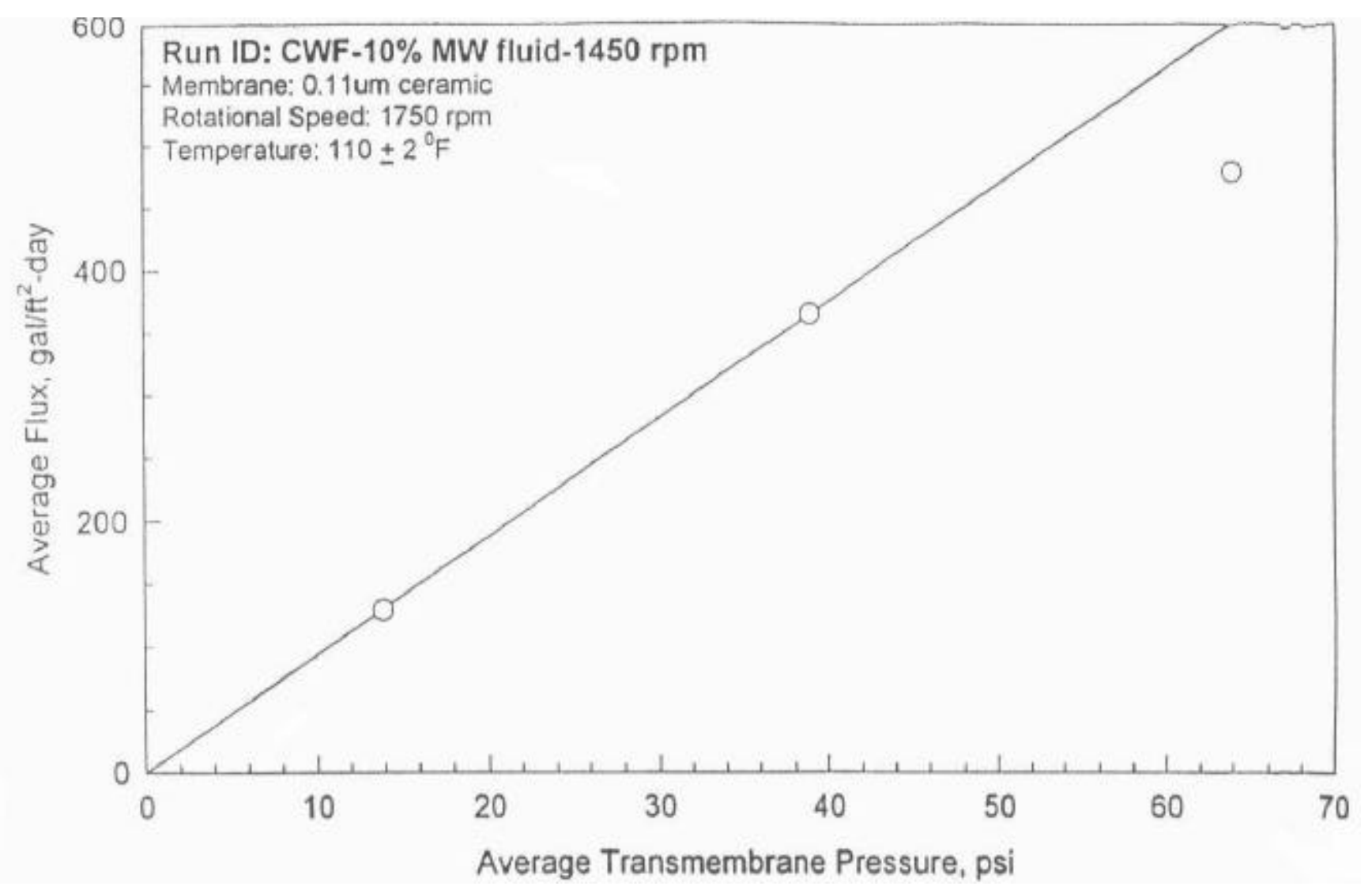

Figure (4.25) - Average Permeate Flux Versus Average Transmembrane Pressure for the 10\%-1,450 rpm Clean Water Flux Experiment 


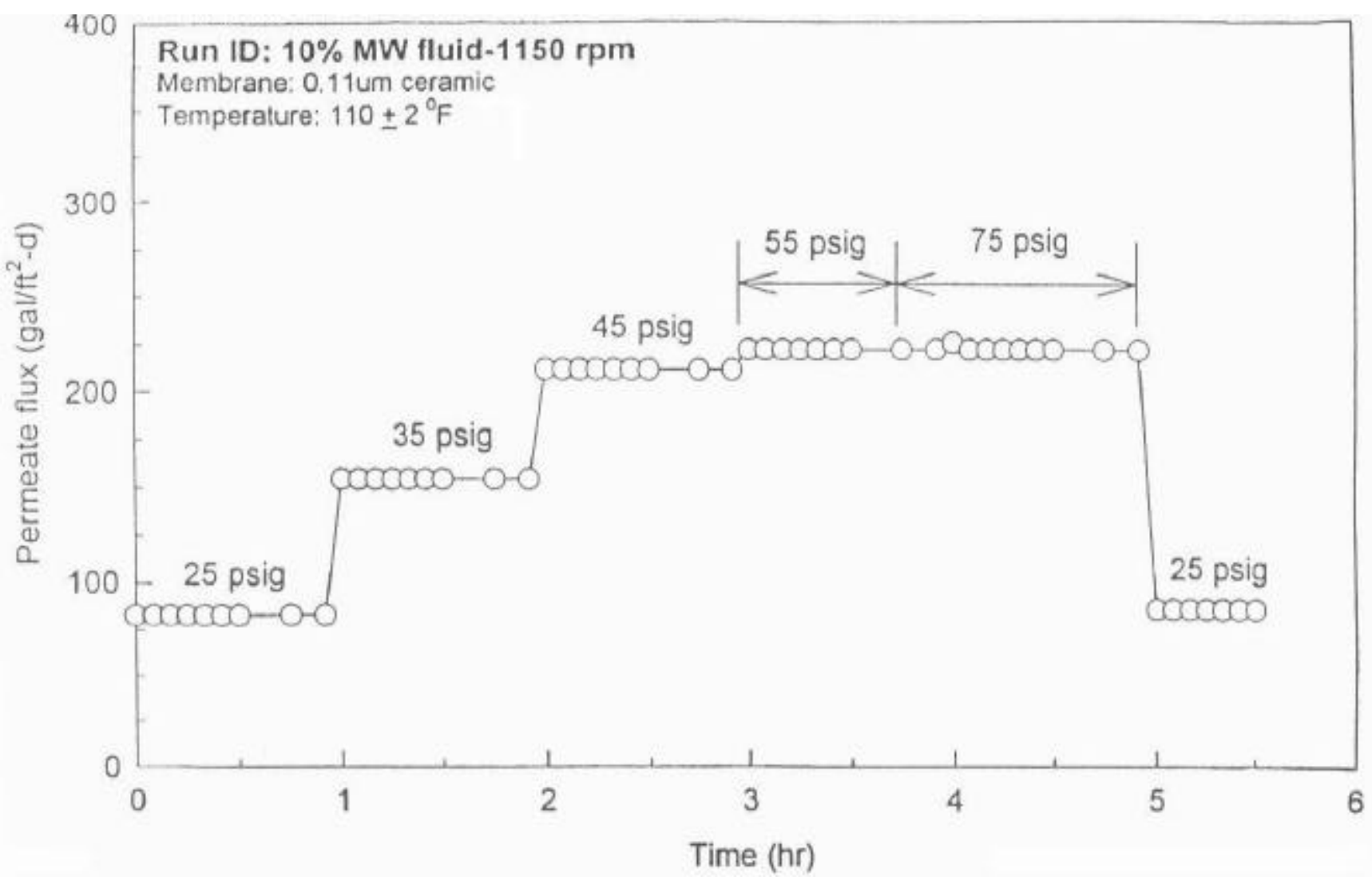

Figure (4.26) - Permeate Flux Versus Time for the 10\%-1,150 rpm Experiment 
permeate flux at the initial $25 \mathrm{psig}$ condition was $83 \mathrm{gal} / \mathrm{ft}^{2}-\mathrm{d}$. The average permeate flux versus average transmembrane pressure for the 10\% MW Fluid-1,150 rpm experiment is presented in Figure (4.27). A limiting flux of $223 \mathrm{gal} / \mathrm{ft}^{2}-\mathrm{d}$ was observed at the 55 to 75 psig applied pressure conditions. The slope of the regression line fitted to the pressurecontrolled data from 0 to $45 \mathrm{psig}$ was $4.793 \mathrm{gal} / \mathrm{ft}^{2}$-d-psi. The total resistance to hydraulic flow in the pressure-controlled region was $4.91 \times 10^{12} \mathrm{~m}^{-1}$.

The permeate $\mathrm{pH}$ ranged from 7.85 to 8.34 and averaged 8.02. The concentrate $\mathrm{pH}$ ranged from 7.46 to 7.97 and averaged 7.64. A net decrease in both permeate and concentrate $\mathrm{pH}$ was observed. The permeate $\mathrm{pH}$ was greater than the concentrate $\mathrm{pH}$ throughout this experiment. The permeate conductivity ranged from 230 to $282 \mu \mathrm{S} / \mathrm{cm}$ and averaged $262 \mu \mathrm{S} / \mathrm{cm}$. The concentrate conductivity ranged from 245 to $333 \mu \mathrm{S} / \mathrm{cm}$ and averaged $300 \mu \mathrm{S} / \mathrm{cm}$. A net decrease in permeate conductivity and a net increase in concentrate conductivity were observed. Permeate conductivity was greater than concentrate conductivity through $\sim 1.25 \mathrm{hr}$. (in the middle of the $35 \mathrm{psig}$ condition). Concentrate conductivity then exceeded permeate conductivity through the end of this experiment. Distinct step-wise changes in permeate and concentrate $\mathrm{pH}$ and conductivity were not observed as applied pressure was increased.

The membrane was cleaned using the standardized cleaning procedure discussed in Chapter 3. No oil was visible on the membrane surface after cleaning. The $\mathrm{pH}$ and conductivity of the distilled water used to determine the membrane resistance after 


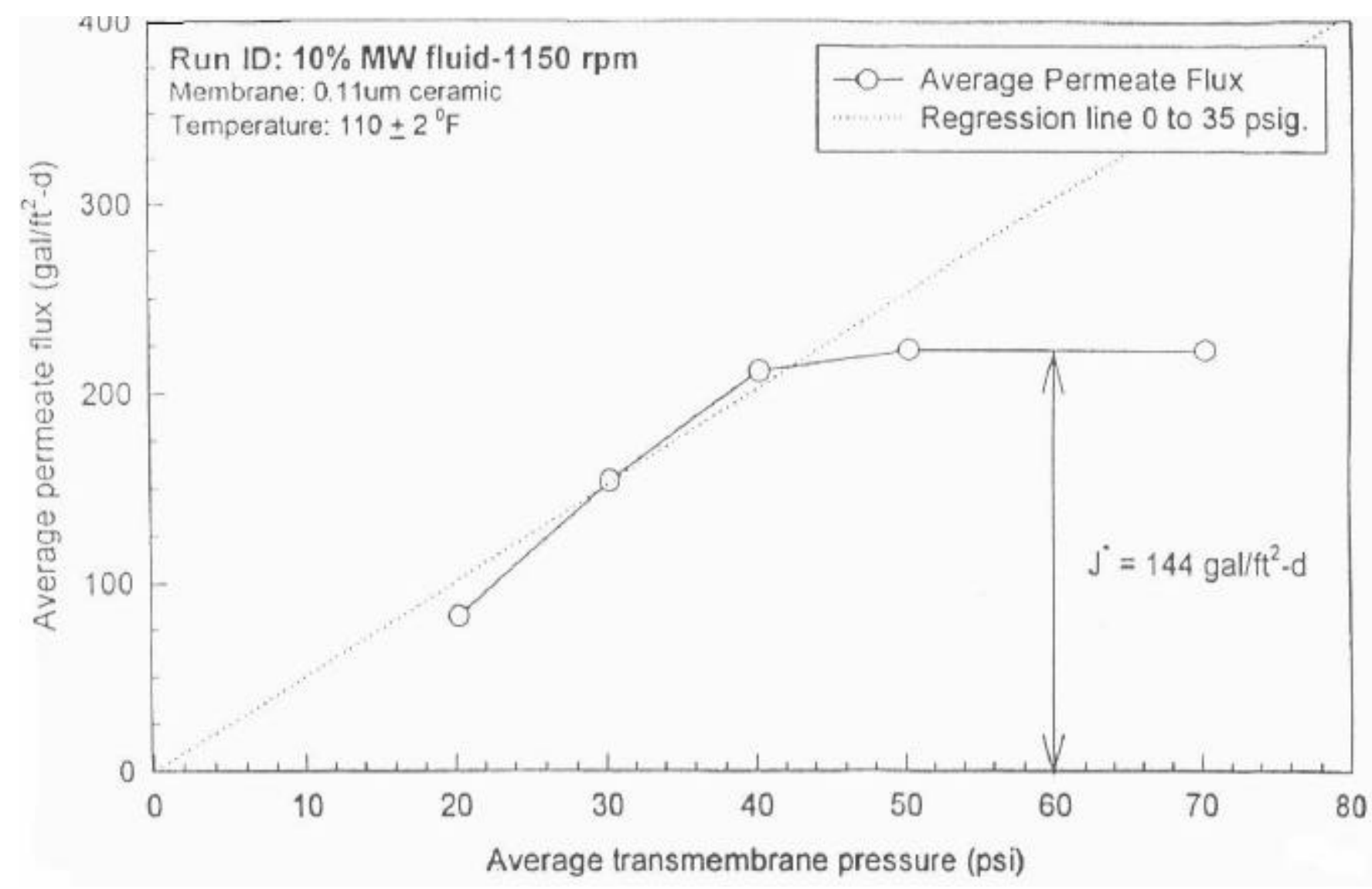

Figure (4.27) - Average Permeate Flux Versus Average Transmembrane Pressure for the 10\%-1,150 rpm Experiment 
cleaning were 7.15 and $4.04 \mu \mathrm{S} / \mathrm{cm}$, respectively. A plot of the average permeate flux versus average transmembrane pressure for the $10 \%$ MW Fluid-1,150 rpm clean water flux experiment is presented in Figure (4.28). The resistance of the membrane was $1.51 \times 10^{12} \mathrm{~m}^{-1}$.

\section{5\% MW Fluid-1,750 rpm}

Permeate flux versus time for the $15 \%$ MW Fluid-1,750 rpm experiment is presented in Figure (4.29). Permeate flux was stable at each applied pressure condition. The system was operated over an applied pressure range of 20 to 70 psig. The average permeate backpressure was $11.1 \mathrm{psi}$ for a membrane rotational speed of 1,750 rpm. The permeate flux was $90 \mathrm{gal} / \mathrm{ft}^{2}-\mathrm{d}$ when the $25 \mathrm{psig}$ applied pressure condition was reinvestigated after the limiting permeate flux was determined. The permeate flux at the initial $25 \mathrm{psig}$ condition was $61 \mathrm{gal} / \mathrm{ft}^{2}-\mathrm{d}$. It is hypothesized that the higher "rebound" flux was due to the effects of membrane-induced turbulence effectively removing solute molecules from the membrane surface when the applied pressure was decreased resulting in a decreased resistance to hydraulic flow of permeate. The average permeate flux versus average transmembrane pressure for the 15\% MW Fluid-1,750 rpm experiment is presented in Figure (4.30). A limiting flux of $305 \mathrm{gal} / \mathrm{ft}^{2}-\mathrm{d}$ was observed at the 65 to 70 psig applied pressure conditions. The slope of the regression line fitted to the pressurecontrolled data from 0 to $55 \mathrm{psig}$ was $6.188 \mathrm{gal} / \mathrm{ft}^{2}$-d-psi. The total resistance to hydraulic flow in the pressure-controlled region was $3.81 \times 10^{12} \mathrm{~m}^{-1}$. 


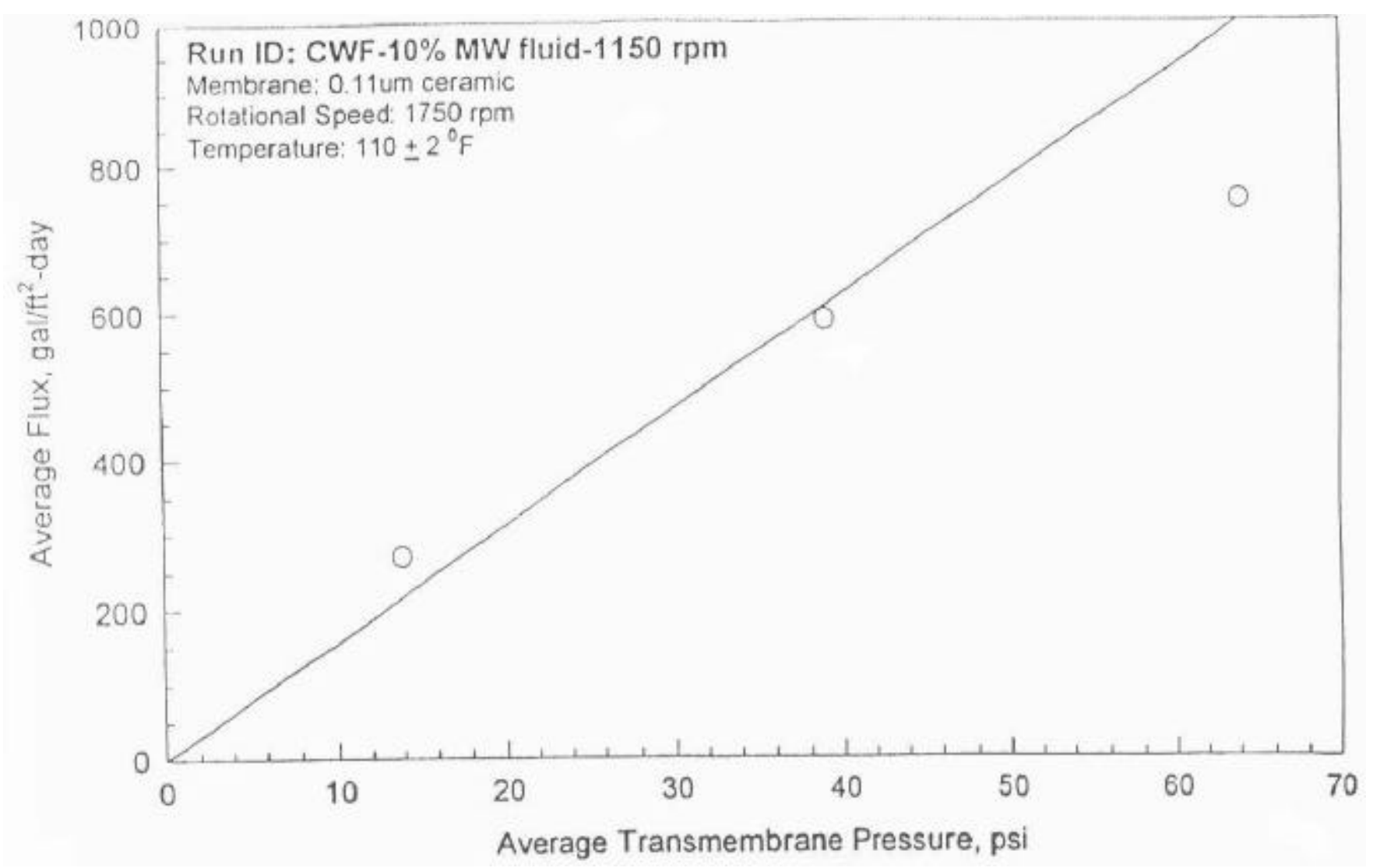

Figure (4.28) - Average Permeate Flux Versus Average Transmembrane Pressure for the 10\%-1,150 rpm Clean Water Experiment 


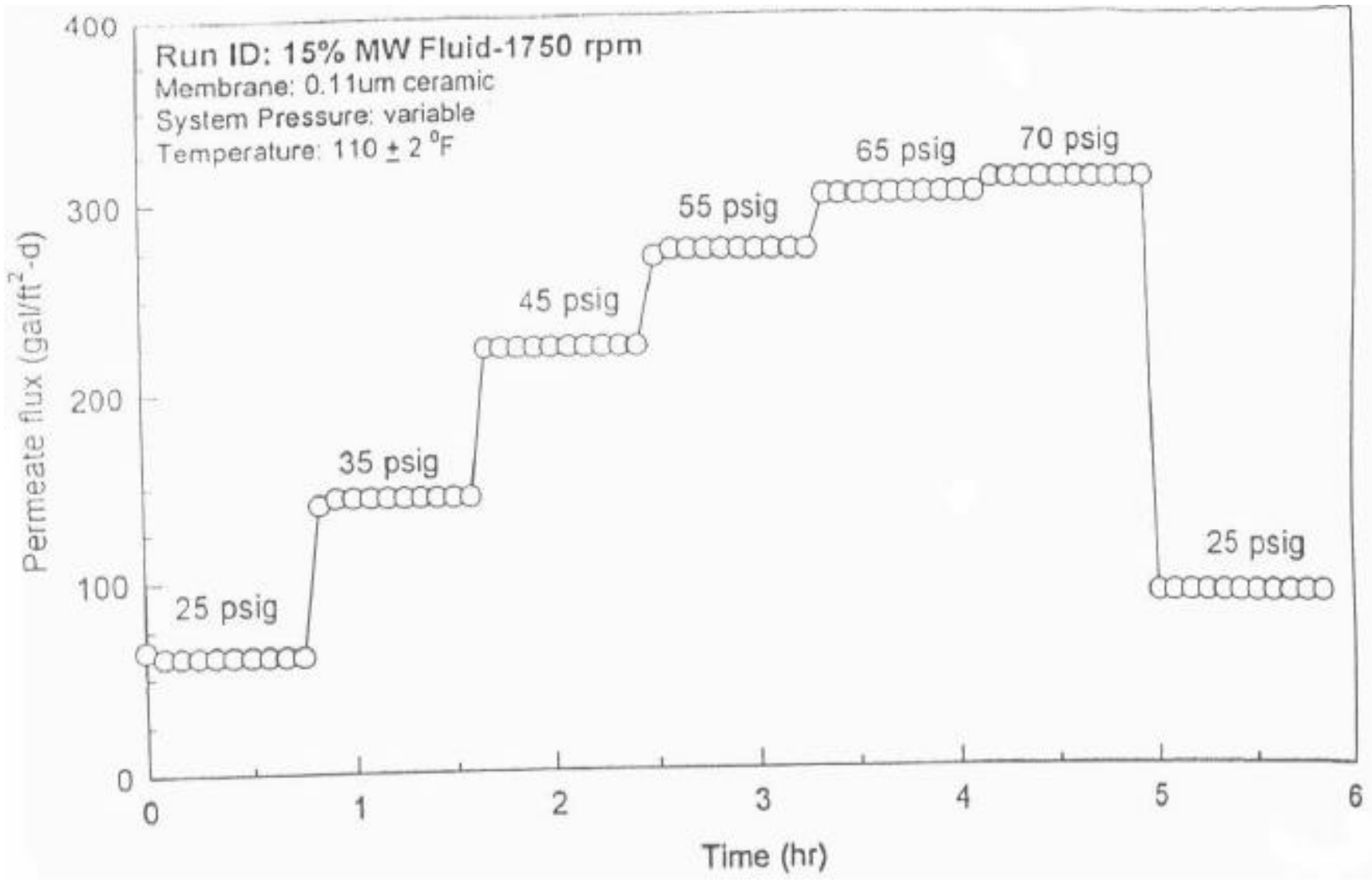

Figure (4.29) - Permeate Flux Versus Time for the 15\%-1,750 rpm Experiment 


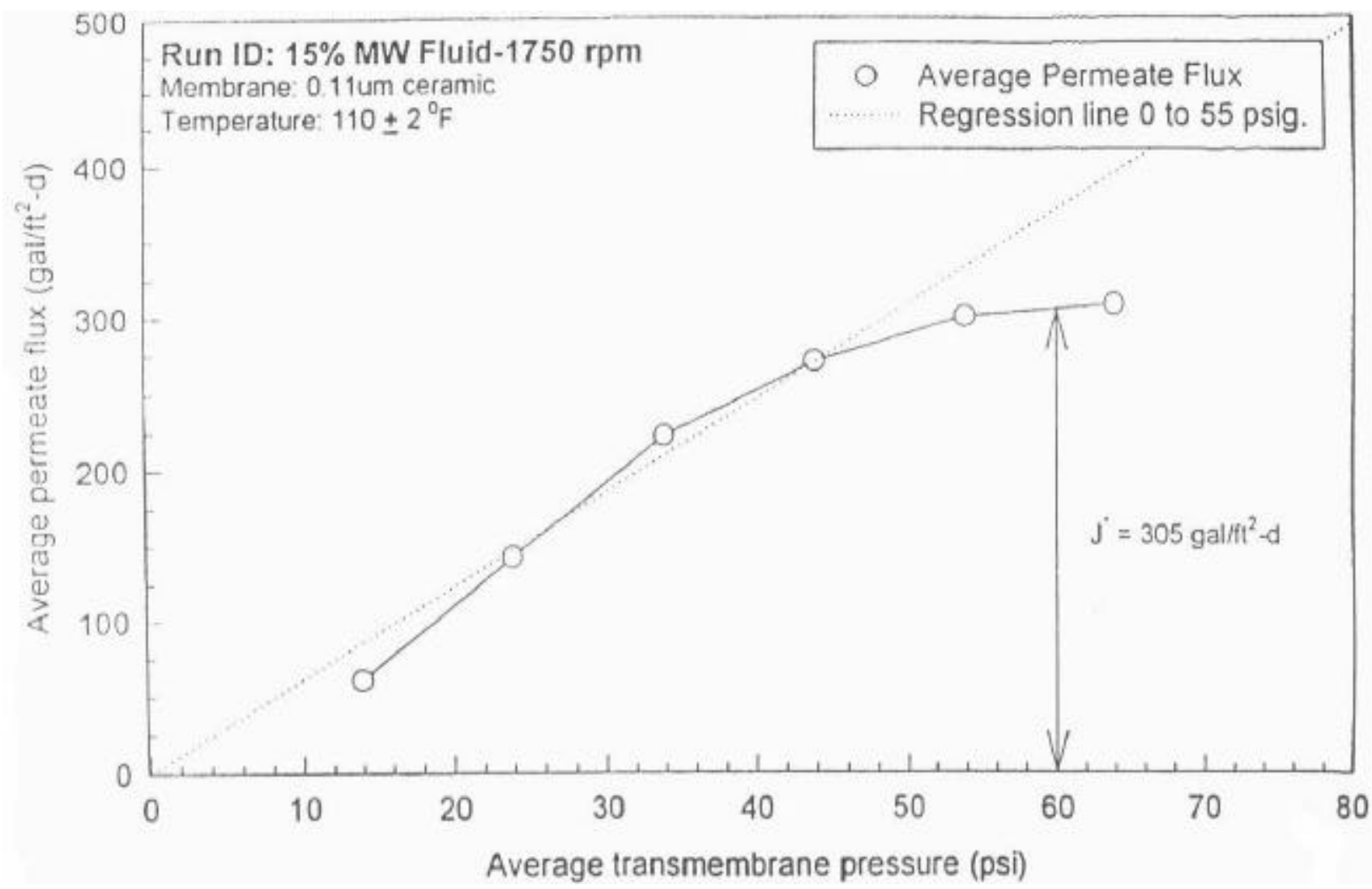

Figure (4.30) - Average Permeate Flux Versus Average Transmembrane Pressure for the 15\%-1,750 rpm Experiment 
The permeate $\mathrm{pH}$ ranged from 5.83 to 7.19 and averaged 6.31. The concentrate $\mathrm{pH}$ ranged from 5.95 to 7.36 and averaged 6.34. A net decrease in both permeate and concentrate $\mathrm{pH}$ was observed in this experiment. Permeate and concentrate $\mathrm{pH}$ values were approximately equal and followed the same general trend: Both permeate and concentrate $\mathrm{pH}$ decreased through $\sim 3 \mathrm{hr}$. then increased through the end of the experiment. The permeate conductivity ranged from 362 to $520 \mu \mathrm{S} / \mathrm{cm}$ and averaged 448 $\mu \mathrm{S} / \mathrm{cm}$. The concentrate conductivity ranged from 459 to $564 \mu \mathrm{S} / \mathrm{cm}$ and averaged 534 $\mu \mathrm{S} / \mathrm{cm}$. Permeate conductivity was greater than concentrate conductivity through $\sim 1 \mathrm{hr}$. Concentrate conductivity exceeded permeate conductivity from $\sim 1 \mathrm{hr}$. through the end of the experiment. Distinct step-wise changes in permeate and concentrate $\mathrm{pH}$ and conductivity were not observed as applied pressure was increased.

The membrane was cleaned using the standardized cleaning procedure discussed in Chapter 3. No oil was visible on the membrane surface after cleaning. The $\mathrm{pH}$ and conductivity of the distilled water used to determine the membrane resistance after cleaning were 6.93 and $3.84 \mu \mathrm{S} / \mathrm{cm}$, respectively. A plot of the average permeate flux versus average transmembrane pressure for the $15 \%$ MW Fluid-1,750 rpm clean water flux experiment is presented in Figure (4.31). The resistance of the membrane was $1.76 \times 10^{12} \mathrm{~m}^{-1}$. 


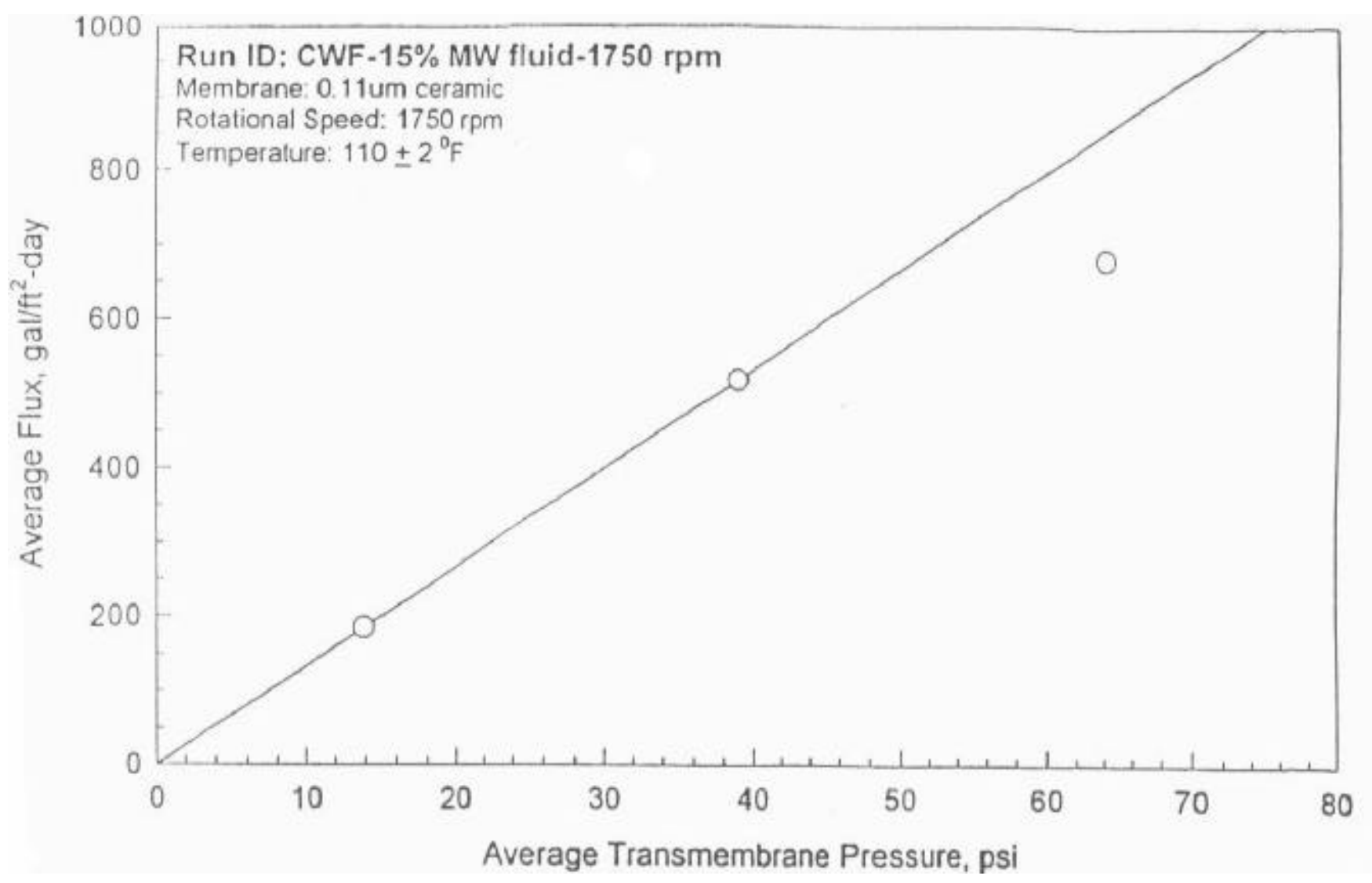

Figure (4.31) - Average Permeate Flux Versus Average Transmembrane Pressure for the 15\%-1,750 rpm Clean Water Flux Experiment 


\section{5\% MW Fluid-1,450 rpm}

Permeate flux versus time for the $15 \%$ MW Fluid-1,450 rpm experiment is presented in Figure (4.32). Permeate flux was stable at each applied pressure condition. The system was operated over an applied pressure range of 25 to 70 psig. The average permeate backpressure was 7.6 psi for a membrane rotational speed of $1,450 \mathrm{rpm}$. The permeate flux was $107 \mathrm{gal} / \mathrm{ft}^{2}-\mathrm{d}$ when the $25 \mathrm{psig}$ applied pressure condition was reinvestigated after the limiting permeate flux was determined. The permeate flux at the initial 25 psig condition was also $107 \mathrm{gal} / \mathrm{ft}^{2}-\mathrm{d}$. It is hypothesized that the solute boundary layer returned to its initial thickness when the applied pressure was decreased to 25 psig and that solute molecules were not forced into the membrane pores and were not adsorbed onto the membrane surface. The average permeate flux versus average transmembrane pressure for the $15 \%$ MW Fluid-1,450 rpm experiment is presented in Figure (4.33). A limiting flux of $266 \mathrm{gal} / \mathrm{ft}^{2}-\mathrm{d}$ was observed at the 55 to $70 \mathrm{psig}$ applied pressure conditions. The slope of the regression line fitted to the pressure-controlled data from 0 to $45 \mathrm{psig}$ was $6.940 \mathrm{gal} / \mathrm{ft}^{2}-\mathrm{d}-\mathrm{psi}$. The total resistance to hydraulic flow in the pressure-controlled region was $3.39 \times 10^{12} \mathrm{~m}^{-1}$.

The permeate $\mathrm{pH}$ ranged from 6.10 to 6.58 and averaged 6.30 . The concentrate $\mathrm{pH}$ ranged from 6.10 to 7.01 and averaged 6.30. The permeate and concentrate $\mathrm{pH}$ were approximately equal in this experiment and followed the same general trend: A decrease in both permeate and concentrate $\mathrm{pH}$ was observed through the first $1 \mathrm{hr}$. then the permeate and concentrate $\mathrm{pH}$ then remained constant at $\sim 6.30$ from $1 \mathrm{hr}$. through the end of the experiment. The permeate conductivity ranged from 348 to $534 \mu \mathrm{S} / \mathrm{cm}$ and 


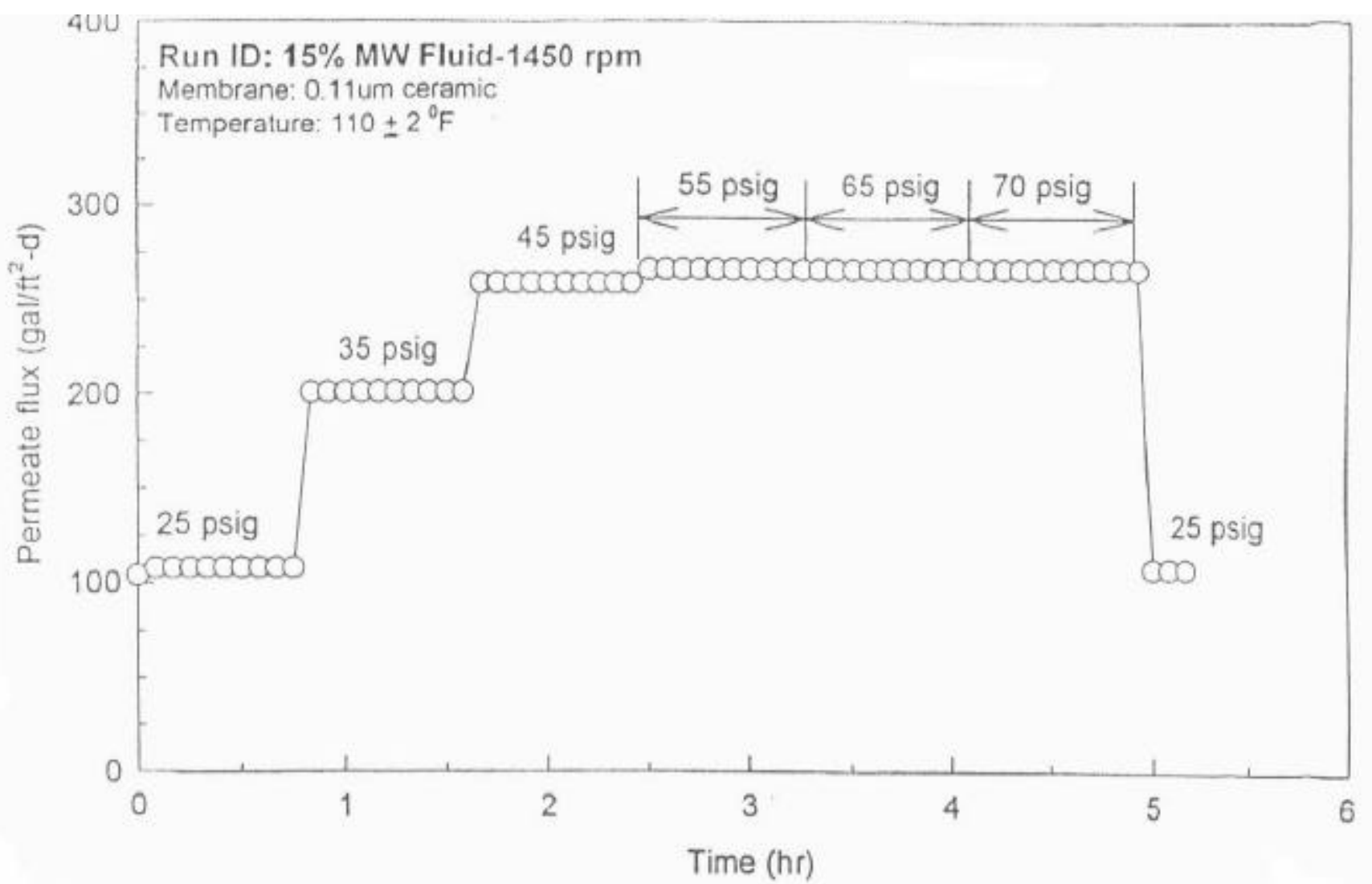

Figure (4.32) - Permeate Flux Versus Time for the 15\%-1,450 rpm Experiment 


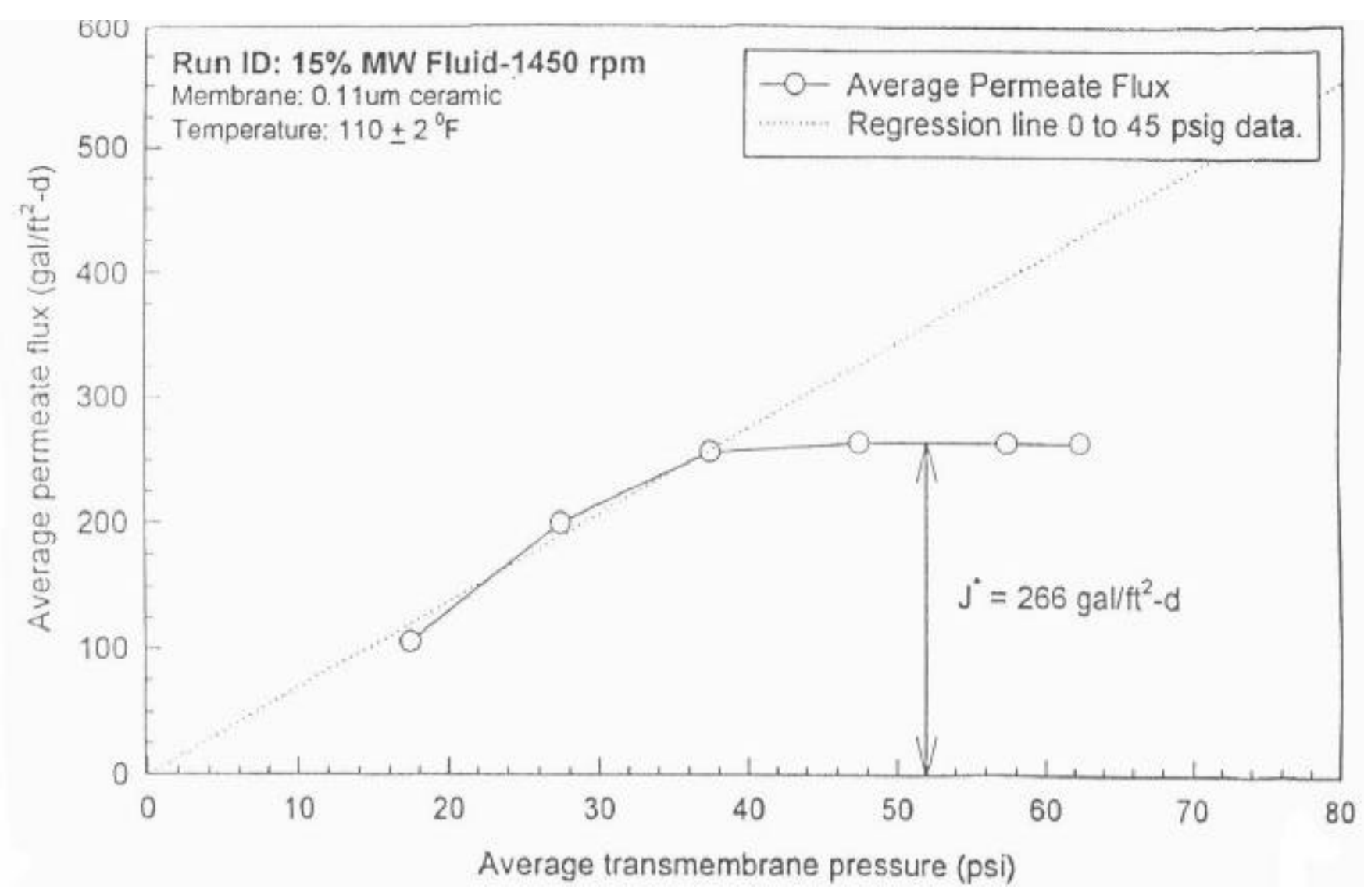

Figure (4.33) - Average Permeate Flux Versus Average Transmembrane Pressure for the 15\%-1,450 rpm Experiment 
averaged $433 \mu \mathrm{S} / \mathrm{cm}$. The concentrate conductivity ranged from 394 to $579 \mu \mathrm{S} / \mathrm{cm}$ and averaged $514 \mu \mathrm{S} / \mathrm{cm}$. A net decrease in permeate conductivity and a net increase in concentrate conductivity were observed. Permeate conductivity was greater than concentrate conductivity through $\sim 1.5 \mathrm{hr}$. The concentrate conductivity then exceeded the permeate conductivity from $\sim 1.5 \mathrm{hr}$. through the end of the experiment. Distinct stepwise changes in permeate and concentrate $\mathrm{pH}$ and conductivity were not observed as applied pressure was increased.

The membrane was cleaned using the standardized cleaning procedure discussed in Chapter 3. No oil was visible on the membrane surface after cleaning. The $\mathrm{pH}$ and conductivity of the distilled water used to determine the membrane resistance after cleaning were 6.91 and $2.89 \mu \mathrm{S} / \mathrm{cm}$, respectively. A plot of the average permeate flux versus average transmembrane pressure for the 15\% MW Fluid-1,450 rpm clean water flux experiment is presented in Figure (4.34). The resistance of the membrane was $2.09 \times 10^{12} \mathrm{~m}^{-1}$.

\section{5\% MW Fluid-1,150 rpm}

Permeate flux versus time for the 15\% MW Fluid-1,150 rpm experiment is presented in Figure (4.35). Permeate flux was stable at each applied pressure condition. The system was operated over an applied pressure range of 15 to $70 \mathrm{psig}$. The average permeate backpressure was $4.8 \mathrm{psi}$ for a membrane rotational speed of $1,150 \mathrm{rpm}$. The

permeate flux was $50 \mathrm{gal} / \mathrm{ft}^{2}-\mathrm{d}$ when the $15 \mathrm{psig}$ applied pressure condition was reinvestigated after the limiting permeate flux was determined. The initial permeate flux at 


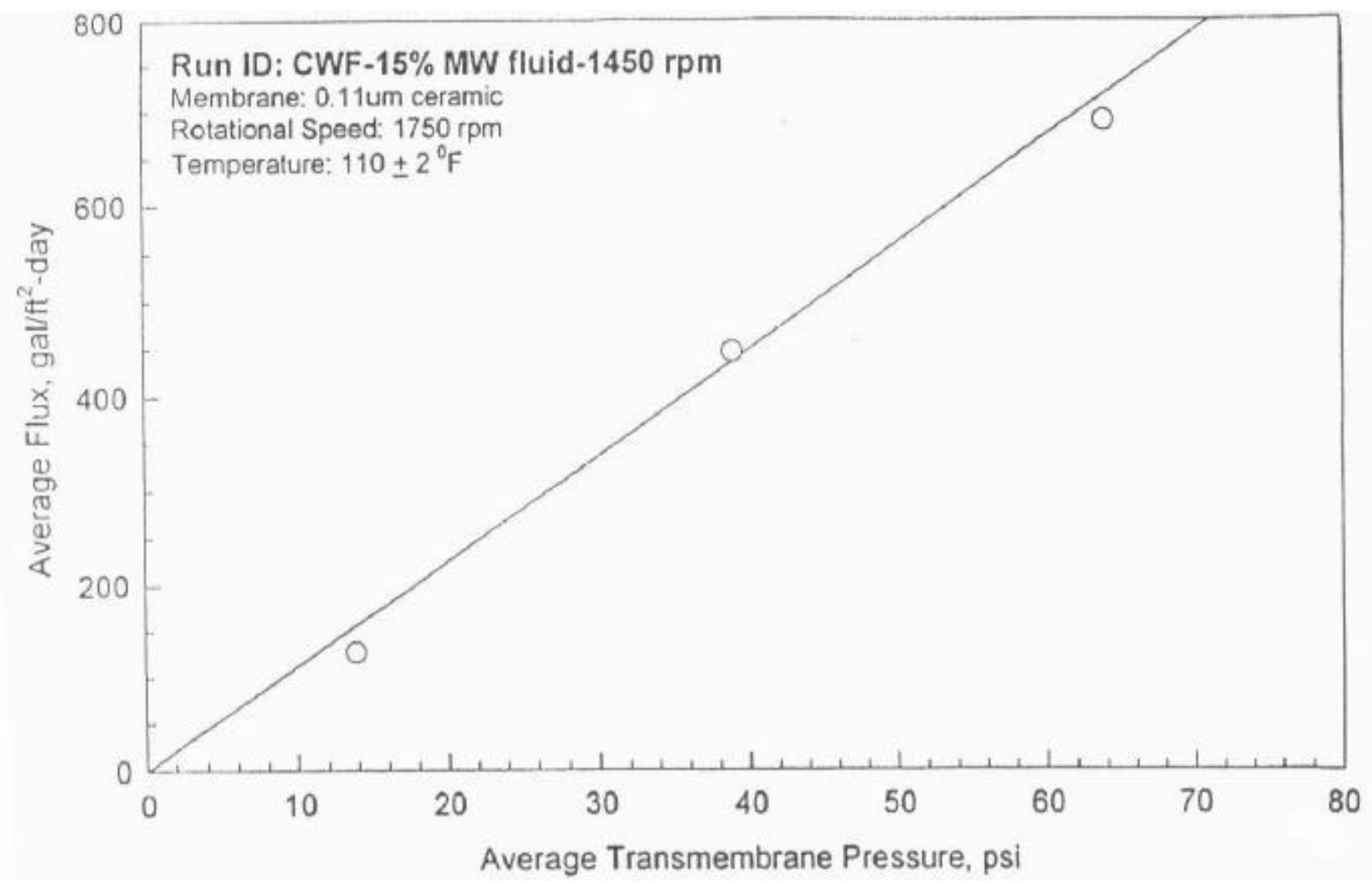

Figure (4.34) - Average Permeate Flux Versus Average Transmembrane Pressure for the 15\%-1,450 rpm Clean Water Flux Experiment 


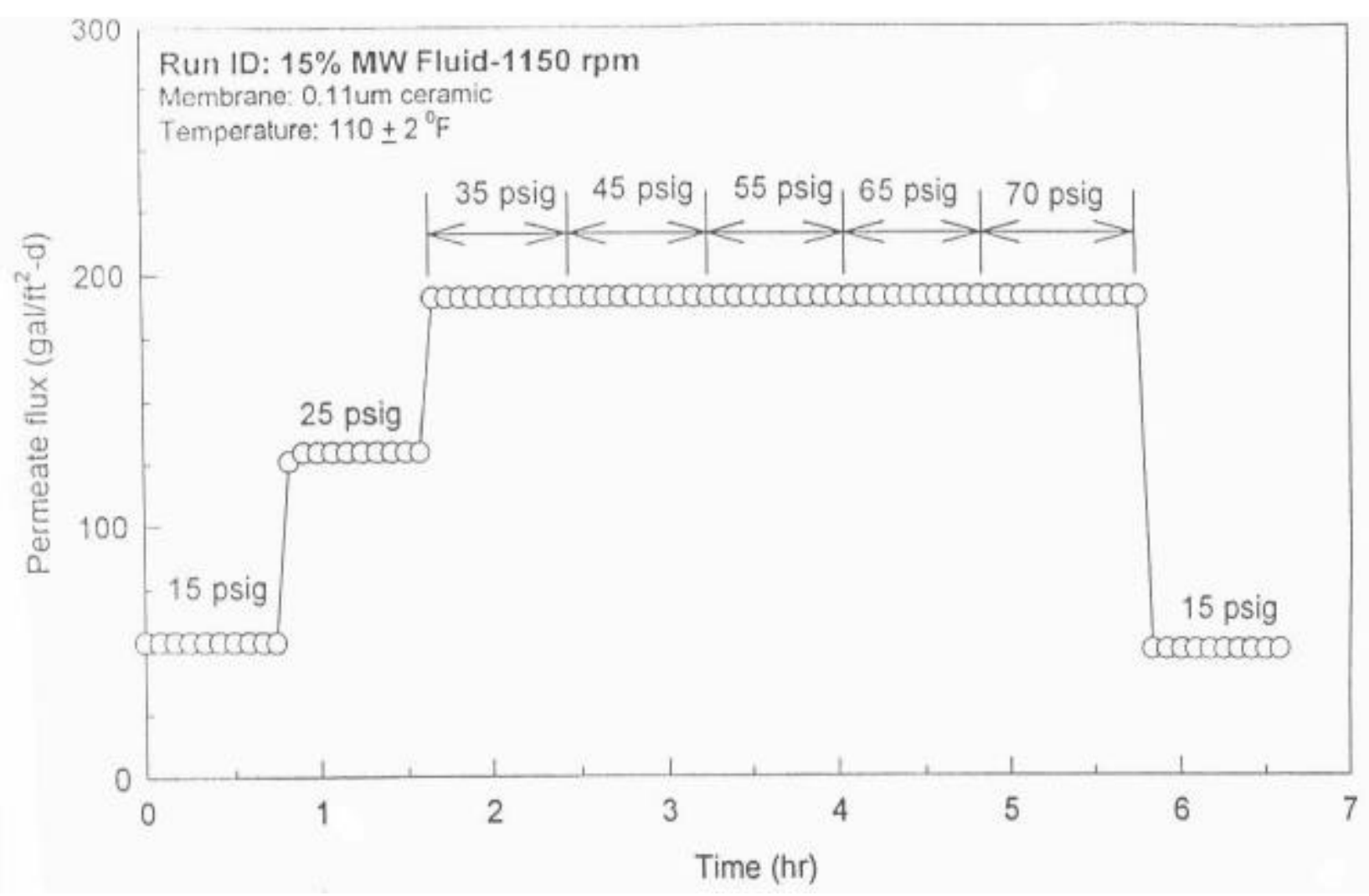

Figure (4.35) - Permeate Flux Versus Time for the 15\%-1,150 rpm Experiment 
the initial 15 psig condition was $54 \mathrm{gal} / \mathrm{ft}^{2}-\mathrm{d}$. The lower "rebound" flux may have been due to membrane pore plugging or adsorption of solute molecules onto the membrane surface. Additionally, it is possible that the thickness of the solute boundary layer was not reduced to its initial value when the applied pressure was decreased. A higher resistance to hydraulic flow of permeate and thus a lower permeate flux would result from a thicker concentration boundary layer. The average permeate flux versus average transmembrane pressure for the $15 \%$ MW Fluid-1,150 rpm experiment is presented in Figure (4.36). A limiting flux of $190 \mathrm{gal} / \mathrm{ft}^{2}-\mathrm{d}$ was observed at the 35 to $70 \mathrm{psig}$ applied pressure conditions. The slope of the regression line fitted to the pressure-controlled data from 0 to $25 \mathrm{psig}$ was $6.164 \mathrm{gal} / \mathrm{ft}^{2}$-d-psi. The total resistance to hydraulic flow in the pressure-controlled region was $3.82 \times 10^{12} \mathrm{~m}^{-1}$.

The permeate $\mathrm{pH}$ ranged from 5.84 to 7.60 and averaged 6.33. The concentrate $\mathrm{pH}$ ranged from 5.89 to 7.54 and averaged 6.42. The permeate and concentrate $\mathrm{pH}$ were approximately equal and followed the same general decreasing trend with time. Permeate conductivity ranged from 282 to $540 \mu \mathrm{S} / \mathrm{cm}$ and averaged $395 \mu \mathrm{S} / \mathrm{cm}$. Concentrate conductivity ranged from 346 to $583 \mu \mathrm{S} / \mathrm{cm}$ and averaged $527 \mu \mathrm{S} / \mathrm{cm}$. A net decrease in permeate conductivity and a net increase in concentrate conductivity were observed in this experiment. Permeate conductivity was greater than concentrate conductivity through $\sim 1.75 \mathrm{hr}$. Concentrate conductivity then exceeded the permeate 


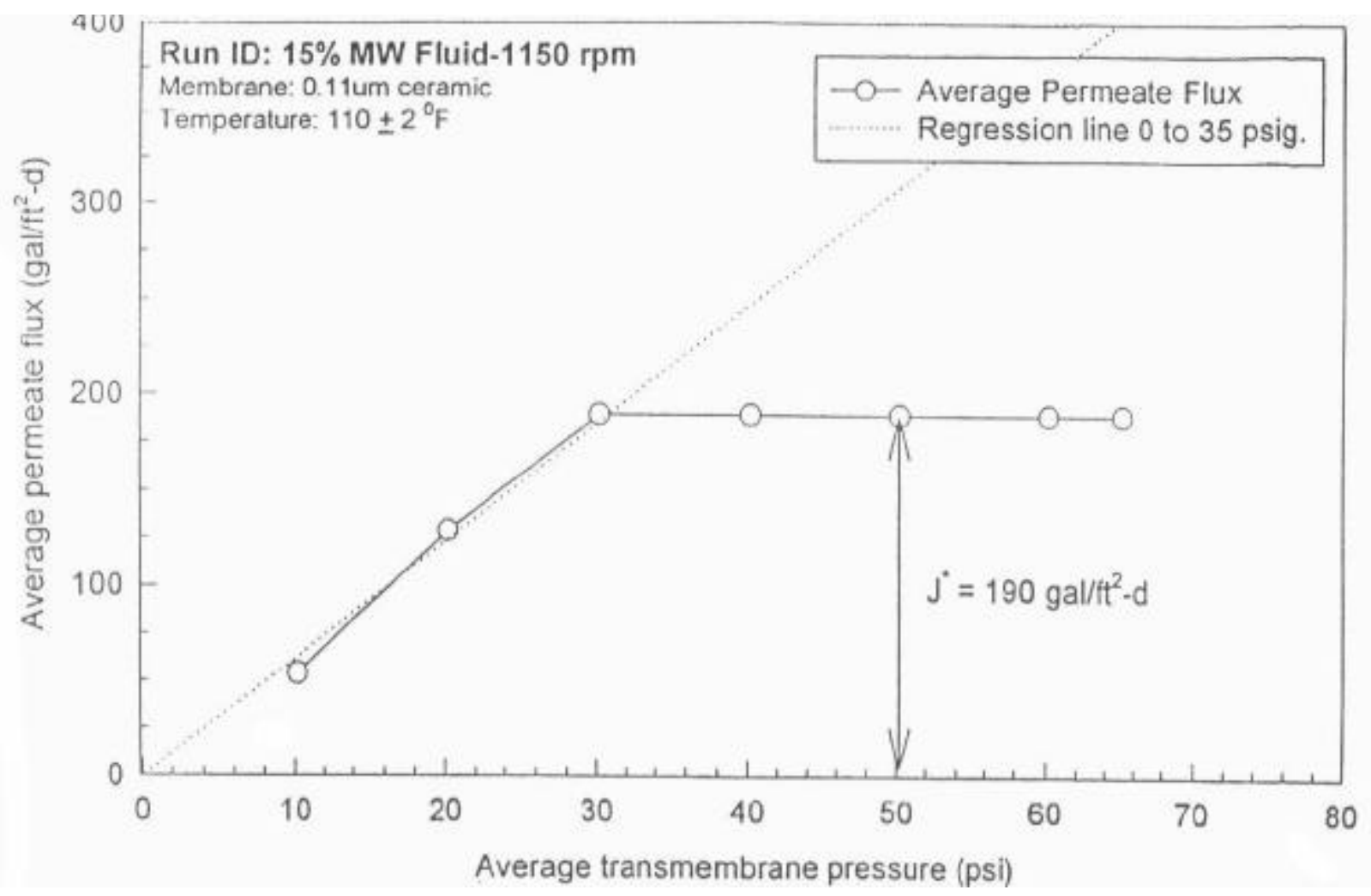

Figure (4.36) - Average Permeate Flux Versus Average Transmembrane Pressure for the 15\%-1,150 rpm Experiment 
conductivity from $\sim 1.75 \mathrm{hr}$. through the end of the experiment. Distinct step-wise changes in permeate and concentrate $\mathrm{pH}$ and conductivity were not observed as applied pressure was increased.

The membrane was cleaned using the standardized cleaning procedure discussed in Chapter 3. No oil was visible on the membrane surface after cleaning. The $\mathrm{pH}$ and conductivity of the distilled water used to determine the membrane resistance after cleaning were 6.98 and $3.98 \mu \mathrm{S} / \mathrm{cm}$, respectively. A plot of the average permeate flux versus average transmembrane pressure for the 15\% MW Fluid-1,150 rpm clean water flux experiment is presented in Figure (4.37). The resistance of the membrane was $1.85 \times 10^{12} \mathrm{~m}^{-1}$

\section{$20 \%$ MW Fluid-1,750 rpm}

Permeate flux versus time for the $20 \%$ MW Fluid-1,750 rpm experiment is presented in Figure (4.38). Permeate flux was stable at each applied pressure condition. The system was operated over an applied pressure range of 20 to $70 \mathrm{psig}$. The average permeate backpressure was 11.1 psi for a membrane rotational speed of $1,750 \mathrm{rpm}$. The permeate flux was $68 \mathrm{gal} / \mathrm{ft}^{2}-\mathrm{d}$ when the $25 \mathrm{psig}$ applied pressure condition was reinvestigated after the limiting permeate flux was determined. The initial permeate flux at the initial $25 \mathrm{psig}$ condition was $83 \mathrm{gal} / \mathrm{ft}^{2}-\mathrm{d}$. The average permeate flux versus average transmembrane pressure for the $20 \%$ MW Fluid-1,750 rpm experiment is presented in Figure (4.39). A limiting flux of $233 \mathrm{gal} / \mathrm{ft}^{2}-\mathrm{d}$ was observed at the 55 to $70 \mathrm{psig}$ applied pressure conditions. The slope of the regression line fitted to the pressure-controlled data 


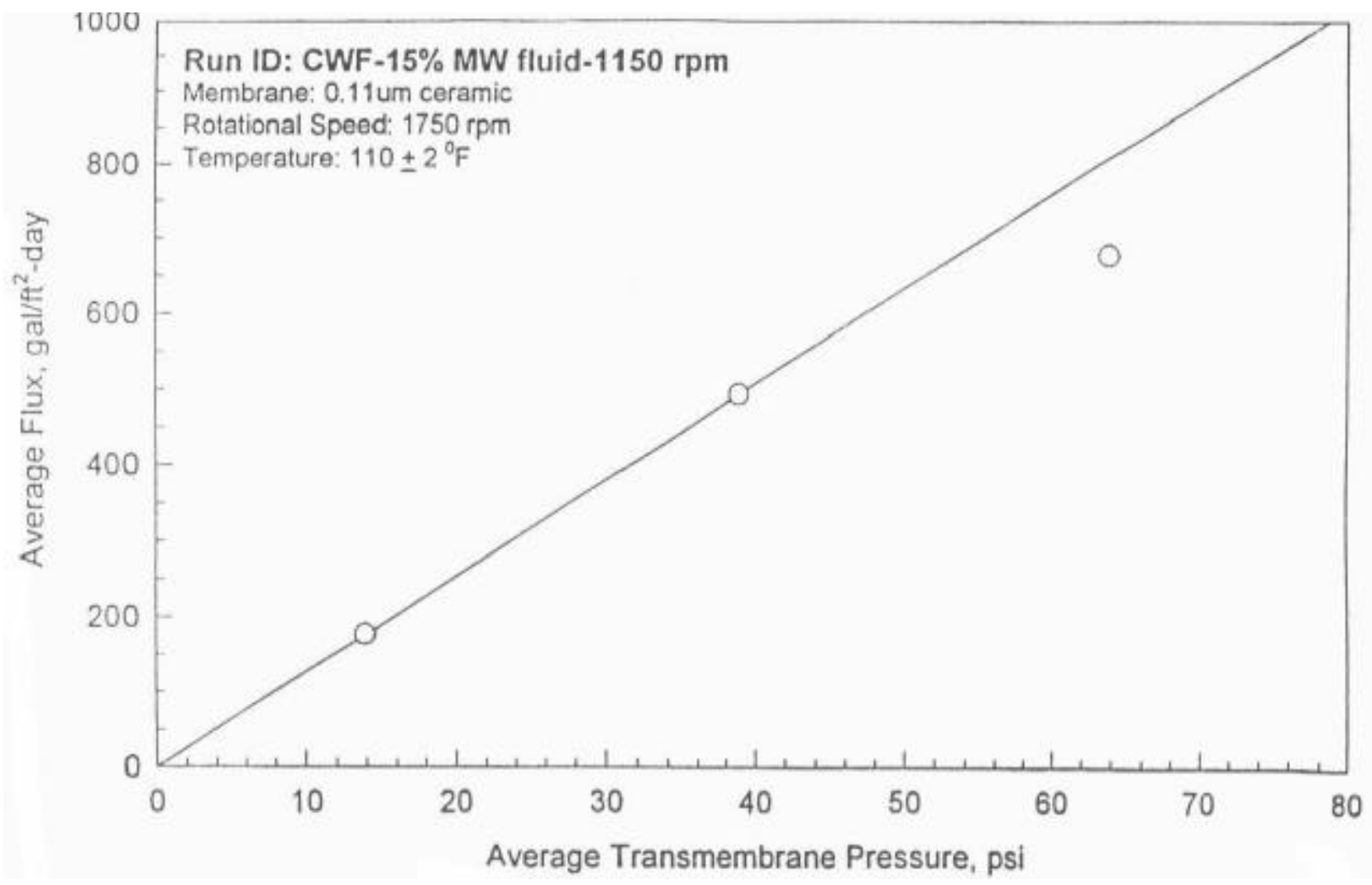

Figure (4.37) - Average Permeate Flux Versus Average Transmembrane Pressure for the 15\%-1,150 rpm Clean Water Experiment 


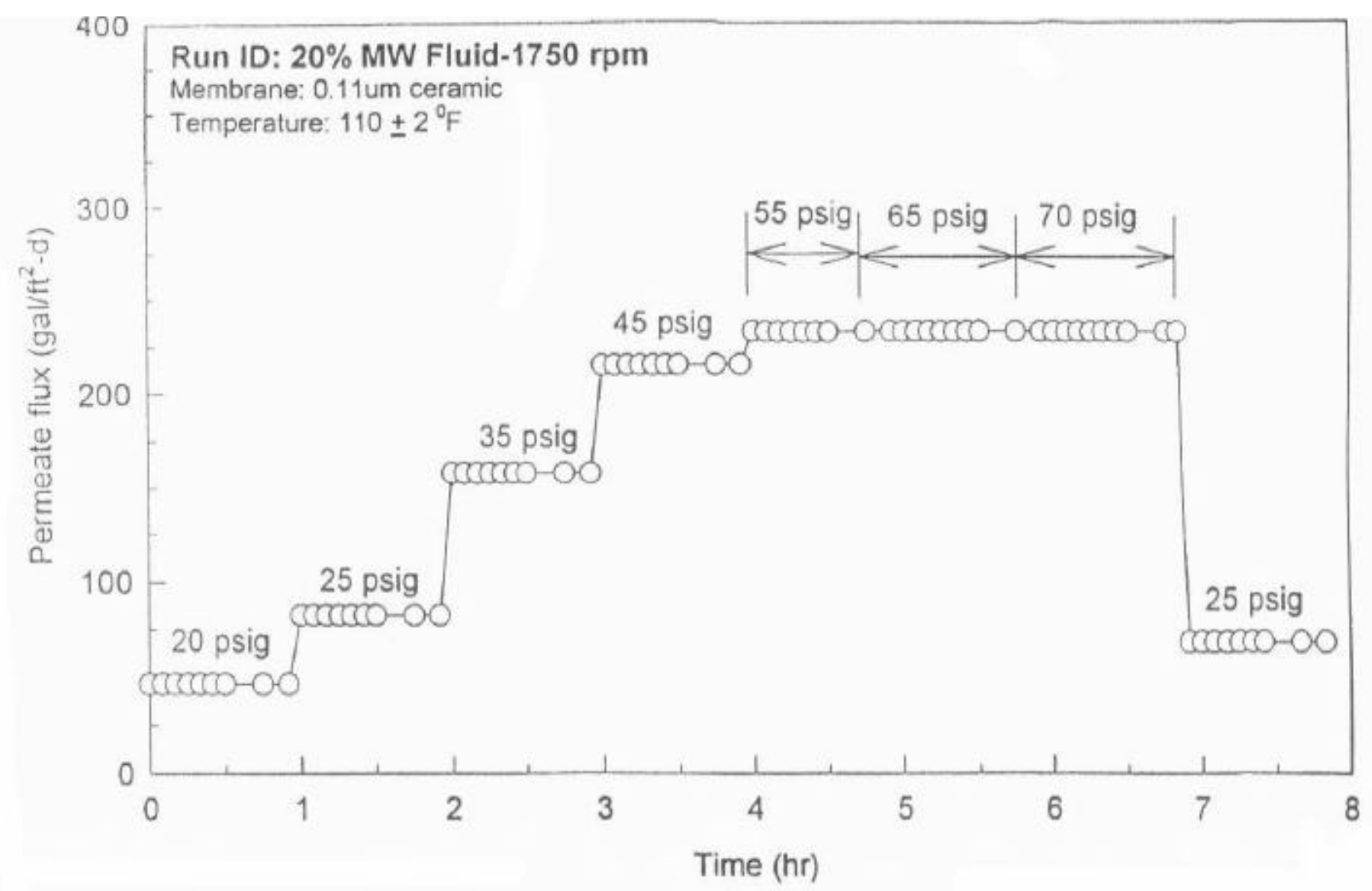

Figure (4.38) - Permeate Flux Versus Time for the 20\%-1,750 rpm Experiment 


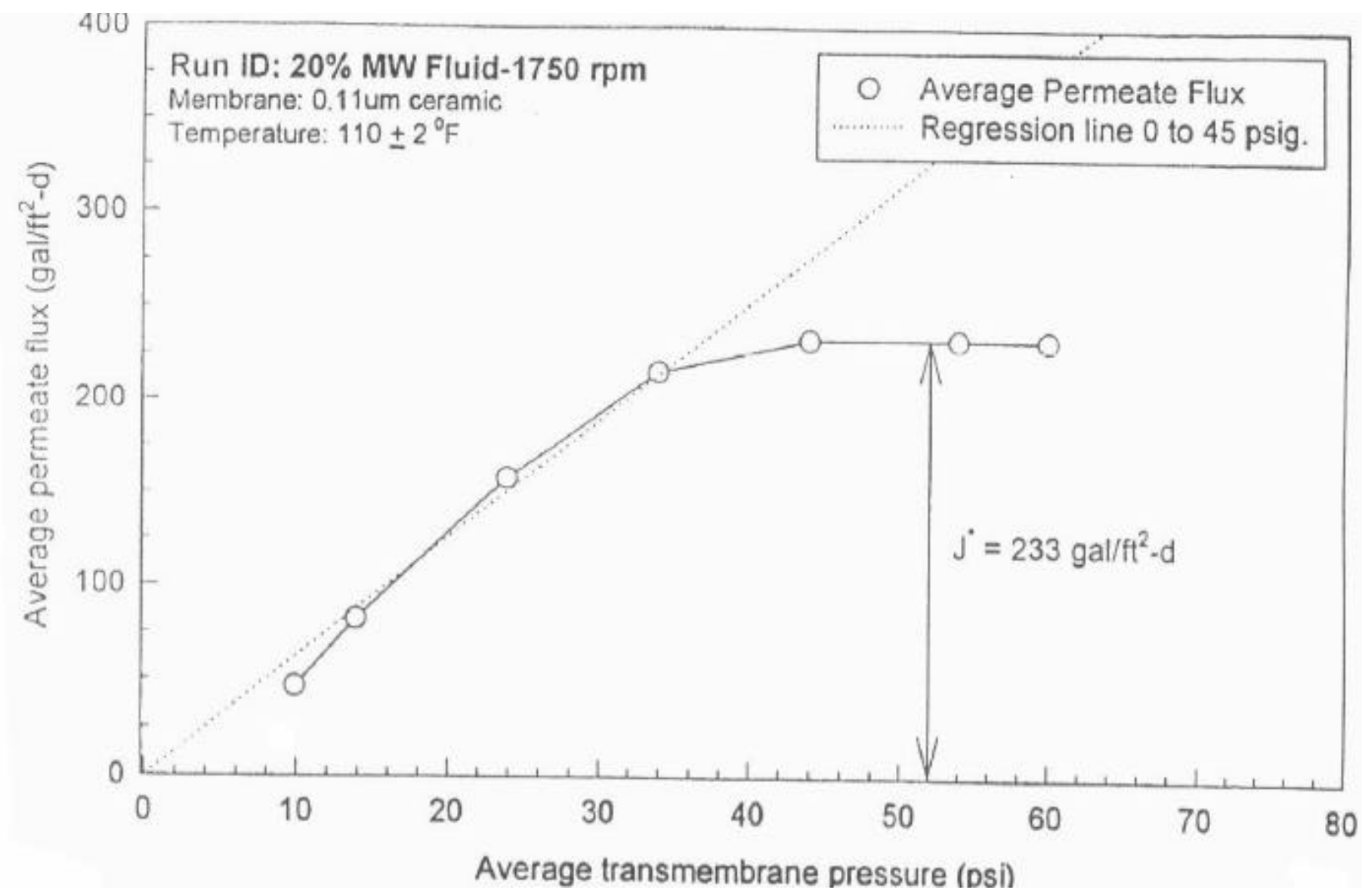

Figure (4.39) - Average Permeate Flux Versus Average Transmembrane Pressure for the 20\%-1,750 rpm Experiment 
from 0 to $45 \mathrm{psig}$ was $6.305 \mathrm{gal} / \mathrm{ft}^{2}-\mathrm{d}-\mathrm{psi}$. The total resistance to hydraulic flow in the pressure-controlled region was $3.74 \times 10^{12} \mathrm{~m}^{-1}$.

The permeate $\mathrm{pH}$ ranged from 7.53 to 8.17 and averaged 7.76 . The concentrate $\mathrm{pH}$ ranged from 7.63 to 7.75 and averaged 7.69. A decrease in permeate $\mathrm{pH}$ from 8.17 to 7.80 was observed over the first $1 \mathrm{hr}$. Permeate $\mathrm{pH}$ then remained constant at $\sim 7.75$ through the end of the $20 \%$ MW Fluid-1,750 rpm experiment. Concentrate pH was constant at $\sim 7.75$. The permeate conductivity ranged from 431 to $726 \mu \mathrm{S} / \mathrm{cm}$ and averaged $569 \mu \mathrm{S} / \mathrm{cm}$. The concentrate conductivity ranged from 481 to $708 \mu \mathrm{S} / \mathrm{cm}$ and averaged $634 \mu \mathrm{S} / \mathrm{cm}$. A net decrease in permeate conductivity and a net increase in concentrate conductivity were observed. Permeate conductivity was greater than concentrate conductivity through $\sim 3 \mathrm{hr}$. The concentrate conductivity then exceeded the permeate conductivity through the end of the experiment. Distinct step-wise changes in permeate and concentrate $\mathrm{pH}$ and conductivity were not observed as applied pressure was increased.

The membrane was cleaned using the standardized cleaning procedure discussed in Chapter 3. No oil was visible on the membrane surface after cleaning. The $\mathrm{pH}$ and conductivity of the distilled water used to determine the membrane resistance after cleaning were 6.87 and $2.91 \mu \mathrm{S} / \mathrm{cm}$, respectively. A plot of the average permeate flux versus average transmembrane pressure for the $20 \%$ MW Fluid-1,750 rpm clean water flux experiment is presented in Figure (4.40). The resistance of the membrane was $1.64 \times 10^{12} \mathrm{~m}^{-1}$ 


\section{$20 \%$ MW Fluid-1,450 rpm}

Permeate flux versus time for the $20 \%$ MW Fluid-1,450 rpm experiment is presented in Figure (4.41). Permeate flux was stable at each applied pressure condition. The system was operated over an applied pressure range of 15 to $70 \mathrm{psig}$. The average permeate backpressure was 7.6 psi for a membrane rotational speed of $1,450 \mathrm{rpm}$. The permeate flux was $47 \mathrm{gal} / \mathrm{ft}^{2}-\mathrm{d}$ when the $25 \mathrm{psig}$ applied pressure condition was reinvestigated after the limiting permeate flux was determined. The initial permeate flux at the initial $25 \mathrm{psig}$ condition was $107 \mathrm{gal} / \mathrm{ft}^{2}-\mathrm{d}$. The average permeate flux versus average transmembrane pressure for the $20 \%$ MW Fluid-1,450 rpm experiment is presented in Figure (4.42). A limiting flux of $159 \mathrm{gal} / \mathrm{ft}^{2}-\mathrm{d}$ was observed at the 35 to $70 \mathrm{psig}$ applied pressure conditions. The slope of the regression line fitted to the pressure-controlled data from 0 to 25 psig was $2.956 \mathrm{gal} / \mathrm{ft}^{2}$-d-psi. The total resistance to hydraulic flow in the pressure-controlled region was $7.97 \times 10^{12} \mathrm{~m}^{-1}$.

The permeate $\mathrm{pH}$ ranged from 7.68 to 8.24 and averaged 7.84 . The concentrate $\mathrm{pH}$ ranged from 7.41 to 7.79 and averaged 7.56. The permeate $\mathrm{pH}$ was greater than the concentrate $\mathrm{pH}$ in the $20 \% \mathrm{MW}$ Fluid-1,450 rpm experiment. A decrease in both permeate and concentrate $\mathrm{pH}$ was observed from 0 to $2 \mathrm{hr}$. The permeate and concentrate $\mathrm{pH}$ were then constant through the end of the experiment. The permeate conductivity ranged from 506 to $992 \mu \mathrm{S} / \mathrm{cm}$ and averaged $792 \mu \mathrm{S} / \mathrm{cm}$. The concentrate conductivity ranged from 616 to $939 \mu \mathrm{S} / \mathrm{cm}$ and averaged $805 \mu \mathrm{S} / \mathrm{cm}$. A net decrease in permeate 


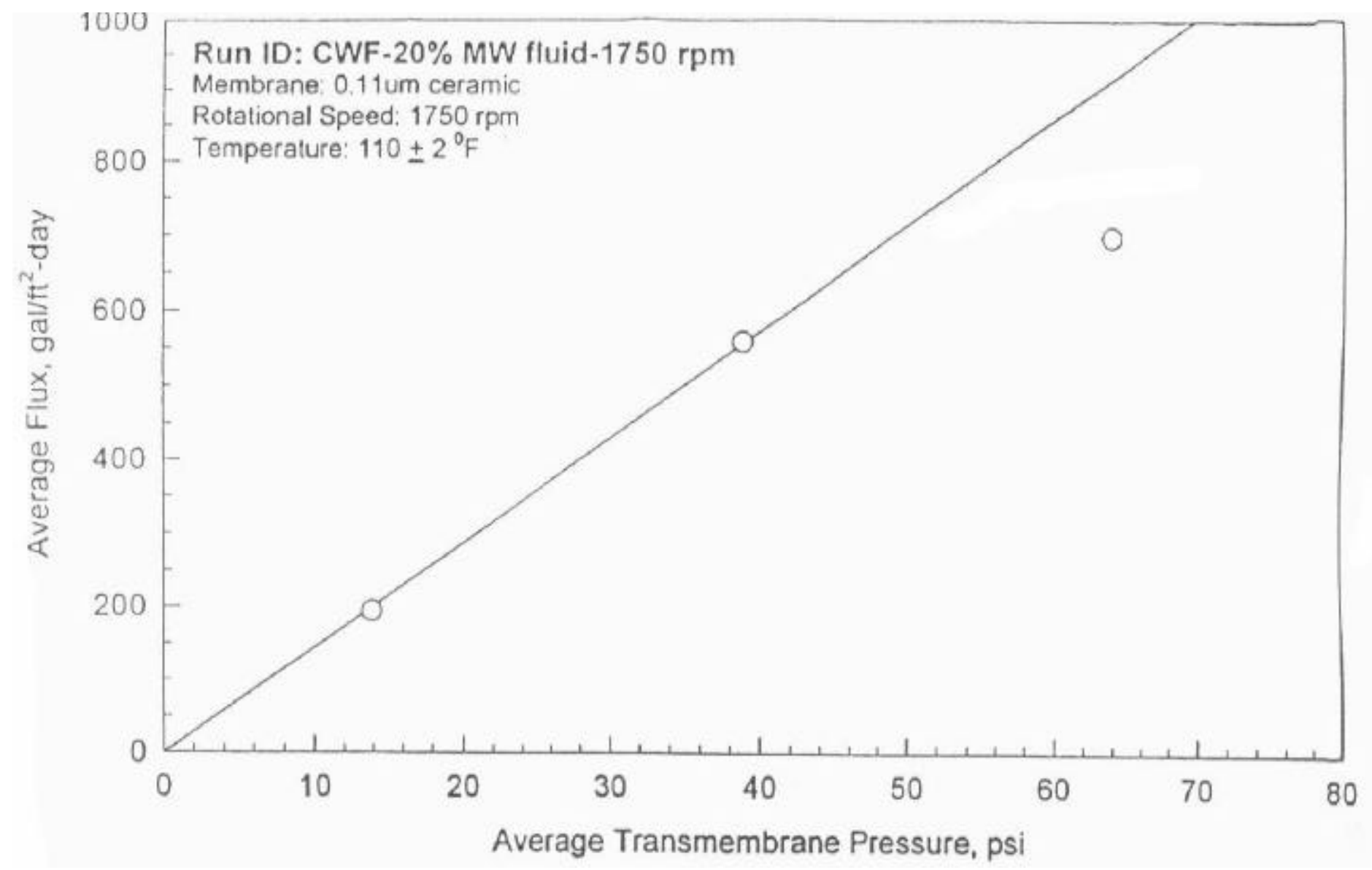

Figure (4.40) - Average Permeate Flux Versus Average Transmembrane Pressure for the 20\%-1,750 rpm Clean Water Flux Experiment 


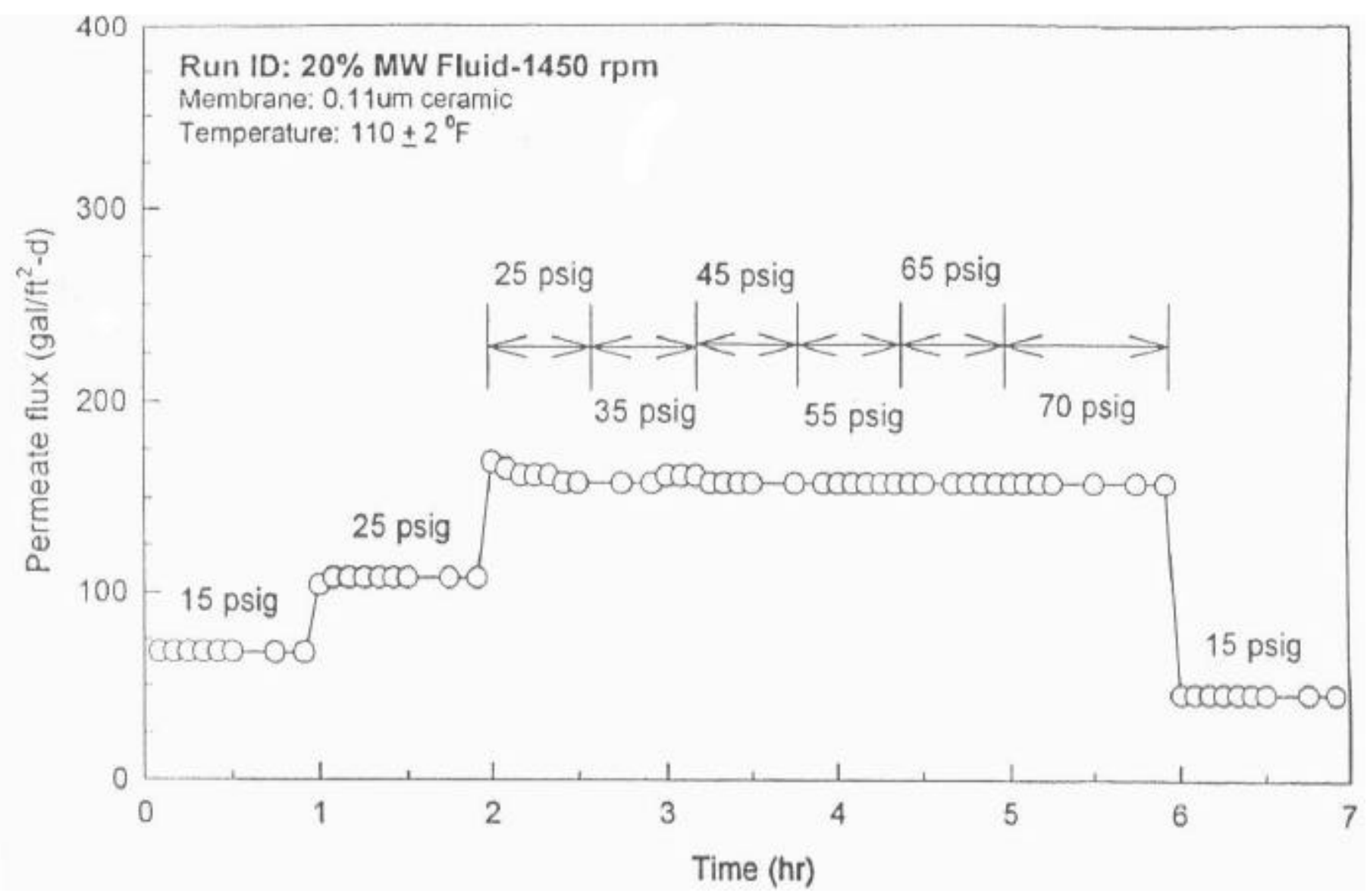

Figure (4.41) - Permeate Flux Versus Time for the 20\%-1,450 rpm Experiment 


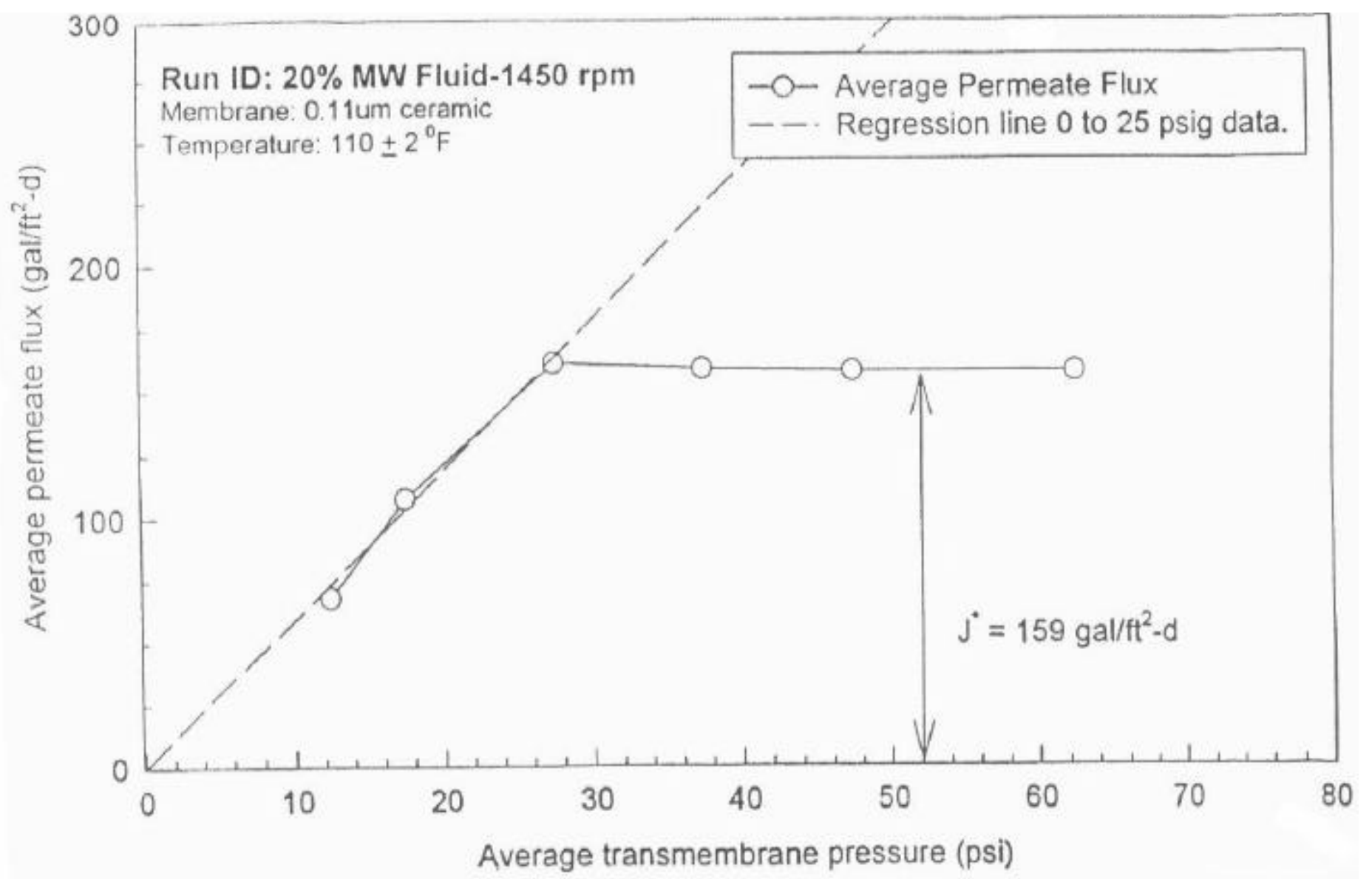

Figure (4.42) - Average Permeate Flux Versus Average Transmembrane Pressure for the 20\%-1,450 rpm Experiment 
conductivity and a net increase in concentrate conductivity was observed in this experiment. Permeate conductivity was greater than concentrate conductivity through $\sim 3.5 \mathrm{hr}$. Concentrate conductivity then exceeded permeate conductivity from $\sim 3.5 \mathrm{hr}$. through the end of the experiment. Distinct step-wise changes in permeate and concentrate $\mathrm{pH}$ and conductivity were not observed as applied pressure was increased.

The membrane was cleaned using the standardized cleaning procedure discussed in Chapter 3. No oil was visible on the membrane surface after cleaning. The $\mathrm{pH}$ and conductivity of the distilled water used to determine the membrane resistance after cleaning were 6.98 and $2.93 \mu \mathrm{S} / \mathrm{cm}$, respectively. A plot of the average permeate flux versus average transmembrane pressure for the $20 \%$ MW Fluid-1,450 rpm clean water flux experiment is presented in Figure (4.43). The resistance of the membrane was $1.93 \times 10^{12} \mathrm{~m}^{-1}$

\section{$20 \%$ MW Fluid-1,150 rpm}

Permeate flux versus time for the 20\% MW Fluid-1,150 rpm experiment is presented in Figure (4.44). Permeate flux was stable at each applied pressure condition. The system was operated over an applied pressure range of 15 to $70 \mathrm{psig}$. The average permeate backpressure was 4.8 psi for a membrane rotational speed of $1,150 \mathrm{rpm}$. The permeate flux was $32 \mathrm{gal} / \mathrm{ft}^{2}-\mathrm{d}$ when the $15 \mathrm{psig}$ applied pressure condition was reinvestigated after the limiting permeate flux was determined. The permeate flux at the initial $15 \mathrm{psig}$ condition was also $32 \mathrm{gal} / \mathrm{ft}^{2}-\mathrm{d}$. It is hypothesized that the solute boundary 


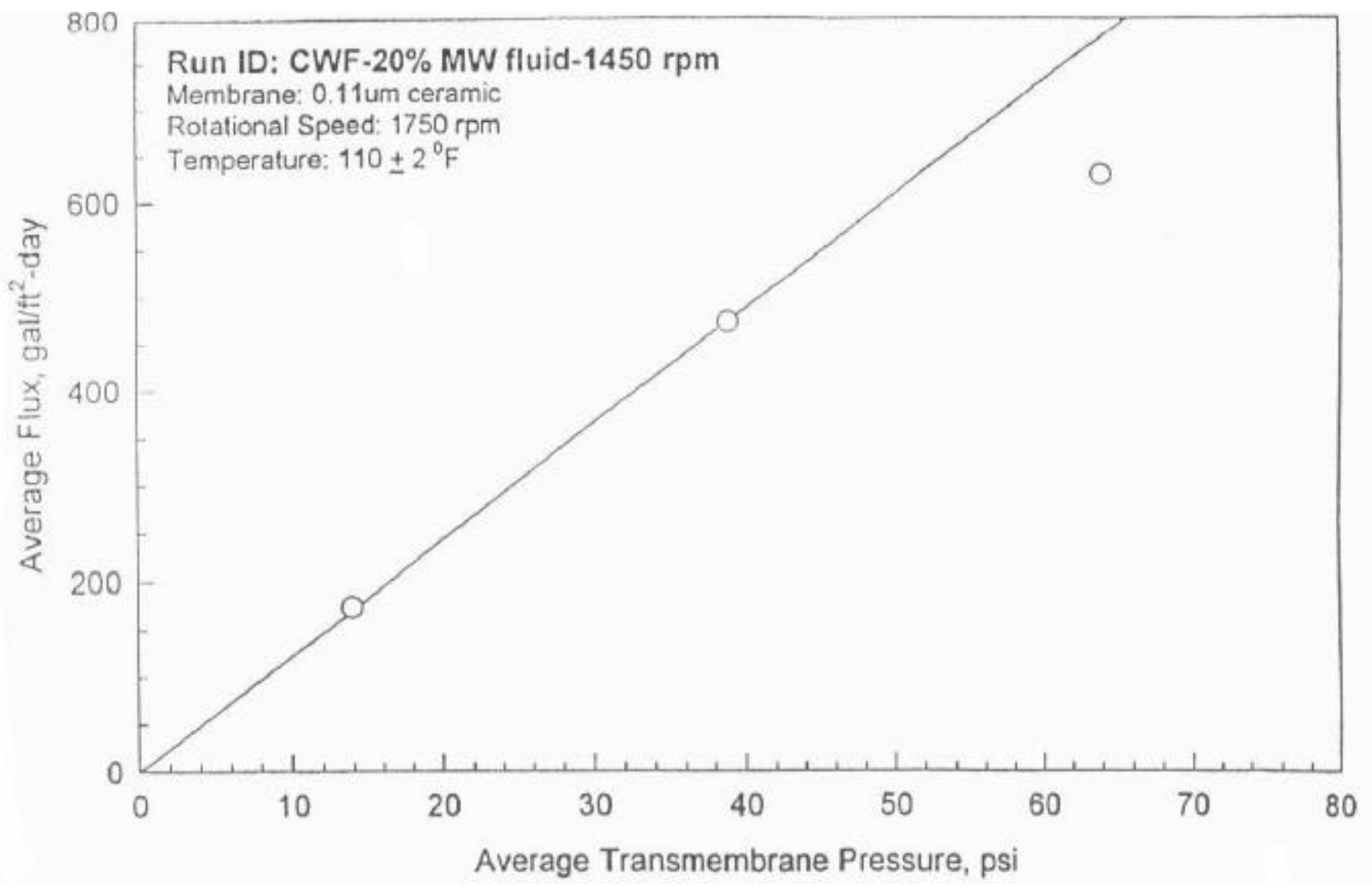

Figure (4.43) - Average Permeate Flux Versus Average Transmembrane Pressure for the 20\%-1,450 rpm Clean Water Flux Experiment 


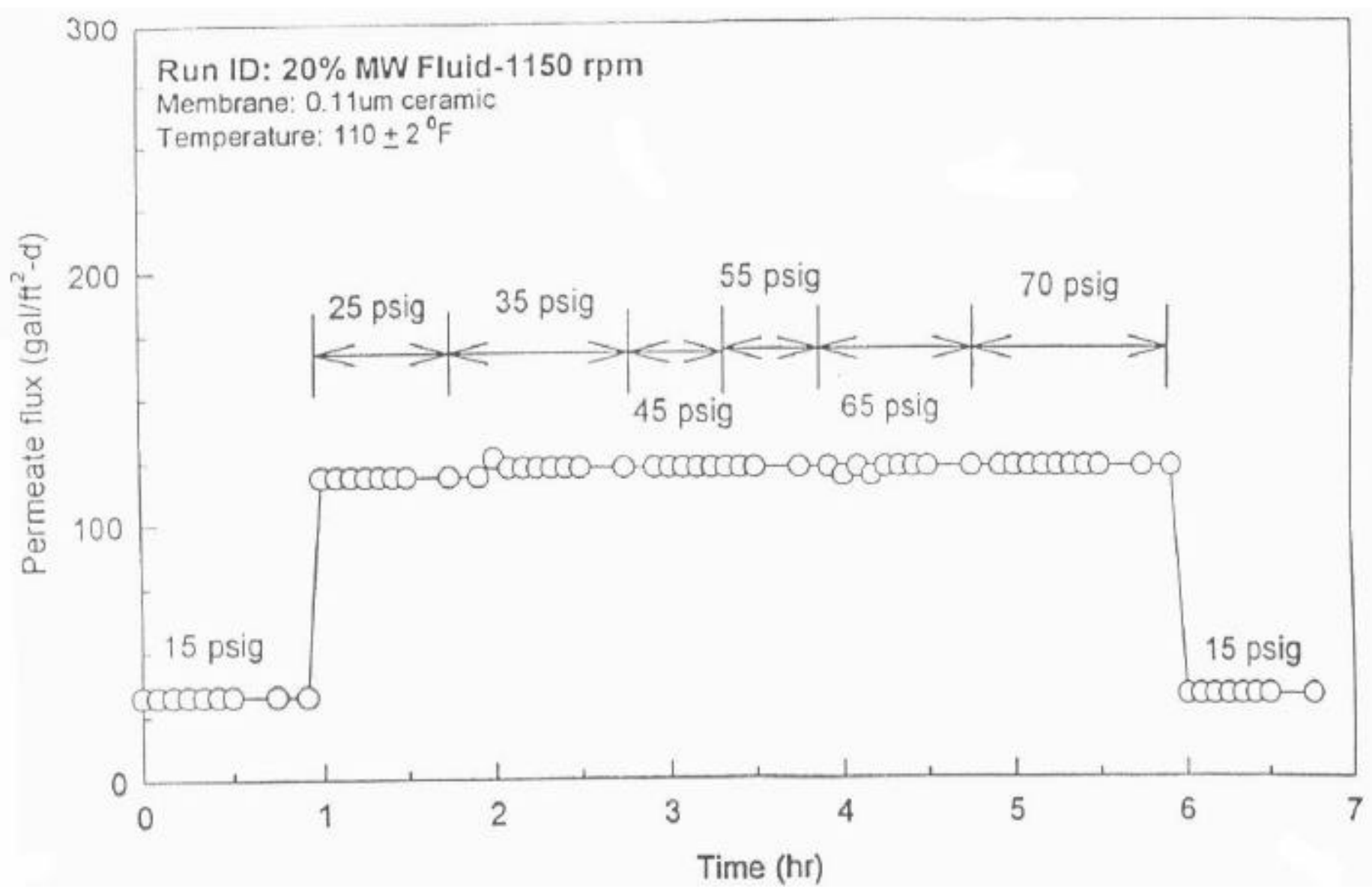

Figure (4.44) - Permeate Flux Versus Time for the 20\%-1,150 rpm Experiment 
ayer returned to its initial thickness when the applied pressure was decreased to $15 \mathrm{psig}$ and that solute molecules were not forced into the membrane pores and were not adsorbed onto the membrane surface. The average permeate flux versus average transmembrane pressure for the 20\% MW Fluid-1,150 rpm experiment is presented in Figure (4.45). A limiting flux of $122 \mathrm{gal} / \mathrm{ft}^{2}-\mathrm{d}$ was observed at the 25 to $70 \mathrm{psig}$ applied pressure conditions. The slope of the regression line fitted to the pressure-controlled data from 0 to 15 psig was $3.137 \mathrm{gal} / \mathrm{ft}^{2}$-d-psi. The total resistance to hydraulic flow in the pressure-controlled region was $7.51 \times 10^{12} \mathrm{~m}^{-1}$.

The permeate $\mathrm{pH}$ ranged from 7.10 to 7.97 and averaged 7.36. The concentrate $\mathrm{pH}$ ranged from 6.67 to 7.55 and averaged 7.04. The permeate $\mathrm{pH}$ was generally greater than the concentrate conductivity in this experiment. At $\sim 6 \mathrm{hr}$. concentrate $\mathrm{pH}$ exceeded permeate $\mathrm{pH}$. A net decrease in both permeate and concentrate $\mathrm{pH}$ was observed. The permeate conductivity ranged from 409 to $702 \mu \mathrm{S} / \mathrm{cm}$ and averaged $527 \mu \mathrm{S} / \mathrm{cm}$. The concentrate conductivity ranged from 390 to $706 \mu \mathrm{S} / \mathrm{cm}$ and averaged $600 \mu \mathrm{S} / \mathrm{cm}$. A net decrease in permeate conductivity and a net increase in concentrate conductivity were observed in this experiment. Permeate conductivity was greater than concentrate conductivity through $\sim 2 \mathrm{hr}$. The concentrate conductivity then exceeded the permeate conductivity from $\sim 2 \mathrm{hr}$. through the end of the experiment. Distinct step-wise changes in permeate and concentrate $\mathrm{pH}$ and conductivity were not observed as applied pressure was increased. 


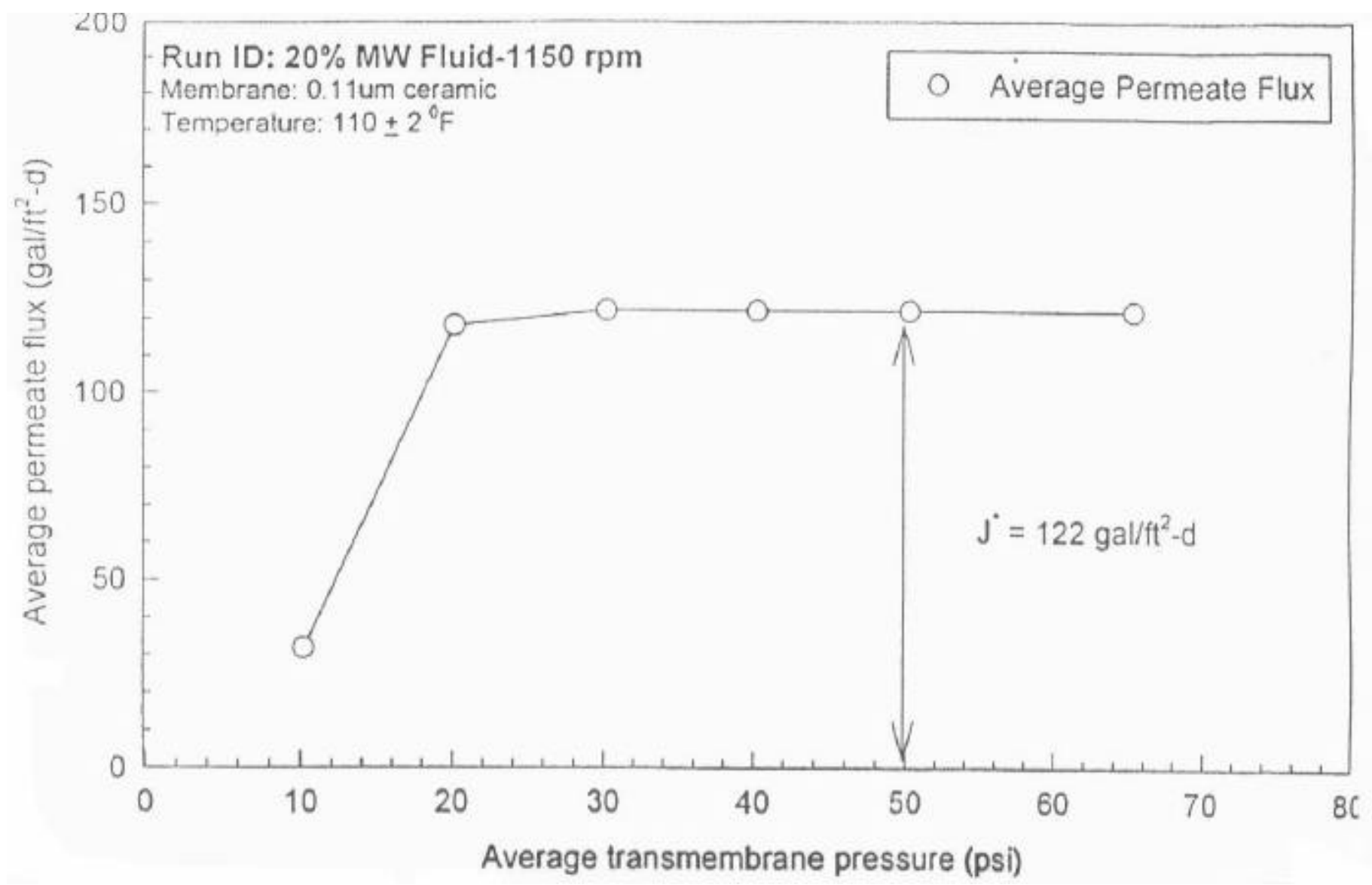

Figure (4.45) - Average Permeate Flux Versus Average Transmembrane Pressure for the 20\%-1,150 rpm Experiment 
The membrane was cleaned using the standardized cleaning procedure discussed in Chapter 3. No oil was visible on the membrane surface after cleaning. The $\mathrm{pH}$ and conductivity of the distilled water used to determine the membrane resistance after cleaning were 6.73 and $4.14 \mu \mathrm{S} / \mathrm{cm}$, respectively. A plot of the average permeate flux versus average transmembrane pressure for the $20 \%$ MW Fluid-1,150 rpm clean water flux experiment is presented in Figure (4.46). The resistance of the membrane was $3.12 \times 10^{12} \mathrm{~m}^{-1}$

\section{$30 \%$ MW Fluid-1,750 rpm}

Permeate flux versus time for the 30\% MW Fluid-1,750 rpm experiment is presented in Figure (4.47). Permeate flux was stable at each applied pressure condition. The system was operated over an applied pressure range of 25 to 70 psig. The average permeate backpressure was 11.1 psi for a membrane rotational speed of $1,750 \mathrm{rpm}$. The permeate flux was $44 \mathrm{gal} / \mathrm{ft}^{2}-\mathrm{d}$ when the $25 \mathrm{psig}$ applied pressure condition was reinvestigated after the limiting permeate flux was determined. The initial permeate flux at the initial $25 \mathrm{psig}$ condition was $56 \mathrm{gal} / \mathrm{ft}^{2}-\mathrm{d}$. The lower "rebound" may have been due to membrane pore plugging or adsorption of solute molecules onto the membrane surface. Additionally, it is possible that the thickness of the solute boundary layer was not reduced to its initial value when the applied pressure was decreased. A higher resistance to the hydraulic flow of permeate and thus a lower permeate flux would result from a thicker solute boundary layer. The average permeate flux versus average transmembrane pressure for the $30 \%$ MW Fluid-1,750 rpm experiment is presented in Figure (4.48). A limiting flux of $97 \mathrm{gal} / \mathrm{ft}^{2}-\mathrm{d}$ was observed at the 25 to 70 psig applied pressure conditions. 


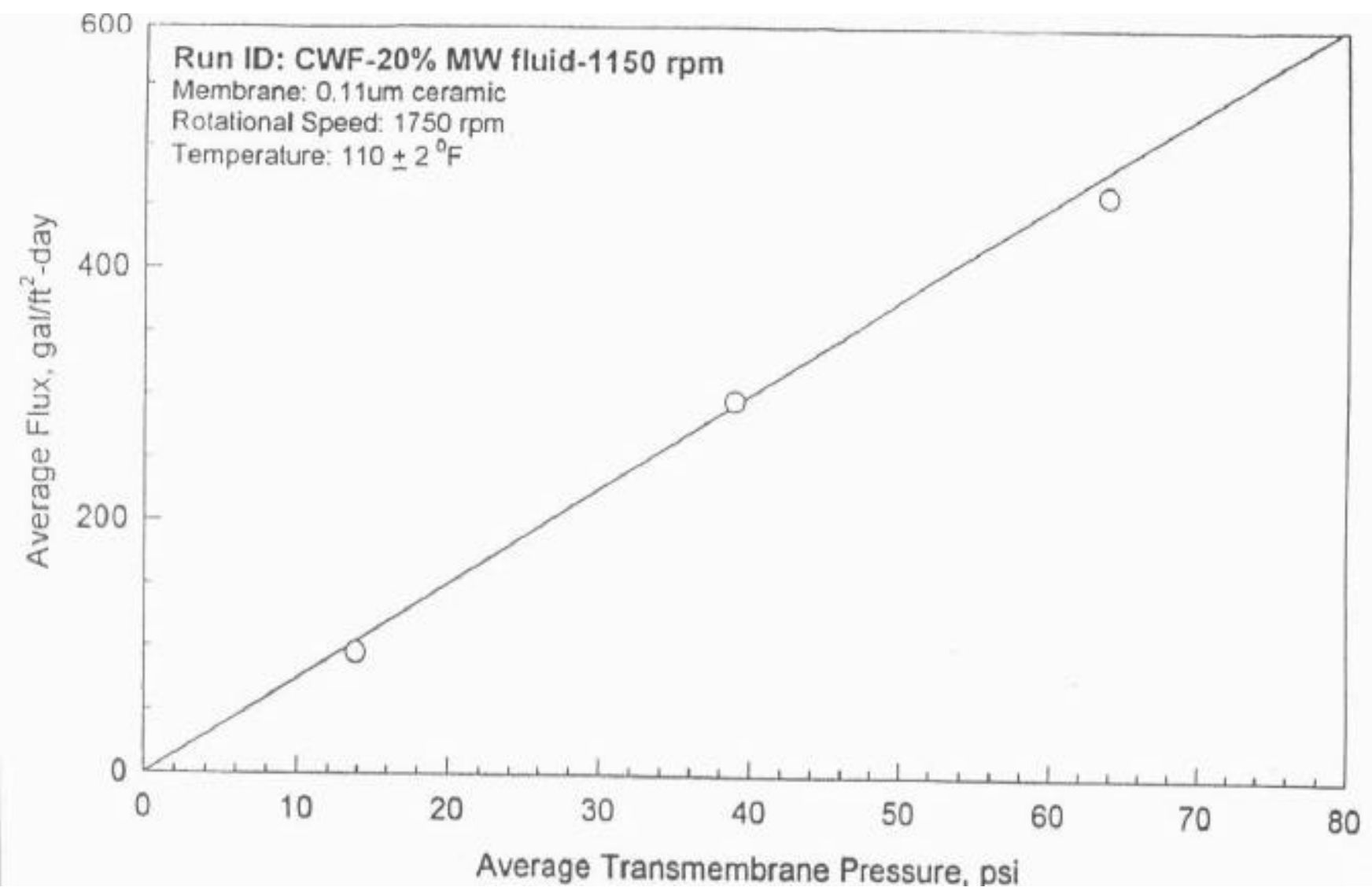

Figure (4.46) - Average Permeate Flux Versus Average Transmembrane Pressure for the 20\%-1,150 rpm Clean Water Experiment 


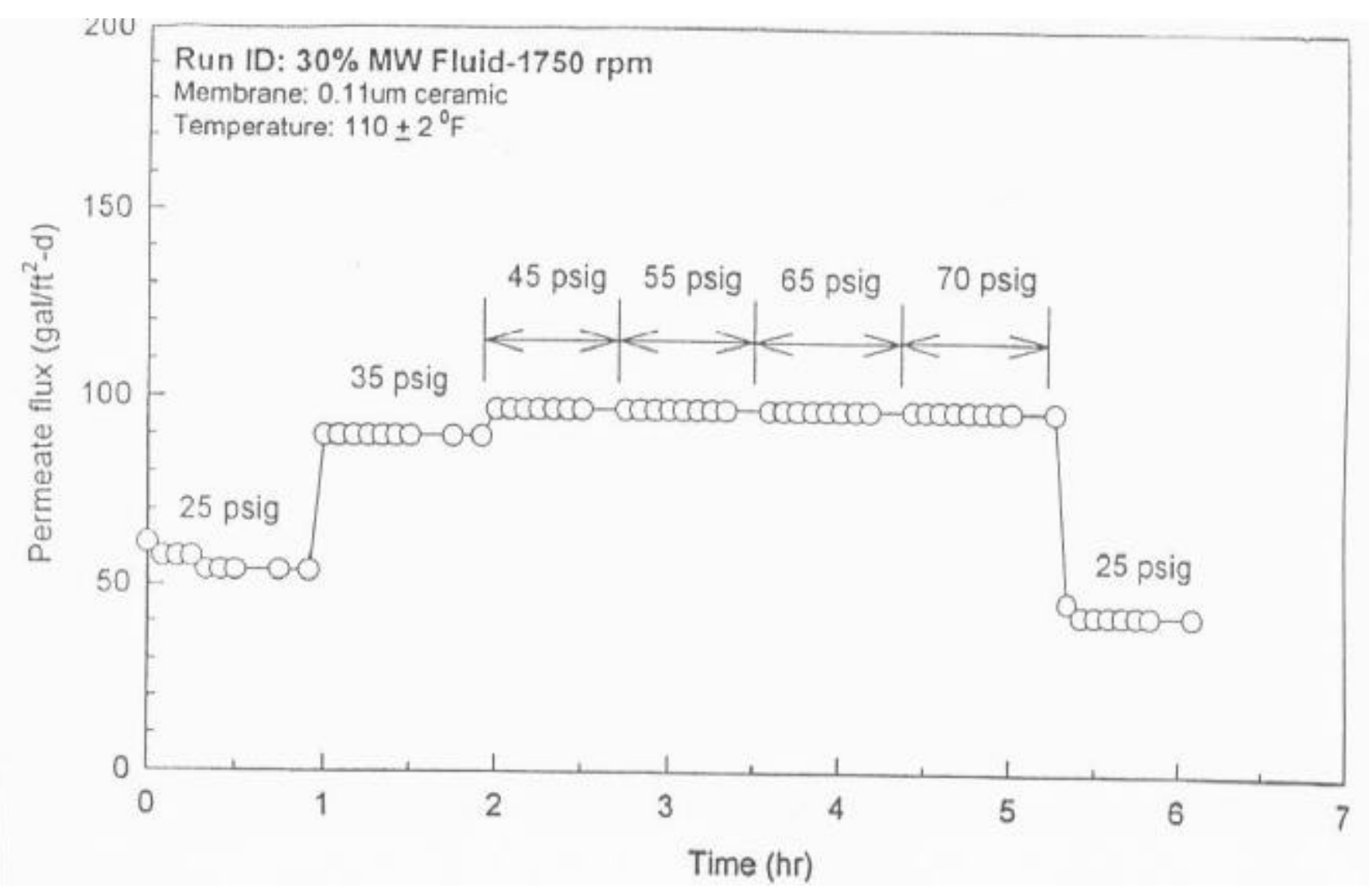

Figure (4.47) - Permeate Flux Versus Time for the 30\%-1,750 rpm Experiment 


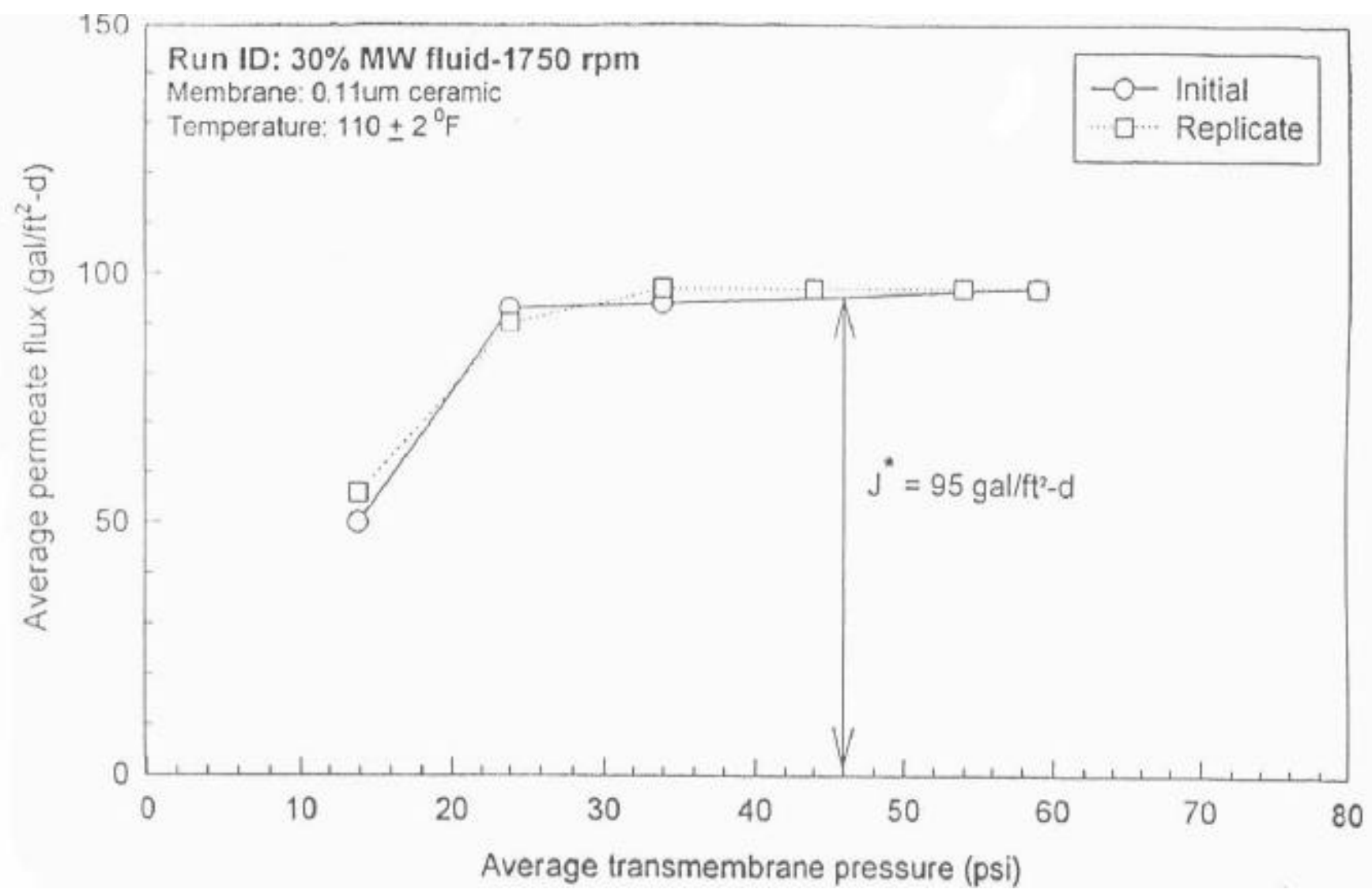

Figure (4.48) - Average Permeate Flux Versus Average Transmembrane Pressure for the 30\%-1,750 rpm Experiment 
The slope of the regression line fitted to the pressure-controlled data from 0 to 25 psig was $3.832 \mathrm{gal} / \mathrm{ft}^{2}$-d-psi. The total resistance to hydraulic flow in the pressure-controlled region was $6.15 \times 10^{12} \mathrm{~m}^{-1}$.

The permeate $\mathrm{pH}$ ranged from 6.20 to 7.41 and averaged 6.74. The concentrate $\mathrm{pH}$ ranged from 5.91 to 7.25 and averaged 6.57. Permeate $\mathrm{pH}$ was greater than the concentrate $\mathrm{pH}$ throughout the $30 \%$ MW Fluid-1,750 rpm experiment. Both permeate and concentrate $\mathrm{pH}$ followed the same general trend in this experiment: $\mathrm{pH}$ decreased through $1 \mathrm{hr}$. then increased from $1 \mathrm{hr}$. through the end of the experiment. Additionally, permeate and concentrate $\mathrm{pH}$ values were approximately equal from $2.5 \mathrm{hr}$. through the end of the experiment. The permeate conductivity ranged from 868 to $1164 \mu \mathrm{S} / \mathrm{cm}$ and averaged $965 \mu \mathrm{S} / \mathrm{cm}$. The concentrate conductivity ranged from 880 to $976 \mu \mathrm{S} / \mathrm{cm}$ and averaged $936 \mu \mathrm{S} / \mathrm{cm}$. A net decrease in permeate conductivity was observed. Concentrate conductivity was constant. Permeate conductivity was greater than concentrate conductivity through $\sim 2.75 \mathrm{hr}$. The concentrate conductivity then exceeded the permeate conductivity from $\sim 2.75 \mathrm{hr}$. through the end of the experiment. Distinct step-wise changes in permeate and concentrate $\mathrm{pH}$ and conductivity were not observed as applied pressure was increased.

The membrane was cleaned using the standardized cleaning procedure discussed in Chapter 3. No oil was visible on the membrane surface after cleaning. The $\mathrm{pH}$ and conductivity of the distilled water used to determine the membrane resistance after cleaning were 6.93 and $3.83 \mu \mathrm{S} / \mathrm{cm}$, respectively. A plot of the average permeate flux versus average transmembrane pressure for the 30\% MW Fluid-1,750 rpm clean water 
flux experiment is presented in Figure (4.49). The resistance of the membrane was $2.42 \times 10^{12} \mathrm{~m}^{-1}$.

\section{$30 \%$ MW Fluid-1,450 rpm}

Permeate flux versus time for the 30\% MW Fluid-1,450 rpm experiment is presented in Figure (4.50). The system was operated over an applied pressure range of 25 to 70 psig. The average permeate backpressure was 7.6 psi for a membrane rotational speed of 1,450 rpm. At the 35 psig applied pressure condition, permeate flux decreased from an initial maximum value of $100 \mathrm{gal} / \mathrm{ft}^{2}-\mathrm{d}$ to $88 \mathrm{gal} / \mathrm{ft}^{2}-\mathrm{d}$. Permeate flux was stable at each other applied pressure condition. The permeate flux was $36 \mathrm{gal} / \mathrm{ft}^{2}-\mathrm{d}$ when the 25 psig applied pressure condition was re-investigated after the limiting permeate flux was determined. The initial permeate flux at the initial $25 \mathrm{psig}$ condition was $75 \mathrm{gal} / \mathrm{ft}^{2}-\mathrm{d}$. The average permeate flux versus average transmembrane pressure for the $30 \% \mathrm{MW}$ Fluid-1,450 rpm experiment is presented in Figure (4.51). A limiting flux of $83 \mathrm{gal} / \mathrm{ft}^{2}-\mathrm{d}$ was observed at the 35 to 70 psig applied pressure conditions. The slope of the linear regression fitted to the pressure-controlled data from 0 to 25 psig was $4.310 \mathrm{gal} / \mathrm{ft}^{2}-\mathrm{d}-\mathrm{psi}$. The total resistance to hydraulic flow in the pressure-controlled region was $5.46 \times 10^{12} \mathrm{~m}^{-1}$. The permeate $\mathrm{pH}$ ranged from 6.11 to 7.80 and averaged 6.48. The concentrate $\mathrm{pH}$ ranged from 5.91 to 7.15 and averaged 6.30 The $\mathrm{pH}$ probe broke at $\sim 4 \mathrm{hr}$. Consequently, $\mathrm{pH}$ measurements were not made from $\sim 4 \mathrm{hr}$. through the end of this 


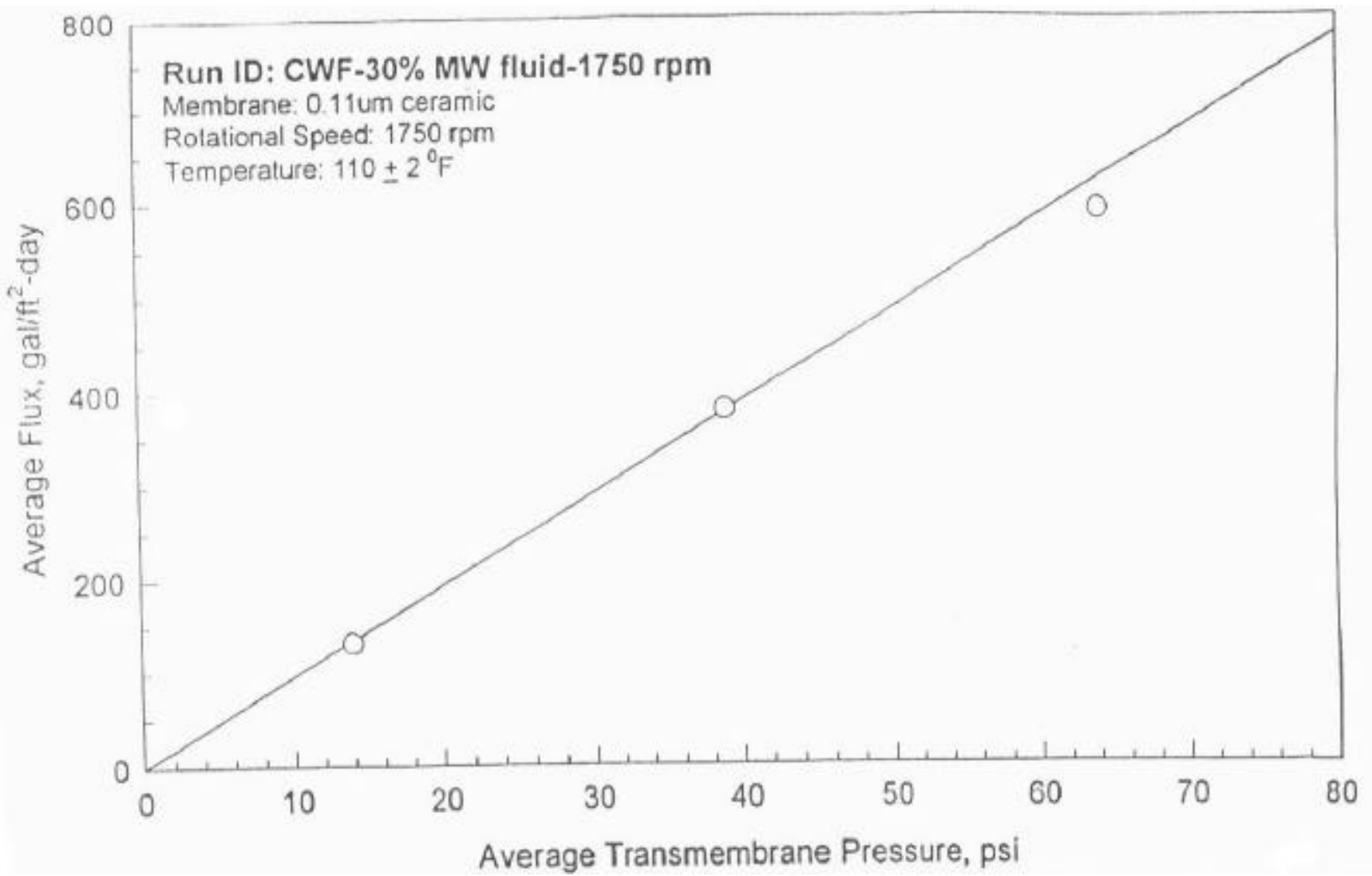

Figure (4.49) - Average Permeate Flux Versus Average Transmembrane Pressure for the 30\%-1,750 rpm Clean Water Flux Experiment 


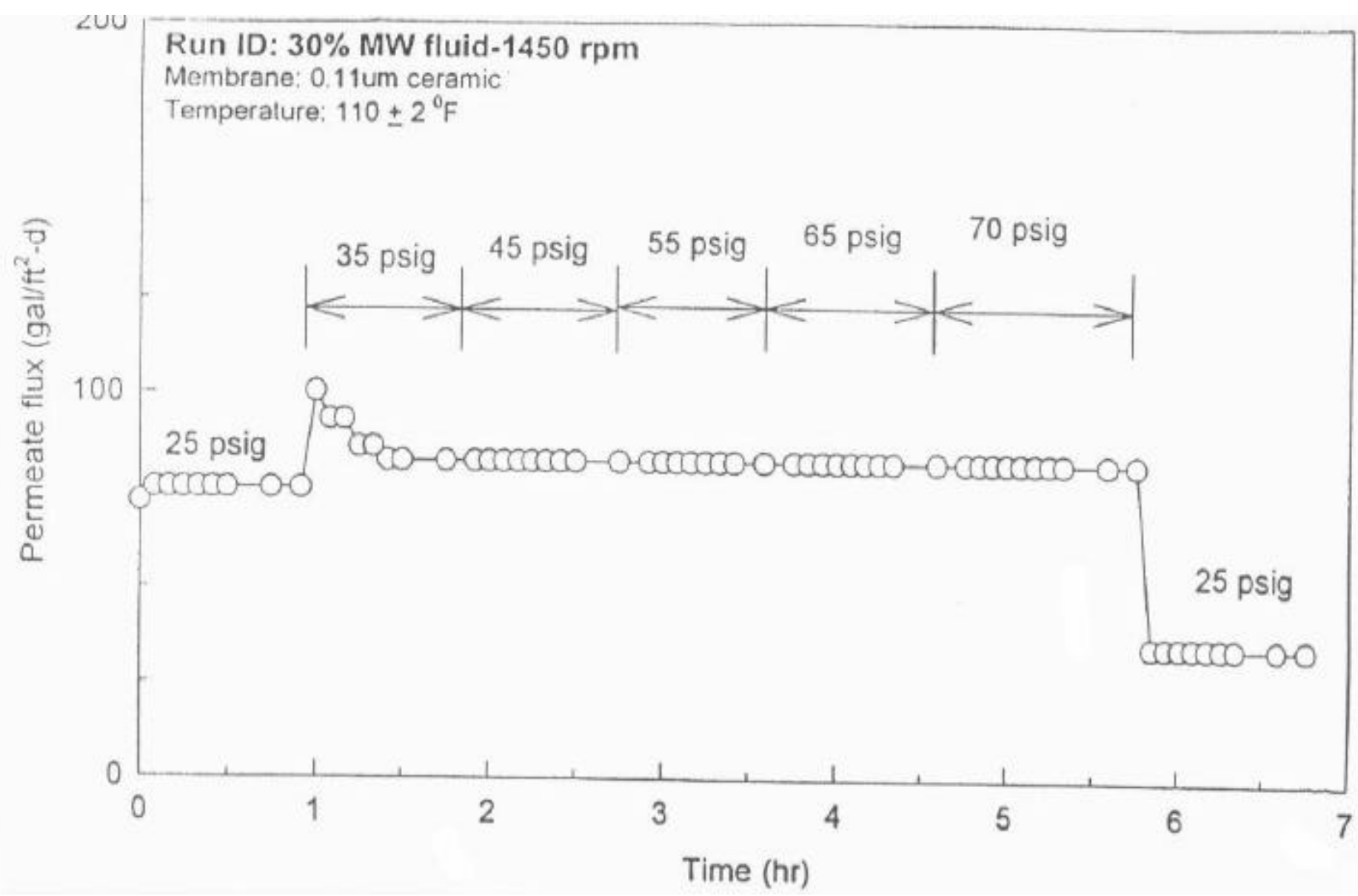

Figure (4.50) - Permeate Flux Versus Time for the 30\%-1,450 rpm Experiment 


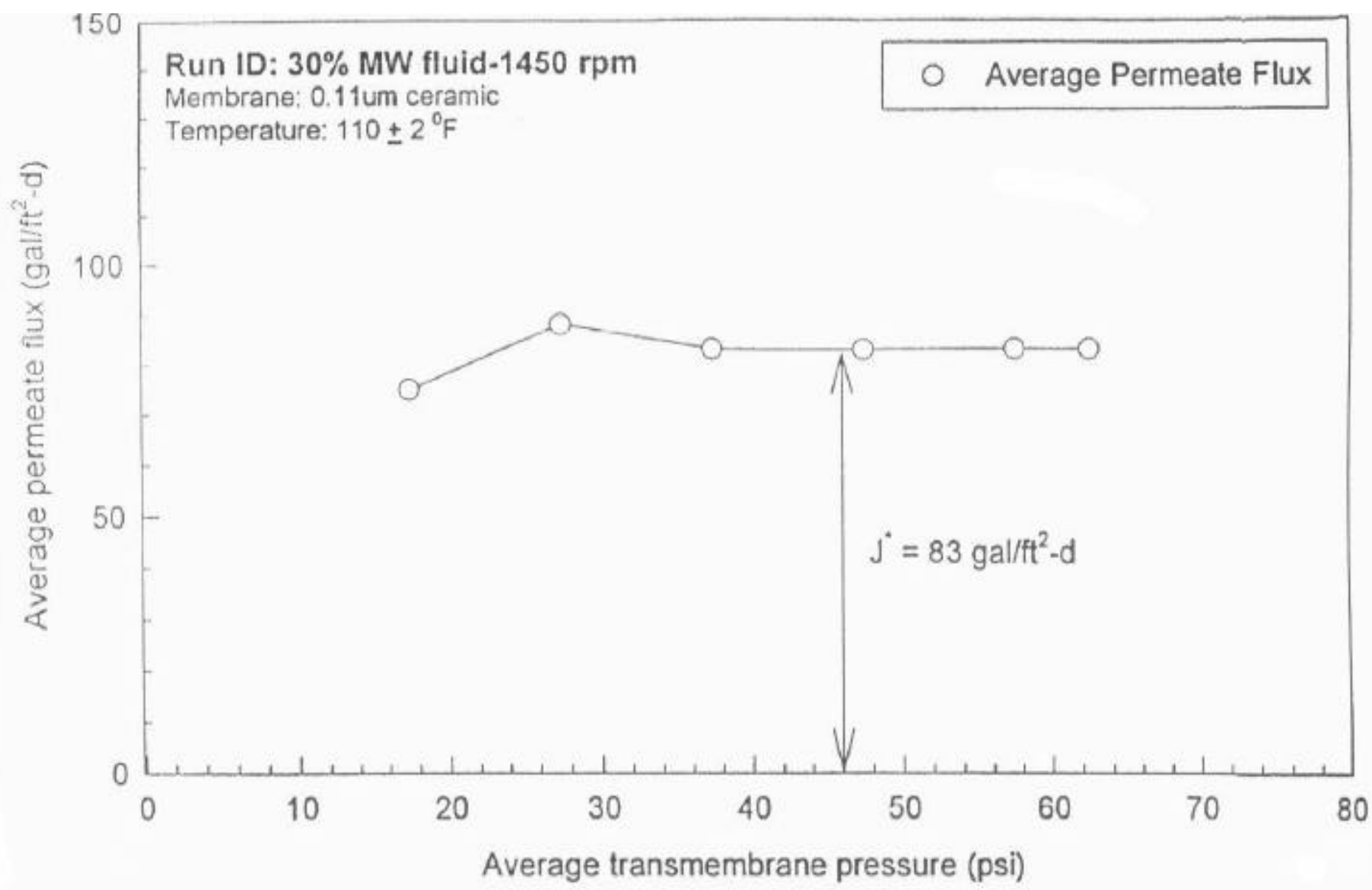

Figure (4.51) - Average Permeate Flux Versus Average Transmembrane Pressure for the 30\%-1,450 rpm Experiment 
experiment. Permeate $\mathrm{pH}$ was greater than the concentrate $\mathrm{pH}$ from 0 to $\sim 4 \mathrm{hr}$. Permeate and concentrate $\mathrm{pH}$ decreased through $\sim 1 \mathrm{hr}$. then were both constant at $\sim 6.20$ through $\sim 4$ hr. The permeate conductivity ranged from 815 to $1001 \mu \mathrm{S} / \mathrm{cm}$ and averaged $945 \mu \mathrm{S} / \mathrm{cm}$. The concentrate conductivity ranged from 833 to $986 \mu \mathrm{S} / \mathrm{cm}$ and averaged $891 \mu \mathrm{S} / \mathrm{cm}$. A net decrease in permeate conductivity and a net increase in concentrate conductivity were observed in the $30 \%$ MW Fluid-1,450 rpm experiment. Permeate conductivity was greater than concentrate conductivity through $\sim 4.25 \mathrm{hr}$. The concentrate conductivity then exceeded the permeate conductivity from $\sim 4.25 \mathrm{hr}$. through the end of he experiment. Distinct step-wise changes in permeate and concentrate $\mathrm{pH}$ and conductivity were not observed as applied pressure was increased.

The membrane was cleaned using the standardized cleaning procedure discussed in Chapter 3. No oil was visible on the membrane surface after cleaning. The $\mathrm{pH}$ and conductivity of the distilled water used to determine the membrane resistance after cleaning were 6.76 and $2.00 \mu \mathrm{S} / \mathrm{cm}$, respectively. A plot of the average permeate flux versus average transmembrane pressure for the 30\% MW Fluid-1,450 rpm clean water flux experiment is presented in Figure (4.52). The resistance of the membrane was $1.76 \times 10^{12} \mathrm{~m}^{-1}$

\section{$30 \%$ MW Fluid-1,150 rpm}

Permeate flux versus time for the 30\% MW Fluid-1,150 rpm experiment is presented in Figure (4.53). Permeate flux was stable at each applied pressure condition. 


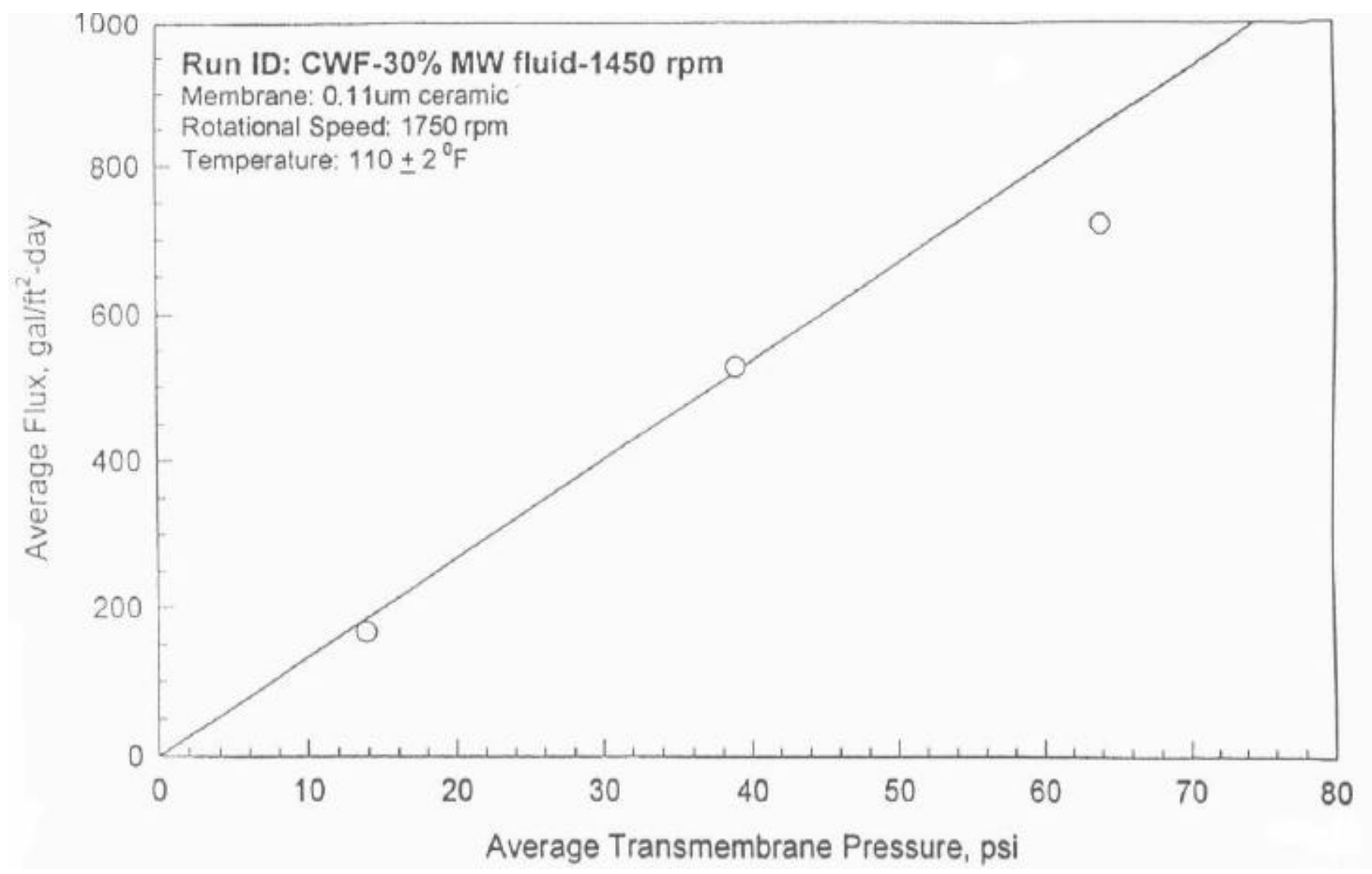

Figure (4.52) - Average Permeate Flux Versus Average Transmembrane Pressure for the 30\%-1,450 rpm Clean Water Flux Experiment 


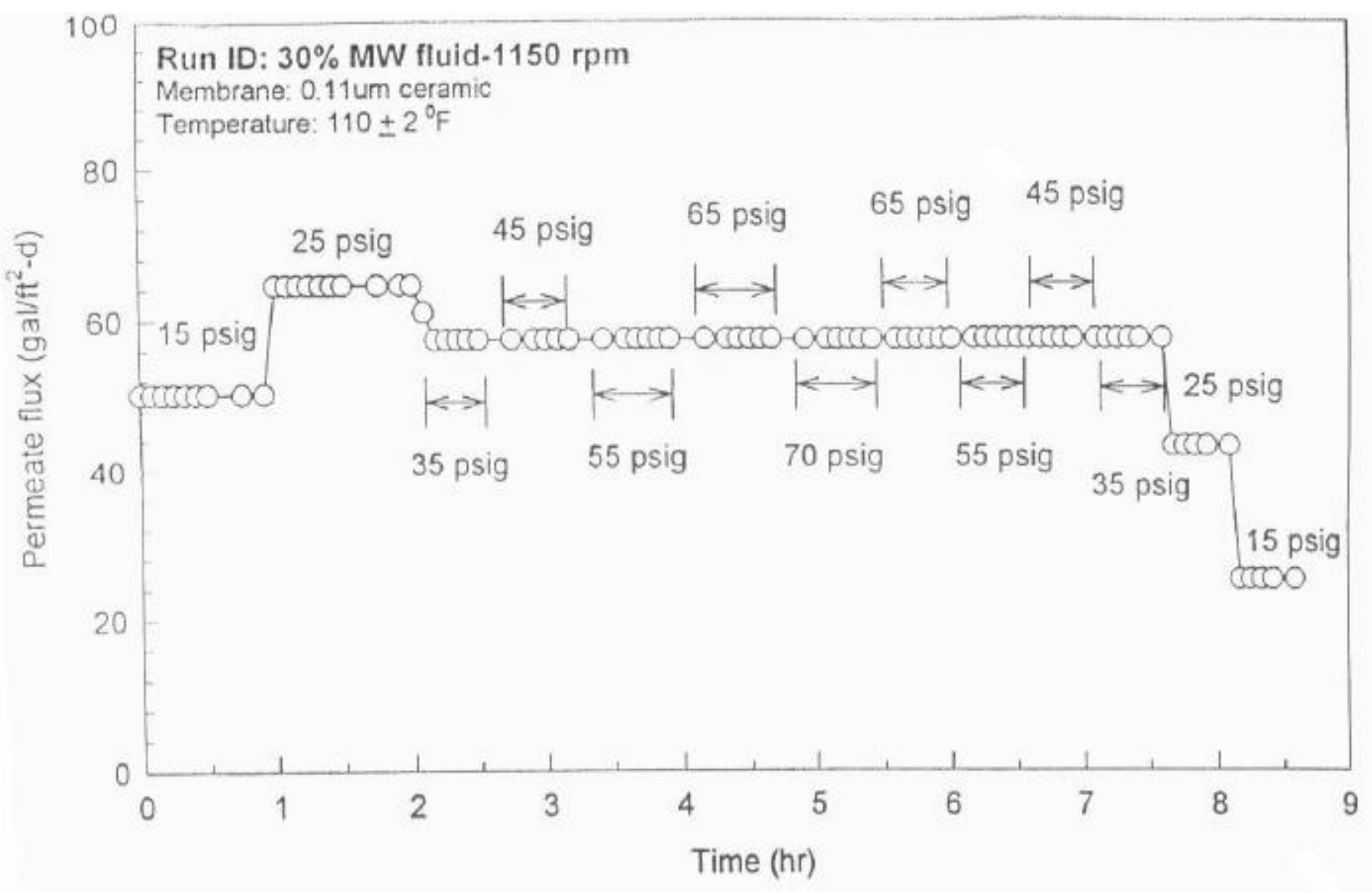

Figure (4.53) - Permeate Flux Versus Time for the 30\%-1,150 rpm Experiment 
The system was operated over an increasing applied pressure range of 15 to $70 \mathrm{psig}$. The applied pressure was then decreased to its initial value of $15 \mathrm{psig}$. The average permeate backpressure was 4.8 psi for a membrane rotational speed of $1,150 \mathrm{rpm}$. The permeate flux at each applied pressure was constant. The average permeate flux versus average transmembrane pressure time for the $30 \%$ MW Fluid-1,150 rpm experiment is presented in Figure (4.54). A limiting flux of $57 \mathrm{gal} / \mathrm{ft}^{2}-\mathrm{d}$ was observed at the 45 to $70 \mathrm{psig}$ applied pressure conditions. The average permeate flux at the $25 \mathrm{psig}$ applied pressure was 65 $\mathrm{gal} / \mathrm{ft}^{2}-\mathrm{d}$. This value was greater than the limiting permeate flux of $57 \mathrm{gal} / \mathrm{ft}^{2}-\mathrm{d}$. When the applied pressure was decreased, the permeate flux in the mass transfer-controlled region was constant at $57 \mathrm{gal} / \mathrm{ft}^{2}-\mathrm{d}$. However, the permeate fluxes in the pressurecontrolled region (at 15 and $25 \mathrm{psig}$ ) were less than values observed as the applied pressure was increased. It is hypothesized that either the membrane pores had been plugged at the higher applied pressure conditions or that the solute boundary layer had become stable and the turbulence induced by membrane rotation was not sufficient to reduce the solute boundary layer thickness. This resulted in a lower permeate flux as the applied pressure was decreased relative to values observed when the applied pressure was increased. The slope of the regression line fitted to the pressure-controlled data from 0 to 15 psig was $4.902 \mathrm{gal} / \mathrm{ft}^{2}$-d-psi. The total resistance to hydraulic flow in the pressurecontrolled region was $4.80 \times 10^{12} \mathrm{~m}^{-1}$. 


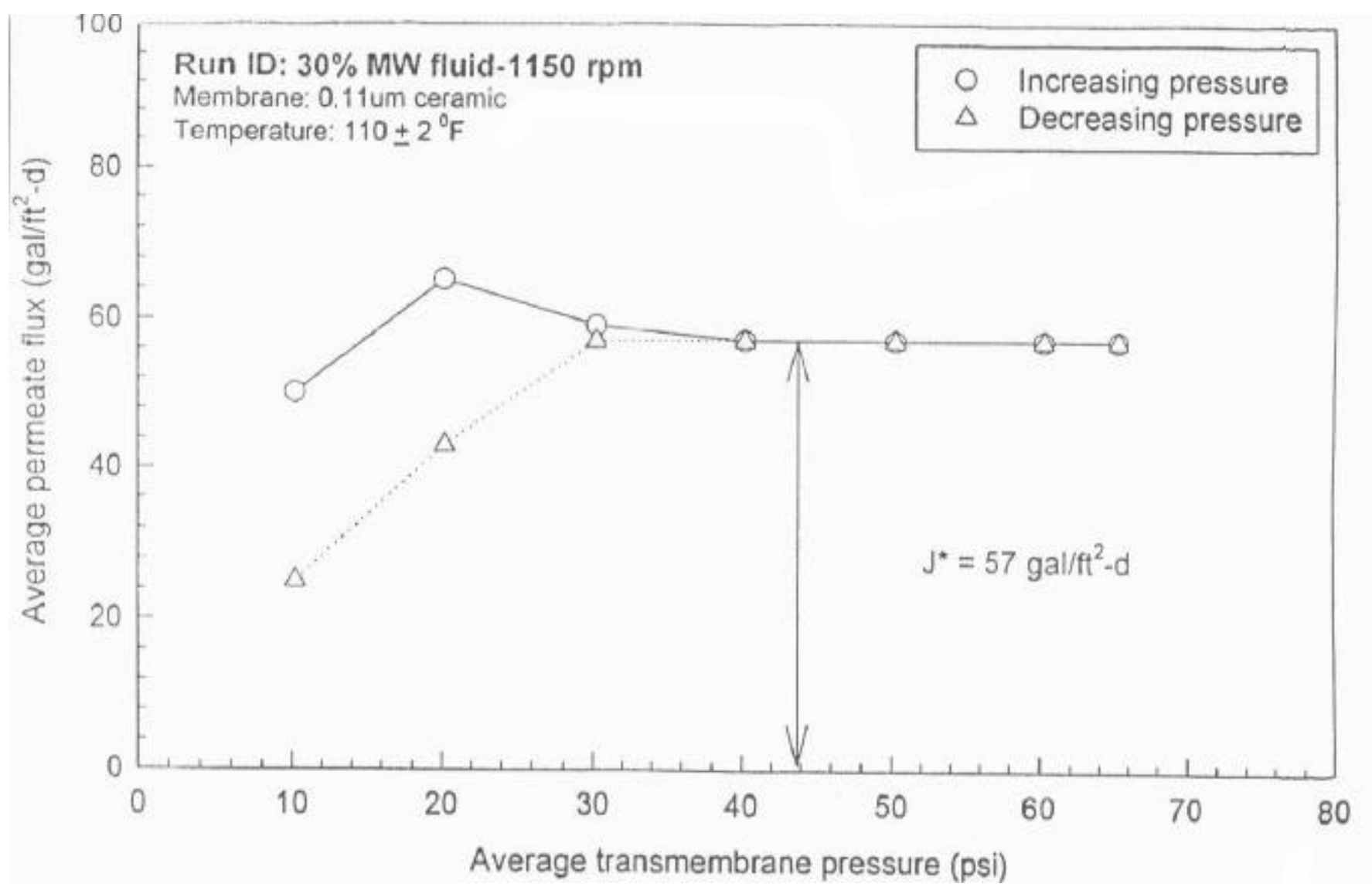

Figure (4.54) - Average Permeate Flux Versus Average Transmembrane Pressure for the 30\%-1,150 rpm Experiment 
The permeate $\mathrm{pH}$ ranged from 7.64 to 7.85 and averaged 7.76. Permeate and concentrate $\mathrm{pH}$ were not measured through the first $3.5 \mathrm{hr}$. due to operational problems with the $\mathrm{pH}$ probe. A $\mathrm{pH}$ meter and probe were borrowed from another laboratory and $\mathrm{pH}$ was measured from $3.5 \mathrm{hr}$. thorough the end of the experiment. The concentrate $\mathrm{pH}$ ranged from 7.41 to 7.69 and averaged 7.51. Permeate $\mathrm{pH}$ was greater than the concentrate $\mathrm{pH}$ throughout the $30 \% \mathrm{MW}$ Fluid-1,150 rpm experiment. Both permeate and concentrate $\mathrm{pH}$ remained constant from 3.5 through the end of the experiment. The permeate conductivity ranged from 755 to $1101 \mu \mathrm{S} / \mathrm{cm}$ and averaged $863 \mu \mathrm{S} / \mathrm{cm}$. The concentrate conductivity ranged from 812 to $961 \mu \mathrm{S} / \mathrm{cm}$ and averaged $871 \mu \mathrm{S} / \mathrm{cm}$. A net decrease in permeate conductivity was observed. Concentrate conductivity was constant in this experiment. Permeate conductivity was greater than concentrate conductivity through $\sim 2.5$ to $3 \mathrm{hr}$. The concentrate conductivity then exceeded the permeate conductivity from $3 \mathrm{hr}$. through the end of the experiment. Distinct step-wise changes in permeate and concentrate $\mathrm{pH}$ and conductivity were not observed as applied pressure was increased.

The membrane was cleaned using the standardized cleaning procedure discussed in Chapter 3. No oil was visible on the membrane surface after cleaning. The $\mathrm{pH}$ and conductivity of the distilled water used to determine the membrane resistance after cleaning were 6.69 and $3.04 \mu \mathrm{S} / \mathrm{cm}$, respectively. A plot of the average permeate flux versus average transmembrane pressure time for the $30 \%$ MW Fluid-1,150 clean water flux experiment is presented in Figure (4.55). The resistance of the membrane was $3.06 \times 10^{12} \mathrm{~m}^{-1}$. 


\section{0\% MW Fluid-1,750 rpm}

Permeate flux versus time for the $40 \%$ MW Fluid-1,750 rpm experiment is presented in Figure (4.56). Permeate flux was stable at each applied pressure condition. The system was operated over an applied pressure range of 25 to 70 psig. The average permeate backpressure was 11.1 psi for a membrane rotational speed of $1,750 \mathrm{rpm}$. The permeate flux was $25 \mathrm{gal} / \mathrm{ft}^{2}-\mathrm{d}$ when the $25 \mathrm{psig}$ applied pressure condition was reinvestigated after the limiting permeate flux was determined. The permeate flux at the initial $25 \mathrm{psig}$ condition was also $25 \mathrm{gal} / \mathrm{ft}^{2}-\mathrm{d}$. It is hypothesized that the solute boundary layer returned to its initial thickness when the applied pressure was decreased to 25 psig and that solute molecules were not forced into the membrane pores and were not adsorbed onto the membrane surface. The average permeate flux versus average transmembrane pressure for the $40 \%$ MW Fluid-1,750 rpm experiment is presented in Figure (4.57). A limiting flux of $36 \mathrm{gal} / \mathrm{ft}^{2}-\mathrm{d}$ was observed at the 35 to $70 \mathrm{psig}$ applied pressure conditions. The slope of the regression line fitted to the pressure-controlled data from 0 to $25 \mathrm{psig}$ was $1.799 \mathrm{gal} / \mathrm{ft}^{2}$-d-psi. The total resistance to hydraulic flow in the pressure-controlled region was $1.31 \times 10^{13} \mathrm{~m}^{-1}$.

The permeate $\mathrm{pH}$ ranged from 7.33 to 7.68 and averaged 7.45 . The concentrate $\mathrm{pH}$ ranged from 7.17 to 7.39 and averaged 7.24. Permeate $\mathrm{pH}$ was greater than the concentrate $\mathrm{pH}$ throughout the $40 \%$ MW Fluid-1,750 rpm experiment. Permeate and concentrate $\mathrm{pH}$ followed the same trend in this experiment: $\mathrm{pH}$ decreased through 0.75 


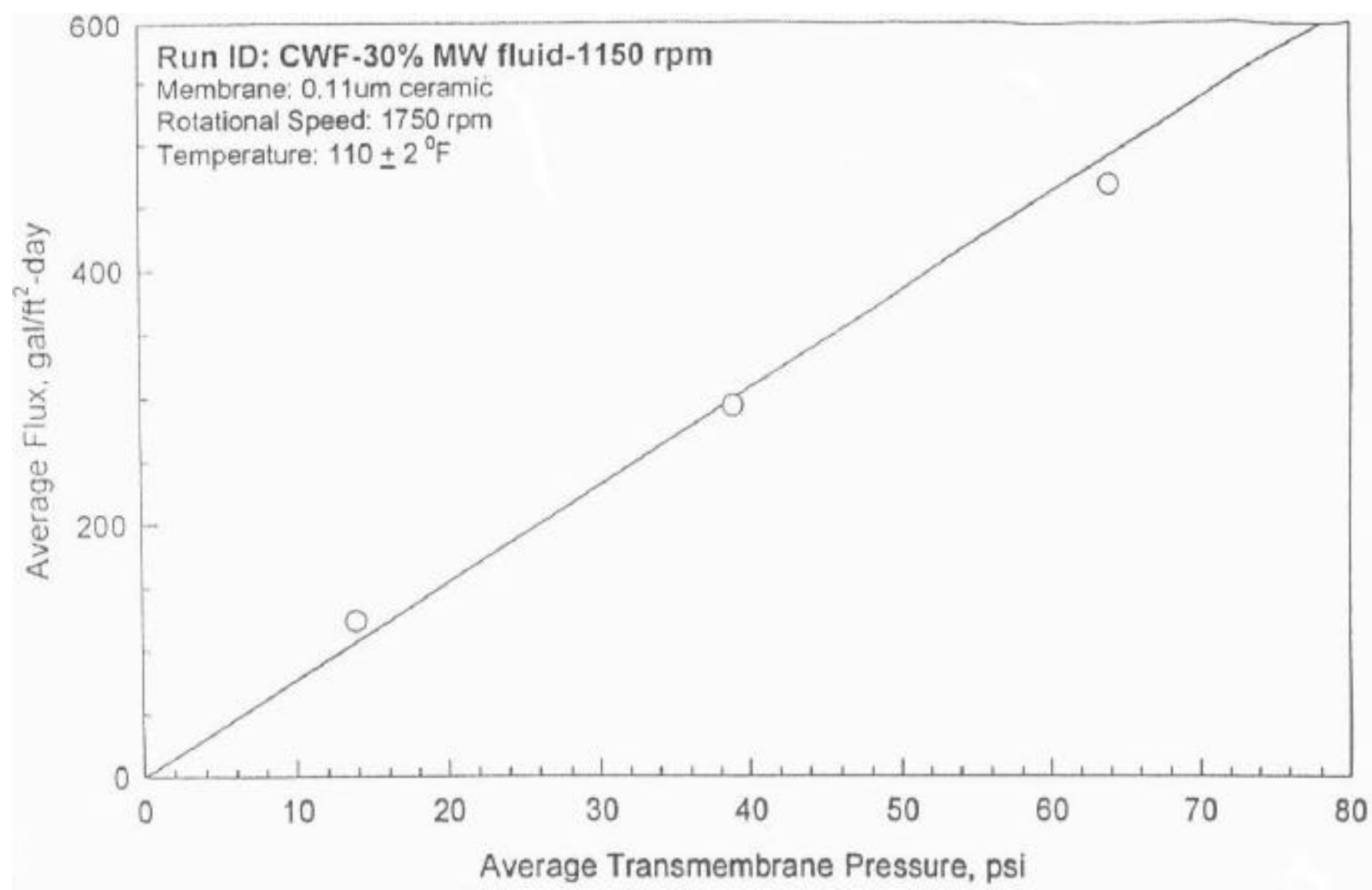

Figure (4.55) - Average Permeate Flux Versus Average Transmembrane Pressure for the 30\%-1,150 rpm Clean Water Experiment 


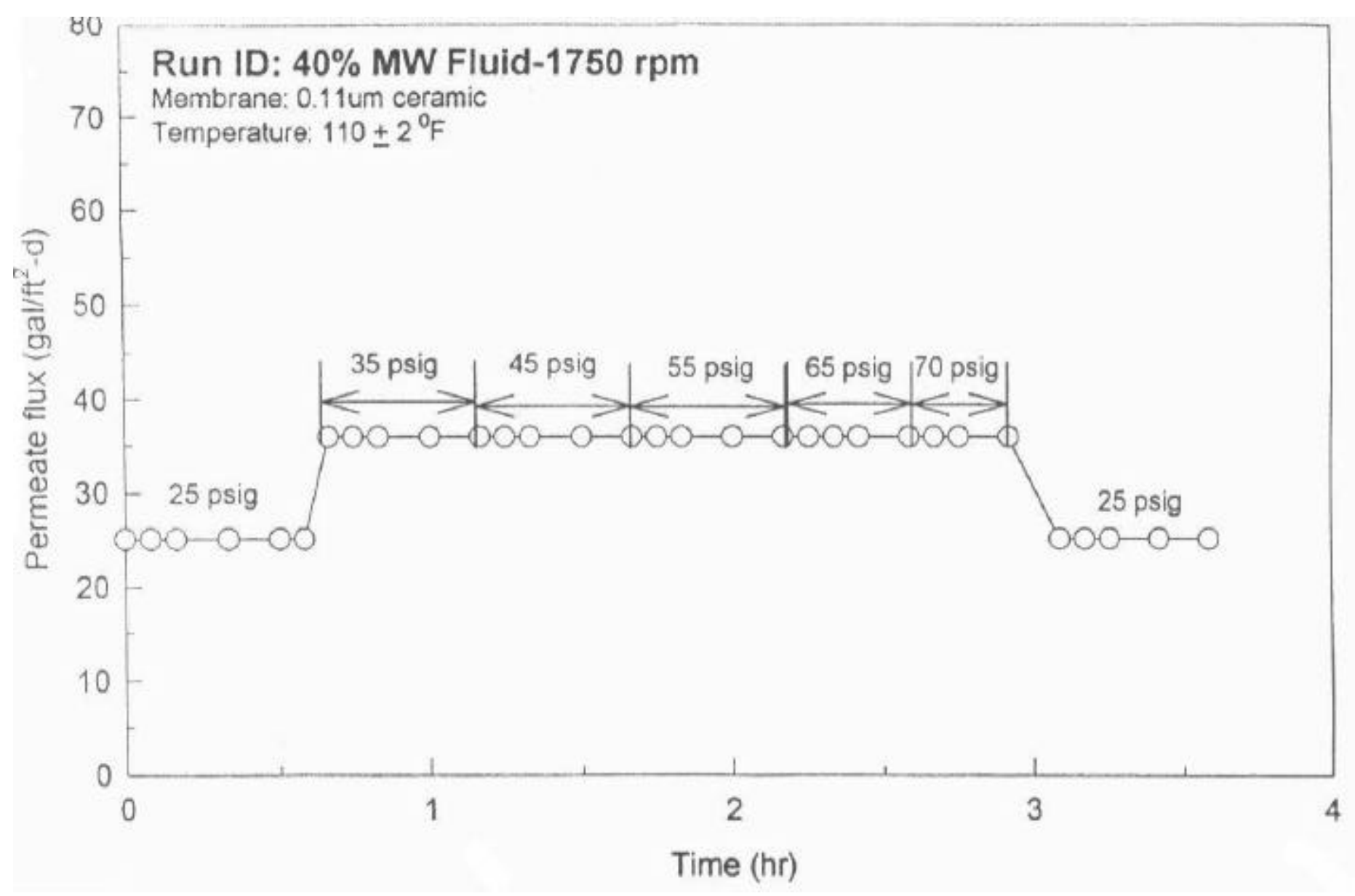

Figure (4.56) - Permeate Flux Versus Time for the 40\%-1,750 rpm Experiment 


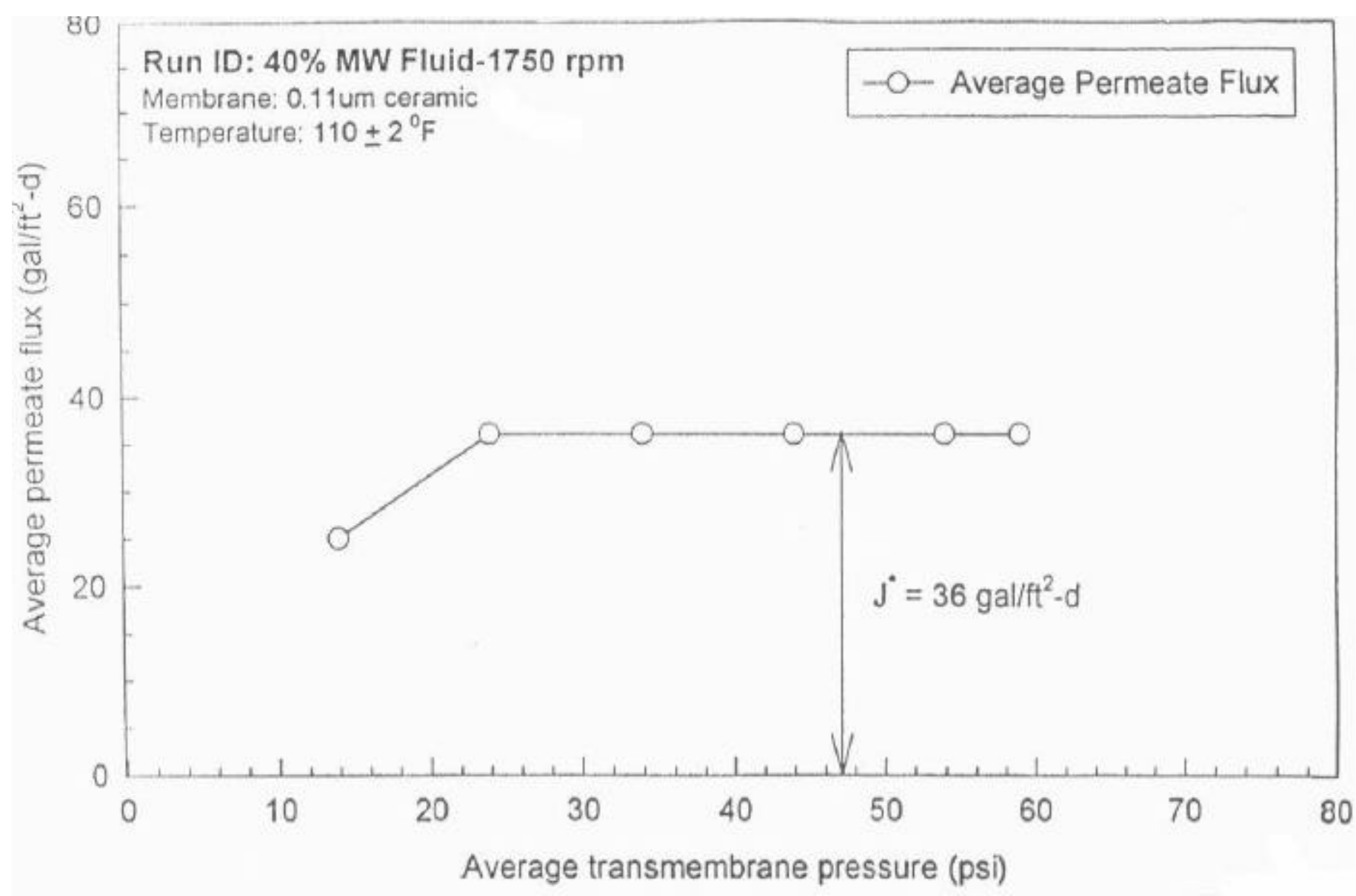

Figure (4.57) - Average Permeate Flux Versus Average Transmembrane Pressure for the 40\%-1,750 rpm Experiment 
hr., increased through $1.25 \mathrm{hr}$., decreased through $1.75 \mathrm{hr}$., and then remained constant. The permeate conductivity ranged from 1058 to $1340 \mu \mathrm{S} / \mathrm{cm}$ and averaged $1174 \mu \mathrm{S} / \mathrm{cm}$. The concentrate conductivity ranged from 1003 to $1267 \mu \mathrm{S} / \mathrm{cm}$ and averaged 1,150 $\mu \mathrm{S} / \mathrm{cm}$. A net decrease in permeate conductivity was observed. The concentrate conductivity was constant. Permeate conductivity was greater than concentrate conductivity through $\sim 1.5 \mathrm{hr}$. The concentrate conductivity then generally exceeded the permeate conductivity from $\sim 1.5 \mathrm{hr}$. through the end of the experiment. Distinct stepwise changes in permeate and concentrate $\mathrm{pH}$ and conductivity were not observed as applied pressure was increased.

The membrane was cleaned using the standardized cleaning procedure discussed in Chapter 3. No oil was visible on the membrane surface after cleaning. The $\mathrm{pH}$ and conductivity of the distilled water used to determine the membrane resistance after cleaning were 6.80 and $2.84 \mu \mathrm{S} / \mathrm{cm}$, respectively. A plot of the average permeate flux versus average transmembrane pressure for the $40 \%$ MW Fluid-1,750 rpm clean water flux experiment is presented in Figure (4.58). The resistance of the membrane was $1.57 \times 10^{12} \mathrm{~m}^{-1}$.

\section{0\% MW Fluid-1,450 rpm}

Permeate flux versus time for the $40 \%$ MW Fluid-1,450 rpm experiment is presented in Figure (4.59). Permeate flux was stable at each applied pressure condition. The system was operated over an applied pressure range of 20 to 70 psig. The average permeate backpressure was $7.6 \mathrm{psi}$ for a membrane rotational speed of 1,450 rpm. The 


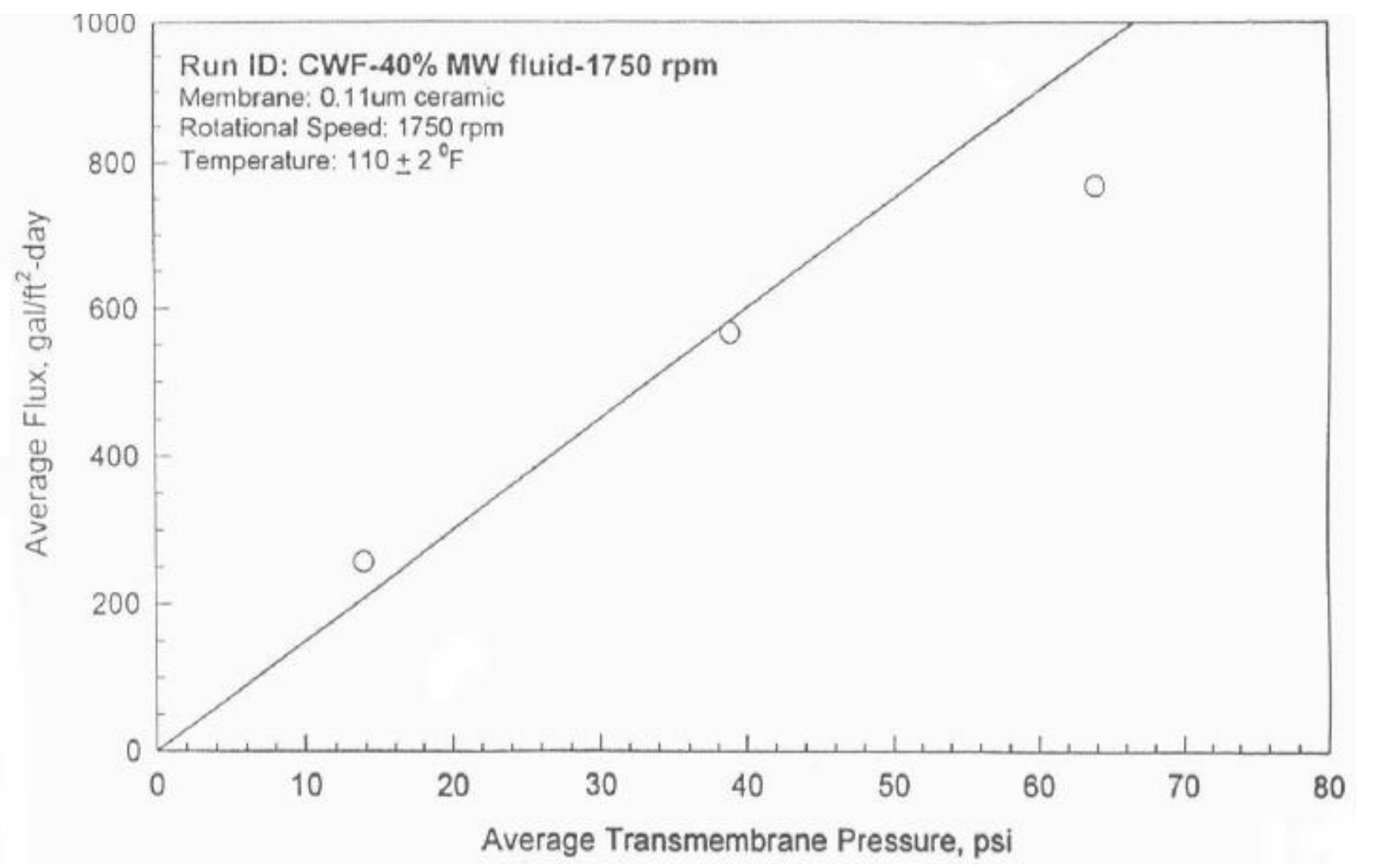

Figure (4.58) - Average Permeate Flux Versus Average Transmembrane Pressure for the 40\%-1,750 rpm Clean Water Flux Experiment 


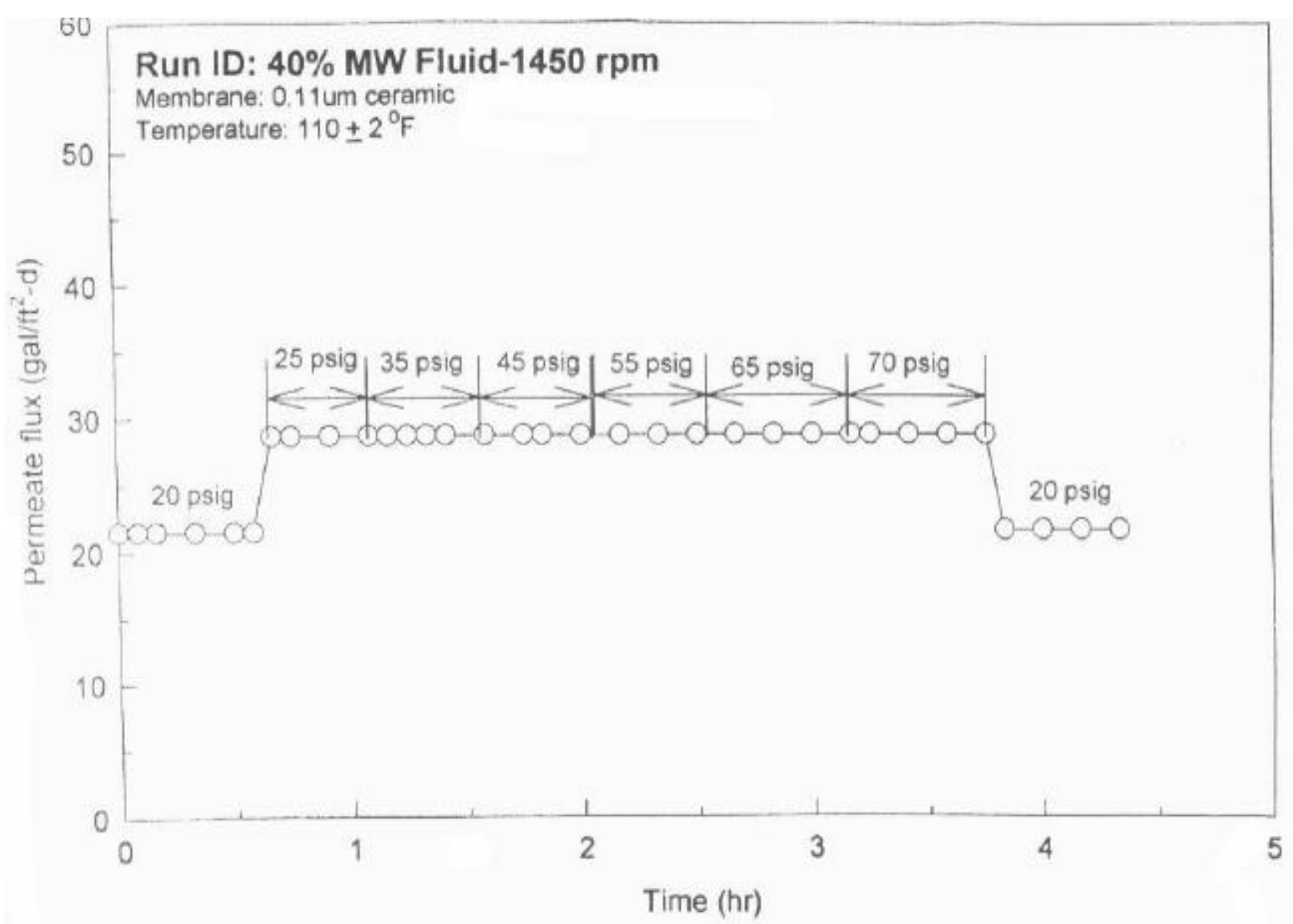

Figure (4.59) - Permeate Flux Versus Time for the 40\%-1,450 rpm Experiment 
permeate flux was $22 \mathrm{gal} / \mathrm{ft}^{2}-\mathrm{d}$ when the $20 \mathrm{psig}$ applied pressure condition was reinvestigated after the limiting permeate flux was determined. The permeate flux at the initial $20 \mathrm{psig}$ condition was also $22 \mathrm{gal} / \mathrm{ft}^{2}-\mathrm{d}$. The average permeate flux versus average transmembrane pressure for the $40 \%$ MW Fluid-1,450 rpm experiment is presented in Figure (4.60). A limiting flux of $29 \mathrm{gal} / \mathrm{ft}^{2}-\mathrm{d}$ was observed at the 25 to $70 \mathrm{psig}$ applied pressure conditions. The slope of the regression line fitted to the pressure-controlled data from 0 to $20 \mathrm{psig}$ was $1.734 \mathrm{gal} / \mathrm{ft}^{2}$-d-psi. The total resistance to hydraulic flow in the pressure-controlled region was $1.36 \times 10^{13} \mathrm{~m}^{-1}$.

The permeate $\mathrm{pH}$ ranged from 6.74 to 7.10 and averaged 6.92. The concentrate $\mathrm{pH}$ ranged from 6.59 to 7.10 and averaged 6.94. Permeate and concentrate $\mathrm{pH}$ were not measured 0 to $\sim 1.75$ due to operational problems with the $\mathrm{pH}$ probe. $\mathrm{A} \mathrm{pH}$ meter and probe were borrowed from another laboratory and $\mathrm{pH}$ was measured from $\sim 1.75 \mathrm{hr}$. thorough the end of the experiment. Permeate and concentrate $\mathrm{pH}$ values were approximately equal and a net increase in both permeate and concentrate $\mathrm{pH}$ was observed. The permeate conductivity ranged from 1061 to $1333 \mu \mathrm{S} / \mathrm{cm}$ and averaged $1184 \mu \mathrm{S} / \mathrm{cm}$. The concentrate conductivity ranged from 1069 to $1243 \mu \mathrm{S} / \mathrm{cm}$ and averaged $1149 \mu \mathrm{S} / \mathrm{cm}$. A net decrease in both permeate and concentrate conductivity was observed in the $40 \%$ MW Fluid-1,450 rpm experiment. Permeate conductivity was greater than concentrate conductivity through $\sim 1.5 \mathrm{hr}$. then both permeate and concentrate conductivities converged at a constant value of $\sim 1070 \mu \mathrm{S} / \mathrm{cm}$. Distinct step- 


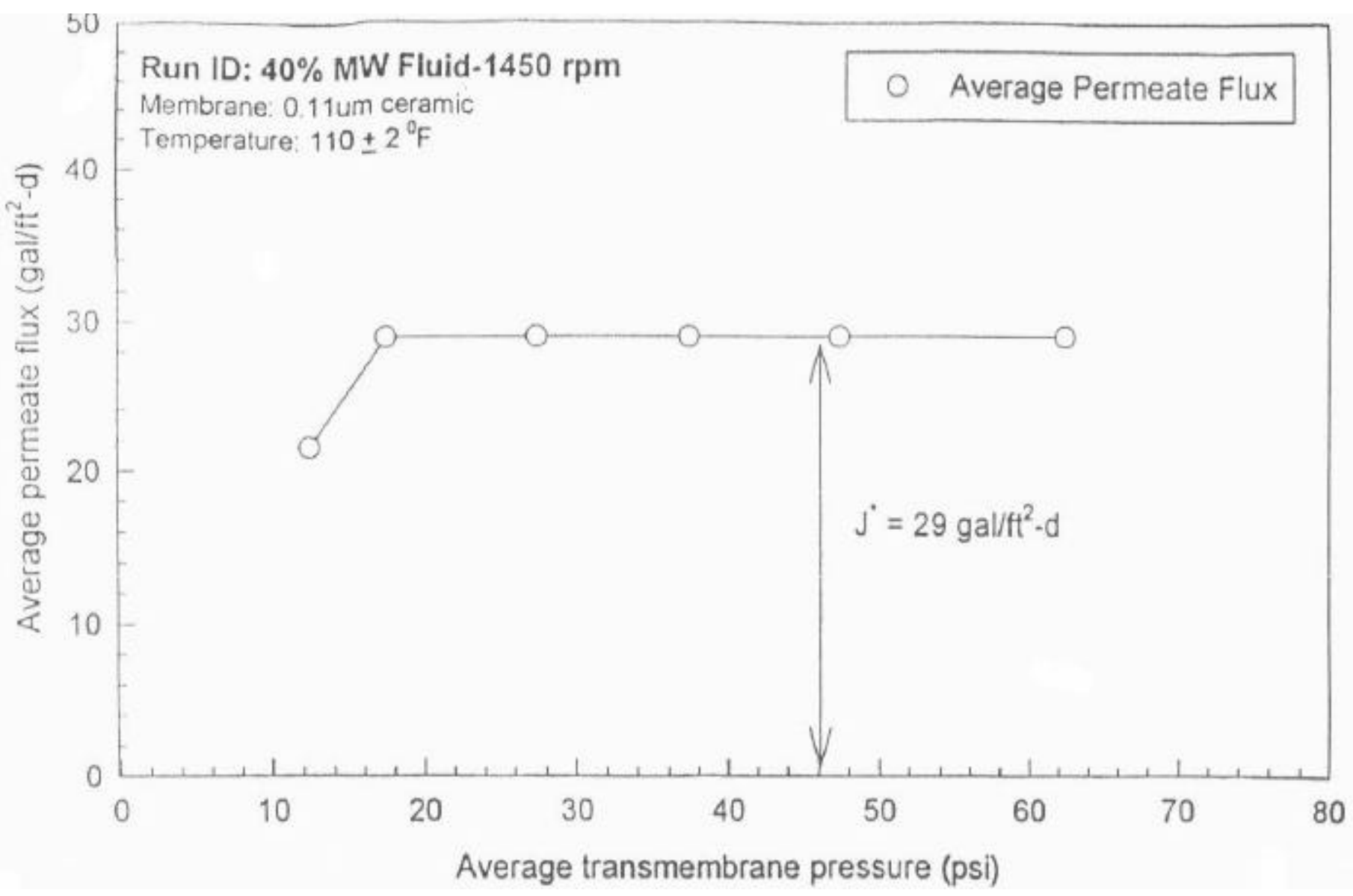

Figure (4.60) - Average Permeate Flux Versus Average Transmembrane Pressure for the 40\%-1,450 rpm Experiment 
wise changes in permeate and concentrate $\mathrm{pH}$ and conductivity were not observed as applied pressure was increased.

The membrane was cleaned using the standardized cleaning procedure discussed in Chapter 3. No oil was visible on the membrane surface after cleaning. The $\mathrm{pH}$ and conductivity of the distilled water used to determine the membrane resistance after cleaning were 7.12 and $1.64 \mu \mathrm{S} / \mathrm{cm}$, respectively. A plot of the average permeate flux versus average transmembrane pressure for the 40\% MW Fluid-1,450 rpm clean water flux experiment is presented in Figure (4.61). The resistance of the membrane was $1.99 \times 10^{12} \mathrm{~m}^{-1}$

\section{0\% MW Fluid-1,150 rpm}

Permeate flux versus time for the $40 \%$ MW Fluid-1,150 rpm experiment is presented in Figure (4.62). Permeate flux was stable at each applied pressure condition. The system was operated over an applied pressure range of 15 to 70 psig. The average permeate backpressure was 4.8 psi for a membrane rotational speed of $1,150 \mathrm{rpm}$. The permeate flux was $14 \mathrm{gal} / \mathrm{ft}^{2}-\mathrm{d}$ when the $15 \mathrm{psig}$ applied pressure condition was reinvestigated after the limiting permeate flux was determined. The initial permeate flux at the initial $15 \mathrm{psig}$ condition was $18 \mathrm{gal} / \mathrm{ft}^{2}-\mathrm{d}$. The average permeate flux versus average transmembrane pressure for the $40 \%$ MW Fluid-1,150 rpm experiment is presented in Figure (4.63). A limiting flux of $22 \mathrm{gal} / \mathrm{ft}^{2}-\mathrm{d}$ was observed at the 20 to $70 \mathrm{psig}$ applied pressure conditions. The slope of the regression line fitted to the pressure-controlled data 


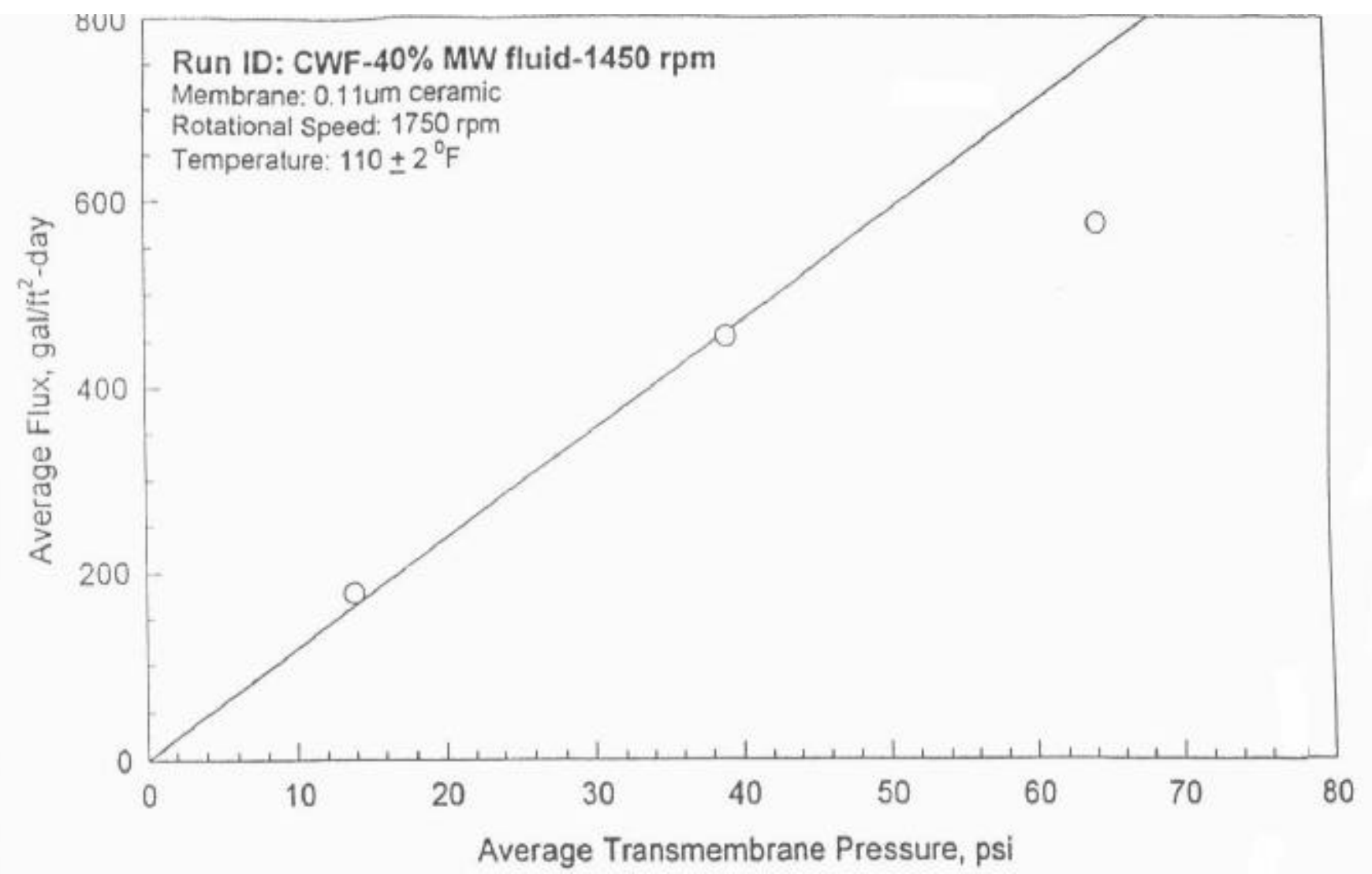

Figure (4.61) - Average Permeate Flux Versus Average Transmembrane Pressure for the 40\%-1,450 rpm Clean Water Flux Experiment 


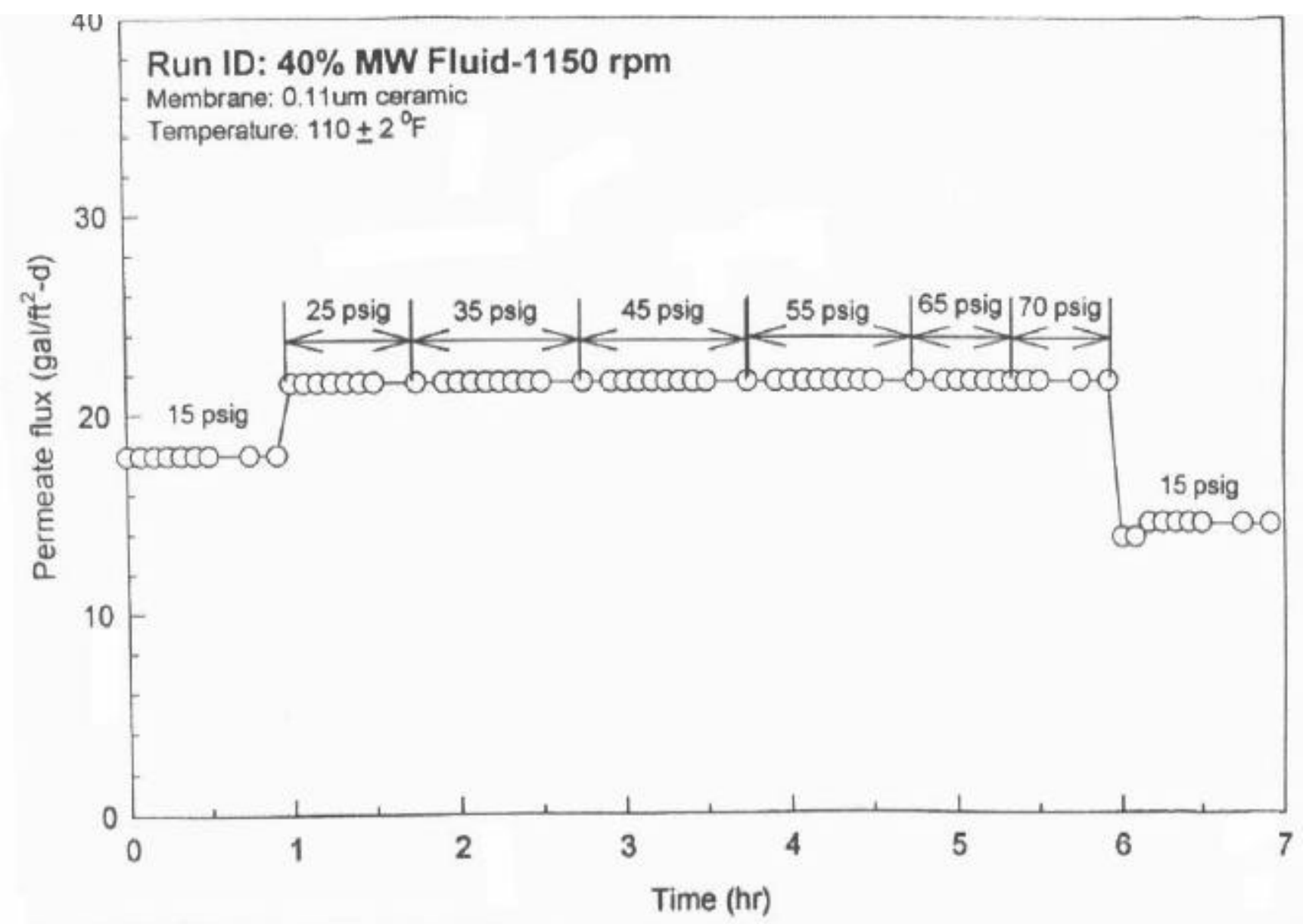

Figure (4.62) - Permeate Flux Versus Time for the 40\%-1,150 rpm Experiment 


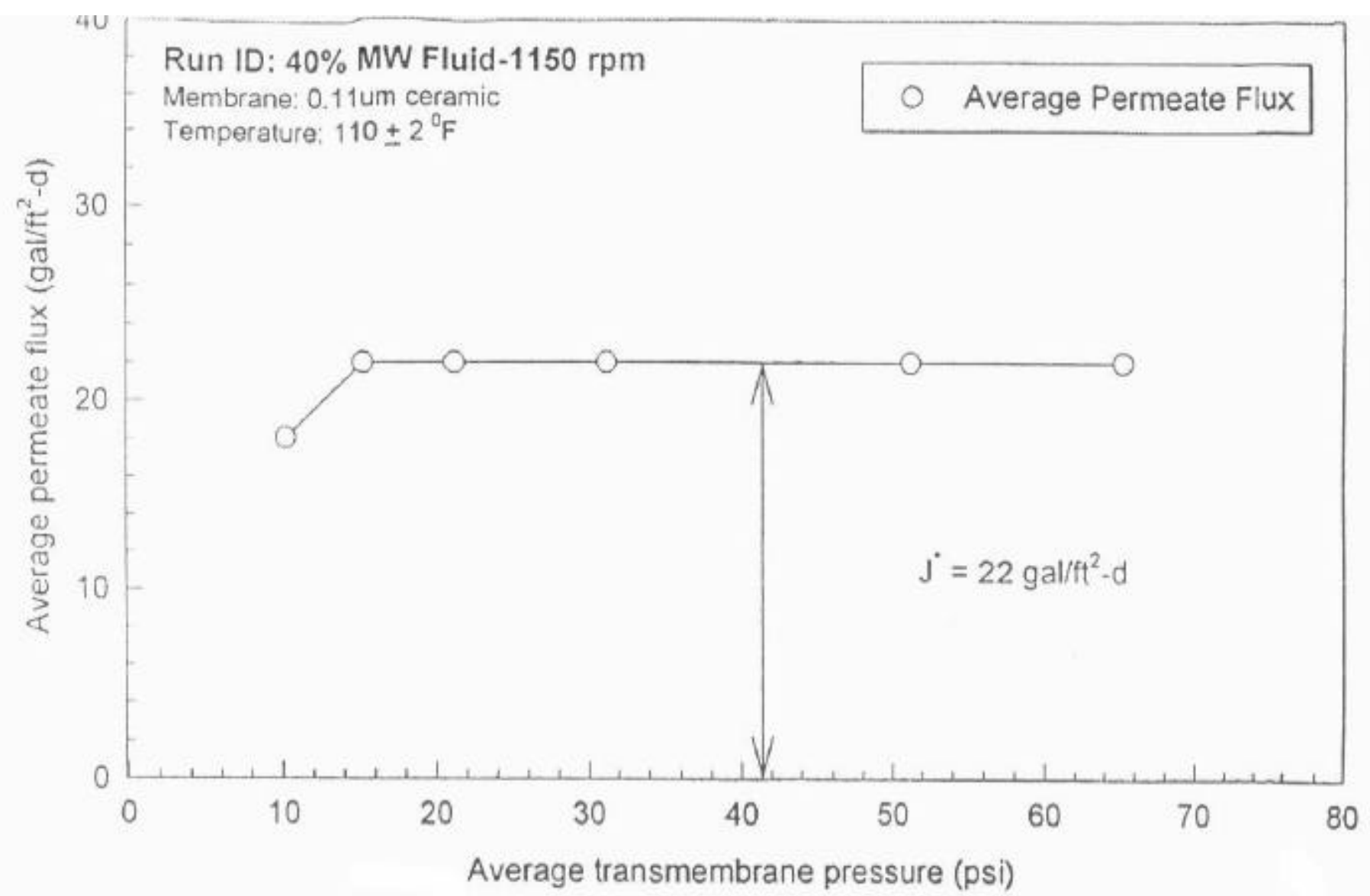

Figure (4.63) - Average Permeate Flux Versus Average Transmembrane Pressure for the 40\%-1,150 rpm Experiment 
from 0 to 15 psig was $1.765 \mathrm{gal} / \mathrm{ft}^{2}$-d-psi. The total resistance to hydraulic flow in the pressure-controlled region was $1.33 \times 10^{13} \mathrm{~m}^{-1}$.

The permeate $\mathrm{pH}$ ranged from 7.60 to 8.10 and averaged 7.73. The concentrate $\mathrm{pH}$ ranged from 7.48 to 7.73 and averaged 7.59. A net decrease in permeate $\mathrm{pH}$ was observed and concentrate $\mathrm{pH}$ remained constant. The permeate conductivity ranged from 348 to $471 \mu \mathrm{S} / \mathrm{cm}$ and averaged $404 \mu \mathrm{S} / \mathrm{cm}$. The concentrate conductivity ranged from 383 to $433 \mu \mathrm{S} / \mathrm{cm}$ and averaged $400 \mu \mathrm{S} / \mathrm{cm}$. A net decrease in permeate conductivity was observed. Concentrate conductivity was constant. Permeate conductivity was greater than concentrate conductivity through $\sim 2.5 \mathrm{hr}$. Concentrate conductivity then exceeded permeate conductivity from $\sim 2.5 \mathrm{hr}$. through the end of the experiment. Distinct stepwise changes in permeate and concentrate $\mathrm{pH}$ and conductivity were not observed as applied pressure was increased.

The membrane was cleaned using the standardized cleaning procedure discussed in Chapter 3. No oil was visible on the membrane surface after cleaning. The $\mathrm{pH}$ and conductivity of the distilled water used to determine the membrane resistance after cleaning were 6.73 and $4.14 \mu \mathrm{S} / \mathrm{cm}$, respectively. A plot of the average permeate flux versus average transmembrane pressure for the $40 \%$ MW Fluid-1,150 rpm for the clean water flux experiment is presented in Figure (4.64). The resistance of the membrane was $1.72 \times 10^{12} \mathrm{~m}^{-1}$ 


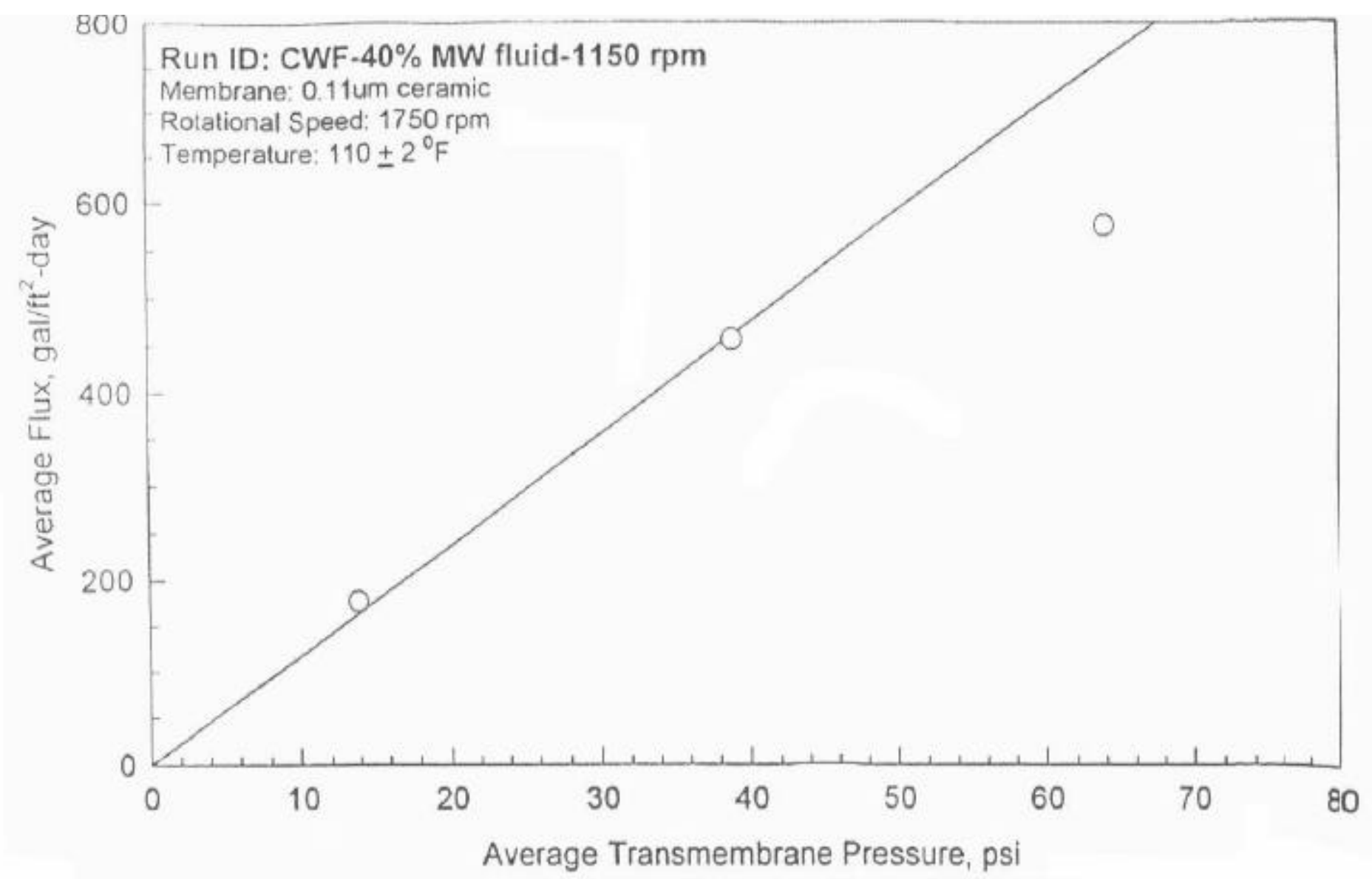

Figure (4.64) - Average Permeate Flux Versus Average Transmembrane Pressure for the 40\%-1,150 rpm Clean Water Experiment. 


\section{CHAPTER 5.0 DISCUSSION}

Average permeate flux versus average transmembrane pressure (calculated using Equation (2.31)) for the $10 \%-1,750 \mathrm{rpm} ; 10 \%-1,150 \mathrm{rpm}$; and $40 \%-1,750 \mathrm{rpm}$ experiments are presented in Figure (5.1). Data presented in Figure (5.1) are representative of the broad range of experimental results obtained in this study. In the 10\%-1,750 rpm experiment, flux increased linearly with pressure through $302 \mathrm{kPa}(43.8$ psi) then deviated from the linear relationship at higher pressures; however, a constant pressure-independent flux was not established over the pressure range investigated. In the 10\%-1,150 rpm experiment, distinct stepwise increases in permeate flux with pressure were evident at pressures less than $277 \mathrm{kPa}$ (40.2 psi). Permeate flux then diverged from the linear pressure-flux relationship at higher pressures and constant a pressureindependent permeate flux of $9.08 \mathrm{~m}^{3} / \mathrm{m}^{2}-\mathrm{d}\left(223 \mathrm{gal} / \mathrm{ft}^{2}-\mathrm{d}\right)$ was ascertained. In general, lower permeate flux was observed when $R_{j}$ was decreased as observed in the $10 \% \mathrm{MW}$ fluid experiments conducted at 1,750 and 1,150 rpm. In the 40\%-1,750 rpm experiment, a limiting permeate flux of $1.46 \mathrm{~m}^{3} / \mathrm{m}^{2}-\mathrm{d}\left(35.9 \mathrm{gal} / \mathrm{ft}^{2}-\mathrm{d}\right)$ was ascertained at average transmembrane pressures in excess of $165 \mathrm{kPa}(9.4 \mathrm{psi})$. When $\mathrm{O}_{\mathrm{k}}$ was increased, lower permeate flux was observed at each $\mathrm{P}_{\mathrm{i}}$, as presented in Figure (5.1) for the 10 and $40 \%$ MW fluid experiments conducted at $1,750 \mathrm{rpm}$. Additionally, the transition from pressure-dependent to pressure-independent permeate flux conditions tended to prevail at lower pressures as $R_{j}$ was decreased and $\mathrm{O}_{k}$ was increased. Based upon the observations of data presented in Figure (5.1), it was hypothesized that the resistance to hydraulic flow 


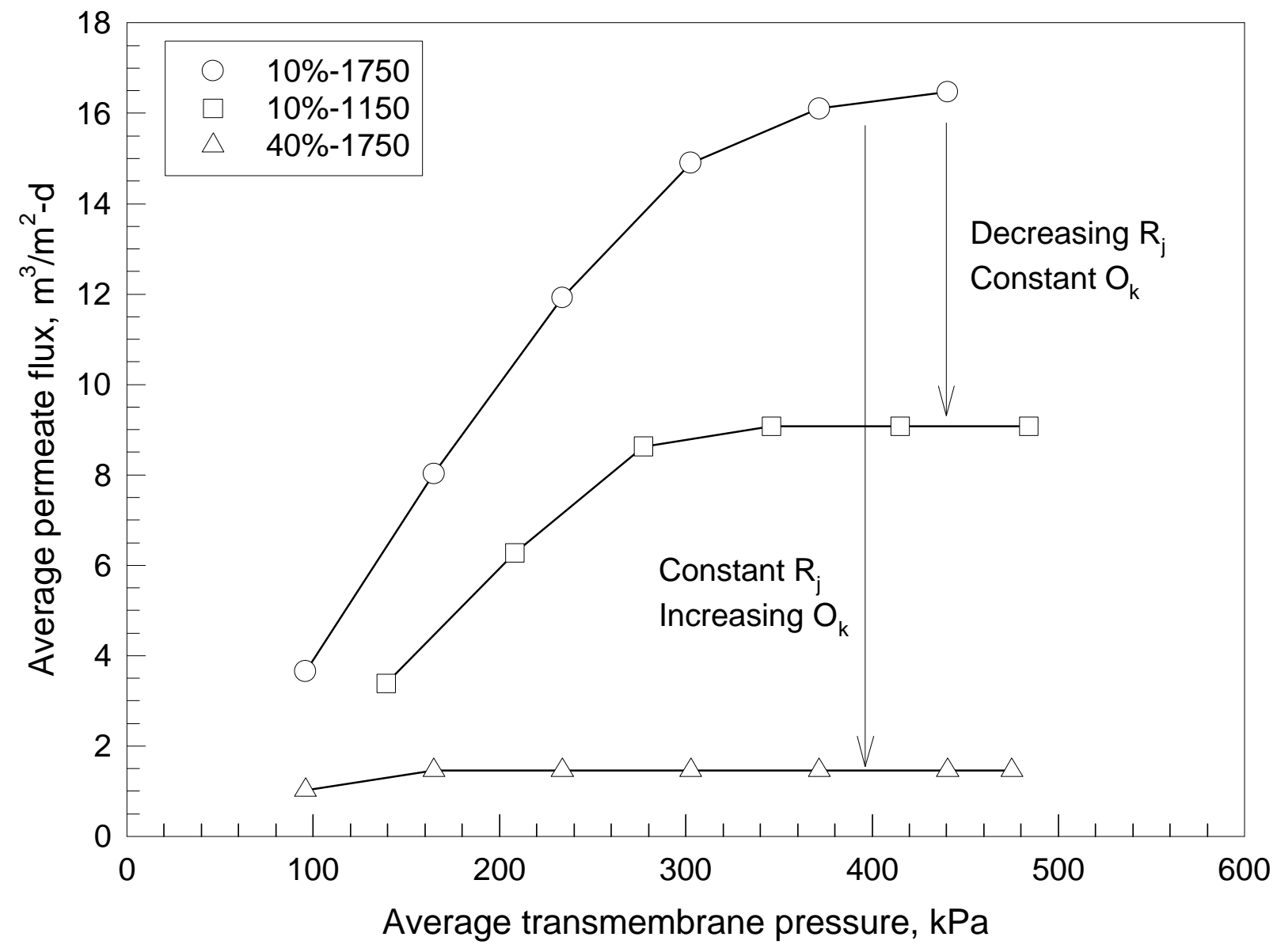

Figure (5.1)--Average permeate flux versus average transmembrane pressure for the $10 \%-1,750 \mathrm{rpm} ; 10 \%-1,450 \mathrm{rpm}$; and 40\%-1,750 rpm experiments. 
of permeate increased as MW fluid was increased and hydraulic turbulence was decreased.

\section{Total membrane resistance}

To develop the RIS model, pressure-flux data for each discrete $\mathrm{R}_{\mathrm{j}} \mathrm{O}_{\mathrm{k}}$ combination were fitted to Equation (2.17) using non-linear regression analysis (SigmaPlot ${ }^{\circledR}$ Version 4.0) and RIS model parameters were determined. $R_{m}$ ' values ranged from 5.14 to 29.2 $\mathrm{m}^{2}-\mathrm{kPa}-\mathrm{d} / \mathrm{m}^{3}$ and were comparable to data ranging from 1 to $10 \mathrm{~m}^{2}-\mathrm{kPa}-\mathrm{d} / \mathrm{m}^{3}$ reported by Nazzal and Wiesner (1996) and Lipp et al. (1988) for UF membranes used in the treatment of soluble oils.

$R_{m}{ }^{\prime}$ versus $O_{k}$ (at each $R_{j}$ ) is presented in Figure (5.2). A two-factor analysis of variance (ANOVA) was conducted using $R_{j}$ and $\mathrm{O}_{k}$ as independent variables and $\mathrm{R}_{\mathrm{m}}{ }^{\prime}$ as the dependent variable to assess the prediction of the dependent variables based upon the independent variables. In ANOVA analysis, the F test statistic was used to determine the contribution of the independent variables in determining the dependent variable. If $\mathrm{F} \simeq 1$, it was concluded that there was no association between the variables; if $\mathrm{F}>>1$, it was concluded that the independent variable contributed to the prediction of the dependent variable. (Case and Brown 1989) Based on the F test statistic of 1.13 determined from the data in this study, it was concluded that $\mathrm{R}_{\mathrm{m}}$ ' was not dependent on either rotational speed or oil concentration. Chiang and Cheryan (1986) reported similar results for the

UF treatment of skim milk in a hollow fiber UF system in which $\mathrm{R}_{\mathrm{m}}$ ' was reported to be 


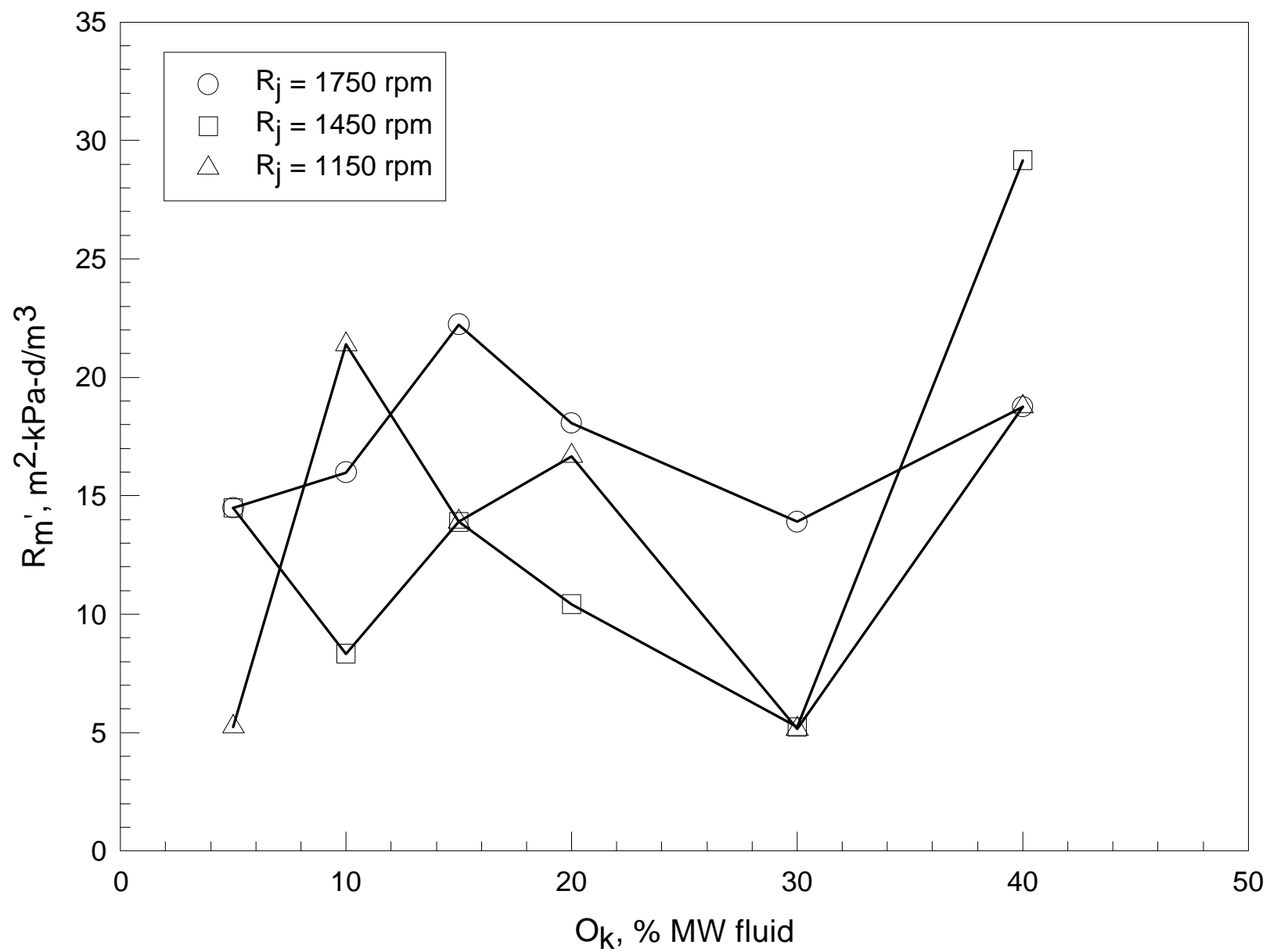

Figure (5.2)-- $R_{m}{ }^{\prime}$ versus $O_{k}\left(\right.$ at each $\left.R_{j}\right)$. 
independent of hydraulic turbulence (expressed as cross-flow velocity) and feed concentration.

The average $R_{m}$ ' value (of all discrete $R_{j} O_{k}$ experiments) was $14.9 \mathrm{~m}^{2}-\mathrm{kPa}-\mathrm{d} / \mathrm{m}^{3}$. The intrinsic resistance of the membrane, $\mathrm{R}_{\mathrm{m}}$, for the virgin membrane (ascertained using clean water prior to initiating MW fluid experiments) was determined to be $13.1 \mathrm{~m}^{2}-\mathrm{kPa}$ $\mathrm{d} / \mathrm{m}^{3}$. Based on Equation (2.15), the average $\mathrm{R}_{\mathrm{f}}$ value from each discrete $\mathrm{R}_{\mathrm{j}} \mathrm{O}_{\mathrm{k}}$ experiment was determined to be $1.8 \mathrm{~m}^{2}-\mathrm{kPa}-\mathrm{d} / \mathrm{m}^{3}$, which was $12 \%$ of the average total membrane resistance, $\mathrm{R}_{\mathrm{m}}$. . The low fouling resistance was attributed to the effective transfer of "cleaning energy" to the membrane surface via membrane rotation. As a result of membrane rotation induced hydraulic turbulence, fewer solute droplets accumulated on the membrane surface, effectively minimizing the potential for membrane pore plugging and solute adsorption onto the membrane surface. (Belfort et al. 1993)

\section{Resistance Index}

Values of $\Phi$ determined in this study ranged from 0.021 to $0.821 \mathrm{~m}^{2}-\mathrm{d} / \mathrm{m}^{3}$ and were generally lower than reported for conventional UF separation systems. Chiang and Cheryan (1986) reported $\Phi$ values of 0.877 to $4.97 \mathrm{~m}^{2}-\mathrm{d} / \mathrm{m}^{3}$ in the UF treatment of skim milk using a hollow fiber UF unit while Wu et al. (1998) reported $\Phi$ values of 0.208 to $1.25 \mathrm{~m}^{2}-\mathrm{d} / \mathrm{m}^{3}$ in a tubular UF module in the treatment of a reactive-dye wastewater. However, $\Phi$ for oily wastewaters have not been reported in the literature.

Resistance index versus $\mathrm{R}_{\mathrm{j}}$ (at each $\mathrm{O}_{\mathrm{k}}$ ) is presented in Figure (5.3). For all $\mathrm{O}_{\mathrm{k}}, \Phi$ decreased linearly with $R_{j}$. Under conditions of high hydraulic turbulence, the thickness 


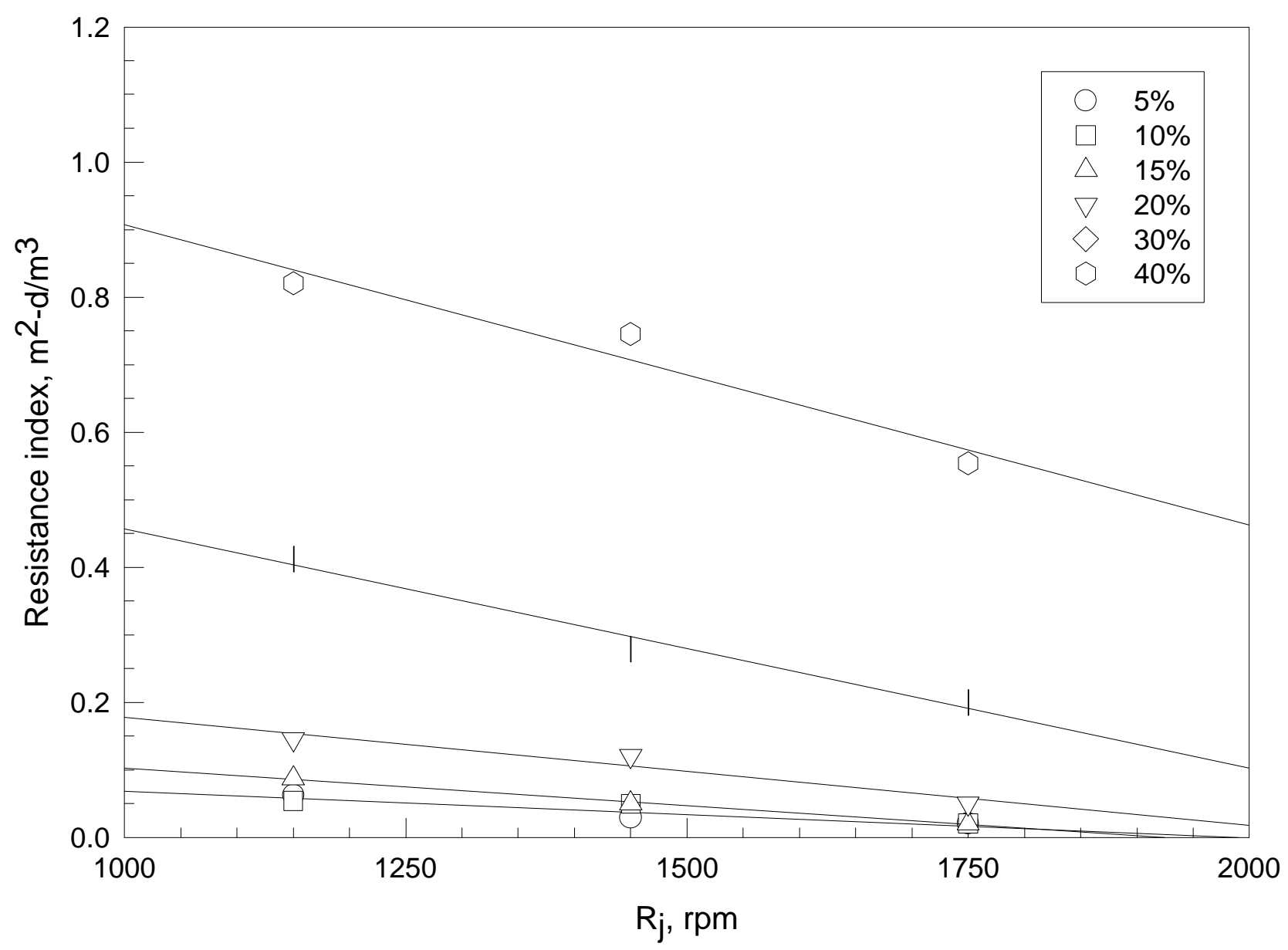

Figure (5.3)-Resistance index versus $\mathbf{R}_{\mathbf{j}}\left(\operatorname{at}\right.$ each $\left.\mathbf{O}_{k}\right)$. 
of the concentration polarization layer was low, which corresponded to an increase in permeate flux. Resistance index versus $\mathrm{O}_{\mathrm{k}}$ (at each $\mathrm{R}_{\mathrm{j}}$ ) is presented in Figure (5.4), as well as MW fluid viscosity versus $\mathrm{O}_{\mathrm{k}}$. For all $\mathrm{R}_{\mathrm{j}}, \Phi$ increased parabolically with $\mathrm{O}_{\mathrm{k}}$. The increase in $\Phi$ with $\mathrm{O}_{\mathrm{k}}$ was similar to the absolute viscosity- $\mathrm{O}_{\mathrm{k}}$ relationship determined in small-scale experiments outside the HSR-UF system at $43 \pm 1^{\circ} \mathrm{C}$, which can be represented by a power series relationship (Cheryan 1986) or in reduced form as a second order polynomial (Chiang and Cheryan 1986). Thus, the resistance index was a function of both membrane rotational speed and MW fluid concentration.

$\Phi$ values for the synthetic MW fluid corresponded to polarization resistances ranging from 0.562 to $487 \mathrm{~m}^{2}-\mathrm{kPa}-\mathrm{d} / \mathrm{m}^{3}$ over the average pressure range examined in this study. When compared with the average total membrane resistance of $14.9 \mathrm{~m}^{2}-\mathrm{kPa}-\mathrm{d} / \mathrm{m}^{3}$, it was determined that the polarization resistance was the predominant rate controlling resistance in the HSR-UF system. $R_{p}$ values were lowest under conditions of low feed concentration (5, 10, and 15\% MW fluid) and high hydraulic turbulence. Thus, higher permeate flux was observed under conditions of high hydraulic turbulence and low MW fluid concentration.

The impact of $\mathrm{R}_{\mathrm{j}}$ and $\mathrm{O}_{\mathrm{k}}$ on permeate flux is most clearly discerned in the limiting case where the concentration polarization layer is thick or dense (i.e., $\mathrm{R}_{\mathrm{p}}>\mathrm{R}_{\mathrm{m}}{ }^{\prime}$ ) and Equation (2.17) reduces to: 


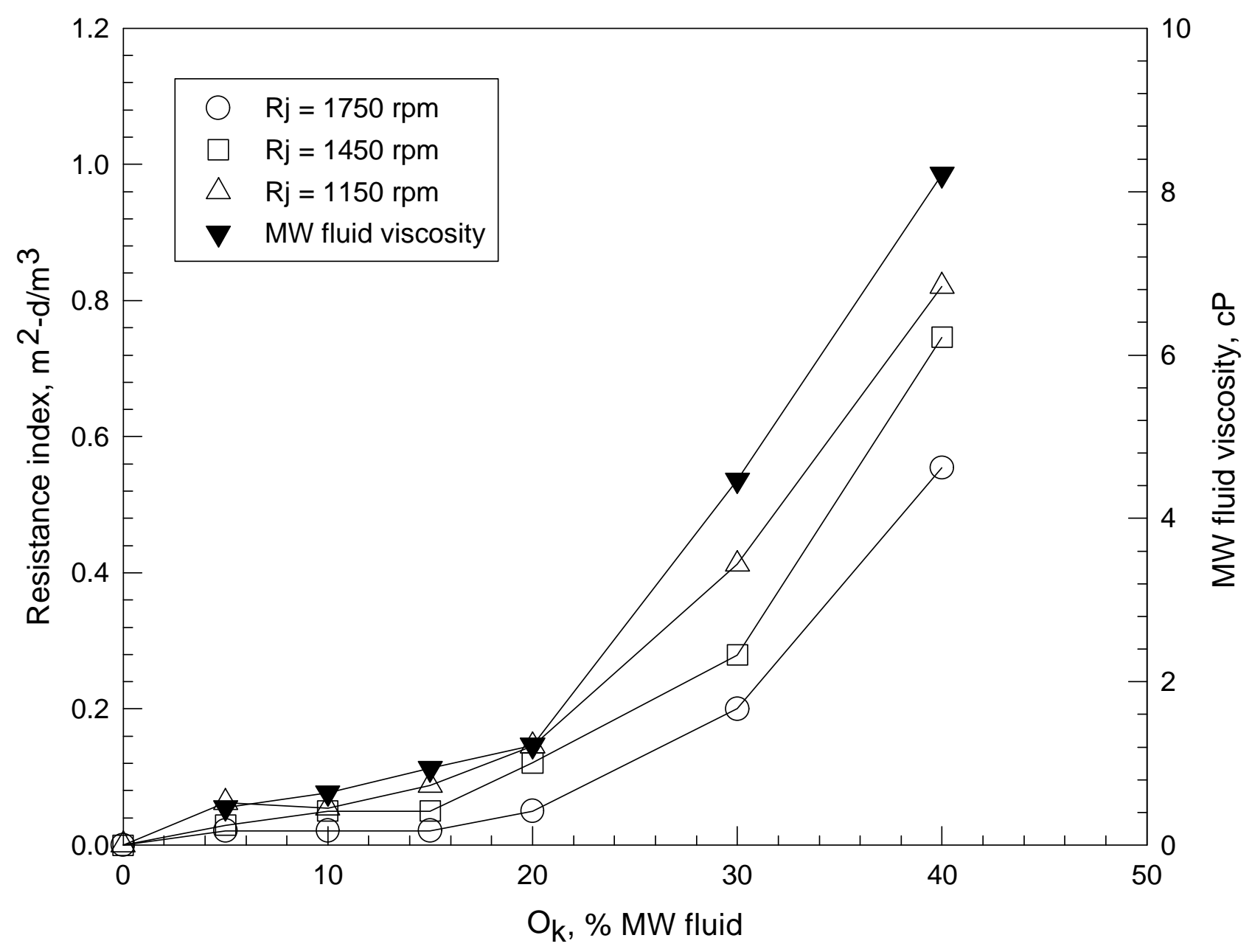

Figure (5.4). Resistance index (at each $R_{j}$ ) and MW fluid viscosity versus $O_{k}$. 


$$
\mathrm{J}^{*}=\frac{1}{\Phi}
$$

Limiting permeate flux, $\mathrm{J}^{*}$, versus MW fluid concentration at 1,$150 ; 1,450$; and 1,750 $\mathrm{rpm}$ is presented in Figure (5.5). (Note: A limiting permeate flux was not observed for the 5 and $10 \%$ MW fluid experiments conducted at 1,750 rpm.) At each MW fluid concentration, $\mathrm{J}^{*}{ }_{1750}>\mathrm{J}^{*}{ }_{1450}>\mathrm{J}^{*}{ }_{1150}$; thus, it was concluded that higher membrane rotational speed corresponded to a decrease in the resistance of the concentration polarization layer through the direct application of "cleaning energy" to the membrane surface. However, the advantage of operating at higher membrane rotational speed decreased as the MW fluid concentration was increased to $40 \%$. Average radial Reynolds number, $\operatorname{Re}_{\mathrm{r} \text {-avg }}$ (calculated using Equation (2.21) at the radius of gyration), at 1,150; 1,450; and 1,750 rpm versus MW fluid concentration is presented in Figure (5.6). A convergence of $\mathrm{Re}_{\mathrm{r} \text {-avg }}$ values, similar to the $\mathrm{J}^{*}-\mathrm{O}_{\mathrm{K}}$ relationship presented previously in Figure (5.5) was observed as MW fluid concentration was increased. Thus, the convergence of permeate flux values at increased MW fluid concentrations was attributed to an increase in MW fluid viscosity and a corresponding decrease in $\mathrm{Re}_{\mathrm{r}}$.

\section{Modification Of The RIS Model}

Since $\Phi$ was a function of both $R_{j}$ and $O_{k}$ as presented in Figures (5.3) and (5.4), a more general form of the resistance index was postulated: 


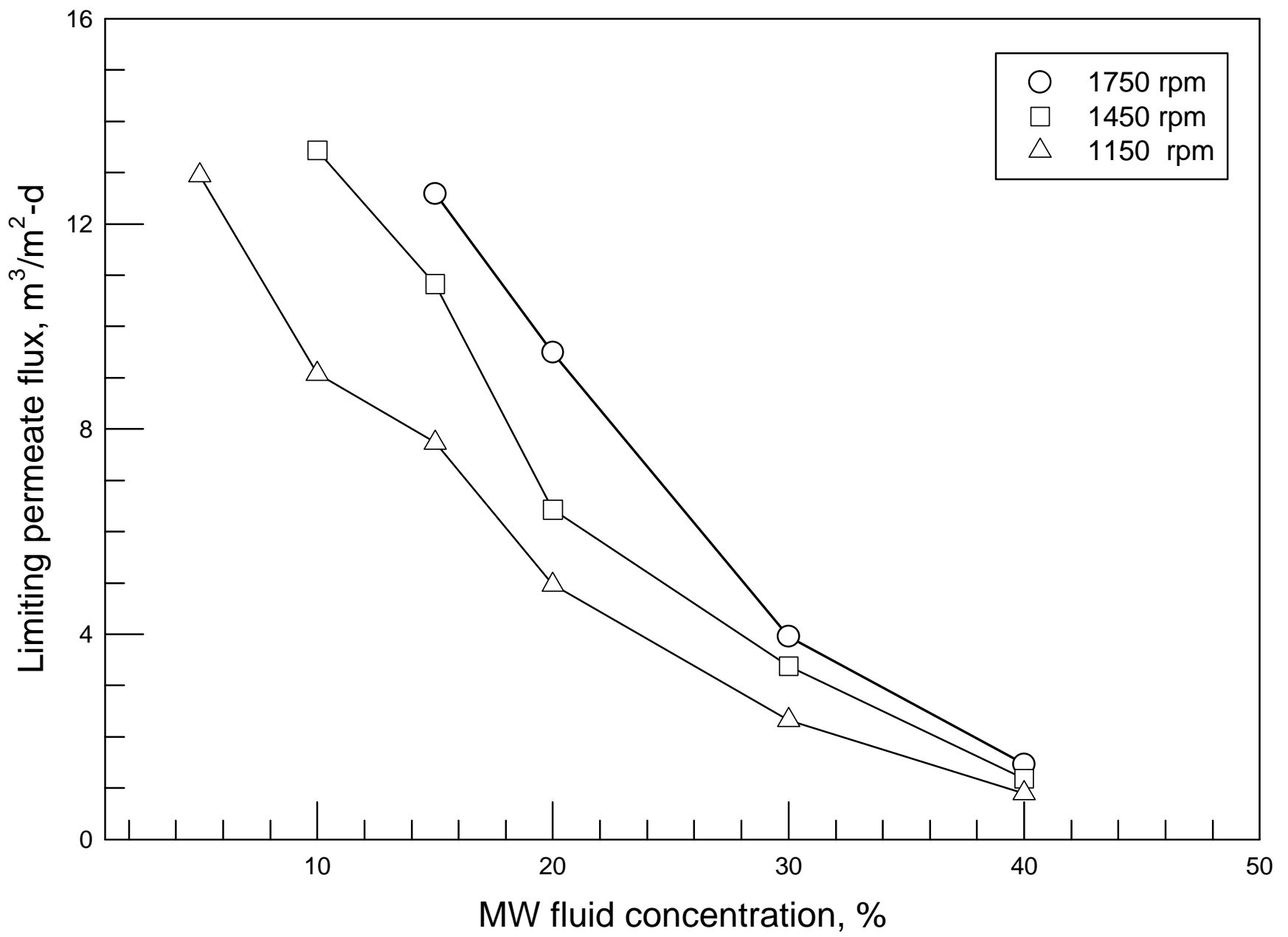

Figure (5.5). Limiting permeate flux versus MW fluid concentration at 1,150; 1,450; and 1,750 rpm. 


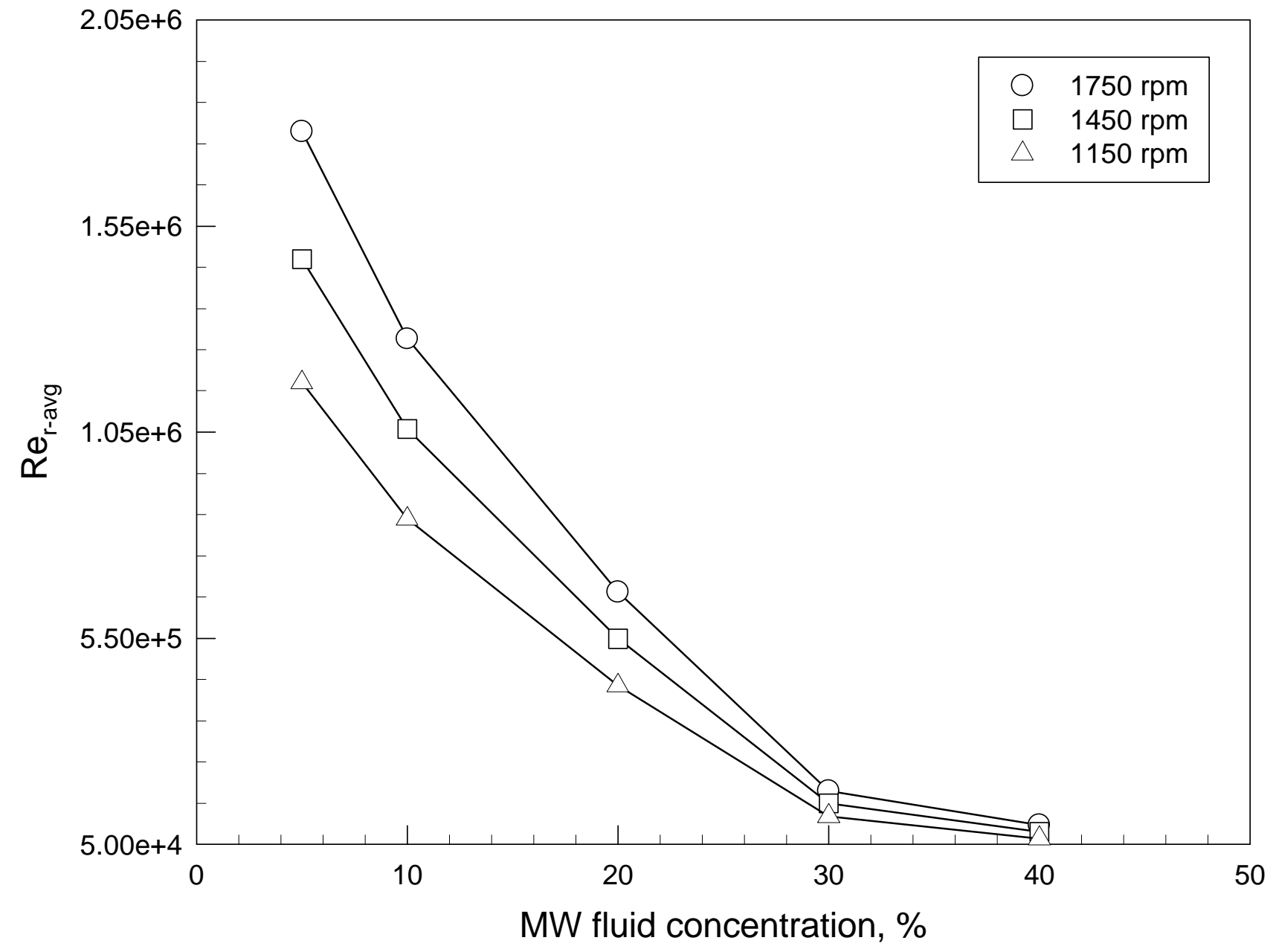

Figure (5.6). Average radial Reynolds number versus MW fluid concentration at 1,150; 1,450; and 1,750 rpm. 


$$
\Phi=\underbrace{\mathrm{a}_{0}+\mathrm{a}_{1} \mathrm{R}_{\mathrm{j}}}_{\begin{array}{c}
\text { linear } \\
\Phi, \mathrm{R} \\
\text { relationship }
\end{array}}+\underbrace{\mathrm{a}_{2} \mathrm{OC}_{\mathrm{k}}+\mathrm{a}_{3}\left(\mathrm{OC}_{\mathrm{k}}\right)^{2}}_{\begin{array}{c}
\text { polynomial } \\
\Phi, \mathrm{O}_{\mathrm{k}} \\
\text { relationship }
\end{array}}
$$

where $\mathrm{a}_{0}, \mathrm{a}_{1}, \mathrm{a}_{2}$, and $\mathrm{a}_{3}$ are curve fitting parameters. Oil content values $\left(\mathrm{OC}_{\mathrm{k}}\right)$ were used in Equation (5.2), since MW fluid concentrations $\left(\mathrm{O}_{\mathrm{k}}\right)$ are typically not known for actual oily wastewaters $\left(\mathrm{OC}_{\mathrm{k}}\right.$ was directly proportional to $\mathrm{O}_{\mathrm{k}}$ as presented previously in Equation (3.1)). The first two terms of Equation (5.2) represent the linear relationship between $\Phi$ and $R_{j}$ as observed in Figure (5.3). The third and fourth terms represent the second order polynomial relationship between $\Phi$ and $\mathrm{O}_{\mathrm{k}}$ (and therefore $\mathrm{OC}_{\mathrm{k}}$ ) as observed in Figure (5.4). Thus, the modified form of the RIS model was:

$$
\mathrm{J}=\frac{\Delta \mathrm{P}_{\mathrm{T}}}{\mathrm{R}_{\mathrm{m}}{ }^{\prime}+\left[\mathrm{a}_{0}+\mathrm{a}_{1} \mathrm{R}_{\mathrm{j}}+\mathrm{a}_{2} \mathrm{OC}_{\mathrm{k}}+\mathrm{a}_{3}\left(\mathrm{OC}_{\mathrm{k}}\right)^{2}\right] \Delta \mathrm{P}_{\mathrm{T}}}
$$

where $\mathrm{a}_{0}=0.1078 ; \mathrm{a}_{1}=-4.5 \times 10^{-5} ; \mathrm{a}_{2}=-5.2 \times 10^{-3} ; \mathrm{a}_{3}=5.0 \times 10^{-4}$. Modified RIS model results and experimental data for representative $\mathrm{R}_{\mathrm{j}} \mathrm{OC}_{\mathrm{k}}$ combinations are presented in Figure (5.7). The hypothetical relationship between $J, \Delta P_{T}, R_{m}$, $R_{j}$, and $O_{k}$ presented in Equation (5.3) adequately predicted both the pressure-dependent and pressureindependent permeate flux behavior. In terms of the magnitude of the $\mathrm{R}_{\mathrm{j}}$ and $\mathrm{OC}_{\mathrm{k}}$ terms in Equation (5.2), it was determined that the feed oil concentration was the predominant parameter contributing to an elevated polarization resistance and thus a lower permeate flux, as observed in the case of the limiting flux presented in Figure (5.5). 


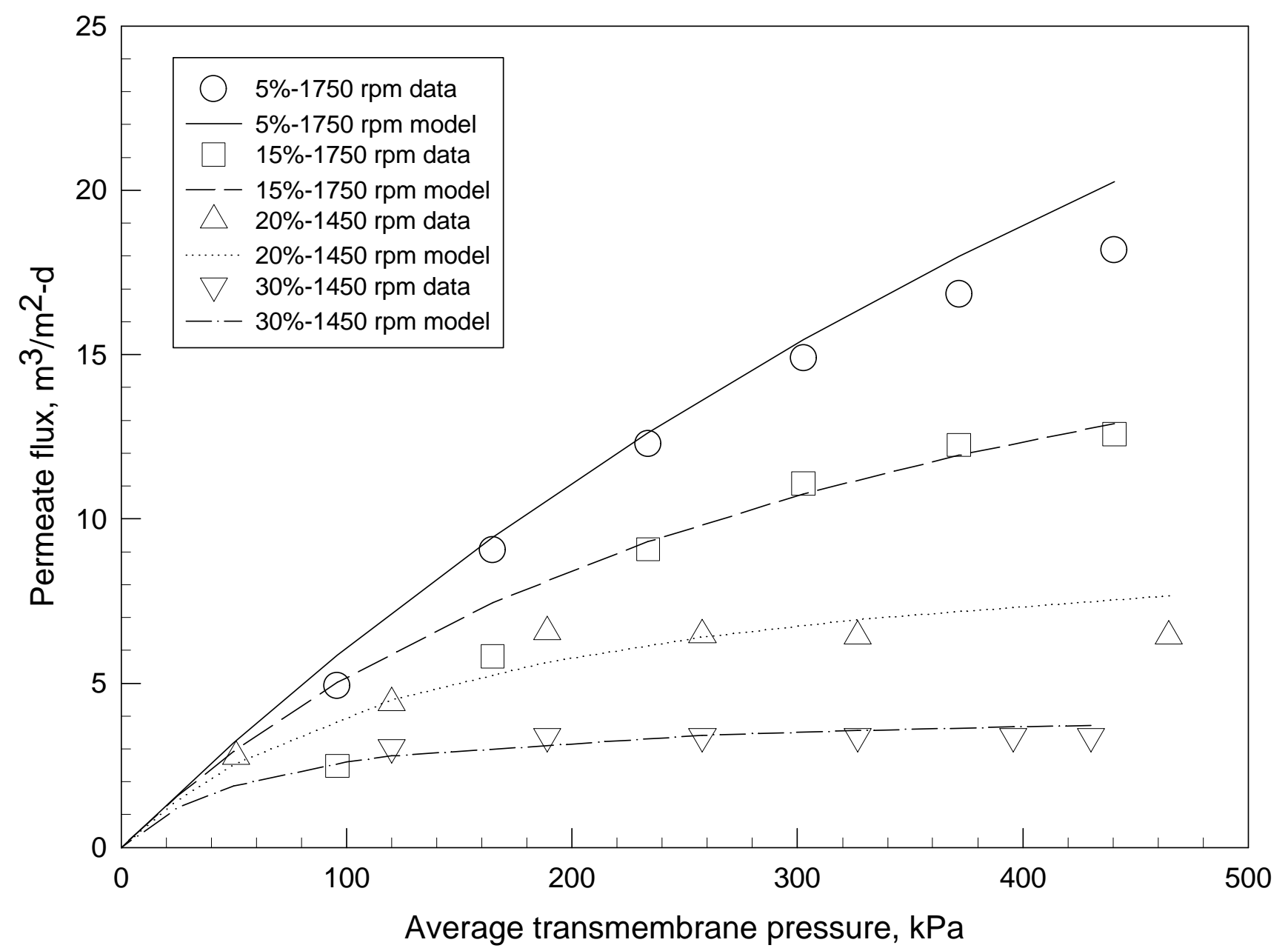

Figure (5.7). Modified RIS model results and experimental data for representative $\mathbf{R}_{\mathbf{j}} \mathbf{O C}_{k}$ combinations. 


\section{CHAPTER 6.0 CONCLUSIONS}

The relationship between permeate flux, transmembrane pressure, membrane rotational speed, and feed concentration in the high-shear rotary ultrafiltration (HSR-UF) of a synthetic metal working (MW) fluid was ascertained and the application of the RIS model was evaluated. A series of eighteen discrete experiments were conducted at constant membrane rotational speed/MW fluid concentration combinations over a range of transmembrane pressures to determine the relationship between RIS model parameters and feed solution characteristics and system operating conditions. Based upon experimental observations, the RIS model was modified and a working relationship between permeate flux, membrane rotational speed, and feed oil concentration was established. The following specific conclusions are forwarded:

1. Membrane resistance after cleaning, $\mathrm{R}_{\text {clean, }}$ did not change significantly over the course of this study; thus, the membrane cleaning procedure was effective at restoring membrane performance after each discrete experiment.

2. Total membrane resistance and resistance of the fouling layer, $R_{m}{ }^{\prime}$ and $R_{f}$, respectively, were not influenced by membrane rotational speed or feed MW fluid concentration. Additionally, $\mathrm{R}_{\mathrm{f}}$ was determined to be only $12 \%$ of $\mathrm{R}_{\mathrm{m}}{ }^{\prime}$. Thus, fewer solute droplets accumulate on the membrane surface and the potential for membrane pore plugging and/or solute adsorption onto the membrane surface is effectively minimized through the efficient transfer of "cleaning energy" to the membrane surface via membrane rotation. 
3. Polarization resistance, $\mathrm{R}_{\mathrm{p}}$, is the predominant rate controlling resistance in the treatment of the synthetic MW fluid in the HSR-UF system. The deleterious effects of increased polarization resistance can be minimized through membrane rotation induced hydraulic turbulence, since polarization resistance decreases with increased membrane rotational speed. However, the effects of rotation induced hydraulic turbulence decrease as MW fluid concentration is increased due to an increase in MW fluid viscosity and a corresponding decrease in the radial Reynolds number. As pilotscale HSR-UF systems are scaled up, the high permeate flux and low fouling and polarization resistances obtained by operating at high membrane rotational speeds must be weighed against the corresponding increase in operating costs as a feed stream is concentrated.

4. The modified RIS model, based upon the interactions of the resistance index with membrane rotational speed and feed MW fluid concentration, adequately predicts permeate flux data from discrete experiments. Thus, the modified model may be used to predict permeate flux at intermediate $\mathrm{P}_{\mathrm{i}} \mathrm{R}_{\mathrm{j}} \mathrm{O}_{\mathrm{k}}$ conditions in the experimental matrix.

5. The experimental approach and conclusions regarding the interaction of permeate flux with membrane rotation and feed MW fluid concentration serve as: (1) a basis to broaden the scientific evaluation of the HSR-UF system by establishing a benchmark for future comparisons and (2) a step toward understanding the interaction between permeate flux, membrane rotational speed, and feed concentration, thus enhancing the application and operating efficiency of systems in the field. 


\section{CHAPTER 7.0 \\ REFERENCES}

Arya, A. (1993). Classical Mechanics, Allyn and Bacon, Needham Heights, Massachusetts.

Belfort, G., Mikulasek, P., Pimbley, J., and K. Chung (1993). "Diagnosis of Membrane Fouling Using a Rotating Annular Filter, Part 1: Cell Culture Media," Journal of Membrane Science, 77, 1-22.

Belfort, G., Mikulasek, P., Pimbley, J., and K. Chung (1993). "Diagnosis of Membrane Fouling Using a Rotating Annular Filter, Part 2: Dilute Particle Suspensions of Known Particle Size," Journal of Membrane Science, 77, 23-39.

Belfort, G. (1988). "Membrane Modules: Comparison of Different Configurations Using Fluid Mechanics," Journal of Membrane Science, 35, 245-270.

Bennett, G. (1988). "The Removal of Oil From Wastewater By Air Flotation, A Review," CRC Critical Reviews in Environmental Control, 18 (3) 220.

Benson, R. (1994). "Processing Apparatus With Wall Conditioning Shuttles," US Patent Number 5,284,581.

Bhave, R. (1991). Inorganic Membranes: Synthesis, Characteristics, and Applications, Van Nostrand Reinhold, New York.

Bird, R., Stewart, W., and E. Lightfoot (1960). Transport Phenomena, John Wiley and Sons, New York.

Blatt, W., David, A., Michaels, A., and L. Nelson (1970). Membrane Science and Technology, J. Flinn, Ed., Plenum Press, New York.

Bodzek, M. and K. Konieczny (1992). "The Use of Ultrafiltration Membranes Made of Various Polymers In The Treatment of Oil-Emulsion Wastewaters," Waste Management, 12, 75-84. 
Bowker, A. and G. Lieberman (1972). Engineering Statistics, $2^{\text {nd }}$ ed., Prentice Hall, Englewood Cliffs, New Jersey.

Bryan, P. (1997). Personal Communication With Senior Process Engineer, Union Carbide Technical Center.

Burke, J. (1991). "Waste Treatment of Metal-Working Fluids, A Comparison of Three Common Methods," Lubrication Engineering, April, 238-246.

Canepa, P., Marignetti, N., Rognoni, U., and S. Calgari (1988). Olive Mills Wastewater Treatment By Combined Membrane Processes," Water Resources, 22 (12), 14911494.

Case, W. and F. Brown (1989). General Statistics, John Wiley and Sons, New York, NY.

Cheryan, M. (1977). "Mass Transfer Characteristics of Hollow Fiber Ultrafiltration of Soy Protein Systems," Journal of Food Process Engineering, 1, 269-287.

Cheryan, M. (1986). Ultrafiltration Handbook, Technomic Publishing Co., Inc., Lancaster, Pennsylvania.

Chiang, B. (1982). Ph.D. Thesis, University of Illinois, Urbana, IL.

Chiang, B. and M. Cheryan (1986). "Ultrafiltration of Skimmilk in Hollow Fibers," Journal of Food Science, 51 (2), 340-344.

de Filipi, R. (1977). Filtration, Principles and Practices Part 1, C. Orr, Ed., MarcelDekker, New York.

Dolecek, P., Mikulasek, P., and G. Belfort (1995). "The Performance of a Rotating Filter. Theoretical Analysis of the Flow in an Annulus with a Rotating Inner Porous Wall," Journal of Membrane Science, 99, 241-248.

Elmaleh, S. and W. Naceur (1992). "Transport of Water Through an Inorgainc Composite Membrane," Journal of Membrane Science, 66, 227-234. 
Eringis, A., Brady, F., and R. Blanck (1993). "Wastewater Treatment in the Die Casting Industry Using Cross-Flow Membrane Filtration," Transactions of the North American Die Casting Association.

Fane, A. and C. Fell (1987). "A Review of Fouling and Fouling Control in Ultrafiltration,” Desalination, 62, 117-136.

Goldsmith, R., Roberts, D., and D. Burre (1974). "Ultrafiltration of Soluble Oil Wastes," Journal of The Water Pollution Control Federation, 46 (9), 2183-2192.

Gutman R. (1987). Membrane Filtration: The Technology of Pressure-Driven Membrane Processes, IOP Publishing, Ltd., Bristol, Great Britain.

Isaacson, K., Duenas, P., Ford, C., and M. Lysaght (1980). "Polymer Science and Technology,” 13, 507.

Jonsson, G. and C. Boesen (1984). "Polarization Phenomena in Membrane Processes," Synthetic Membrane Processes, G. Belfort, Ed., Academic Press, Inc., New York.

Jonsson, A. and G. Tragardh (1990). "Fundamental Principles of Ultrafiltration," Chemical Engineering Processes, 27, 67-81.

Ketola, H. and J. McGrew (1968). "Pressure, Frictional Resistance, and Flow Characteristics of the Partially Wetted Rotating Disk," Journal of Lubrication Technology, April, 395-404.

Klinestreuer, C. and G. Belfort (1984). "Mathematical Modeling of Fluid Flow and Solute Distribution in Pressure-Driven Membrane Modules," Synthetic Membrane Processes, G. Belfort, Ed., Academic Press, Inc., New York.

Kozinski, A and E. Lightfoot (1972). American Institute of Chemical Engineering Journal, 18, 1030.

Laemmle, J. (1992). Metalworking Lubricants, American Petroleum Institute. 
Lee, S., Aurelle, Y., and H. Roques (1984). "Concentration Polarization, Membrane Fouling, And Cleaning In Ultrafiltration Of Soluble Oil," Journal Of Membrane Science, 19, 23-38.

Liberherr, J. (1978). Scherifiltration im Ringspalt, Ph.D. Thesis, ETH, Zurich.

Lipp, P., Lee, C., Fane, A., and C. Fell (1988). "A Fundamental Study of the Ultrafiltration of Oil-Water Emulsions," Journal of Membrane Science, 36, 161177.

Lopez-Leiva (1980). "Ultrafiltration at Low Degrees of Concentration Polarization: Technical Possibilities," Desalination 35, 115-128.

MacNeil, J. and D. McCoy (1989). "Membrane Separation Technologies," Standard Handbook of Hazardous Waste Treatment and Disposal, McGraw-Hill Book Co., New York, 6.91-6.106.

Mahdi, S. and R. Skold (1991). "Membrane Filtration for the Recycling of Water-Based Synthetic Metalworking Fluids," Filtration and Separation, 28 (6), 407-414.

Mir, L., Eykamp, W., and R. Goldsmith (1977). "Current and Developing Applications for Ultrafiltration," Industrial Water Engineering, May/June, 14-19.

Murkes, J. and C. Carlsson (1988). Crossflow Filtration, John Wiley and Sons, Ltd., Bath, Great Britain.

Nazzal, F. and M. Wiesner (1996). "Microfiltration of Oil-in-Water Emulsions," Water Environment Research, 68 (7), 1187-1191.

Perry, R. and D. Green (1997). Perry's Chemical Engineering Handbook, $7^{\text {th }}$ ed., McGraw-Hill, New York.

Pinto, S. (1978). "Ultrafiltration for Dewatering of Waste Emulsified Oils," Proceedings, $I^{\text {st }}$ International Conference, IIT Research Institute, Chicago, Illinois, 1-4. 
Porter, M. (1979). Handbook of Separation Techniques for Chemical Engineers, P. Schweitzer, Ed., McGraw-Hill, New York.

Porter, M. and A. Michaels (1972). Chemical Technology, 2, 56.

Reed, B., Lin, W., Viadero, R., and J. Young (1997). "Treatment of Concentrated Oily Wastes Using Centrifugal Membrane Separation (CMS)," ASCE Journal of Environmental Engineering, 123 (12), 1-9.

Reed, B., Lin, W., Dunn, C., Carriere, P., and G. Roark (1997). "Treatment of an Oil/Grease Wastewater Using Ultrafiltration: Pilot-Scale Results," Separation Science and Technology, 32 (9), 1493-1511.

Singh, R. (1996). "Investigation of Ultrafiltration Rejection of Surfactant Micelles by Dynamic Light Scattering," Separation Science and Technology, 31 (9), 13511356.

Smith, A. and S. Circle (1972). Soybeans: Chemistry and Technology, Avi Publishing Co., New York.

Snoeyink, V. and D. Jenkins (1980). Water Chemistry, John Wiley and Sons, New York.

Spriggs, H. and N. Li (1976). "Liquid Permeation Through Polymeric Membranes," Membrane Separation Processes, P. Meares, Ed., Elsevier Publishing Co, New York.

Standard Methods for the Examination of Water and Wastewater. (1985). American Public Health Association (APHA), Washington, D.C.

Vigo, F., Uliana, C., and P. Lupino (1985). "The Performance of a Rotating Module in Oily Emulsions Ultrafiltration," Separation Science and Technology, 20 (2\&3), 213-230.

Yan, S., Hill, C., and C. Amundson (1979). Journal of Dairy Science, 62, 23. 
Weast, R., Ed. (1976). Handbook of Chemistry and Physics, CRC Press, Cleveland, OH.

Woerner, D. (1983). Ph.D. Thesis, University of Washington.

Wu, J., Eiteman, M., and S. Law. (1998). "Evaluation of Membrane Filtration and Ozonation Processes for Treatment of Reactive-Dye Wastewater," ASCE Journal of Environmental Engineering, 124 (3), 272-277.

Zaidi, A., Simms, K., and S. Kok (1992). "The Use of Micro/Ultrafiltration for the Removal of Oil and Suspended Solids From Oilfield Brines," Water Science and Technology, 25 (10), 163-176. 


\title{
RESISTANCE-IN-SERIES MODELING IN HIGH-SHEAR ROTARY \\ ULTRAFILTRATION
}

\author{
By \\ Ronald L. Vaughan, Jr. \\ A THESIS \\ Submitted to \\ West Virginia University \\ in partial fulfillment of the requirements \\ for the degree of \\ Master of Science \\ APPROVAL OF EXAMINING COMMITTEE
}

David Martinelli, Ph.D.

Brian E. Reed, Ph.D.

Date

Roger C. Viadero, Ph.D., Chair 